\title{
Surface Fault Rupture and Slip Distribution of the Jordan-Kekerengu-Needles Fault Network during the $2016 M w$ 7.8 Kaikōura Earthquake, New Zealand
}

\section{JESSE KEARSE}

\author{
A thesis \\ Submitted to the Victoria University of Wellington \\ in fullfilment of the requirements for the degree of Master of Science in Geology
}

Victoria University of Wellington

2018

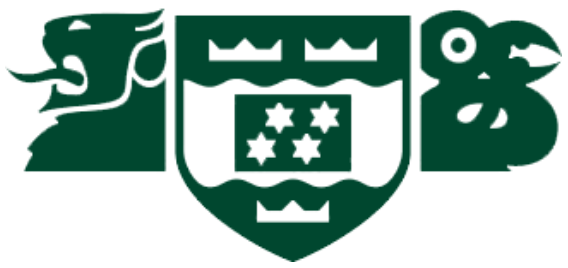


Lat -1

\section{$204 x+205$}

-
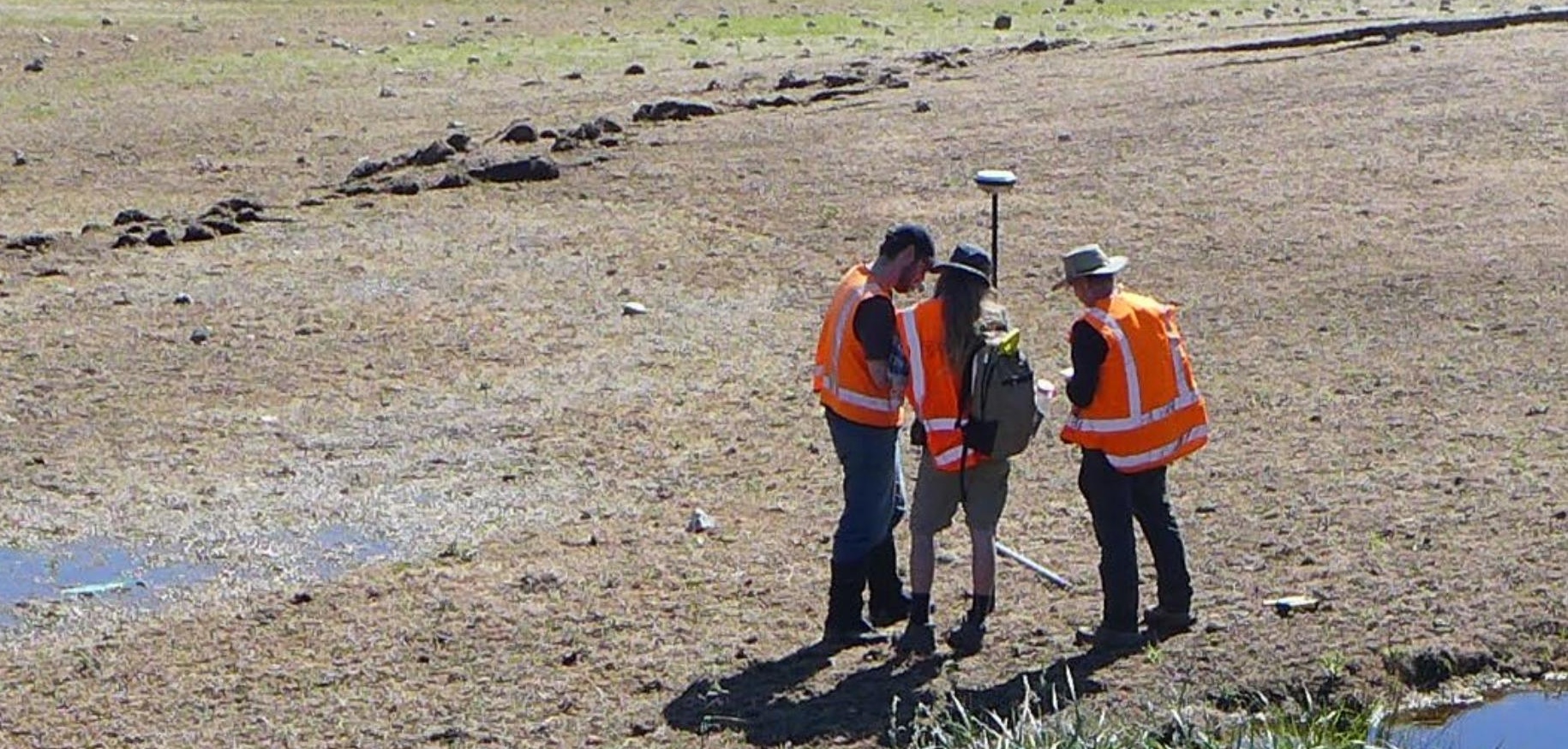
Wha

\section{8}

1.

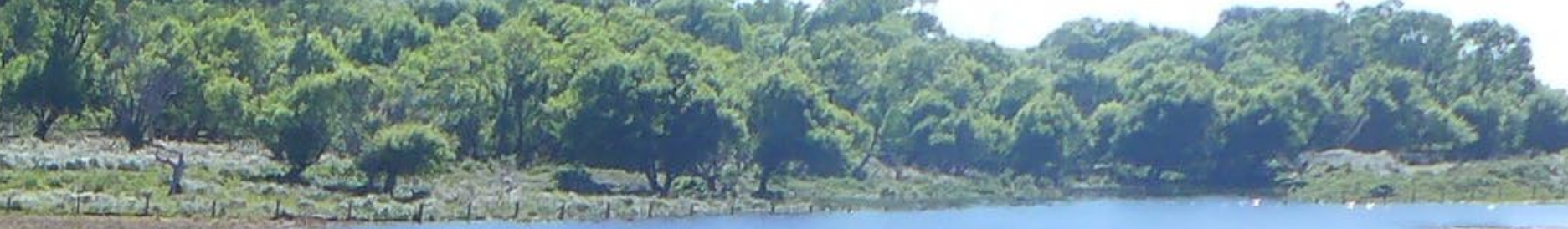

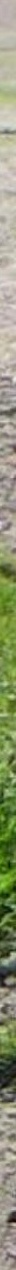

-tictions

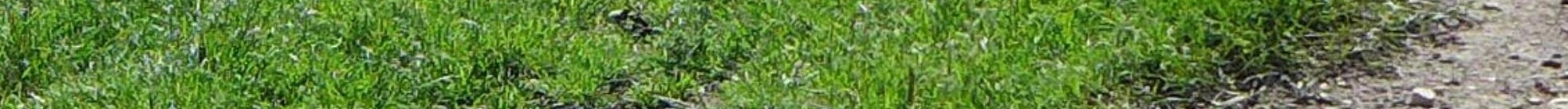

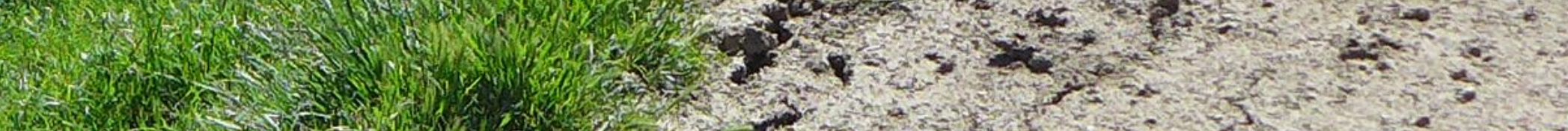

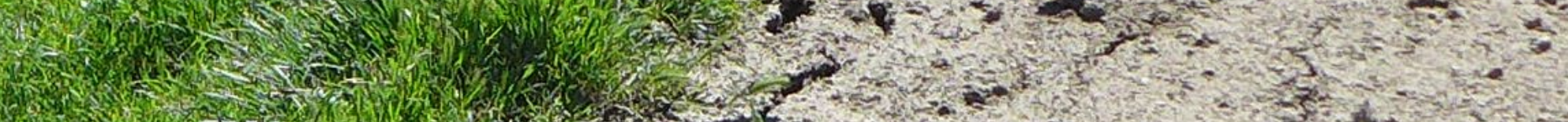
(2)

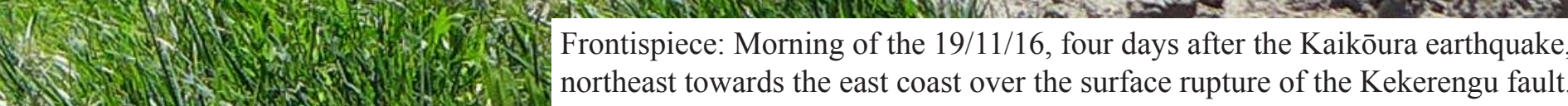

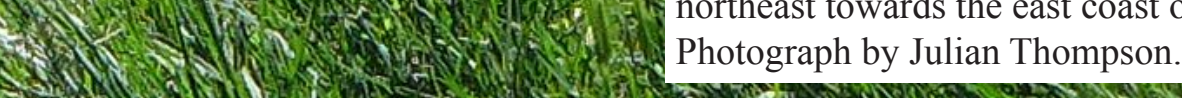




\section{Abstract}

During the 2016, Mw 7.8 Kaikōura earthquake the Kekerengu fault ruptured the ground surface producing a maximum of $\sim 12 \mathrm{~m}$ of net displacement (dextral-slip with minor reverseslip), one of the largest five co-seismic surface rupture displacements so far observed globally. This thesis presents the first combined onshore to offshore dataset of co-seismic ground-surface and vertical seabed displacements along a near-continuous $\sim 83 \mathrm{~km}$ long strike-slip dominated earthquake surface rupture of large slip magnitude. Onshore on the Kekerengu, Jordan Thrust, Upper Kowhai, and Manakau faults, we measured the displacement of 117 cultural and natural markers in the field and using airborne LiDAR data. Offshore on the dextral-reverse Needles fault, multibeam bathymetric and high-resolution seismic reflection data image a throw of the seabed of up to $3.5 \pm 0.2 \mathrm{~m}$. Mean net slip on the total $\sim 83 \mathrm{~km}$ rupture was $5.5 \pm 1$ $\mathrm{m}$, this is an unusually large mean slip for the rupture length compared to global strike-slip surface ruptures. Surveyed linear features that extend across the entire surface rupture zone show that it varies in width from 13 to $122 \mathrm{~m}$. These cultural features also reveal the acrossstrike distribution of lateral displacement, $80 \%$ of which is, on average, concentrated within the central $43 \%$ of the rupture zone. Combining the near-field measurements of fault offset with published, far-field InSAR, continuous GPS, and coastal deformation data, suggests partitioning of oblique plate convergence, with a significant portion of co-seismic contractional deformation (and uplift) being accommodated off-fault in the hanging-wall crust to the northwest of the main rupturing faults.

This thesis also documents in detail the onshore extent of surface fault rupture on the Kekerengu, Jordan Thrust, Upper Kowhai and Manakau faults. I present large-scale maps (up to $1: 3,000)$ and documentary field photographs of this $53 \mathrm{~km}$-long onshore surface rupture zone utilizing field data, post-earthquake LiDAR-derived Digital Elevation Models (DEMs), and post-earthquake ortho-rectified aerial photography. Ground deformation data is most detailed near the Marlborough coast where the 2016 rupture trace is well-exposed on agricultural grassland on the Kekerengu fault. In the southwest, where surface fault rupture traversed the alpine slopes of the Seaward Kaikoura ranges, fault mapping relied heavily on the LiDAR-derived DEMs.

At 24 sites along the Kekerengu fault, I document co-seismic wear straie that were formed 
during the earthquake and were preserved on free face fault exposures. Nearly all of these striae were distinctly curved along their length, demonstrating that the direction of near-surface fault slip changed with time during rupture of the Kekerengu fault. Co-seismic displacement on the Kekerengu fault initiated as oblique-dextral (mainly dextral-reverse), and subsequently rotated to become nearly-pure dextral slip. These slip trajectories agree with directions of net displacements derived from offset linear features at nearby sites. Temporal rotation of the slip direction may suggest a state of low shear stress on the Kekerengu fault before the earthquake, and a near-complete reduction in stress during the earthquake, as has been inferred for other historic earthquakes that show evidence for changing slip direction with time. 


\section{Acknowledgements}

First and foremost I would like to thank my principle supervisor Tim Little. Thank you for your dedication to my education during this MSc, and for always having an open door and unlimited time to discuss whatever happened to be on my mind, be that academic or otherwise. I would also like to thank my supervisor Russ Van Dissen for guidance throughout these last two years. To my beautiful partner Rosie Sievers, thank you for your unwavering support. I could not have done this without you, you're the best. I would like to thank everyone who has contributed directly to the science of this thesis since the Kaikoura earthquake. This includes the earthquake surface rupture response team, who made me feel valued and a welcome participant in the scientific response efforts. I would also like to thank Adrian Benson for continued technical support, both in the field and back in the office. To Sam Taylor-Offord and Alec Yates, both of whom gave up their free time to help me in the field, thank you. I would like to acknowledge the Earthquake Commission for my MSc funding, this has helped me to focus on the science. To my office colleagues, thanks for all the encouraging banter, and great work atmosphere.

A special thankyou to my Mum and Dad, for your encouragement throughout my life, no matter what. 


\section{Table of Contents}

\section{Chapter One: Introduction}

1.1 Research Motivation

1.2 The Kaikōura Earthquake 3

1.2.1 Surface Ruptures of the Kaikōura Earthquake 3

1.2.2 Earthquake Response Fieldwork 4

$\begin{array}{ll}1.3 \text { Tectonic Setting } & 6\end{array}$

$\begin{array}{ll}1.4 \text { Thesis Outline } & 8\end{array}$

1.4.1 Chapter Two 8

1.4.2 Chapter Three 9

$\begin{array}{ll}1.4 .3 \text { Chapter } 4 & 10\end{array}$

1.4.4 Chapter Five 11

Chapter Two: Mapping and Documenting the 2016 Surface Fault Rupture 13

2.1 Introduction 13

2.2 Datasets 13

2.2.1 Ground-Surface Rupture Data 13

2.2.2 Co-seismic Displacement Data 16

2.2.3 Wear Striae and Fault Attitude Data 16

2.2.4 Throw and Scarp Facing Direction 17

$\begin{array}{ll}\text { 2.2.5 Particular Fault Rupture Morphologies } & 17\end{array}$

$\begin{array}{ll}2.3 \text { Fault Rupture Map Tiles } & 18\end{array}$

$\begin{array}{ll}\text { 2.3.1 Individual Map Tiles } & 18\end{array}$

Chapter Three: Onshore to Offshore Ground-Surface and Seabed Rupture 49

3.1 Introduction $\quad 50$

3.1.1 Background 51

3.2 Datasets and Methods 55

3.2.1 Onshore 55

$\begin{array}{ll}3.2 .2 \text { Offshore } & 58\end{array}$

3.3 Surface Rupture Expression $\quad 60$

$\begin{array}{ll}3.3 .1 \text { Onshore } & 60\end{array}$

$\begin{array}{ll}\text { 3.3.2 Offshore } & 68\end{array}$

3.4 Co-seismic Slip Distribution $\quad 72$ 
3.4.1 Horizontal Slip Distribution $\quad 72$

3.4.2 Vertical Slip Distribution $\quad 74$

3.4.3 Across-Strike Distribution of Dextral Slip 76

3.5 Discussion $\quad 79$

3.5.1 Magnitudes of Slip and Surface Slip Distribution 79

3.5.2 Co-seismic 3-D Surface Displacement 82

3.5.3 On-Fault Deformation $\quad 85$

3.5.4 Width of Surface Fault Rupture Deformation 86

$\begin{array}{ll}3.6 \text { Conclusions } & 87\end{array}$

3.7 Acknowledgements $\quad 88$

Chapter Four: Wear Striae Formed on the Kekerengu Fault 91

4.1 Introduction 91

4.2 Methods of Data Collection 92

4.2.1 Calculating Direction of Finite Slip 93

4.3 Surface Rupture Morphology 93

4.3.1 Bedrock Free Faces 94

4.3.2 Crevasses 96

$\begin{array}{ll}\text { 4.3.3 Moletracks } & 97\end{array}$

4.4 Results 99

4.4.1 Co-seismic Wear Striae on the Kekerengu Fault: 99

4.5 Discussion 106

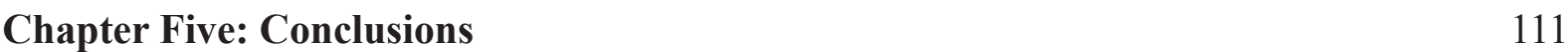

Appendix 1 - Catalogue of Field Photographs along the Kekerengu Fault Network 113

Appendix 2 - Supplimentary Tables and Figure for Chapter Three 123

Appendix 3 - Individual Site Summaries for Chapter Four 135

$\begin{array}{ll}\text { References } & 148\end{array}$ 


\section{List of Figures}

Figure 1.0: Strike-slip fault displacement of a fence line. 2

Figure 1.2: Map of surface fault rupture associated with the Kaikōura earthquake. 5

Figure 1.3: Summary of slip-rate data. $\quad 8$

Figure 2.1: Map of LiDAR and DSM aerial extent. 14

Figure 2.2: Example of DEM and orthophotography resolution. $\quad 15$

Figure 2.3: Index map of map tiles \#1 — \#20. 19

Figure 2.4: Map tile \#1. 20

Figure 2.5: Map tile \#2. 22

Figure 2.6: Map tile \#3. 22

Figure 2.7: Map tile \#4. 24

Figure 2.8: Map tile \#5. 26

Figure 2.9: Map tile \#6. 27

Figure 2.10: Map tile \#7. 29

Figure 2.11: Map tile \#8. 31

Figure 2.12: Map tile \#9. 33

Figure 2.13: Map tile \#10. 33

Figure 2.14: Map tile \#11.

Figure 2.15: Map tile \#12.

Figure 2.16: Map tile \#13.

Figure 2.17: Map tile \#14. 39

Figure 2.18: Map tile \#15. 41

Figure 2.19: Map tile \#16.

Figure 2.20: Map tile \#17.

Figure 2.21: Map tile \#18.

Figure 2.22: Map tile \#19.

Figure 2.23: Map tile \#20.

Figure 3.0: Map of study area.

Figure 3.1: Kaikōura earthquake northern domain surface fault ruptures. $\quad 54$

Figure 3.2: Graphical explanation of the method of dextral displacement calculation. $\quad 55$

Figure 3.3a: Onshore expressions of surface fault rupture. 62

Figure 3.3b: Onshore expressions of surface fault rupture. 63 
Figure 3.4: Offshore expression of seabed rupture on the Needles fault.

Figure 3.5: Distribution of dextral and vertical surface rupture displacement resulting from the 2016 Kaikōura earthquake.

Figure 3.6: Histograms showing widths of surface rupture deformation. $\quad 77$

Figure 3.7: Networks of re-surveyed fence posts. 78

Figure 3.8: Scatter plot comparing large-magnitude strike-slip earthquakes. $\quad 81$

Figure 3.9: Kinematic map of co-seismic displacements. 83

Figure 4.1: Field Photograph depicting a freshly-exposed free face. $\quad 91$

Figure 4.2: Close-up photograph of an exposed Kekerengu fault plane. 92

Figure 4.3: Examples of free faces on the Kekerengu fault plane. 94

Figure 4.4: Example of fault crevasses on the Kekerengu fault. 95

Figure 4.5: Photographs of moletrack deformation. $\quad 97$

Figure 4.6: Collection of wear striae measurements from each site. $\quad 100-102$

Figure 4.7: Spatial distribution and orientation of wear straie measurements. 103

Figure 4.8: Summary of site “ $m$ ". 104

Figure 4.9: Summary of site "w".

Figure 4.10: Cartoon depicting the formation of curved wear striae. 106

Figure A1.0: Collection of field photographs from map tiles \#1 \#2 and \#3. 114

Figure A1.1: Collection of field photographs from map tiles \#3 and \#4. 115

Figure A1.2: Collection of field photographs from map tiles \#5 and \#6. 116

Figure A1.3: Collection of field photographs from map tiles \#6 and \#7. 117

Figure A1.4: Collection of field photographs from map tiles \#7 and \#8. 118

Figure A1.5: Collection of field photographs from map tiles \#8 and \#9. 119

Figure A1.6: Collection of field photographs from tmap tiles \#9 \#11 and \#12. 120

Figure A1.7: Collection of field photographs from map tiles \#12 \#13 \#16 \#17 and \#18. 121

Figure A1.8: Field photograph from map tile \#19. 122

Figure A2.0: Marine shipping track data. 134

Figure A2.1: Bathymetry in the region of 2016 Kaikōura earthquake rupture termination. 134 


\section{Chapter One: Introduction}

\subsection{Research Motivation}

Active strike-slip faults are responsible for accommodating large portions of relative plate motion. At the surface, they accomplish this chiefly through co-seismic rupture in large magnitude earthquakes ( $\geq \mathrm{Mw}$ 7.0). Scientific efforts to document slip during large-magnitude strike-slip surface ruptures have been undertaken since the late 19th Century (e.g., Fig 1.0); however, such earthquakes are not common on a human timescale. As a result, our understanding of the co-seismic behaviour and surface deformation associated with their occurrence remains poor.

Recent advances in survey technology, have allowed co-seismic deformation of the ground to be documented in unprecedented detail. For example real-time kinematic (RTK) surveying with differential Global Positioning System methods (GPS), satellite-based synthetic aperture radar (SAR) and subpixel optical image correlation of satellite photographs (Peltzer et al., 1998; Zinke et al., 2014; Hamling et al., 2017), and Light Detection And Ranging (LiDAR) technology (e.g., Oskin et al., 2012). Unfortunately, there have been only a few recent examples of large-magnitude surface-rupturing strike-slip earthquakes, many of which have been in remote locations or offshore, making scientific access and study difficult (e.g., Lin et al., 2001; Haeussler et al., 2004; Gold et al., 2015). For these reasons, important questions remain regarding the nature of slip during large-magnitude earthquakes. What are the characteristics of meter to km-scale surface deformation resulting from a large-magnitude strikeslip earthquake? How does the width and style of surface deformation vary along the length of strike-slip surface ruptures? What along-strike distribution of surface slip should we expect in a future strike-slip surface rupture? What across-strike slip distribution or gradients of slip are typical of these events, and why might they be different from one earthquake to the next? Are rupture kinematics the same everywhere along a fault during an earthquake, or do 


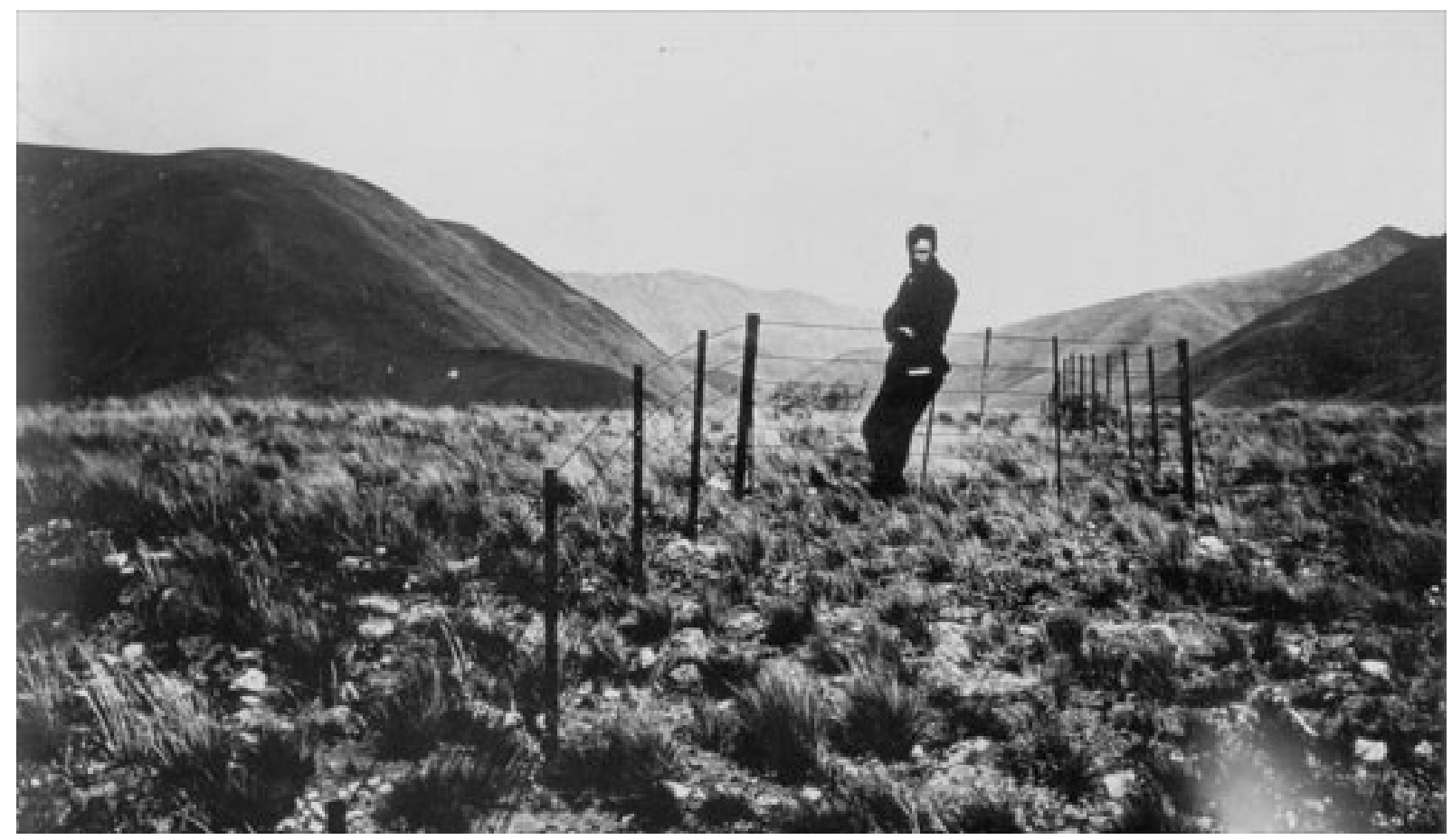

Figure 1.0: Strike-slip fault displacement of a fence line across the surface rupture of the Hope fault, resulting from the $\mathbf{1 8 8 8}$, North Canterbury earthquake. Photograph by Alexander Mckay. Source: teara. govt.nz

they vary in space or with time? These are ambitious questions and their answers are not yet clear. Yet the answers to them are important to communities who live nearby to active faults capable of sustaining large-magnitude earthquakes. They have implications for how best to mitigate and adapt to the hazard posed by such earthquakes. Seismic hazard evaluations worldwide are underpinned by observations of large surface rupturing earthquakes, however the current sample dataset is small.

The 2016 Mw 7.8 Kaikōura earthquake produced over $165 \mathrm{~km}$ of ground surface (and seabed) rupture in New Zealand's northern South Island (Fig. 1.2). At least 17 active faults broke the ground during this event, some of them sustaining co-seismic displacements of up to 12 $\mathrm{m}$. Co-seismic uplift of much of the coastline accompanied this event, as well as over $30 \mathrm{~km}$ of offshore rupture on submarine active faults (Litchfield et al., 2018). Much of this surface faulting occupied agricultural grassland, which made field access easy and also provided excellent opportunities for mapping surface ruptures with precision and continuity. Moreover, new tools were now available with which to document surface deformation. This earthquake therefore provides an exceptional opportunity to document the ground surface effects and slip distribution during a large-magnitude earthquake, and to address several of the above-mentioned questions pertaining to these rare but damaging natural disasters. 


\subsection{The Kaikōura Earthquake}

Close to midnight (00:03, local time) on the 14th of November 2016, the South Island of New Zealand was struck by the Mw 7.8 Kaikōura earthquake (Kaiser et al., 2017). The epicentre was located in North Canterbury, where it was assigned an oblique thrust mechanism based on the global Centroid Moment Tensor solution (Kaiser et al., 2017) (Fig. 1.2). The immediate impacts were most severe in the areas close to the epicentre where two fatalities occurred, and in the capital city of Welligton where liquefaction-induced settlement caused significant damage to the wharves and buildings erected on reclaimed land (Cubrinovski et al., 2018). Ground shaking triggered over 10,000 landslides, many of which buried parts of the coastal State Highway 1, and the main truck rail link with the North Island (Massey et al., 2018). Road access to Kaikōura along this route was unavailable for several months following this event and efforts to establish a permanent connection are still on-going today (Mason, 2017). During the Kaikōura earthquake, ground surface (and seabed) rupture of at least 17 crustal faults was accompanied by large displacements of the earth surface of up to $12 \mathrm{~m}$ laterally and up to $10 \mathrm{~m}$ vertically, before northward termination of the earthquake rupture offshore near Cape Campbell (Hamling et al., 2017; Stirling et al., 2017; Litchfield et al., 2018) (Fig. 1.2).

\subsubsection{Surface Ruptures of the Kaikōura Earthquake}

In the North Canterbury region where the earthquake began, surface ruptures were characterised by short $(\leq 3.4 \mathrm{~km})$ en echelon or branching segments separated by gaps or stepovers. These formed a complex array of dextral-oblique, reverse and sinistral- slip ruptures with net surface displacements up to $5.5 \mathrm{~m}$ (Stirling et al., 2017; Nicol et al., 2018). The Hope fault lies at the centre of the Kaikōura earthquake surface rupture zone (Fig. 1.2), yet produced only minor surface rupture despite having the highest known slip rate in the Marlborough and North Canterbury region. By contrast, the surface ruptures to the north of the Hope fault comprise a nearly continuous northeast-striking zone of fault rupture over a cumulative strike length of $\sim 83 \mathrm{~km}$ (Fig. 1.2). The entirety of the previously-mapped onshore Kekerengu fault $(27 \mathrm{~km})$ ruptured along with $\sim 30 \mathrm{~km}$ of the contiguous offshore Needles fault zone to the northeast and $30 \mathrm{~km}$ of the adjacent onshore Jordan Thrust, Upper Kowhai, and Manakau faults to the southwest (Fig. 1.2). Rupture in this northern domain also occured on 
the north-northwest-striking Papatea fault (Langridge et al., 2018), and the northeast-striking dextral-slip Fidget fault (Litchfield et al., 2018) (Fig. 1.2).

This thesis focuses on the five major northeast-striking faults that collectively comprise the longest and most continuous element of the 2016 Kaikōura surface rupture. Slip on these five faults was predominantly dextral, and typically included a subordinate vertical component that was variably either reverse (i.e., Kekerengu and Needles faults) or normal (Jordan Thrust, Upper Kowhai, and Manakau faults). Of these five faults, the Kekerengu, Jordan Thrust and Needles faults were known to be active prior to this event (we use the word "active" to describe faults with demonstrable movement during the Holocene) (Van Dissen \& Yeats, 1991; Barnes \& Audru, 1999; Townsend, 2001; Barnes et al., 2015). The Upper Kowhai fault was mapped as possibly active (Van Dissen, 1991), and the Manakau fault was unmapped prior to the 2016 rupture. Several other short sections of faults $(<2 \mathrm{~km})$ ruptured the surface within the northern domain: Marfells Beach fault, Cape Campbell fault, Lighthouse fault, Heaver's Creek fault and the Tinline Downs fault (Litchfield et al., 2018).

Surface displacements reach a maximum on the Kekerengu fault of $\sim 12 \mathrm{~m}$ (this thesis), one of the largest five co-seismic surface displacement magnitudes so far observed globally (Sieh, 1978; Baljinnyam, 1993; Lin et al., 2001; Rodgers \& Little, 2006; Lin et al., 2007; Wesnousky, 2008; Zinke et al., 2014; Gold et al., 2015). Local strong-motion and high-rate GPS data indicate rupture of three successive asperities on the Kekerengu fault, from southwest to northeast (Holden et al., 2017). The final and largest of these nucleated at the southern end of the Kekerengu fault at $\sim 10 \mathrm{~km}$ depth, $\sim 60 \mathrm{~s}$ after the earthquake sequence had begun, and propagated northeast along the Kekerengu-Needles fault until terminating offshore of Cape Campbell (Holden et al., 2017). These seismological and geodetic data suggest this alone contributed a moment release equivalent to a Mw 7.8 earthquake (Holden et al., 2017).

\subsubsection{Earthquake Response Fieldwork}

The scientific response to this event was rapid. Both onshore and offshore surveying commencing within days of the earthquake. Onshore, field parties from the Kaikōura Earthquake Surface Rupture Response Team, coordinated by GNS Science, included more than 50 people from 25 institutions from New Zealand and overseas who undertook field work in the rupture 


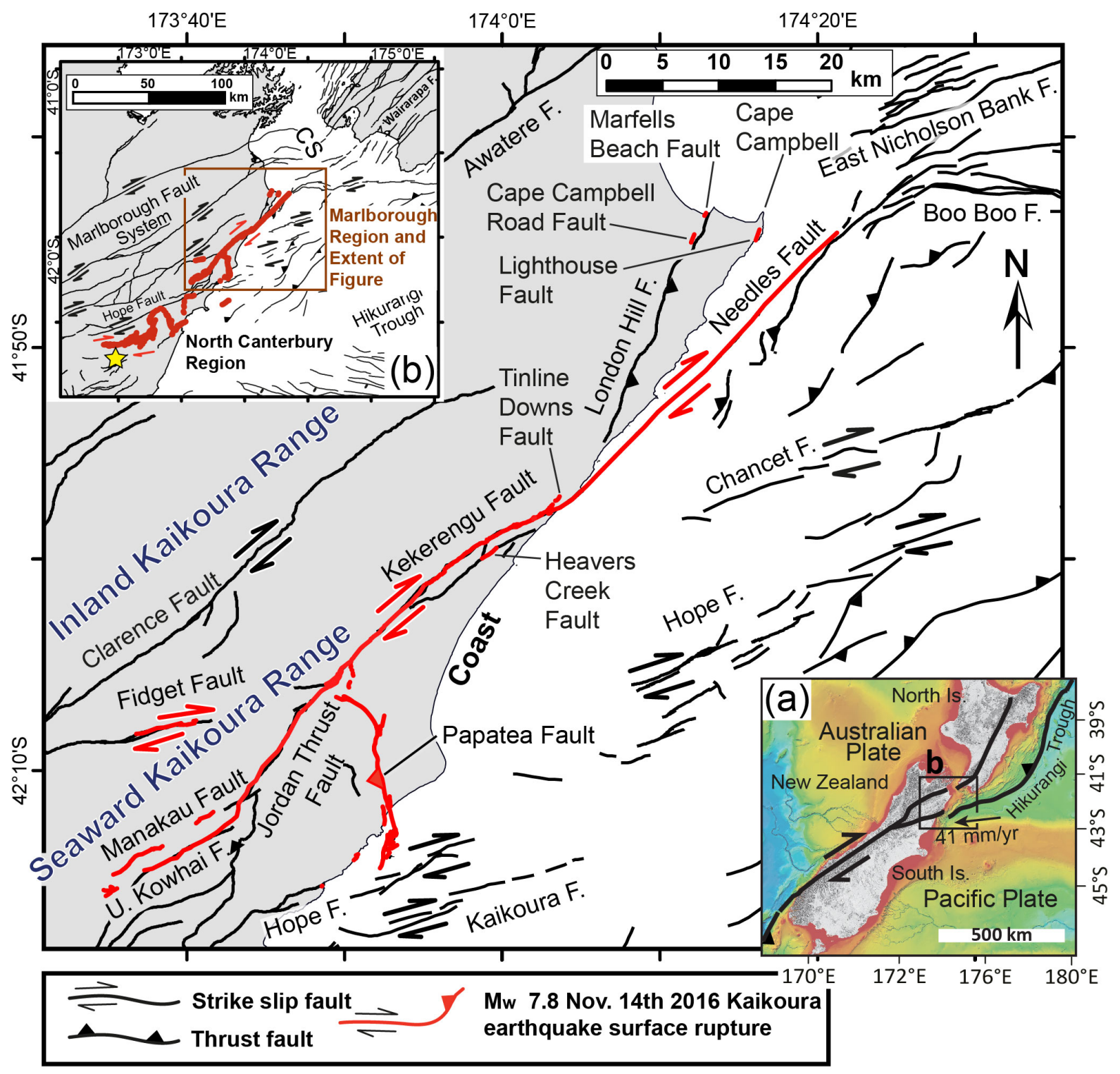

Figure 1.2: Map of surface fault rupture associated with the Kaikōura earthquake (red, Litchfield et al., 2018) and active faults that did not rupture in 2016 (black, from New Zealand Active Fault Database [NZAFDB]; Langridge et al., 2016). a) Regional plate boundary setting showing Pacific-Australia relative plate motion vector (black arrow, De Mets et al., 2010), and the extent of part b. b) All surface ruptures associated with the Kaikōura earthquake (red), yellow star is the epictente from Kaiser et al., (2017), brown box denotes the aerial extent of this figure, $\mathrm{CS}=$ Cook Strait

zone for up to eight weeks. I was part of this team, and was deployed on the Kekerengu fault from 19/11/2016, five days after the earthquake, and worked until 15/12/2016. Other team members (in no particular order) who also collected post-earthquake data on the Kekerengu, Jordan Thrust, Upper Kowhai and Manakau faults were: Nicola Litchfield (GNS Science, and team coordinator), Tim Little (Victoria University of Wellington $V U W$ ), Russ Van Dissen (GNS science), Rob Langridge (GNS Science), Will Ries (GNS science) Pilar Villamor (GNS Science), Adrian Benson (GeoNet), Philip Barnes (NIWA), Geoffroy Lamarche (NIWA, University of Auckland), Mark Hemphill-Haley (Humbolt State University, California), Mat- 
thew Hill (GNS Science), Chris Madugo (Pacific Gas and Electricity, Sacramento), Dougal Townsend (GNS Science), Kate Clark (GNS Science), Steve Lawson (GNS Science), John Manousakis (Elxis Group, Greece), Alex Hatem (University of Southern California), Rob Zinke (University of Southern California), and Rachel Carne (Ministry for Business, Innovation and Employment, New Zealand). Field data collected by this team were pooled at the end of each day, during the initial two weeks of earthquake-response fieldwork. By December of 2016, smaller teams of three - five geologists (including myself) continued further, more detailed surface rupture surveying on the Kekerengu and Jordan Thrust faults. These people were: Tim Little, Russ Van Dissen, Rob Langridge, Will Ries, Steve Lawson, Adrian Benson and Sam Taylor-Offord (GeoNet). During four weeks from early February to early March 2017, I continued to document ground deformation and survey offset features on the Kekerengu fault, with the help of a field assistant, Alec Yates (VUW). The raw data collection leading to the onshore ground surface rupture trace map and co-seismic offset data in this thesis are therefore the work of many people.

The offshore response was executed in two phases, both led by the National Institute for Water and Atmospheric Research (NIWA). The first survey involved re-deployment of the RV Tangaroa research vessel, from work taking place off the east coast of the North Island at the time of the earthquake. Post-earthquake surveys commenced on the Marborough shelf on 19/11/2016, and were directed by Philip Barnes and Geoffroy Lamarche. Data collection above the submarine Needles fault in this initial phase included collection of multibeam bathymetric and backscatter sonar together with high-frequency seismic reflection data. Because this vessel was limited to water depths $>30 \mathrm{~m}$, only the northern $\sim 12 \mathrm{~km}$ of seafloor rupture was surveyed. The second phase of offshore surveying took place between 6/01/2017 and $13 / 01 / 2017$, and was carried out by the coastal research vessel Ikatere, under the direction of Joshu Mountjoy (NIWA). This phase included collection of multibeam bathymetric data along the southern $20 \mathrm{~km}$ of the Needles fault rupture to within $750 \mathrm{~m}$ of where the Kekerengu fault rupture was observed to cross beach deposits at the coast. I was not involved in any way with the collection of these offshore datasets.

\subsection{Tectonic Setting}

The Kekerengu fault is part of the Marlborough Fault System (MFS), a zone of active 
dextral-slip faulting that transfers Pacific-Australian plate motion between the Hikurangi subduction zone to the north and the Alpine fault to the southwest (e.g., Wallace et al., 2012) (Fig. 1.2). Near Cook Strait, plate motion (Pacific relative to Australia) is $\sim 40 \mathrm{~mm} / \mathrm{y}$ with an azimuth of $264^{\circ}$ (DeMets et al., 2010). The faults that comprise the MFS have late-Quaternary dextral slip rates of $\sim 3.4 \mathrm{~mm} / \mathrm{y}$ in the north on the Wairau fault, increasing to $20-27 \mathrm{~mm} / \mathrm{y}$ on the Hope fault in the south (Berryman et al., 1992; Benson et al., 2001; Langridge et al., 2003; Langridge and Berryman, 2005; Mason et al., 2006; Langridge et al., 2010) (Fig. 1.3). The MFS is underlain at 20-50 km depth by the southern end of the Hikurangi subduction interface (Eberhart-Phillips and Bannister, 2010), which is inferred to be strongly coupled on the basis of a) late Quaternary dextral-slip-rates on the MFS faults that approximately sum to the full plate motion (e.g., Beanland and Haines, 1998; Litchfield et al., 2014); and b) GPS geodetic data recording contemporary strain accumulation across the MFS (Wallace et al., 2012).

Prior to 2016, two historic large-magnitude surface rupturing earthquakes had occurred on the MFS: the $1848 \mathrm{Mw} 7.5$ Marlborough earthquake, which ruptured $\sim 100 \mathrm{~km}$ of the Awatere fault with mean dextral displacement of $5.3 \mathrm{~m}$ (Mason and Little, 2006), and the 1888 North Canterbury earthquake that ruptured $\sim 30 \mathrm{~km}$ of the Hope fault with dextral displacements of up to $2.6 \mathrm{~m}$ (Khajavi et al., 2016) (Fig. 1.3). Earthquake Recurrence Intervals (RI) have been calculated for the Hope fault $(\mathrm{RI}=180-310 \mathrm{yrs}$ on the Conway segment and RI $=300-400$ yrs on the Hurunui segment, Langridge et al., 2013; Khajavi et al., 2016; Langridge et al., $2003)$ and Awatere fault (RI = 820-950 yrs, Mason et al., 2006) based on paleoseismic studies (Fig. 1.3). Prior to 2016, the Kekerengu fault was the only major fault within the MFS to have a completely unknown paleoseismic history. In January 2016 three trenches were excavated across the Kekerengu fault to uncover past earthquake activity (Little et al., 2018). Evidence for at least three surface-rupturing earthquakes was found in those trenches. Based on ${ }^{14} \mathrm{C}$ ages these took place at $249-108$ cal. B.P., 528-356 cal. B.P. and $1249-903$ cal. B.P., revealing a RI of 322-438 yrs (95\% confidence) (Little et al., 2018). Nine months later the most recent surface rupture of the Kekerengu fault offset two of these trenches during the Kaikoura earthquake. Based on these data, Little et al (2018) concluded that together with the Hope fault, the Kekerengu fault was responsible for transferring the majority of plate boundary deformation from the Alpine fault, through the MFS into Cook Strait, as first proposed by Van Dissen and Yeats (1991). 


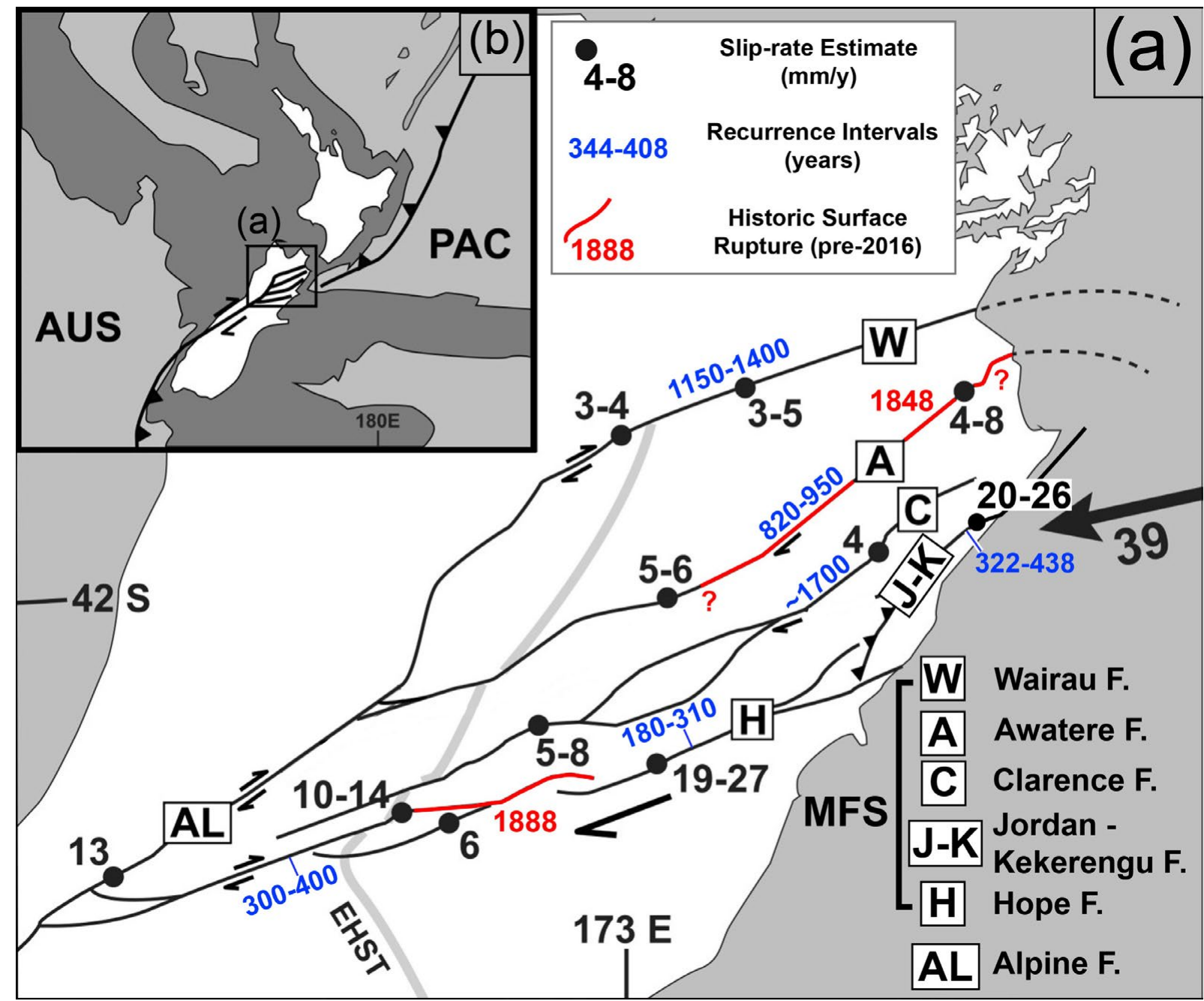

Figure 1.3: Summary of slip-rate data (Berryman et al., 1992; Benson et al., 2001; Langridge et al., 2003; Langridge and Berryman, 2005; Mason et al., 2006; Langridge et al., 2010; Van Dissen et al., 2016) Historic surface-rupturing earthquakes (Mason and Little et al., 2006; Khajavi et al., 2016) and recurrence intervals (Cowan and McClone, 1991; Langridge et al., 2003; Mason et al., 2006; Zachariasen et al., 2006; Van Dissen and Nicol, 2009; Khajavi et al., 2016) for the Marlborough Fault System (MFS). Pacific-Australian plate motion vector (bold arrow) shown in $\mathrm{mm} / \mathrm{y}$ (DeMets et al., 2010)

\subsection{Thesis Outline}

This thesis is divided into four remaining chapters. Chapters two, three and four each focus on a different research question or questions, and contain different Kaikōura earthquake rupture datasets. In order to keep this thesis concise, I have compiled an appendix of supplementary data for Chapters two (Appendix 1), three (Appendix 2) and four (Appendix 3 ). Finally, each of these is then drawn together in a conclusions chapter. In-text references cited in the body of this thesis are listed together in a separate section at the end. 


\subsubsection{Chapter Two}

Chapter two presents detailed maps (scales up to 1:3000) of $53 \mathrm{~km}$ of onshore surface rupture, incorporating the Kekerengu, Jordan Thrust, Upper Kowhai and Manakau faults. These maps are based on post-earthquake field data, high-resolution LiDAR, and ortho-rectified aerial photography. They represent an unusually detailed account of surface rupture deformation during a large-magnitude earthquake that slipped up to $12 \mathrm{~m}$, and demonstrate the power of these techniques in allowing large regions of surface rupture to be rendered into useful and detailed maps.

Other researchers contributed to the field data collection and digitization of the rupture traces in Chapter two; in particular, Will Ries, Kate Clark, Nicola Litchfield, Russ Van Dissen, Dougal Townsend, Pilar Villamor and Tim Little. My responsibility, besides contributing to the fieldwork and rupture trace digitization, was to evaluate and interpret the shapefiles, LiDAR and aerial imagery and field observations. Using these datasets I then compiled and drafted a detailed set of tectonic maps along the $53 \mathrm{~km}$ of earthquake rupture that show the internal structure and width of the surface rupture deformation, and the locations of all field measurements of co-seismic displacement, slip-plane exposures, wear striae observations, and interesting deformation features.

Appendix 1 is an accompanying catalogue of documentary field photographs that are cited in Chapter two. This collection draws on the rich archive of photographs that were acquired during the post-earthquake field work. These images are valuable because many of the interesting earthquake rupture features that they depict have been completely eroded away. The acquisition dates of each image are also included.

\subsubsection{Chapter Three}

Chapter three documents - for the first time - the onshore to offshore distribution of co-seismic surface displacement during a large-magnitude strike-slip earthquake rupture. In addition, it presents the across-strike gradient of dextral-slip at 14 sites. This Chapter was peer reviewed and published as part of a special issue of the Bulletin of the Seismological Society of America (BSSA) that focused on the Kaikōura earthquake. It was accepted on 
4/02/2018. Although Chapter three has the same formatting as does the rest of this thesis, the material is exactly as it appears in the BSSA publication. Due to the article being a standalone report, there is some unavoidable repetition of the other material in this thesis.

Other researchers are listed as co-authors on this article. In particular, the collection and processing of the offshore data on the Needles fault was all done by P. Barnes, J. Mountjoy and Geoffroy Lamarche. The text in sections 3.2.2 and 3.3.2 of Chapter three was written by P. Barnes. The raw field data for 12 displacement measurements were collected by Robert Langridge and Will Ries on the southern Kekerengu fault and Jordan Thrust; however, I processed these data and calculated the displacement for each of these 12 sites. Eight LiDAR-derived displacement calculations for the mountainous region of the Jordan Thrust, and Upper Kowhai faults were performed by Pilar Villamor (see Appendix 2). Seven comparative, LiDAR derived displacement calculations were performed by Kate Clark, using a slightly different method. Clark also wrote a short piece of text in Appendix 2 that details this method. I collected, processed and calculated the remaining 90 measurements of co-seismic slip. The rest of the work is my own, including the production of all maps, figures, appendices, and writing the first and subsequent drafts of the article. Moreover, all of the interpretation is my own. I did however, receive guidance and many editorial suggestions on early drafts from my supervisors T. Little and R. J. Van Dissen. Additional minor edits to the paper were suggested by the co-authors and the reviewers of the paper, all of which were incorporated into the final draft that was published with me as the first author.

\subsubsection{Chapter Four}

A common assumption in active tectonics is that fault displacement during an earthquake is linear or constant, in other words, the direction of fault slip does not change during that event (Twiss and Moores, 1992). Yet there are several historic cases of surface rupturing earthquakes displaying geological evidence of non-linear slip behaviour during fault displacement. The evidence for this is the occurrence of curved fault striae that are preserved on exposed fault surfaces following such events. These data imply that the dynamics of earthquake rupture and displacement are not necessarily as simple as one might assume, based on the geomorphic record of paleo earthquakes. During the Kaikōura earthquake, large co-seismic displacements created many striated exposures of the Kekerengu faults slip surface. Chapter 
four documents these observations, and investigates the slip history of the Kekerengu fault during the 2016 earthquake, as recorded by striae on these slip surfaces. This analysis leads to exiting results which shed light on the dynamics of large-magnitude strike-slip earthquakes. All work in Chapter four is my own.

\subsubsection{Chapter Five}

To conclude this thesis, Chapter five draws on the discussion presented in Chapters two, three and four, to summarise the main results. 
J. Kearse, 2018 


\section{Chapter Two: Mapping and Documenting the 2016 Surface Fault Rupture of the Kekerengu, Jordan Thrust, Upper Kowhai, and Manakau Faults.}

\subsection{Introduction}

During the 14th November 2016 Kaikōura earthquake, approximately $220 \mathrm{~km}$ of surface fault rupture occurred near the South Island's east coast between North Canterbury and Marlborough. Of the many active faults which broke the ground surface during this event, the Kekerengu fault experienced slip magnitudes of up to $\sim 12 \mathrm{~m}$, and produced $27 \mathrm{~km}$ of ground deformation along its trace, much of it in agricultural grassland without tree cover. This provided an exciting opportunity to map ground-surface rupture in the days to months following an unusually large-displacement strike-slip earthquake. A primary goal of this thesis is to document the spatial extent of 2016 ground-surface rupture of the Kekerengu fault and its southwest extensions (collectively referred to in this Chapter as the Kekerengu Fault Network or KFN). This chapter presents a series of 20 maps that detail the onshore surface rupture of the KFN, and constitutes an unusually detailed account of surface fault rupture deformation during the Kaikōura earthquake.

\subsection{Datasets}

\subsubsection{Ground-Surface Rupture Data}

Ground-surface rupture data in this chapter are the result of field-based mapping, interpretation of post-earthquake LiDAR topographic models and post-earthquake aerial photography. Field-based fault rupture mapping of the KFN commenced on the 16th of November 2016, and continued intermittently until 29th of February 2017. Traverses of the fault rupture were performed primarily on foot, with location information being recorded with hand-held and/or Real Time Kinematic (RTK) GPS. This was supplimented by helicopter reconnaissance of the selected, mostly alpine parts of the KFN surface rupture, for example along the Jordan Thrust, Upper Kowhai and Manakau faults, where on-foot traverses were not practical. 
From late 2016 to early 2017, fixed-wing LiDAR and aerial photographic surveys of the KFN were flown after the earthquake in two stages. The first phase was commissioned by the New Zealand Transport Agency (NZTA) and included a $1.5 \mathrm{~km}$-wide swath flown along coastal State Highway 1 between the 19th and 21st of November 2016 (Fig. 2.1). The second acquisition phase was commissioned by Land Information New Zealand (LINZ) and took place between the 3rd of December 2016 and the 6th of January 2017. This survey encompassed all surface fault rupture produced during the Kaikōura earthquake, except for $\sim 15 \mathrm{~km}$ of discontinuously expressed surface rupture on the Manakau fault in the Seaward Kaikoura Ranges (Fig. 2.1). The average point cloud shot density in the study area is 10.1 points per square meter. These data were processed into a one-meter Digital Elevation Model (DEM). The processing removed laser pulses reflected from vegetation cover, and retained those returning from the ground surface. The resolution of the resulting DEM is therefore at a minimum where the fault rupture extends through forest cover, and at a maximum in unobscured terrain. Average point cloud shot density of ground returns only is 6.3 points per square meter.

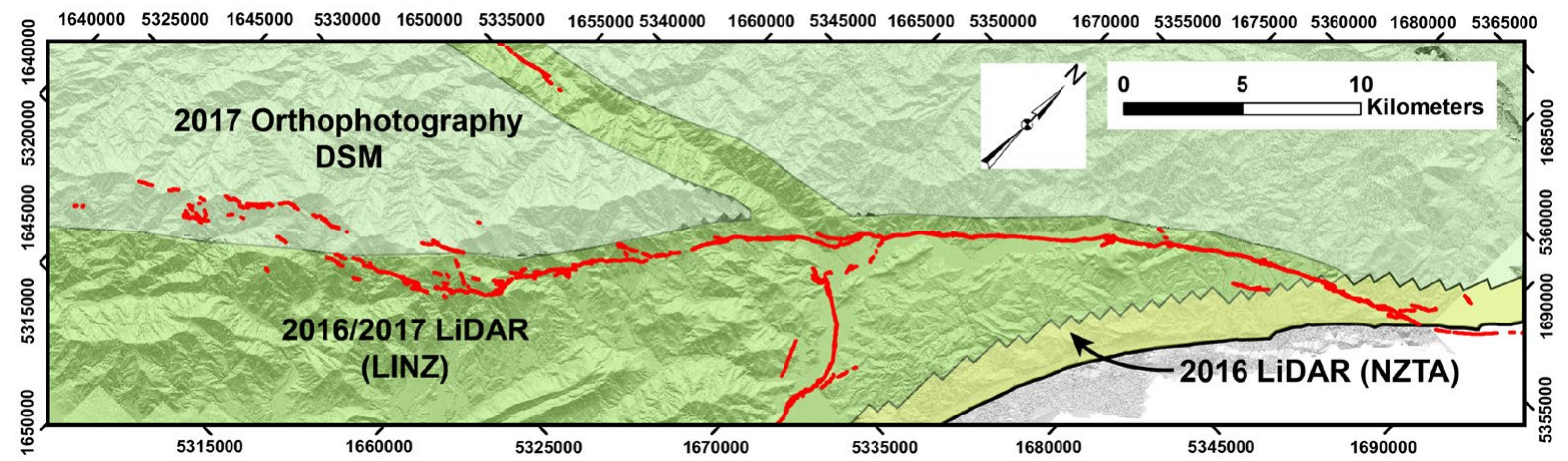

Figure 2.1: Map of LiDAR and DSM aerial extent. Bold red lines are the 2016 surface rupture. See text above for details.

In addition to this, a Digital Surface Model (DSM) was compiled in the area where LiDAR coverage was lacking on the Manakau fault (Fig. 2.1). This DSM was processed photogrametrically from an aerial photographic survey flown during 15-16th, 21st, 24th of February 2017, and was commissioned by LINZ. The ground distance spacing between photographs was $0.3 \mathrm{~m}$, resulting in a DSM cell size of $1 \mathrm{~m}$.

Digitizing of the 2016 surface fault rupture traces was performed in ESRI ArcMap software at a scale of 1:1000, utilising combinations of the LiDAR-derived DEM and accompanying ortho-rectified aerial photographs, the photography-derived DSM, and field the observations. 

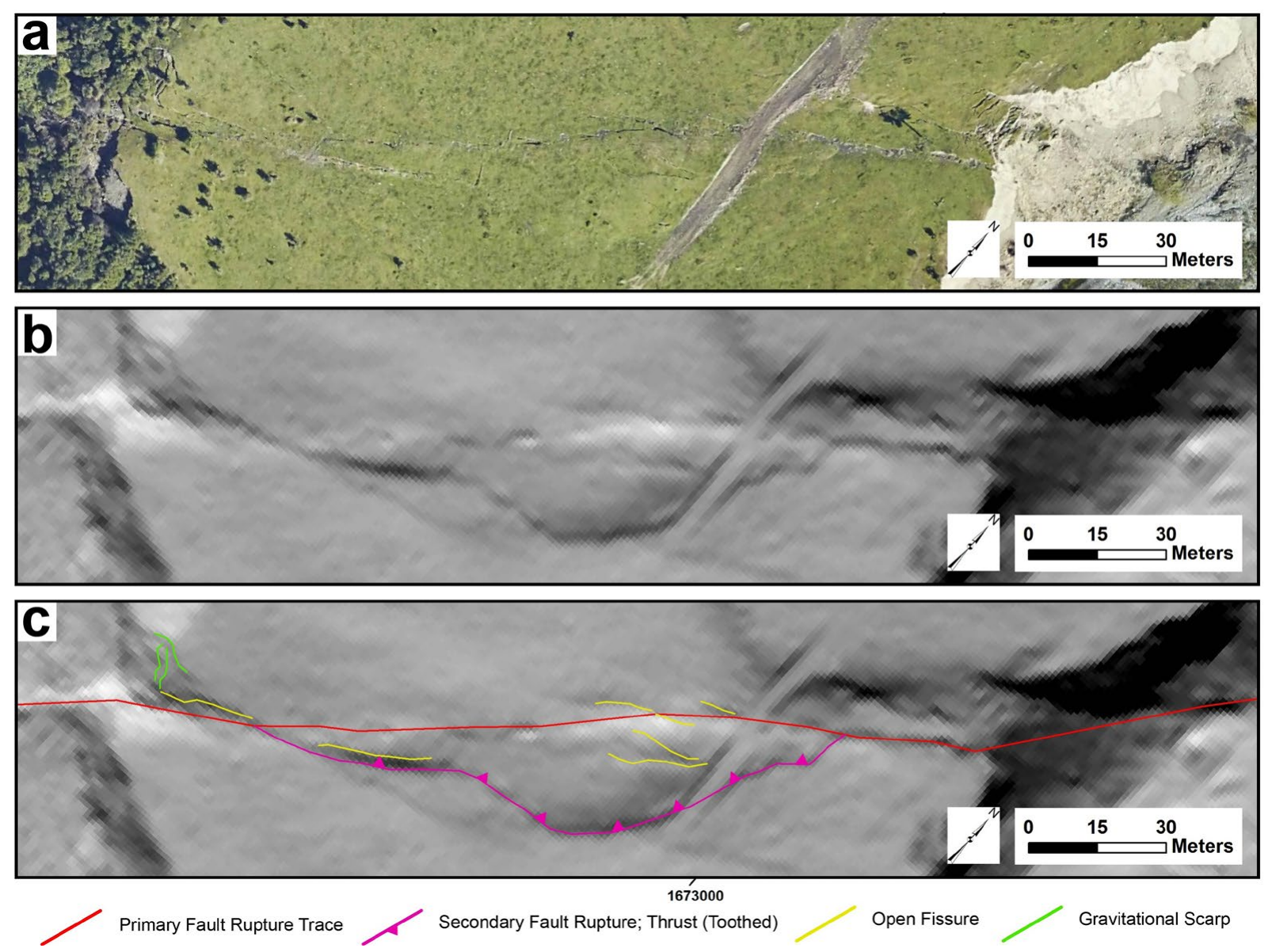

Figure 2.2: Example of DEM and orthophotography resolution, before and after fault rupture digitizing. (a) orthophotography of a $250 \mathrm{~m}$ length of surface fault rupture (b) LiDAR-derived DEM of the same area of fault rupture. (c) LiDAR-derived DEM superimposed with fault rupture digitizing.

Post-earthquake aerial ortho-photography was especially valuable to identify fine-scale features such as ground fissures that could not be resolved by the DEM. In areas where DEM resolution was poor (e.g., in forested areas) and where aerial photography was uninformative, digitizing instead relied heavily on direct field observation. Even in areas where the surface rupture was obvious in the DEM, field observations were always considered first before digitizing fault traces from the remote data. Figure 2.2 shows an $\sim 1: 2000$ scale example of the aerial photography and DEM before and after interpretation and digitizing was executed.

Individual fault rupture traces encompass a zone of ground rupture deformation that is between 0.2 - 5m wide. Head scarps of gravitationally-induced failures have also been digitized (called "gravitational scarp") by us, although these may not be the result of direct earthquake-induced shear failure (Fig. 2.2). "Primary surface ruptures" accomodated the majority of the co-seismic strike-slip displacement during the earthquake. "Secondary surface rup- 
tures", where identified, represent traces that accommodated relatively minor displacement. "Open fissures" are largely extensional structures, although many also accommodated shear displacement.

\subsubsection{Co-seismic Displacement Data}

Co-seismic displacements along the KFN during the 2016 Kaikōura earthquake are described and evaluated in detail in Chapter Three. For completeness and ease of reference, these data are plotted on the map tiles displayed below. Beside each measured displacement magnitude is the corresponding site ID that refers to a locality cited in Chapter Three. Dextral displacements are coloured black, while vertical displacements are coloured red and are positive (up-to-the-northwest) or negative (up-to-the-southeast, and coloured blue) depending on the sense of throw.

\subsubsection{Wear Striae and Fault Attitude Data}

During field investigations we observed many free face exposures of the 2016 surface fault rupture on the Kekerengu fualt. Free faces were seen on the steep walls of some deep fault fissures and crevasses, and also on fresh fault planes in bedrock that were exposed by large strike-slip displacements. The exposed fault surfaces were sub-planar to planar, and were commonly smeared with a 1-2 cm-thick layer of soft fault gouge. Fine wear striae were inscribed on this gouge layer and in some cases were traceable over distances of up to $6 \mathrm{~m}$. Chapter 4 is concerned with documenting these striae in detail, but the locations where striae were observed are plotted and labelled on the map tiles below.

The orientations of wear striae were recorded as a pitch angle and pitch direction that made an acute angle with respect to fault strike. These data were measured using a protractor and bubble level. Because most striae were curved along their length with one end being at a near-horizontal pitch $\left(0^{\circ}\right)$, the angles reported in map tiles below represent the steepest part of that curve. These measurements are displayed both as a blue arrow that points in the direction that made an acute angle with respect to fault strike, and a pitch angle in degrees plotted near the head of that arrow (that is the maximum angle of pitch observed). The attitudes of the fault surfaces that contained the observed striae were also measured. These measurements 
were performed with a geological compass. Fault attitudes are displayed with a black arrow in the dip direction of the free face surface, together with dip angle in degrees. Each site where striae were measured is given a unique letter code (e.g., "a" "b" "c" etc.), which are the same as those used in Chapter Four.

\subsubsection{Throw and Scarp Facing Direction}

Much of the 2016 surface rupturing of the KFN broke pre-existing scarps. Because the degree of pre-existing fault topography at a particular site was commonly uncertain, determining the magnitude of vertical displacement during the 2016 earthquake was not always straightforward. This is because the scarp of the 2016 rupture typically included some height that was inherited from previous earthquakes. In the map tiles below, I have not plotted scarp heights, only the scarp facing directions. These are displayed as either "NE", "SE", "SW" or "NW" and placed adjacent to the trace to which they refer. Although in many cases scarp facing direction may reflect 2016 co-seismic throw, it is common for strike-slip motion to juxtapose separate elements of the pre-existing topography, a displacement that can generate a scarp without necessarily any vertical motion. Where known, the actual sense of 2016 co-seismic throw (vertical slip of the northwest side relative to the southeast side) is mapped as either up-to-the-northwest or up-to-the-southeast, and is plotted on the map tiles as red or blue, respectively.

\subsubsection{Particular Fault Rupture Morphologies and Accompanying Field Photographs}

The locations of particularly interesting or informative ground surface rupture features are included in the fault rupture maps. Such features include: free faces; collapsed hanging walls; shutter ridges; moletracks; sag ponds; fault crevasses; offset stream channels; compressional bulges; fault-dammed lake/ponds; uphill-facing scarps; split trees; and even an offset paleoseismic trench. For the majority of these features, many of which have been eroded or otherwise degraded since the earthquake, I have included documentary field photographs, and these are displayed in Appendix 3. The location of each image is displayed in the map tiles below, and each image has an index number corresponding to the particular map tile where it is found. For example, a photograph of the fault rupture at the coast has an index number "ph1.0" displayed in the top left of that image, and its location can be found in map tile 1. 
"ph" refers to 'photograph' and "1.0" refers to the map tile on which the photograph is located. The date that each photograph was captured is displayed next to its index number.

\subsection{Fault Rupture Map Tiles}

To include as much of the surveyed detail as possible, the $\sim 53 \mathrm{~km}$ of ground-surface rupture has been divided into 20 tiles, each of which are displayed at a scale between 1:4,800 and 1:27,000. Areas of surface fault rupture that contain detailed structure are displayed at a larger scale than those which are simpler. Fault rupture mapping has been superimposed upon a hill-shaded version of the one-meter LiDAR DEM, which has been illuminated from an azimuth of $315^{\circ}$. Figure 2.3 is an accompanying index map that shows the extent of each individual map tile. In order to optimise the area each tile occupies, the orientations of individual map tiles have been rotated between $30^{\circ}$ and $50^{\circ}$ clockwise.

\subsubsection{Individual Map Tiles}

20 high-resolution fault rupture maps are presented below. They are arranged in a northeast-to-southwest sequence starting at the east coast of the South Island (Map Tile \#1), and continuing to the Seaward Kaikōura Ranges in northern Canterbury (Map Tile \#20). The tiles depict surface fault rupture features on the Kekerengu, Jordan thrust, Upper Kowhai and Manakau faults. The offshore continuation of seabed rupture of the Needles fault between Kekerengu and Cape Campbell is presented in Chapter Three.

Map Tile \#1. Near the Marlborough coast, the most north-easterly part of the onshore Kekerengu fault rupture extended across a field of coastal sand dunes and gravel-rich beach face deposits (Fig. 2.4). Here the surface rupture trace became submarine as it continued northeast into the Pacific Ocean where the Kekerengu fault is renamed the Needles fault. Approximately $200 \mathrm{~m}$ southwest from the coast, the Kekerengu fault rupture displaced the main-trunk railway line and State Highway 1, both of which are important infrastructural routes that connect the North and South Islands. Tirohanga Lagoon formed immediately after the earthquake due to $\sim 2 \mathrm{~m}$ of ground subsidence near the fault rupture trace together with damming of Tirohanga Stream against the fault rupture scarp. The width of the surface rup- 


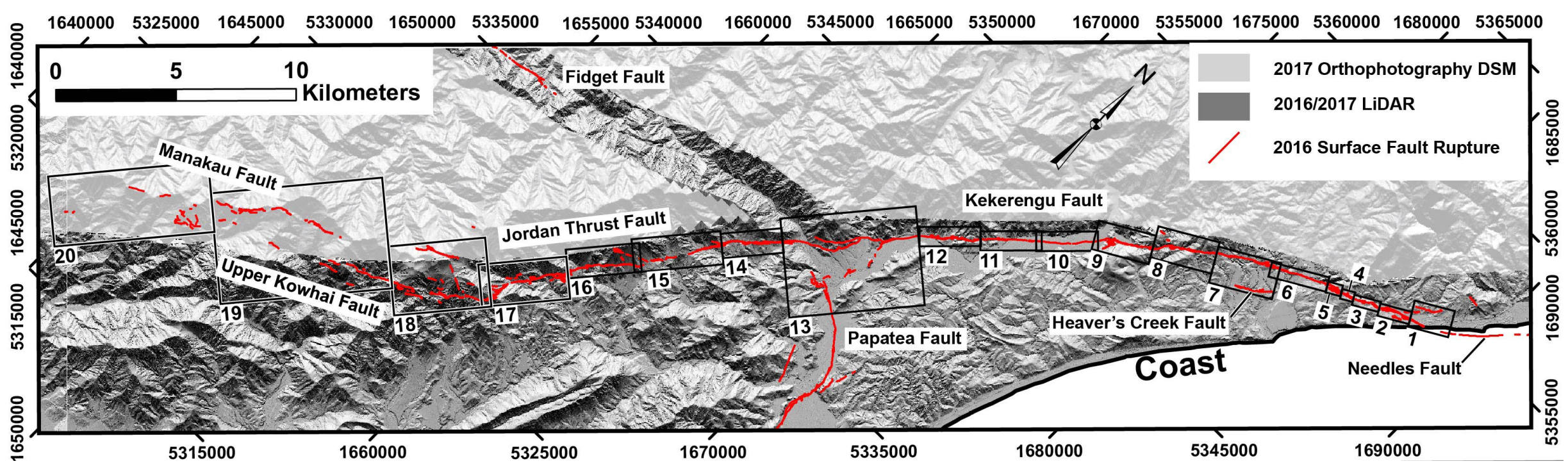

Figure 2.3: Index map showing the location of each map tile from \#1 to \#20. Aerial coverage of LiDAR-derived DEM and photography-derived DSM also shown. 


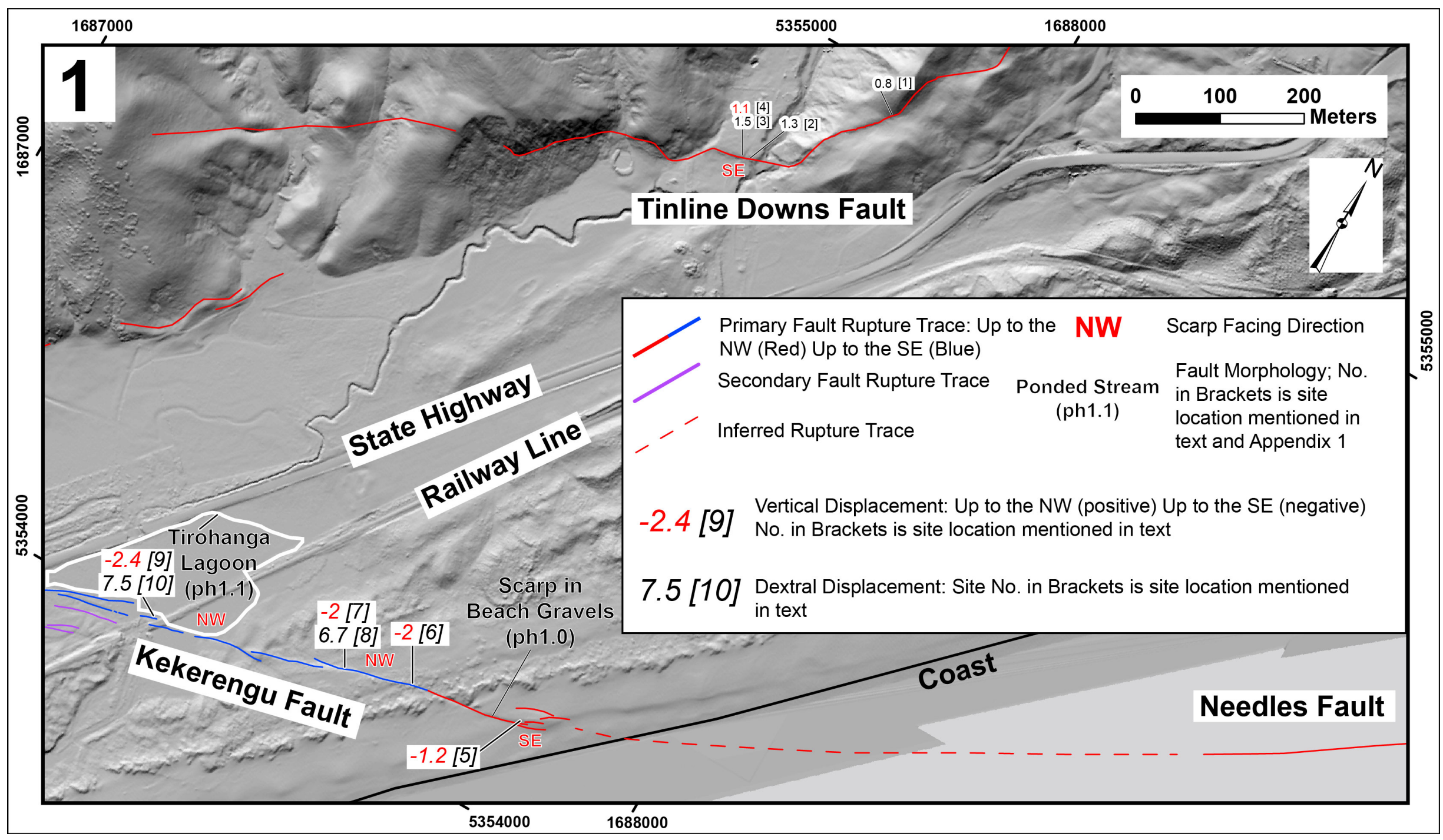

Figure 2.4: Map tile \#1, depicting surface rupture deformation on the Kekerengu fault. Background topography is the hill-shaded LiDAR DEM, illuminated from the northwest. 
ture ground deformation between the coast and the railway line was mostly between 5-10 m where traversing unconsolidated sand dunes; however, it was locally up to $30 \mathrm{~m}$ wide where crossing unconsolidated beach gravels at the coast (Fig. 2.4). Three secondary fault strands, spaced between 5 and $20 \mathrm{~m}$ apart were mapped between the railway line and State Highway. These strands occupy a surface rupture ground deformation zone that is $\sim 70 \mathrm{~m}$ wide. No exposures of the Kekerengu fault plane were observed in this area. Dextral displacements along this coastal stretch of the Kekerengu fault were between 6.7 and $7.5 \mathrm{~m}$, whereas vertical displacement on the Kekerengu fault at the coast was $1.2 \mathrm{~m}$, upthrown to the northwest where it was distributed across a width of $<10 \mathrm{~m}$ on the beach. Approximately $100 \mathrm{~m}$ to the southwest of the beach, the sense of throw changes to become up-to-the-southeast with magnitudes between -2 and $-2.4 \mathrm{~m}$ (this includes subsidence on the northwest side). This sense of throw continues southwest to the margins of map tile \#1. Using the railway line as a displaced marker, $-2.4 \mathrm{~m}$ of vertical displacement was observed to be accommodated over an acrossstrike distance of $1100 \mathrm{~m}(1.1 \mathrm{~km})$. Over half of this vertical slip $(1.5 \mathrm{~m})$ was focused over an across-strike width of $<10 \mathrm{~m}$ at the fault trace. A northern splay of the Kekerengu fault called the Tin Line Downs fault, produced $<1.5 \mathrm{~km}$ of surface rupture during the Kaikōura earthquake. This strand had up to $1.5 \mathrm{~m}$ of dextral displacement and $1.1 \mathrm{~m}$ of vertical displacement.

Map Tile \# 2 Surface fault rupture extended southwest from the state highway across a ploughed field where a small lagoon formed immediately after the earthquake (Fig. 2.5). Continuing further southwest, surface rupture traversed steep northwest-facing grassy slopes formed of hard limestone, and was expressed there as an $\sim 80-\mathrm{m}$-wide belt of extensional open fissures. Scarp heights within this area were less than $0.5 \mathrm{~m}$ high. A fence line that extends across this belt of open fissures (site 15), was surveyed after the earthquake, revealing that $8.1 \mathrm{~m}$ of co-seismic dextral displacement was distributed (nearly homogeneously) across the width of this belt. This zone of distributed dextral shear extended beyond the observable width of ground fissuring, to a distance of $112 \mathrm{~m}$ across the strike of the Kekerengu fault. Out of the many sites that allowed the across-strike distributions of co-seismic slip to be investigated using fence lines as linear strain markers $(n=40)$, this site recorded the most widely distributed zone of dextral displacement that was observed. By contrast, on flat ground between sites 12 and 13, the width of surface rupture deformation is mostly between $3-5 \mathrm{~m}$ and is up to $15 \mathrm{~m}$ wide at site 13 . Scarp heights here were less than $0.5 \mathrm{~m}$ high, except for a restraining bulge near site 13 where the scarp was $1.5 \mathrm{~m}$ high. Across limestone bedrock 


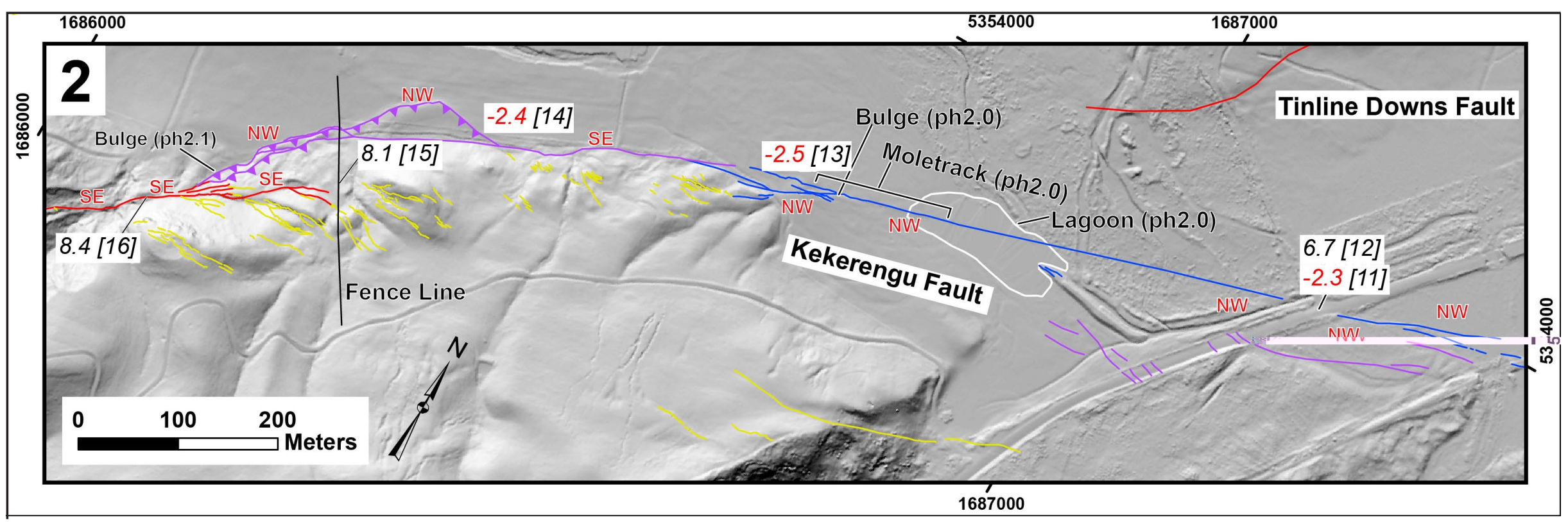

Figure 2.5: Map tile \#2, depicting surface rupture deformation on the Kekerengu fault. Background topography is the hill-shaded LiDAR DEM, illuminated from the northwest.

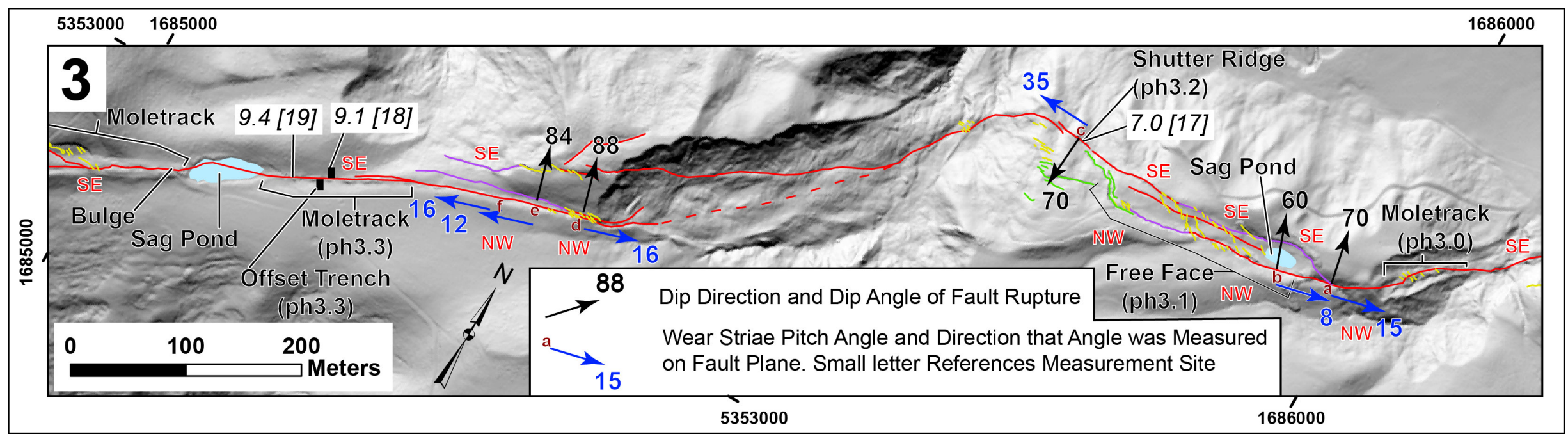

Figure 2.6: Map tile \#3, depicting surface rupture deformation on the Kekerengu fault. Background topography is the hill-shaded LiDAR DEM, illuminated from the northwest. 
hillslopes between sites 13 and 16, the width of surface rupture deformation averages $100 \mathrm{~m}$, and is locally up to $140 \mathrm{~m}$. Secondary reverse faults and turf rolls were mapped at the base of the steep northwest-facing hillslopes. These features collectively accommodated minor $(<1$ m) dextral displacement. No exposures of co-seismic slip planes were observed within map tile \#2. Co-seismic dextral displacement increased from 6.7 - 8.4 m between sites 12 and 16 . Measurement of co-seismic vertical displacement was only available east of site 14 where throw was between $-2.3--2.5 \mathrm{~m}$ in an up-to-the-southeast sense. Southwest of site 15, the scarp faced consistently to the southeast, suggesting that throw had changed to become upto-the-northwest.

Map Tile \#3 Figure 2.6 depicts surface fault rupture extending along the crests of coastal grass hillslopes, where it re-occupied the pre-existing fault topography. Noteworthy features include a sag pond $\sim 100 \mathrm{~m}$ east of site 17 . There co-seismic deepening of this pond was accompanied by the formation of wear striae on an $\sim 2 \mathrm{~m}$-high free face exposure of a fault splay on the southern side of the pond (see "ph3.1", Appendix 1). Scarp heights were between 1.5 - $3 \mathrm{~m}$ high and surface rupture deformation was $25 \mathrm{~m}$ wide in this ponded area. Scarps heights everywhere else in map tile \#3 were between 0 - $1 \mathrm{~m}$ except for the shutter ridge at site 17 where oblique fault motion juxtaposed the topography of a small spur to create a 2.5 $\mathrm{m}$-high, southwest-facing scarp. $500 \mathrm{~m}$ to the southwest of the pond, strongly-localised lateral displacement caused the ground surface to become buckled and twisted into what is known as a moletrack ("ph3.3”), with localised bulges up to $1.5 \mathrm{~m}$ high. A paleoseismic trench that had been excavated in early 2016 before the earthquake was displaced dextrally by $9.1 \mathrm{~m}$ (site 18) across this moletrack. Surface rupture width remained narrow $(<5 \mathrm{~m})$ between site 17 and west margin of the tile, except $\sim 150$ m northeast of site 18 , where multiple rupture strands overlapped to span a width of $30 \mathrm{~m}$. Six exposures of the co-seismic slip plane (sites

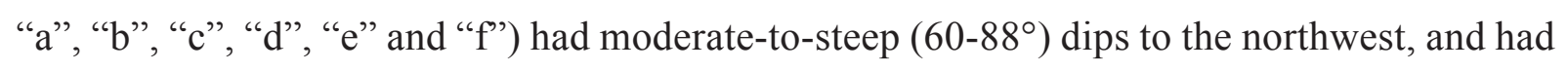
wear striae preserved on their surfaces. Dextral displacement at site 17 was $7.1 \mathrm{~m}$; however, only one strand out of a 70 m-wide zone was sampled here. In contrast, at sites 18 and 19 where $100 \%$ of co-seismic displacement was captured, dextral slip was up to $9.4 \mathrm{~m}$. Due to pre-existing fault topography at in this area, vertical displacements could not be measured.

Map Tile \#4 Surface fault rupture in Figure 2.7 bounded a string of sag ponds ("ph4.0”) where deformation was between 30 - $50 \mathrm{~m}$ wide, and continued southwest along a pre-exist- 


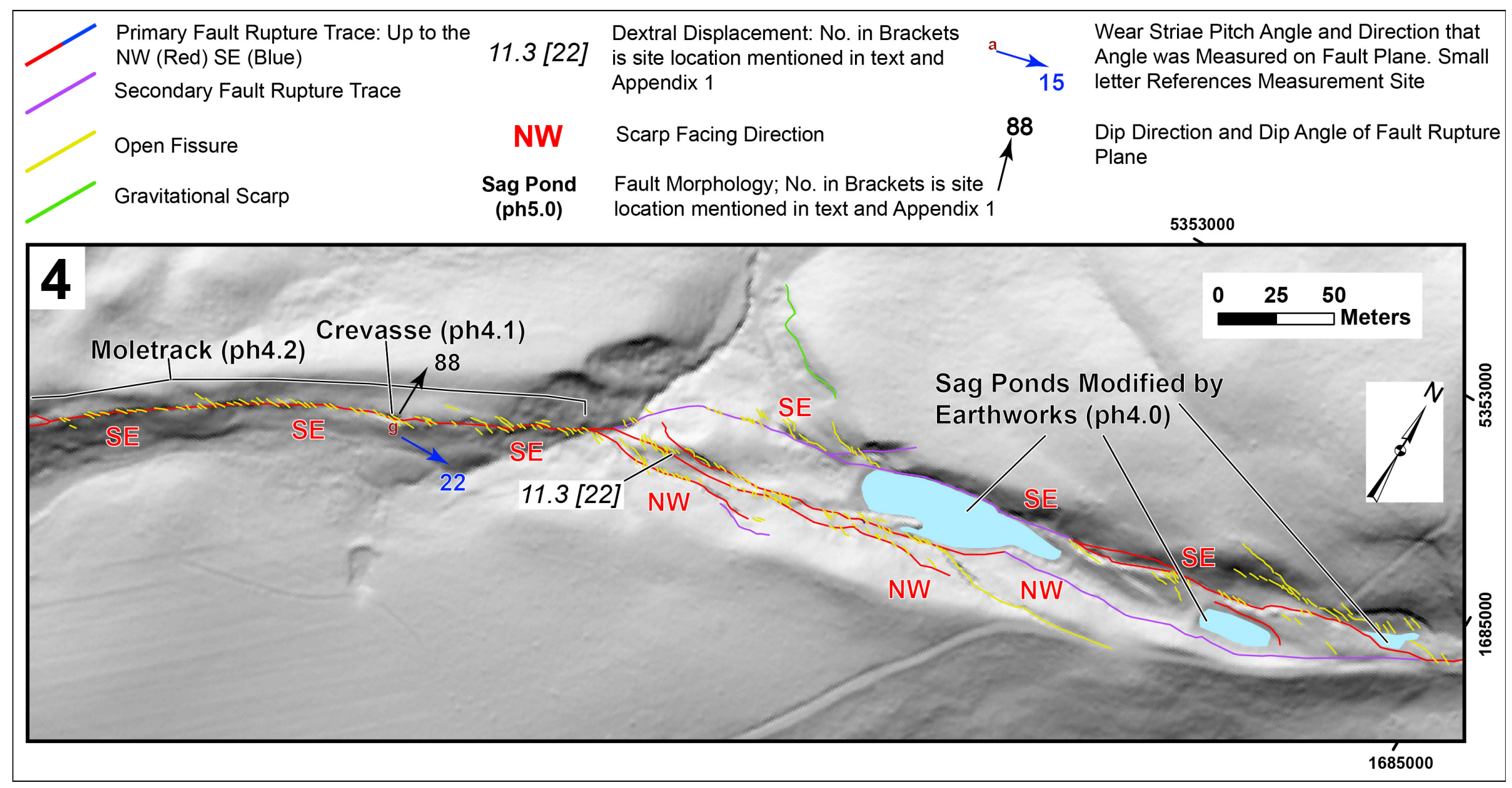

Figure 2.7: Map tile \#4, depicting surface rupture deformation on the Kekerengu fault. Background topography is the hill-shaded LiDAR DEM, illuminated from the northwest. 
ing 5 - 10 m-high fault scarp ("ph4.2"). Scarps that were facing into-and bounding-the sag pond depression were all between $0-1 \mathrm{~m}$ high. Within one moletrack to the southwest ("ph4.2"), dozens of open fissures - most also including some dextral shear displacement (up to $40 \mathrm{~cm}$ ) - are mapped within this zone of primary fault rupture. These features were arranged in a left-stepping en echelon manner at a cockwise angle of $20-30^{\circ}$ to the trend of the moletrack, were spaced 2 - $5 \mathrm{~m}$ apart and had typically had apertures between $30-50 \mathrm{~cm}$. Surface rupture width across this moletrack was $3-5 \mathrm{~m}$, while relief across the scarp was between $0.5-1 \mathrm{~m}$. Observations at this meter-scale were made possible by the ground surface being covered by only short grass at the time of the earthquake. One particularly large ( 5 m-long, 2 m-deep, 3 m-wide) extensional crevasse ("ph4.1") was observed with wear striae inscribed on its northwest wall (site "g"). Except for this large fault crevasse, no exposures of fault plane were observed. One displaced fence line at site 22 showed that dextral slip in this area was $11.3 \mathrm{~m}$; however no suitable markers of throw were measured.

Map Tile \#5 Figure 2.8 is centred on a 50 clockwise (releasing) bend in the Kekerengu fault, where a pull-apart graben has formed over many earthquake cycles. Primary surface rupture passed through the centre of this graben and separated up-to-the-northeast scarps to the northeast, from up-to-the-southwest scarps to the southwest. Immediately east of this extensional basin is the location of two other paleoseismic trenches that were excavated in early 2016 before the Kaikoura earthquake; one was offset during the earthquake by $\sim 9 \mathrm{~m}$, and the other was not, because it was excavated across a fault furrow that did not rupture in 2016. Surface rupture entered the pull-apart graben from the east—and exited to the west — as a narrow, 5 m-wide moletrack. Within the graben, ground deformation spans a width of 300 $\mathrm{m}$; this consists of an array of oblique-normal fault scarps. They comprise the widest zone of ground rupture deformation that we observed on the Kekerengu fault. Fault dips were not observed here, except for the wall of a $1 \mathrm{~m}$-wide, $\sim 3 \mathrm{~m}$-deep crevasse on the northeast side of the graben that was near vertical ("ph 5.0"). This wall had horizontal wear striae preserved on its surface. Individual scarp heights were between $0.5-1 \mathrm{~m}$, and the scarps faced towards the centre of the graben. Co-seismic dextral displacement was $\sim 7.5 \mathrm{~m}$, as was measured from a displaced farm track and an adjacent fence line (sites 23 and 24). There were no vertical displacement measurements made in this area. 


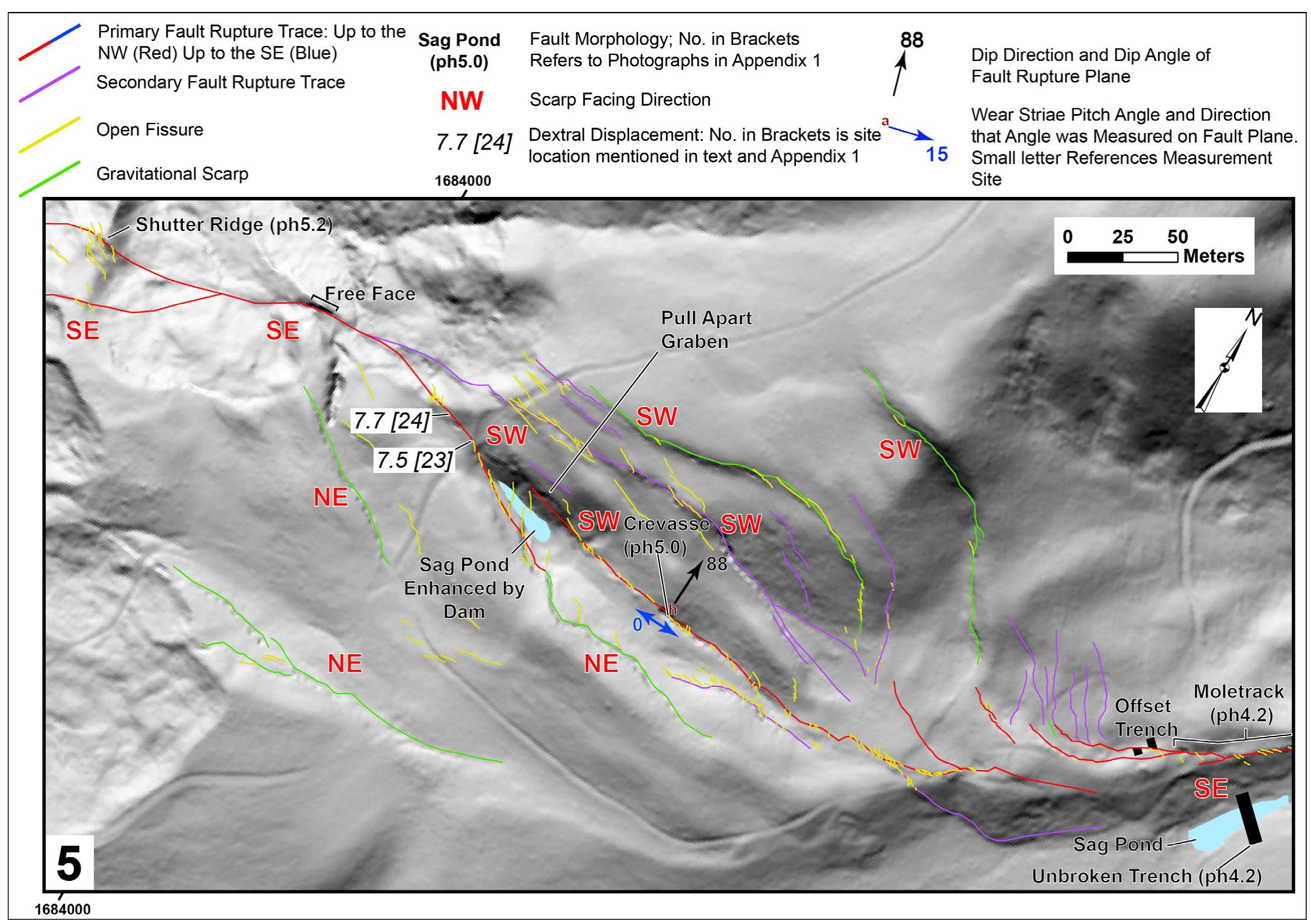

Figure 2.8: Map tile \#5, depicting surface rupture deformation on the Kekerengu fault. Background topography is the hill-shaded LiDAR DEM, illuminated from the northwest. 


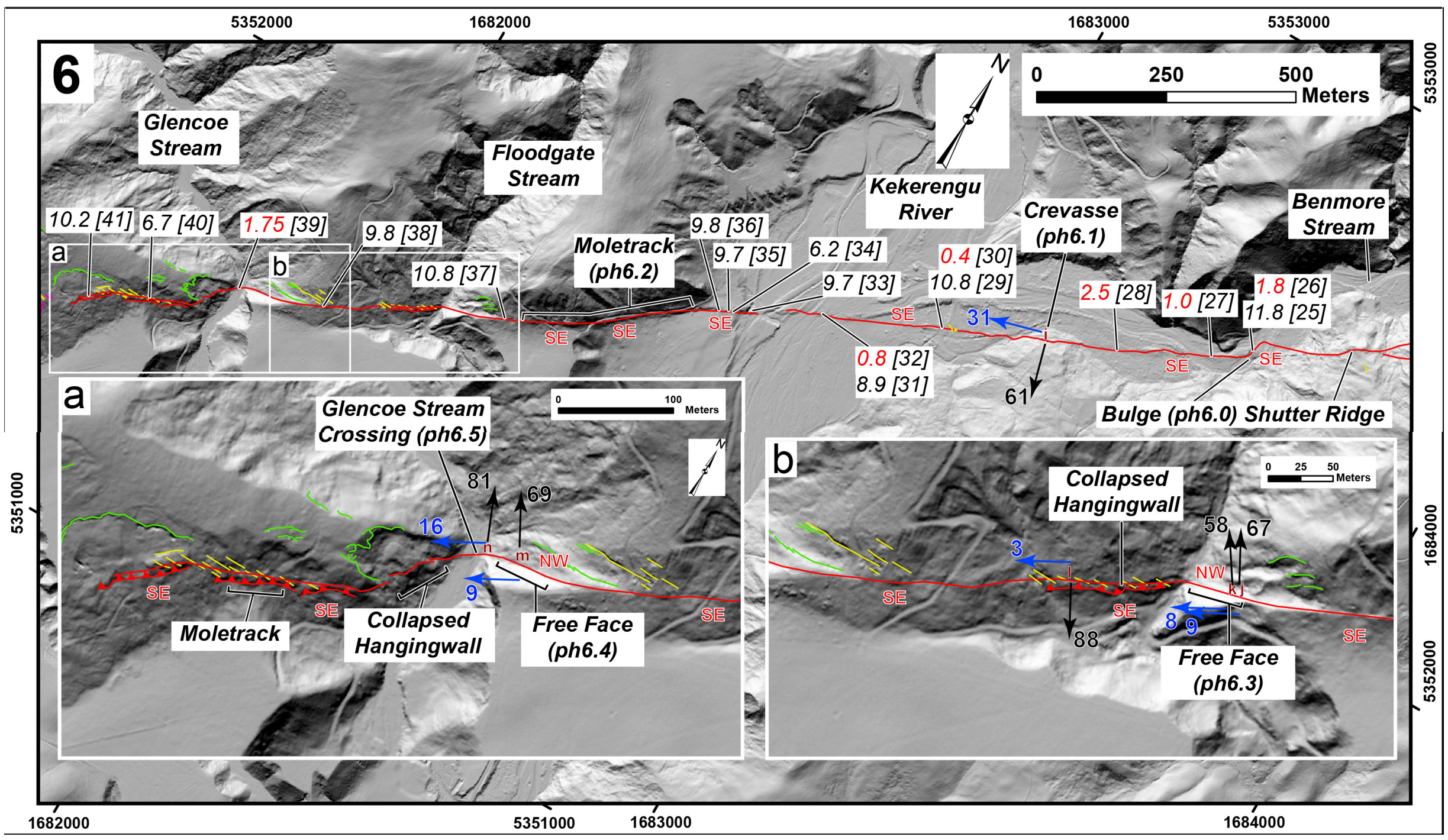

Figure 2.9: Map tile \#6, depicting surface rupture deformation on the Kekerengu fault. Background topography is the hill-shaded LiDAR DEM, illuminated from the northwest. 
Map Tile \#6 Figure 2.9 depicts 2016 surface fault rupture near the Kekerengu River, and three of its deeply-incised tributary streams: Ben More Stream, Floodgate Stream and Glencoe Steam. At Glencoe and Floodgate Streams, co-seismic dextral displacement of west-facing canyon walls exposed footwall free faces, which were $\sim 7 \mathrm{~m}$-wide in the slip direction ("ph6.3" and "ph6.4"). A farm cottage that was built across the trace of the Kekerengu fault (site 34), was offset during the earthquake, detached from its foundations and dextrally displaced by $6.2 \mathrm{~m}$. Ground rupture deformation was generally less than $5 \mathrm{~m}$ wide in the unconsolidated Ben More, Kekerengu and Glencoe Stream alluvial gravels, and scarp heights here were between $0.8-2.5 \mathrm{~m}$. Ground deformation width was $\sim 3 \mathrm{~m}$ on the west-facing canyon walls of Floodgate and Glencoe Streams, and scarp heights were between 0.5 - 2 m (primarily the result of dextral displacement of the canyon walls). Yet on east-facing walls where dextral slip created over-steepened hanging walls that collapsed gravitationally, deformation width was $\sim 20 \mathrm{~m}$ (insets a and b). Fault-plane exposure was excellent on the west-facing canyon walls of Floodgate and Glencoe Streams, and fault dips were to the northwest at angles between $67^{\circ}-81^{\circ}$. Wear striae were abundant on these planar fault surfaces, and recorded early oblique-reverse motion followed by an apparantly larger phase of dextral strike-slip. Another exposure of the fault was observed on the walls of a 4 m-deep, 2 m-wide, $15 \mathrm{~m}$-long fault crevasse ("ph6.1"). Co-seismic dextral displacement measurements were densely spaced in this area, have magnitudes between $8.9-11.8 \mathrm{~m}$ as provided by offset fences, stream channels, farm tracks, a hedge row and the aformentioned cottage foundation. Site 25 marks the maximum co-seismic dextral displacement observed during the Kaikōura earthquake which was $11.8 \mathrm{~m}$. Co-seismic throw was measured at 6 locations within the stream gravels. Because these areas were flat lying before the earthquake, the heights of the scarps are equal to the magnitude co-seismic throw (between $0.8-2.5 \mathrm{~m}$ ).

Map Tile \#7 Kekerengu fault rupture deformation crosses 7 spurs and tributary stream canyons of the Kekerengu River (Fig. 2.10). Between sites 47 and 58, native Manuka forest cover made it difficult to map detailed ground deformation structure-both in the field and using the DEM. However, a $5 \mathrm{~m}$-wide swath of fallen and uprooted trees made the trace easy to follow on foot, and clear in the aerial imagery. On a recently deforested, steep grass slope between sites 41 and 47, the trace of the 2016 surface rupture was difficult to identify, as it was not expressed at the surface except for several open fissures and landslide head scarps. This was probably due to gravitational collapse of the hangingwall, which occupies most 


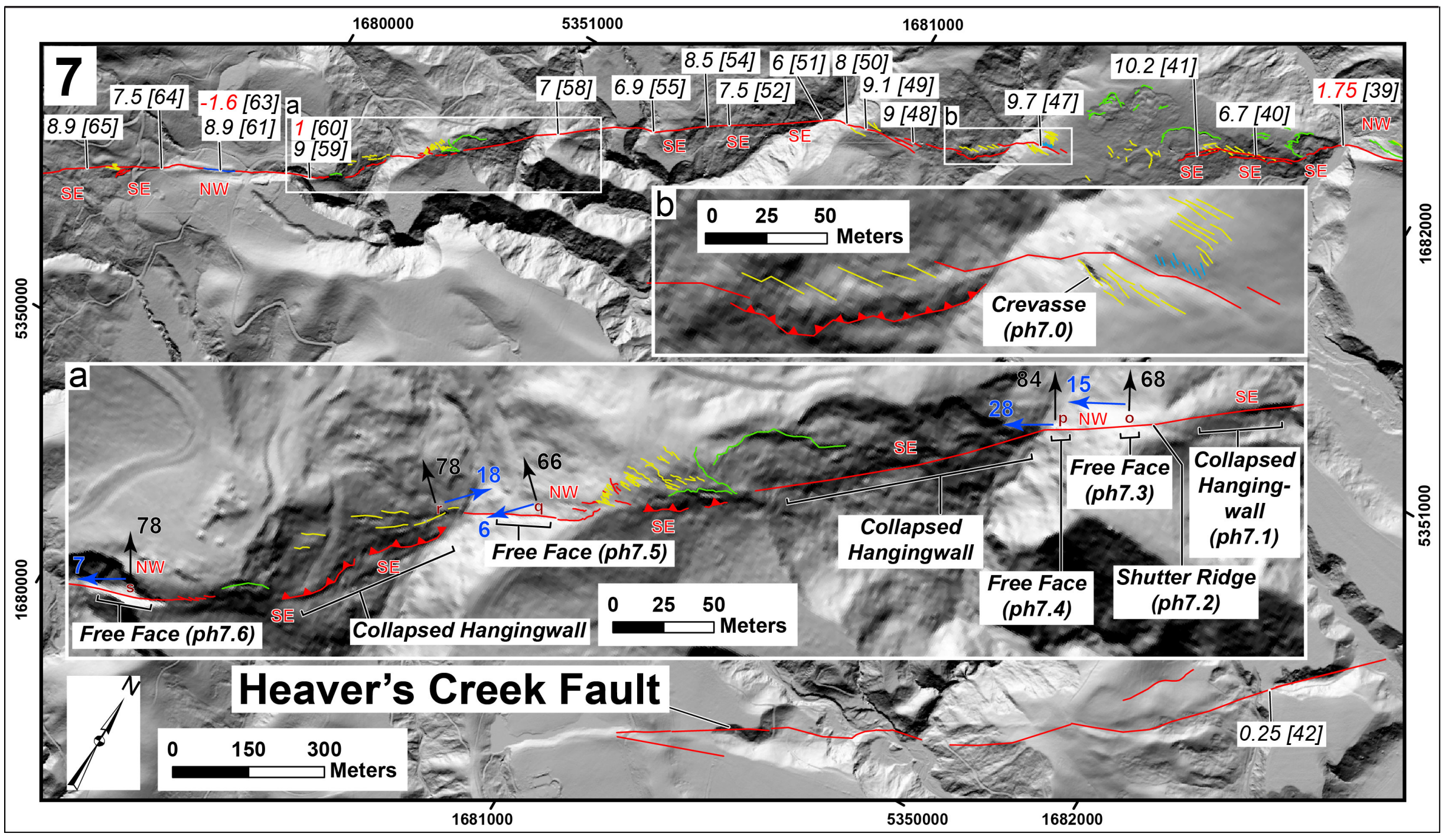

Figure 2.10: Map tile \#7, depicting surface rupture deformation on the Kekerengu fault. Background topography is the hill-shaded LiDAR DEM, illuminated from the northwest. 
of this hillslope. Here the width of ground deformation was particulalry wide $(150 \mathrm{~m})$. The width of surface rupture deformation was hard to assess beneath the forest canopy between sites 47 and 58, but appeared to be $\sim 5-10 \mathrm{~m}$. Where surface rupture crossed the crests of spurs between adjacent streams, fault rupture was between $15-30 \mathrm{~m}$. Deformation was $\sim 3$ $\mathrm{m}$ wide on west-facing stream canyon walls, and $\sim 20 \mathrm{~m}$ the opposite side of the streams. Several free face exposures on west-facing stream canyon walls provided fault plane attitude measurements ("o" "p" “q" "r" "s"), which showed northwest dips angles between $66-84^{\circ}$. Wear striae were obvious on all free face exposures and all showed southwest pitch directions (oblique-dextral-reverse motion), some of which curved to become horizontal (dextral strike-slip motion) later in the earthquake sequence. Scarp heights in this area were generally between $0.5-1.5 \mathrm{~m}$ high, except for where stream-canyon walls were dextrally displaced $\sim 10 \mathrm{~m}$, creating free face scarps up to $2.5 \mathrm{~m}$ high. Co-seismic dextral slip was measured from displaced fence lines, ridge spurs, free faces and tree roots, with magnitudes between $6-9$ $\mathrm{m}$. Vertical displacements were only measured at two locations (sites 60 and 63). Offset tree roots at site 63 provided precise piercing points with which to measure an up-to-the-southeast throw of $-1.6 \mathrm{~m}$, while $200 \mathrm{~m}$ to the east at site 60 , an up-to-the-northwest throw of $1 \mathrm{~m}$ was measured using the DEM.

The Heaver's Creek fault surface rupture is located $\sim 2 \mathrm{~km}$ to the south of the Kekerengu fault and is $\sim 1.5 \mathrm{~km}$ long. It was identified in the field by discontinuous surface cracking that occupied the previously-mapped scarp of the Heaver's Creek fault (where the fault crosses Northing 5350000). A fence line at site 42 recorded $\sim 0.25 \mathrm{~m}$ of dextral displacement, but no vertical deformation could be identified.

Map Tile \#8 Notable features in Figure 2.11 include a spectacular example of a farm track that is offset $\sim 10 \mathrm{~m}$ across a $3-5 \mathrm{~m}$-wide moletrack "ph 8.0". Also of note is the left bend in the fault rupture at the southwest margin of Figure 2.11, with the bend in the trace deflecting sub-parallel to topographic contours of northwest-facing ridge. This bend is accompanied by a reversal in both the dip direction and sense of uplift on the Kekerengu fault, scarp heights between $1-2.5 \mathrm{~m}$ and ground deformation between 5 - $10 \mathrm{~m}$ wide. Free faces-both overhanging (hanging wall exposed "ph 8.5") and stable (footwall exposed) —were observed to dip southeast (e.g., site "u") within this bend. Wear striae preserved on one of these surfaces were curved, with an initially steep pitch $\left(40^{\circ}\right)$ indicative of dextral-reverse 


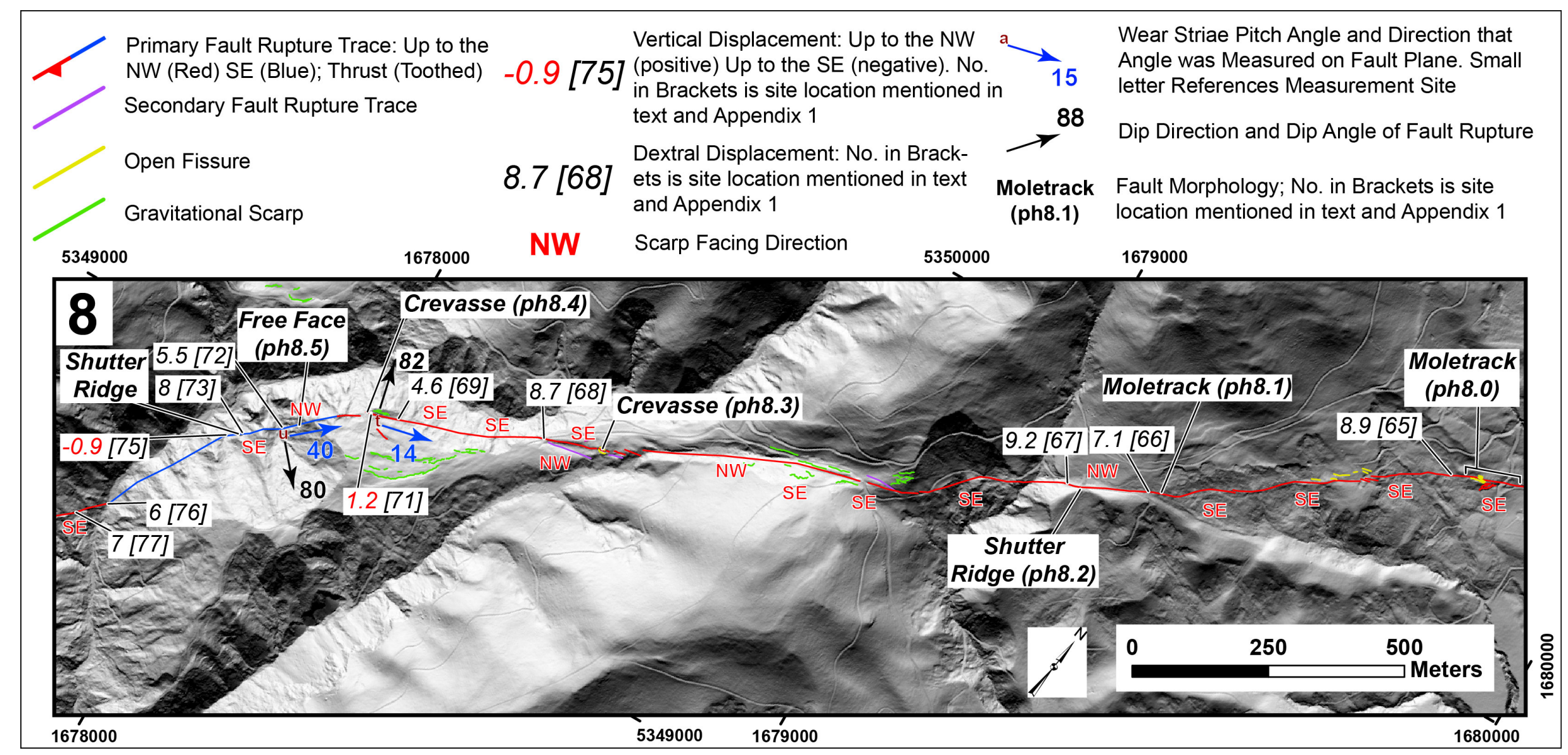

Figure 2.11: Map tile \#8, depicting surface rupture deformation on the Kekerengu fault. Background topography is the hill-shaded LiDAR DEM, illuminated from the northwest. 
motion, which became horizontal over a distance of $50 \mathrm{~cm}$ (site "u"). Surface fault rupture between sites 65 and 66 traversed slump-prone hillslopes where it was poorly expressed as a $5-10 \mathrm{~m}$-wide swath of open fissures and slope failures. Here scarp heights were $0.5 \mathrm{~m}$ or less. Between sites 68 and 69, surface rupture cut a $5 \mathrm{~m}$-wide swath of fallen and uprooted pine trees along a steep north-facing hillslope. The fault rupture scarp here was uphill-facing and between 0.5 - $1.5 \mathrm{~m}$ high. Between sites 75 and 77, the rupture was entirely buried by landslide debris. Fence lines, small spurs, canyon walls and tree roots were used to measure co-seismic dextral displacement magnitudes between 4.6-9.2 m. Vertical measurements of co-seismic slip were restricted to two locations (sites 71 and 75) where tree-root piercing points recorded throw of between $-0.9-1.2 \mathrm{~m}$.

Map Tile \#9 Surface fault rupture in Map Tile \#9 extended beneath pine forest cover to the northeast of site 82 , and continued across barren limestone scree slopes between sites 85 and 92 before reaching the Clarence River gorge in the southwest (Fig. 2.12). Interesting features in this area include two free faces that dip in opposite directions, and are spaced less than $50 \mathrm{~m}$ apart, both of which have striae recording oblique reverse motion (inset "a"). Where surface rupture cut across a water-saturated debris flow deposit, it was expressed as a 5 - 10 m-wide zone of deep (1 - 2 m), water-filled en echelon crevasses ("ph 9.3"). During the Kaikoura earthquake, the formation of an $\sim 2.4 \mathrm{~m}$-high, northwest-facing fault scarp in the gravels of the Clarence River gorge dammed the south-flowing Clarence River, forming a 400 m-long lake (“ph 9.5”). Width of surface deformation between sites 76 and 82 was $5 \mathrm{~m}$ or less, except at the ridge saddle near site 82 , where ground deformation was dispersed across an $\sim 100 \mathrm{~m}$ width. Within the limestone scree, surface fault rupture width was between $3-5$ $\mathrm{m}$ and formed an uphill-facing scarp. Between sites 92 and the Clarence River Gorge, surface rupture was not well expressed, and comprised an $~ 250$ m-wide zone of gravitational head scarps formed on the steep north-northwest-facing slopes. Information of fault dip was only available at sites "v" and "w" (inset "a"), where the fault rupture plane dipped both northwest and southeast at $>85^{\circ}$. Wear striae were preserved on both of these surfaces and showed curved trajectories indicative of initial dextral-reverse motion followed by later strike-slip. Scarp heights were most pronounced on these two canon-wall free faces (between $1.5-3 \mathrm{~m}$ high). Everywhere else to the northeast of the Clarence River gorge scarp heights were $0.5 \mathrm{~m}$ high or less, except for site 86 located in the bed of a small stream (1.5 m high). Fence lines, free faces, farm tracks, a gully and a split tree were used to measure co-seismic dextral slip magnitudes between $2.7-10.9 \mathrm{~m}$. Vertical displacement was calculated from the displace- 


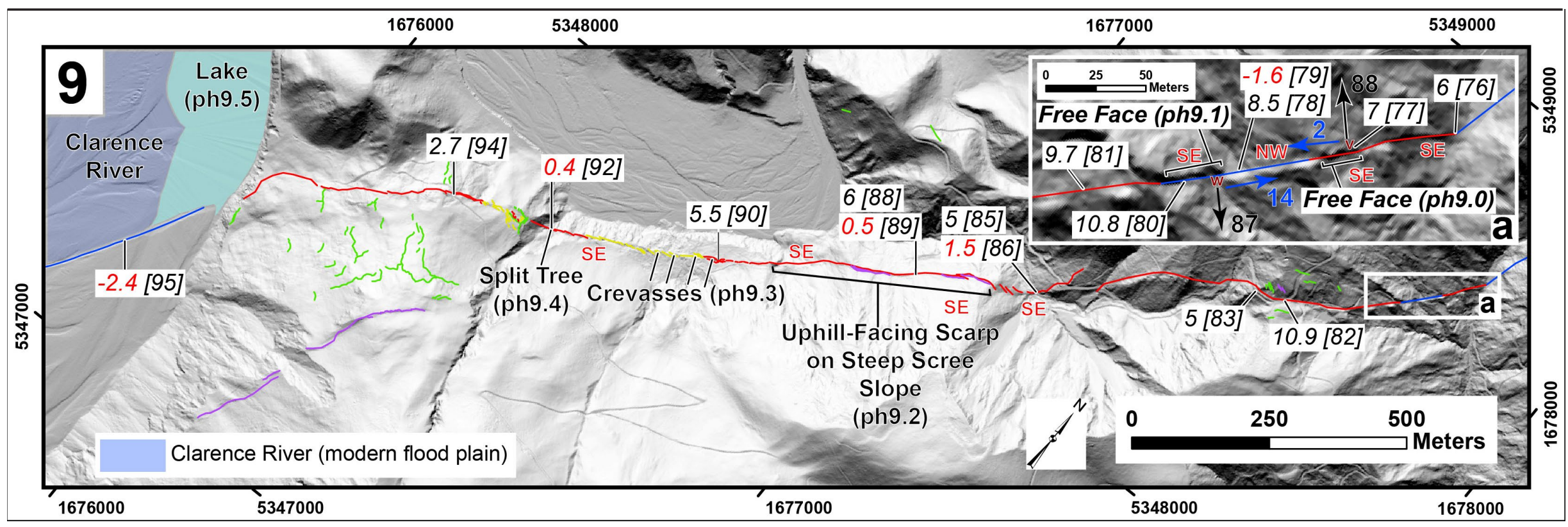

Figure 2.12: Map tile \#9, depicting surface rupture deformation on the Kekerengu fault. Background topography is the hill-shaded LiDAR DEM, illuminated from the northwest.

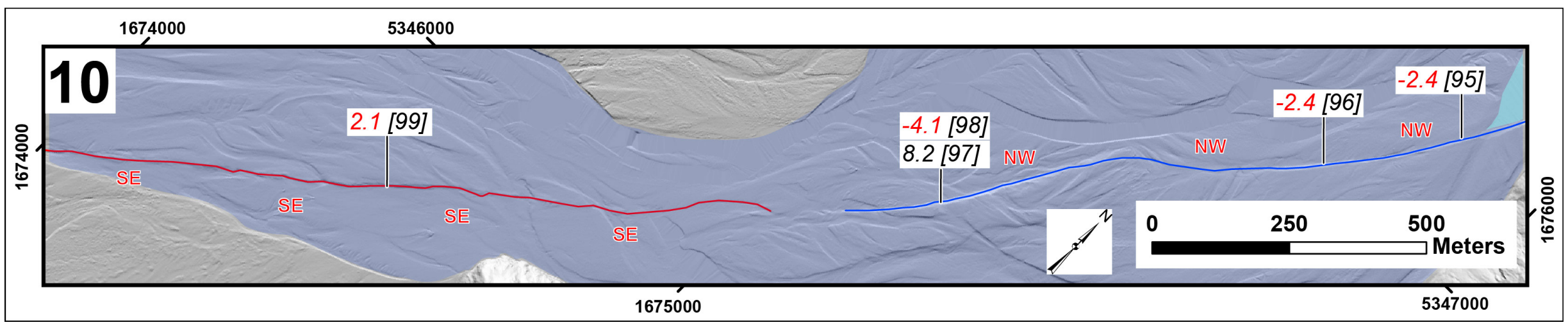

Figure 2.13: Map tile \#10, depicting surface rupture deformation on the Kekerengu fault. Background topography is the hill-shaded LiDAR DEM, illuminated from the northwest. 
ment of a split tree piercing point and the height of 2016 scarps on both the scree slope and the Clarence Riverbed (magnitudes between $0.4--2.4 \mathrm{~m}$ ). Throw was mainly up-to-thenorthwest, however this changed to become up-to-the-southeast in the Clarence River gorge.

Map Tile \#10 Figure 2.13 depicts surface fault rupture extending $\sim 2.5 \mathrm{~km}$ across the Clarence River braid plain, where it is formed a near-continuous scarp in modern river gravels. The largest observed scarp height on the Kekerengu fault of $4.1 \mathrm{~m}$ was observed at site 98 . Also of note was the simple geometry of the fault rupture, both in terms of its single-strand scarp-normal profile and the map-view linearity of its trace. Ground surface deformation was $\sim 10$ m wide where the scarp was high (e.g., site 98), and $4-5$ m-wide where scarp height was less (e.g., site 99). No exposures of the fault surface were available within the unconsolidated fluvial deposits. Scarp heights were mostly between $2-2.5 \mathrm{~m}$, but were locally up to 4.1 where the fault had a more northerly strike (site 98). One displaced river channel margin was used as a piercing point to calculate the magnitude of co-seismic dextral displacement ( $8.2 \mathrm{~m}$, site 97). Due the ground surface being flat lying before the earthquake, the height of the 2016 scarp was used as a measure of co-seismic vertical displacement. Between sites 95 and 98, vertical displacement was between $-2.4-4.1 \mathrm{~m}$ and was up-to-the-southeast; whereas southwest of site 97 , magnitudes of vertical motion were $\sim 2.1 \mathrm{~m}$ and up-to-the-northwest.

Map Tile \#11 Surface fault rupture deformation continued southwest within the Clarence River gorge, where significant post-earthquake modification had taken place before field observation commenced (between sites 100 and 102, Fig. 2.14). West of site 101 the rupture trace left the Clarence River to cut across terraces, steep stream beds and bedrock ridges of the Shag Bend, all of which were largely obscured by forest cover west of "ph 11.1". Ground deformation within the gorge was mostly $\sim 5 \mathrm{~m}$ wide, however was locally $20 \mathrm{~m}$ wide near site 100. Across the terrace and bedrock topography on Shag Bend to the southwest, surface rupture deformation was mostly less than $5 \mathrm{~m}$ wide; however, near bedrock crests and terrace risers it was wider $(25-50 \mathrm{~m})$. No fault exposures were observed within this area, except for several open fissures. The sinuosity of the map-view fault rupture trace as it traversed a $25 \mathrm{~m}$-high terrace suggests a moderate to steep northwest dip $\left(60-80^{\circ}\right)$. Co-seismic fault scarps were between $0.5-2.5 \mathrm{~m}$ high. West of "ph 11.1" scarp height was unknown, but was expected to be $\sim 1.5 \mathrm{~m}$ and facing southeast. Dextral displacements were derived from two fence lines and a stream channel margin, and were between $8-9.5 \mathrm{~m}$. Co-seismic vertical 


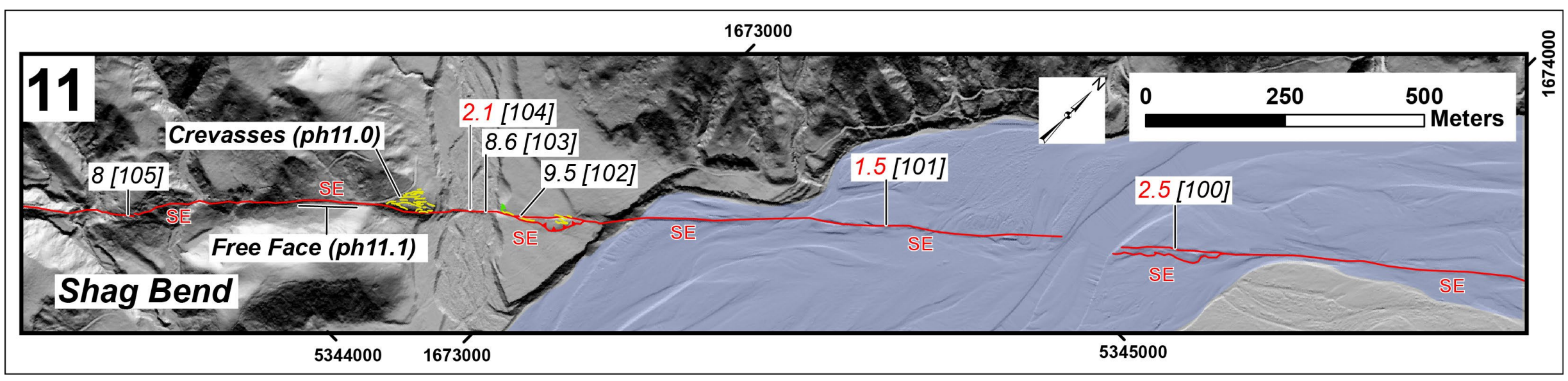

Figure 2.14: Map tile \#11, depicting surface rupture deformation on the Kekerengu fault. Background topography is the hill-shaded LiDAR DEM, illuminated from the northwest.

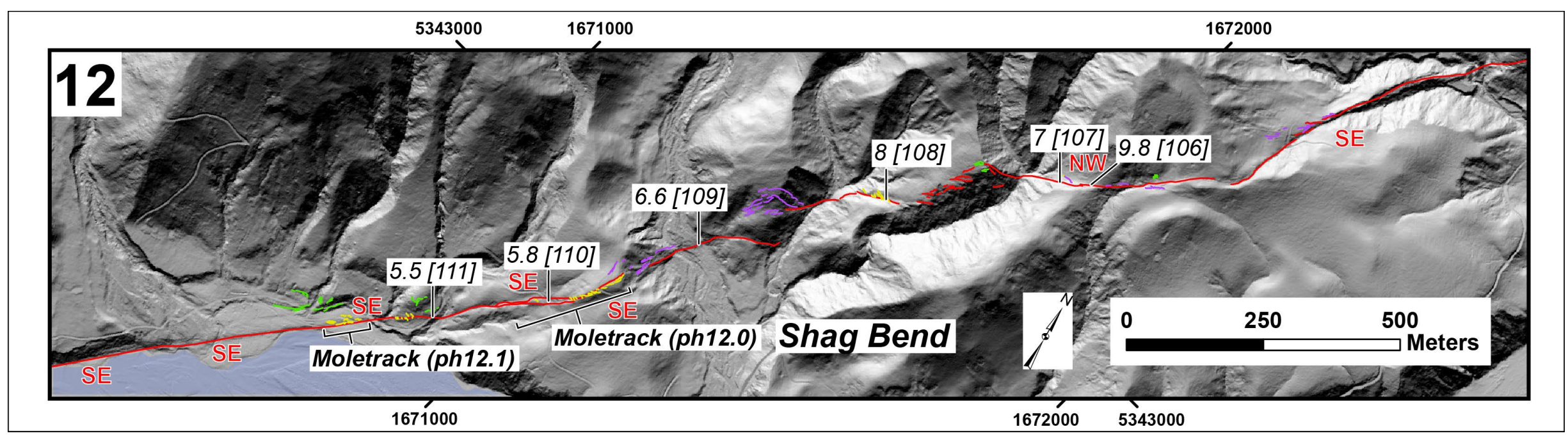

Figure 2.15: Map tile \#12, depicting surface rupture deformation on the Kekerengu fault. Background topography is the hill-shaded LiDAR DEM, illuminated from the northwest. 
displacements were measured from the heights of fault scarps within loose fluvial gravels and were between $1.5-2.5 \mathrm{~m}$.

Map Tile \#12 Surface fault rupture extended across $\sim 2 \mathrm{~km}$ of steep bedrock valleys and ridges before re-joining the Clarence River in the southwest of Figure 2.15. Between sites 106 - 110 was the most broken and discontinuous part of the 2016 Kekerengu fault surface rupture that we observed, while southwest of site 110 (" "ph 12.1) a well-expressed moletrack deformed a young river terrace. Surface deformation width was highly variable to the east of the Clarence River, and was particularly wide $(50-100 \mathrm{~m})$ where it cut bedrock ridge crests between sites 107 and 110. Elsewhere surface deformation was mostly between $5-10$ $\mathrm{m}$ wide, and was $\sim 5 \mathrm{~m}$ or less in the Clarence River gorge to the southwest of site 111 . No fault exposures were observed within this area, yet the sinuosity of the Kekerengu fault trace indicates a moderate to steep northwest dip $\left(60-80^{\circ}\right)$. Scarp heights were between $0.5-1.5$ $\mathrm{m}$, and mostly faced to the southeast. Dextral displacements were measured from farm tracks, fence lines and a large tree trunk, and were between $5.5-9.8 \mathrm{~m}$. No vertical displacement could be measured in this area.

Map Tile \#13 Figure 2.16 depicts the area near the three-way junction between the surface ruptures of the Kekerengu, Jordan Thrust and Papatea faults. This junction coincides with a northeast to southwest transition in sense of throw on the KFN, from predominantly up-tothe-northwest (to the northeast) to predominantly up-to-the-southeast (to the southwest). This transition spanned a distance of $\sim 2 \mathrm{~km}$ where the Kekerengu and Jordan Thrust fault ruptures overlapped one another, and were separated by a distance of $<70 \mathrm{~m}$ at their nearest point. Within this zone of overlap, the otherwise predominantly up-to-the-southeast Jordan Thrust fault ruptured the surface with an up-to-the-northwest (reverse) sense of throw; whereas the Kekerengu fault had an up-to-the-southeast sense of vertical displacement. Here the scarp of the Jordan Thrust was low lying $(<0.5 \mathrm{~m})$; however, southwest of this, where throw was up-to-the-southeast, scarp height was $\sim 3 \mathrm{~m}$. Dextral slip magnitudes on the Kekerengu Fault Network were between $2-7.6 \mathrm{~m}$, and were shared equally between the Kekerengu and Jordan Thrust faults where they overlapped one another (sites 121 and 122). Information on fault attitude was provided only by the sinuosity of the rupture traces, which revealed that the Jordan Thrust fault dipped to the northwest at a moderate angle $\left(40-60^{\circ}\right)$ southwest of site 121 , and more shallow angle $\left(20-30^{\circ}\right)$ where it became reverse to the northeast of site 


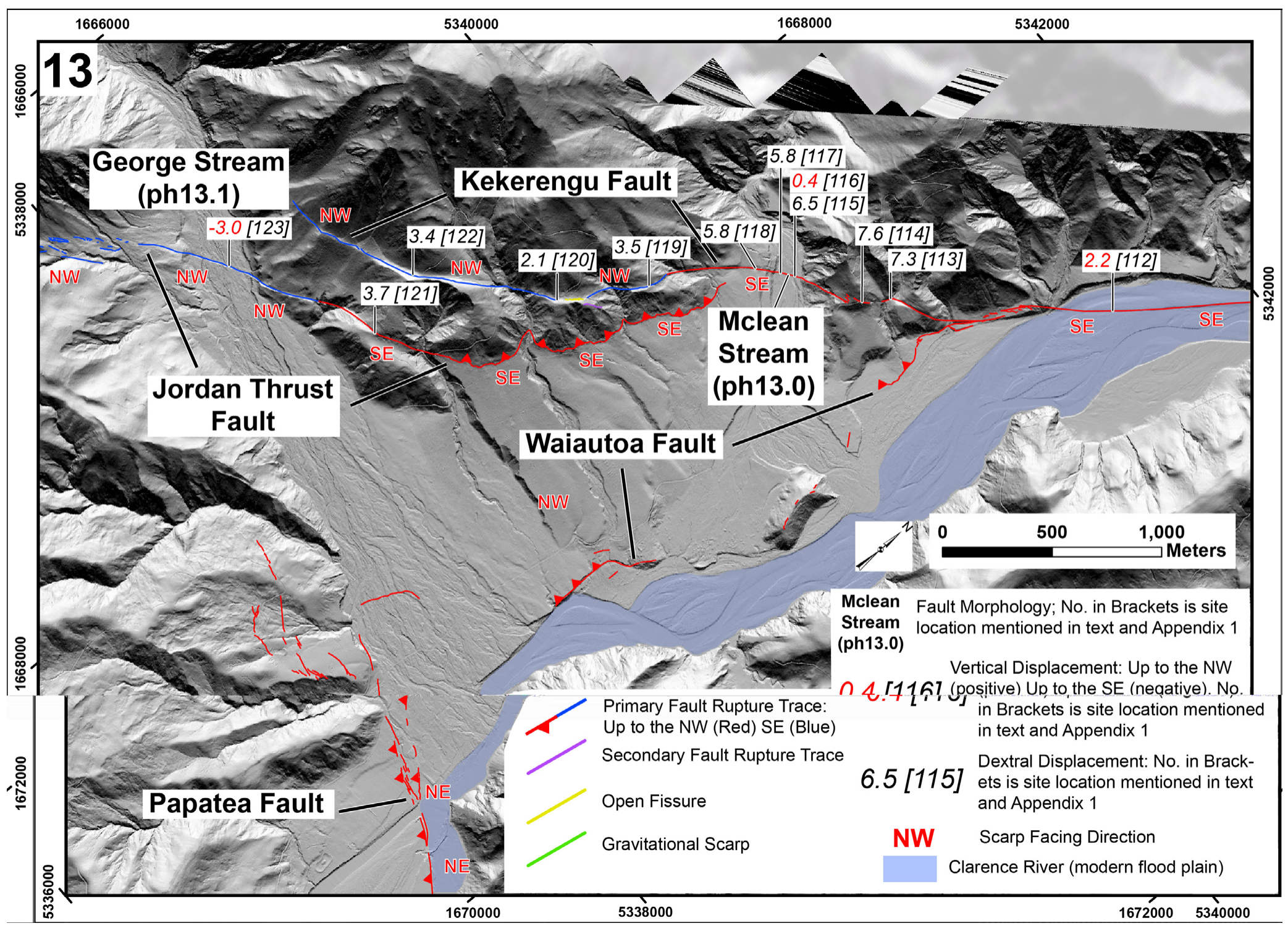

Figure 2.16: Map tile \#13, depicting surface rupture deformation on the Kekerengu, Jordan Thrust, Papatea and Waiautoa faults. Background topography is the hill-shaded LiDAR DEM, illuminated from the northwest. 
121. The sinuous trace of the Kekerengu fault indicates a moderate to steep northwest dip $\left(60-80^{\circ}\right)$. Northeast of George Stream on the Jordan Thrust fault, surface rupture width was less than $5 \mathrm{~m}$. Southwest of George Stream, discontinuous fault rupture strands spanned a width of up to $100 \mathrm{~m}$. Surface rupture width on other faults within this junction were mostly narrow ( $5-10 \mathrm{~m}$ wide). Ground deformation width on the Kekerengu fault was mostly $5 \mathrm{~m}$ wide except for the ridge crests near sites 114 and 120 where ground deformation was $20-30$ wide, and near site 118 where the fault trace climbed out of Mclean Stream and the zone was $20 \mathrm{~m}$ wide. Scarp heights on the Kekerengu fault were $\sim 2 \mathrm{~m}$ in the Clarence River gravels, $0.4 \mathrm{~m}$ in the bed of Mclean Stream and between $0.5-1.5 \mathrm{~m}$ elsewhere. Vertical displacement measurements were only available where the fault offset flat-lying gravel deposits (sites 112, 116 and 123), and were between $0.4--3.2 \mathrm{~m}$. Surface rupture on the Waiautoa fault connected the traces of the Kekerengu and Papatea faults, and produced minor reverse displacement and folding of the ground surface (vertical displacement $<0.5 \mathrm{~m}$ ).

Map Tile \#14 Continuing southwest into the Seaward Kaikoura Ranges, the Jordan Thrust fault ruptured across steep-sloped bedrock and stream valleys that were commonly obscured by dense forest (Fig. 2.17). Few helicopter landings were possible in this mountainous area (and further southwest on the KFN), which meant that observations of the fault rupture were mostly restricted to LiDAR DEM and ortho-photography datasets. The surface rupture zone varies between a single 5-10 m wide trace, and a $120 \mathrm{~m}$ wide zone of sub-parallel fault traces each spaced between 5-50 m apart. A narrow, single-trace morphology is more common in stream crossings at topographic lows; whereas a wide, multi-stranded zone of fault rupture is more typical of the ridge-crest highs. Fault dip information was only available through inspection of the sinuosity of the surface trace, which indicates a moderate $\operatorname{dip}\left(40-60^{\circ}\right)$ to the northwest. Observations of scarp height were less abundant than on the Kekerengu fault, and were between $0.8-3.6 \mathrm{~m}$ and faced in a northwest direction. Dextral slip magnitudes were derived from offset landforms such as terrace risers, thawlegs and landslide margins, and were between $3.3-9.5 \mathrm{~m}$. Vertical displacements were all up-to-the-southeast and between $-0.8--3.6 \mathrm{~m}$.

Map Tile \#15 Surface fault rupture in Figure 2.18 was almost entirely obscured by dense forest cover, making the identification of 2016 surface fault rupture incomplete. It is difficult to say if surface rupture here was discontinuous, or whether this was due to a lack 


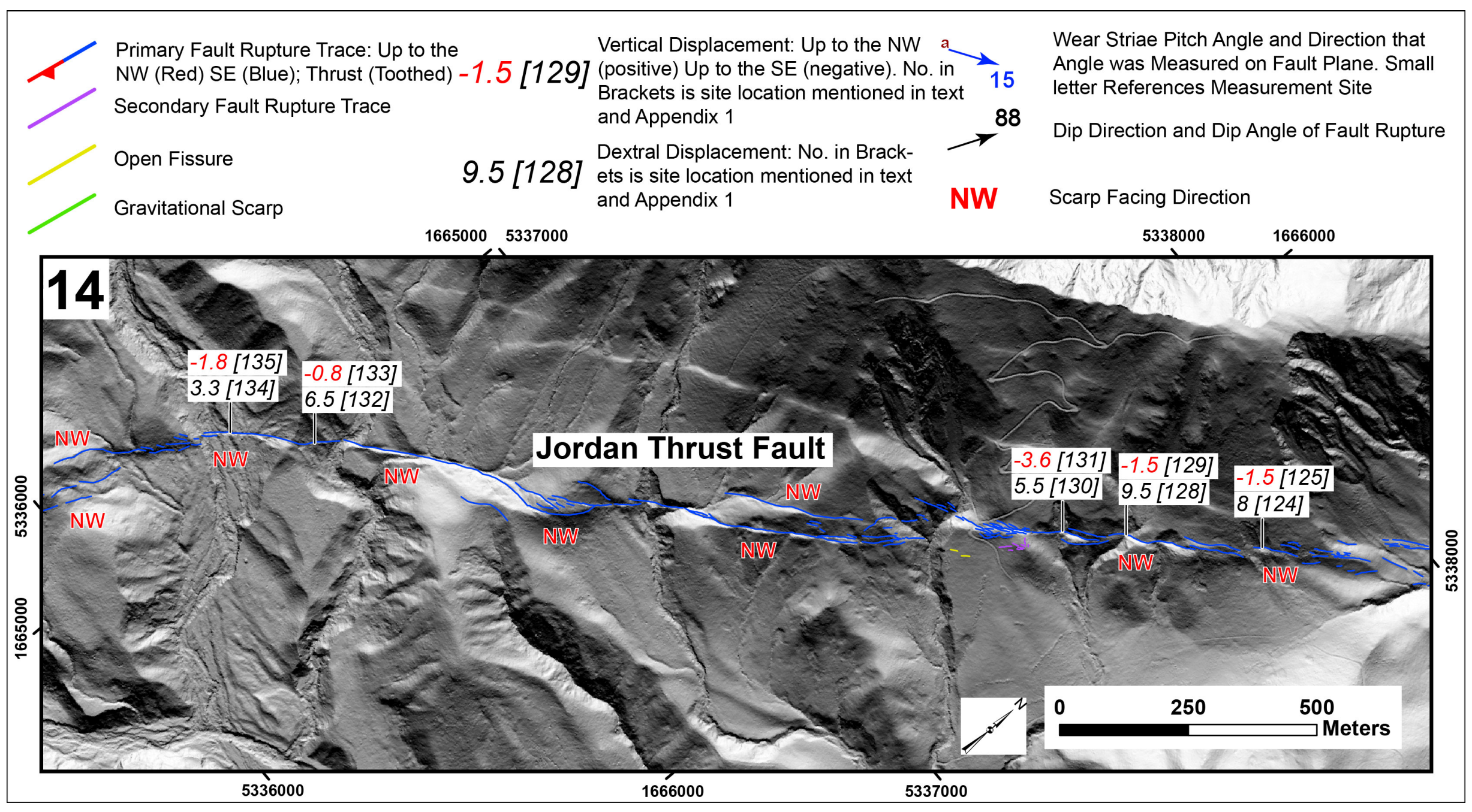

Figure 2.17: Map tile \#14, depicting surface rupture deformation on the Jordan Thrust fault. Background topography is the hill-shaded LiDAR DEM, illuminated from the northwest. 
of exposure. Ground deformation near site 138 consisted of parallel strands that together spanned a width of between $10-30 \mathrm{~m}$. North of site 139, surface rupture formed a $50-100$ m wide swath of left stepping, en echelon traces, which strike $\sim 30^{\circ}$ clockwise of the main rupture zone. Between this swath and site 139 was an 200 m-wide left step in the principle displacement zone. No fault exposures were observed in this area; however, surface trace sinuosity indicates a moderate dip to the northwest $\left(40-60^{\circ}\right)$. Scarp heights were uphill-facing and between $0.5-2.1 \mathrm{~m}$. Two dextral displacements were calculated, one using a gully thawleg with a magnitude of $1.7 \mathrm{~m}$ (site 136), the other using a fence line (site 139), with a magnitude of $3.9 \mathrm{~m}$. Vertical displacement was between $-1.5-2.1 \mathrm{~m}$, and was measured across two gully thawlegs (sites 137 and 138).

Map Tile \#16 Surface fault rupture extended across scree slopes and bedrock ridges between sites 139 - 142 (Fig. 2.19), where the trace was expressed as a single or as multiple uphill-facing scarps ("ph 16.0"). A field party (consisting of Russ Van Dissen, Rob Langridge, and Will Ries) landed at site 139 and traversed $\sim 500 \mathrm{~m}$ southwest along the trace to document ground rupture deformation and to measure the dextral displacement of a rill at site 140. Ground deformation within the zone of principle displacement was characterised by one or several individual $2-5 \mathrm{~m}$-wide swales of reduced slope, spaced $5-15 \mathrm{~m}$ apart. An additional ground rupture $\sim 400 \mathrm{~m}$ northwest of this was observed; however, it was unclear whether this accommodated any shear displacement. Fault dip was inferred to be moderately northwest dipping $\left(40-60^{\circ}\right)$ on the basis of surface-trace sinuosity, yet no exposures were observed. Scarp height across the scree slopes was between $0-1 \mathrm{~m}$ (e.g. site 141), whereas a $0.2 \mathrm{~m}$ high scarp was observed in the young stream gravels (site 143). Co-seismic dextral displacement was between $2-4.6 \mathrm{~m}$, as calculated from a displaced fence line, rill and terrace riser. Vertical displacements were between $-0.2--0.7 \mathrm{~m}$, and calculated from the height of the northwest facing scarps.

Map Tile \#17 Figure 2.20 depicts the southwest end of rupture on the Jordan Thrust fault, which traversed steep alpine slopes mantled with scree and sparse vegetation. Surface rupture deformation on the KFN continued southwest on the Upper Kowhai and Manakau faults for $\sim 15 \mathrm{~km}$. Northeast of site 145 , Surface rupture occupied a zone that was up to 350 $\mathrm{m}$ wide, and consisted of sub-parallel strands spaced between $10-250 \mathrm{~m}$ apart. Central to this zone, however, was a well expressed, 10 - 15 m-wide uphill-facing scarp, that is suspect- 


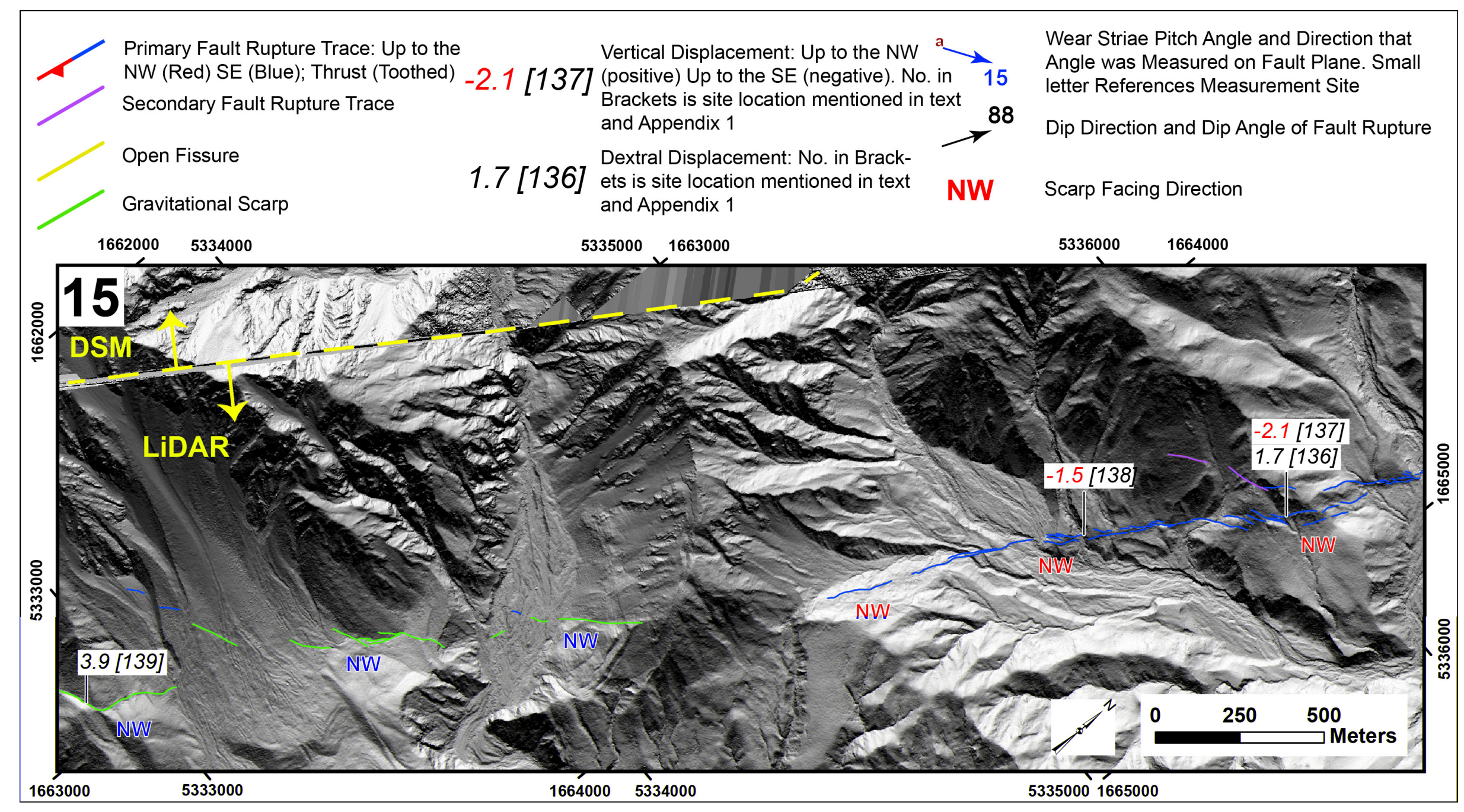

Figure 2.18: Map tile \#15, depicting surface rupture deformation on the Jordan Thrust fault. Background topography is the hill-shaded LiDAR DEM, illuminated from the northwest. 


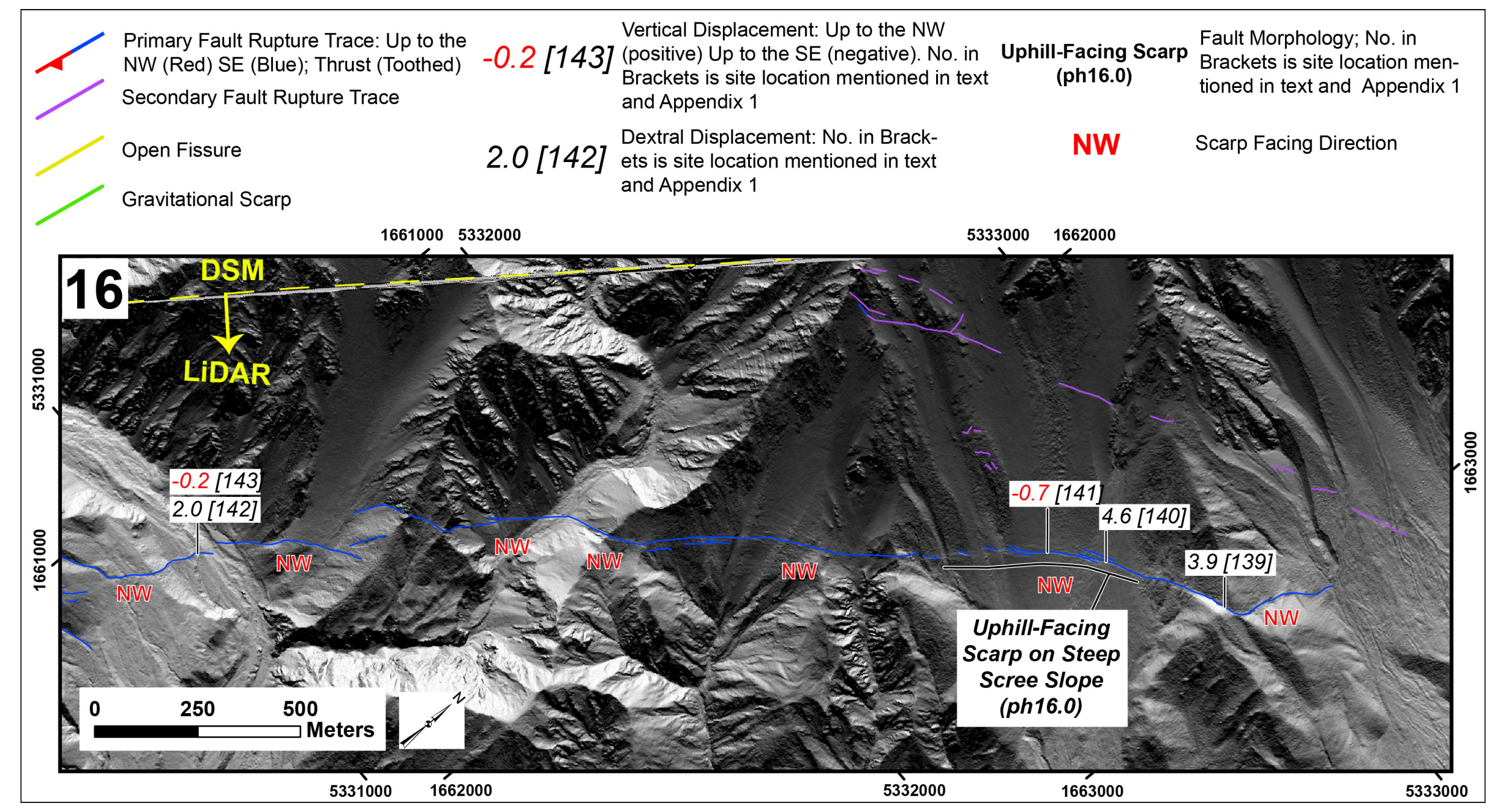

Figure 2.19: Map tile \#16, depicting surface rupture deformation on the Jordan Thrust fault. Background topography is the hill-shaded LiDAR DEM, illuminated from the northwest. 


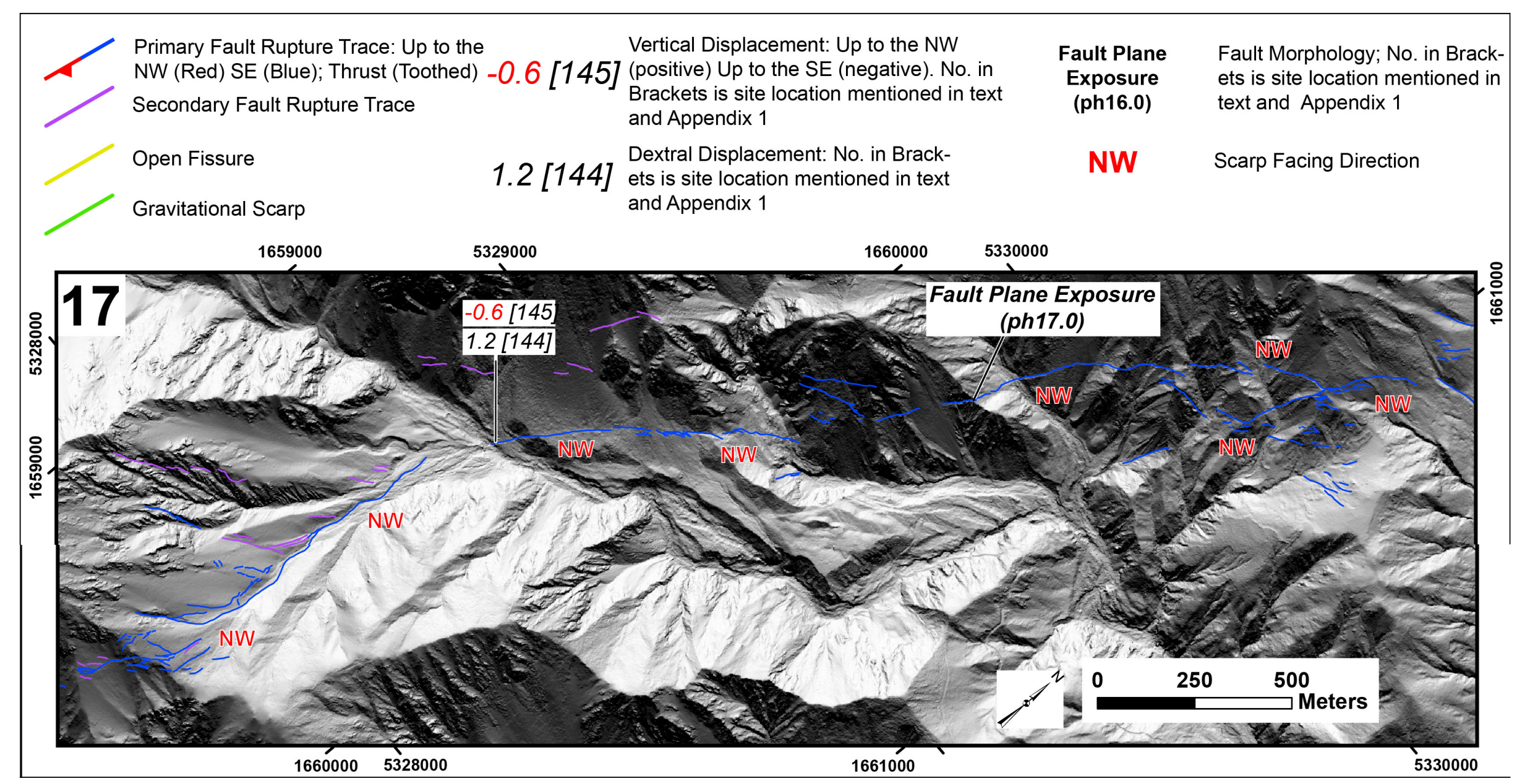

Figure 2.20: Map tile \#17, depicting surface rupture deformation on the Jordan Thrust fault. Background topography is the hill-shaded LiDAR DEM, illuminated from the northwest. 
ed to have carried the majority of co-seismic displacement. Southwest of site 145, the width of surface rupture widened to $400-500 \mathrm{~m}$. A bedrock exposure of the co-seismic fault plane was observed at "ph 17.0", which showed a moderate northwest dip $\left(40-60^{\circ}\right)$, however no one was able to measure this on the ground. Scarp heights in this area were between $0.5-1.5$ $\mathrm{m}$ and were facing northwest. Dextral and vertical displacement was measured on a stream thawleg, and had magnitudes of 1.2 and $-0.6 \mathrm{~m}$, respectively.

Map Tile \#18 Figure 2.21 depicts the bifurcation of 2016 surface rupture between the Upper Kowhai and Manakau faults across high-elevation (1500 - $2200 \mathrm{~m}$ elevation) alpine topography. These two faults strike parallel to one another and are oriented $30^{\circ}$ clockwise of the Jordan Thrust fault to the northeast. Surface rupture width on the Upper Kowhai fault was highly variable, and consisted of both a well-expressed, $5 \mathrm{~m}$-wide swale of reduced slope (inferred principle displacement zone), and sub-parallel strands that are spaced between 5 $300 \mathrm{~m}$. Together these structures occupied a surface rupture width of up to $800 \mathrm{~m}$. Ground deformation on the Manakau fault in this area comprised a $5 \mathrm{~m}$ wide, uphill-facing scarp, and locally became $100 \mathrm{~m}$ wide as it crossed a ridge line. Fault attitudes were inferred from the sinuosity of the Upper Kowhai and Manakau rupture traces. Sinuosity of the Upper Kowhai faults trace indicated a moderate dip to the northwest $\left(40-60^{\circ}\right)$, whereas the Manakau fault outcropped with a moderate southeast dip $\left(40-60^{\circ}\right)$. Scarp heights on both these faults are between $0.5-1 \mathrm{~m}$, however their scarps face in opposite directions from one another; Upper Kowhai fault rupture scarp faces northwest, Manakau fault rupture scarp faces southeast. Dextral displacement was only available at one location where a ridgeline was offset by 2.8 $\mathrm{m}$ (site 146). No vertical displacements were measured in this area.

Map Tile \#19 Surface fault rupture on the Upper Kowhai fault terminated within the area of Figure 2.22; however, discontinuous surface rupture of KFN extended further southwest on the Manakau fault. On the Upper Kowhai fault at "ph 19.0", ground rupture extended along the base of a $20 \mathrm{~m}$-high, uphill-facing paleo scarp. Overlapping individual strands of the 2016 surface rupture on the Upper Kowhai fault were $\sim 5$ m wide, spaced between 20 $-300 \mathrm{~m}$, and together embraced a width of up to $300 \mathrm{~m}$ (Fig. 2.22). Surface rupture on the Manakau fault was mostly less than $5 \mathrm{~m}$ wide; however, in places where multiple fault strands overlap one another, this width was between 50-600 m. Fault dip information was derived from the surface trace sinuosity. Both fault appeared to have a moderate dip angle $\left(40-60^{\circ}\right)$, 


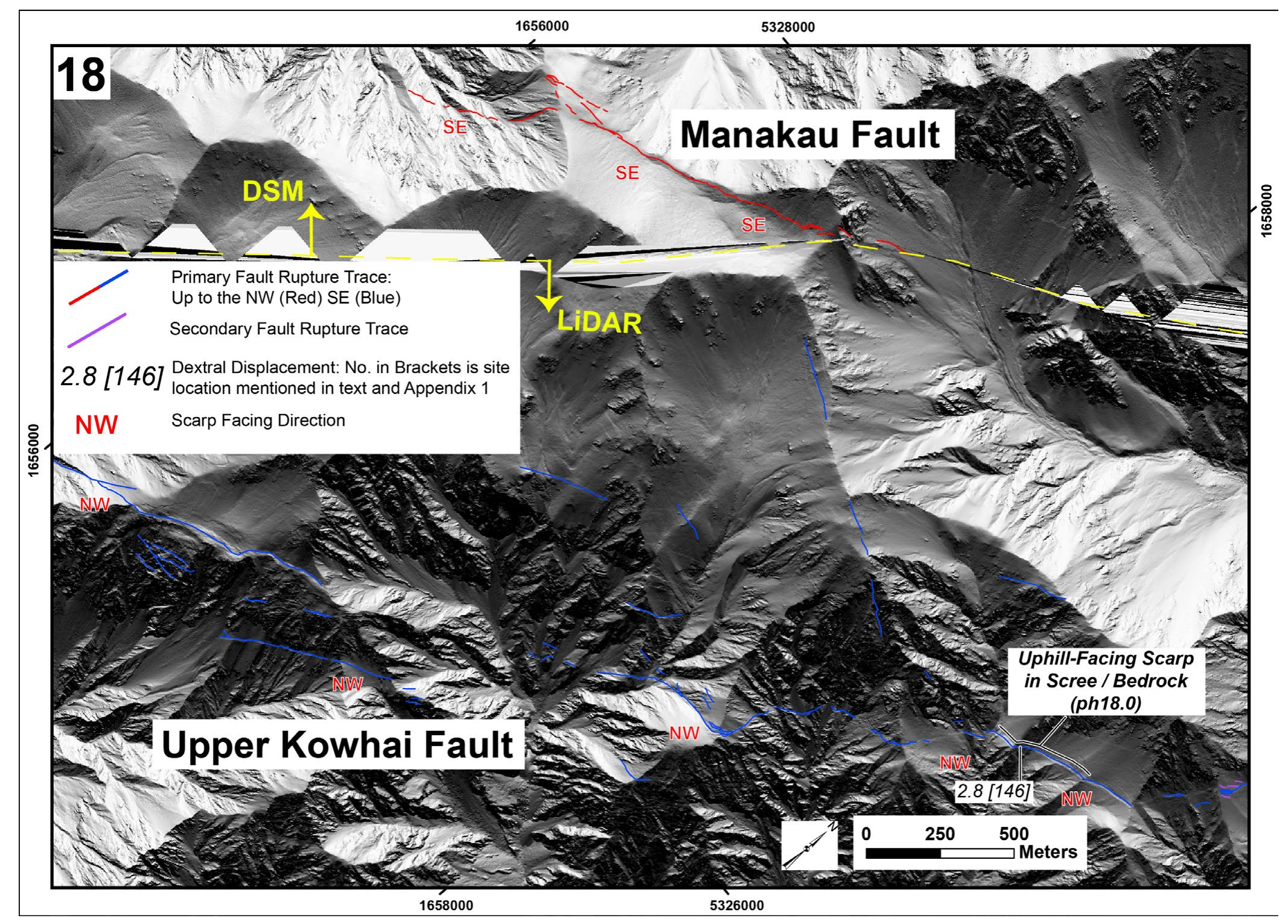

Figure 2.21: Map tile \#18, depicting surface rupture deformation on the Upper Kowhai and Manakau faults. Background topography is the hill-shaded LiDAR DEM, illuminated from the northwest. 


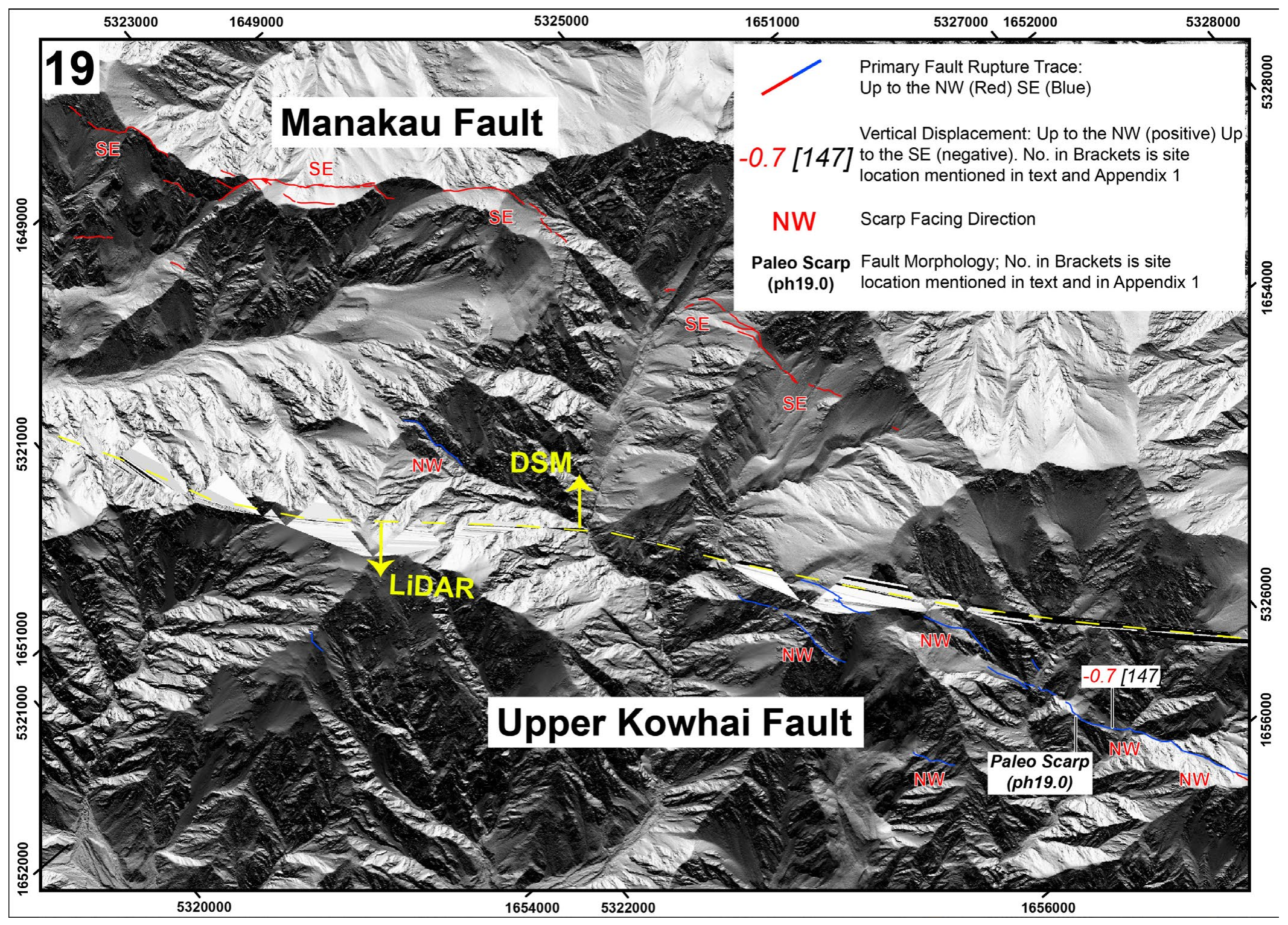

Figure 2.22: Map tile \#19, depicting surface rupture deformation on the Upper Kowhai and Manakau faults. Background topography is the hill-shaded LiDAR DEM, illuminated from the northwest. 


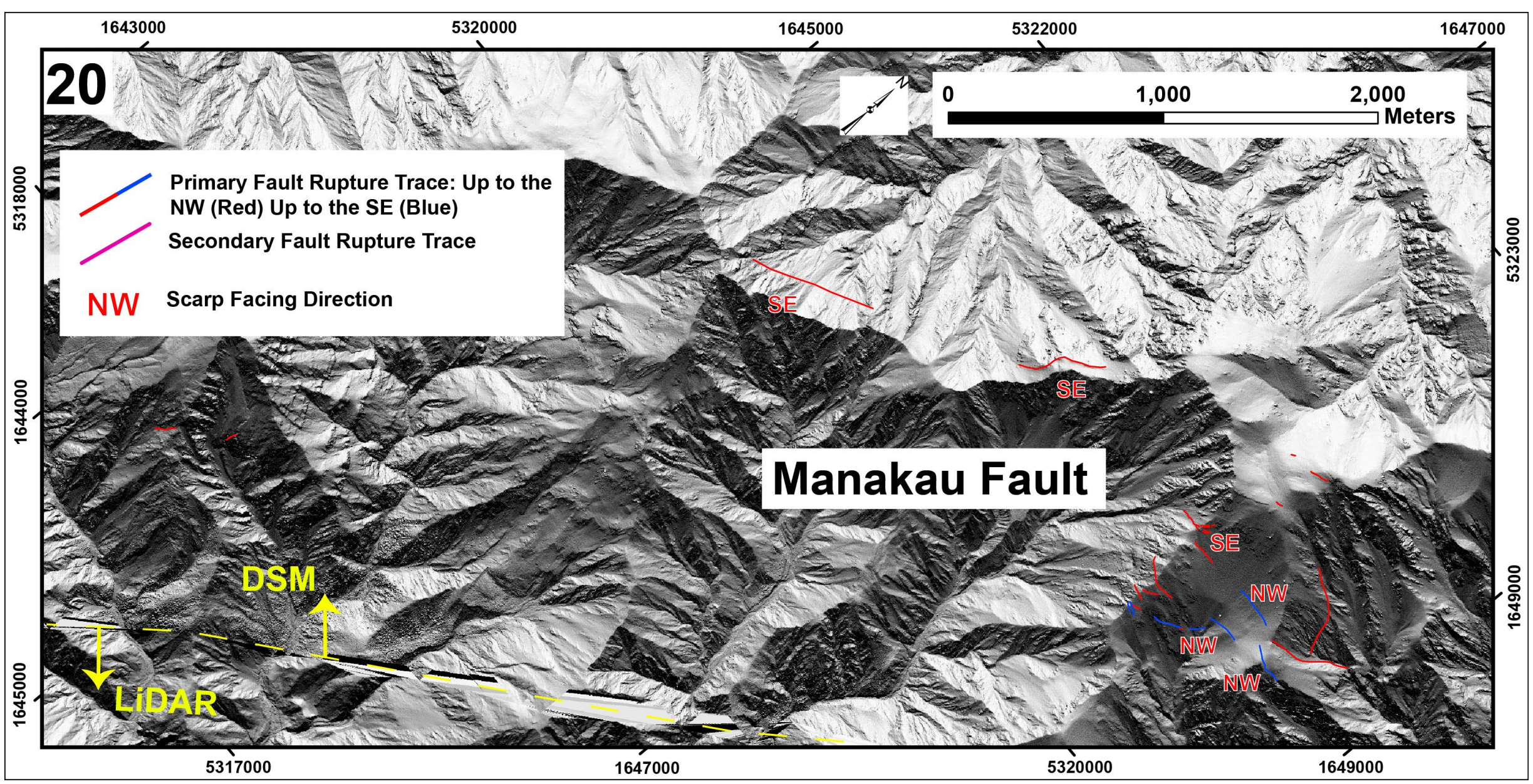

Figure 2.23: Map tile \#20, depicting surface rupture deformation on the Manakau fault. Background topography is the hill-shaded LiDAR DEM, illuminated from the northwest. 
and the Upper Kowhai dips northwest, while the Manakau dips southeast. Scarp heights in this area were between $0.5-1.5 \mathrm{~m}$, and were facing northwest on the Upper Kowhai fault, and southeast on the Manakau fault. No lateral displacements were available in this area. The height of an uphill-facing scarp in loose scree on the Upper Kowhai fault was used to derive a vertical displacement magnitude of $0.7 \mathrm{~m}$.

Map Tile \#20 Figure 2.23 shows the southwest extent of KFN surface rupture on the Manakau fault. This southwest margin was characterised by short $(<1 \mathrm{~km})$ rupture traces separated by along-strike gaps of up to $\sim 1.5 \mathrm{~km}$ (Fig. 2.23). Ground surface deformation across individual fault strands was 3-5 m wide; however, in the eastern corner of Figure 2.23 , overlapping, sub-parallel ground rupture traces span an $\sim 800 \mathrm{~m}$ width. Fault dip was difficult to determine in this area. Scarp heights were between $0-0.5 \mathrm{~m}$, and were facing both northwest and southeast. No offset features were identified with which to document co-seismic displacement. 


\title{
Chapter Three: Onshore to Offshore Ground-Surface and Seabed Rupture of the Jordan-Kekerengu-Nee- dles Fault Network During the 2016, Mw 7.8 Kaikou- ra Earthquake, New Zealand.
}

\begin{abstract}
Authors
Jesse Kearse, Timothy A. Little, Russ J. Van Dissen, Philip M. Barnes, Robert Langridge, Joshu Mountjoy, Will Ries, Pilar Villamor, Kate J. Clark, Adrian Benson, Geoffroy Lamarche, Matthew Hill, Mark Hemphill-Haley
\end{abstract}

Abstract

During the 2016, MW 7.8 Kaikōura earthquake the Kekerengu fault ruptured the ground surface producing a maximum of $\sim 12 \mathrm{~m}$ of net displacement (dextral-slip with minor reverse slip), one of the largest five co-seismic surface rupture displacements so far observed globally. This study presents the first combined onshore to offshore dataset of co-seismic ground-surface and vertical seabed displacements along a near-continuous $\sim 83 \mathrm{~km}$ long strike-slip dominated earthquake surface rupture of large slip magnitude. Onshore on the Kekerengu, Jordan Thrust, Upper Kowhai and Manakau faults, we measured the displacement of 117 cultural and natural markers in the field and using airborne LiDAR data. Offshore on the dextral-reverse Needles fault, multibeam bathymetric and high-resolution seismic reflection data image a throw of the seabed of up to $3.5 \pm 0.2 \mathrm{~m}$. Mean net slip on the total $\sim 83 \mathrm{~km}$ rupture was $5.5 \pm 1$ $\mathrm{m}$, this is an unusually large mean slip for the rupture length compared to global strike-slip surface ruptures. Surveyed linear features that extend across the entire surface rupture zone show that it varies in width from 13 to $122 \mathrm{~m}$. These cultural features also reveal the acrossstrike distribution of lateral displacement, $80 \%$ of which is, on average, concentrated within the central $43 \%$ of the rupture zone. Combining the near-field measurements of fault offset with published, far-field InSAR, continuous GPS and coastal deformation data, suggests partitioning of oblique plate convergence, with a significant portion of co-seismic contractional deformation (and uplift) being accommodated off-fault in the hanging-wall crust to the northwest of the main rupturing faults. 


\subsection{Introduction}

Measurement of co-seismic slip along surface fault ruptures following large magnitude earthquakes has, in recent decades, become routine practise. Empirical rupture parameters such as the length, magnitude and distribution of co-seismic surface displacements are key inputs into fault scaling relationships used in seismic hazard evaluations worldwide (e.g., Wells and Coppersmith, 1994; Stirling et al., 2013). Observations of surface ruptures in large-magnitude earthquakes are of particular importance because these events are relatively rare, they accommodate large displacements that typically dominate the long-term slip budget of a fault or faults, and they are capable of causing widespread damage. The study of co-seismic surface fault displacement has benefited recently from the application of remote sensing technology, such as interferometric synthetic aperture radar (InSAR) (e.g., Peltzer et al., 1998; Hamling et al., 2017) light detection and ranging (LiDAR) (e.g., Oskin et al., 2012) and high-resolution optical satellite image correlation (e.g., Zinke et al., 2014). Despite the ability of these techniques to characterize fault rupture deformation over wide regions, there remains no substitute for field-based investigation for characterizing the amount, style and distribution of on-fault deformation. This is especially true where the faulted region is criss-crossed by fence lines and other elongate once-straight markers that allow on-fault (and near-fault) deformation to be documented in detail.

Traditionally, co-seismic displacement has been determined in the field by matching once-contiguous geomorphic features across the fault rupture over short distances $(<10$ $\mathrm{m})$. However, several recent studies have shown that significant amounts of co-seismic displacement (30-40\%) can be distributed off the primary fault rupture, and thus are not easily recognized in the field. Although off-fault displacement can be identified by correlation of high-resolution optical satellite images taken before and after an earthquake (e.g. Zinke et al., 2014; Gold et al., 2015), this technique does not resolve the detail with which co-seismic slip is distributed across the strike of the fault. Rockwell et al (2002) demonstrated that the accurate survey of displaced long-baseline, linear cultural features was effective at recording the distribution of on-fault and near-fault deformation associated with the $1999 \mathrm{Mw} 7.4$ Izmit and Mw 7.1 Duzce strike-slip earthquakes. 
Our study documents the distribution of horizontal and vertical surface displacement along the $\sim 83 \mathrm{~km}$ of near-continuous surface rupture during the Mw 7.8 Kaikōura earthquake of the Manakau, Upper Kowhai, Jordan Thrust, Kekerengu and Needles faults. We document changes in slip with distance along strike and, in places, with distance perpendicular to the strike of the main surface rupture trace. This study presents the first combined onshore to offshore dataset of co-seismic ground-surface and vertical seabed displacements along a near-continuous strike-slip dominated earthquake surface rupture of large slip magnitude. Onshore analysis is based primarily on field surveys, and secondarily on analysis of airborne LiDAR topographic data and orthorectified aerial photographs. High-resolution bathymetric data and TOPAS seismic reflection profiles were used to image the seafloor trace and identify co-seismic throw along the Needles fault. We compare this co-seismic surface slip distribution with those for other large historic strike-slip ruptures and show that together, these five faults (which we refer to as the "northern domain" - see Litchfield et al. (in review) for more detail) (Fig. 3.0a) displayed remarkably large mean and maximum slip magnitudes relative to their surface rupture length during the Kaikōura earthquake. We also document variations in surface rupture morphology and ground deformation width, including the spatial distribution of slip in the near surface in an across-strike direction at locations where displaced fence lines lie at high angles to the rupture strike, and extend to well beyond the zone of observable ground rupture deformation. These across-strike slip data have relevance both for developing fault rupture-resilient engineering applications and for defining rupture zone deformation widths relevant for land-use planning and fault avoidance mapping along strike slip faults. Finally, combining our near-field measurements of fault offsets with previously published, far-field InSAR and campaign GPS datasets, and with coastal deformation data, we compare the kinematics of slip on the Jordan Thrust, Kekerengu and Needles faults, particularly around significant changes in fault strike, with the off-fault distribution of co-seismic ground displacement.

\subsubsection{Background}

On the 14th of November 2016, the Mw 7.8 Kaikōura earthquake struck the South Island of New Zealand at 12:03am local time (Kaiser et al., 2017). Propagating northeast from the epicentre in North Canterbury, this event ruptured the ground surface (and seabed) along $>20$ faults before terminating offshore $\sim 180 \mathrm{~km}$ to the northeast near Cape Campbell (Hamling 


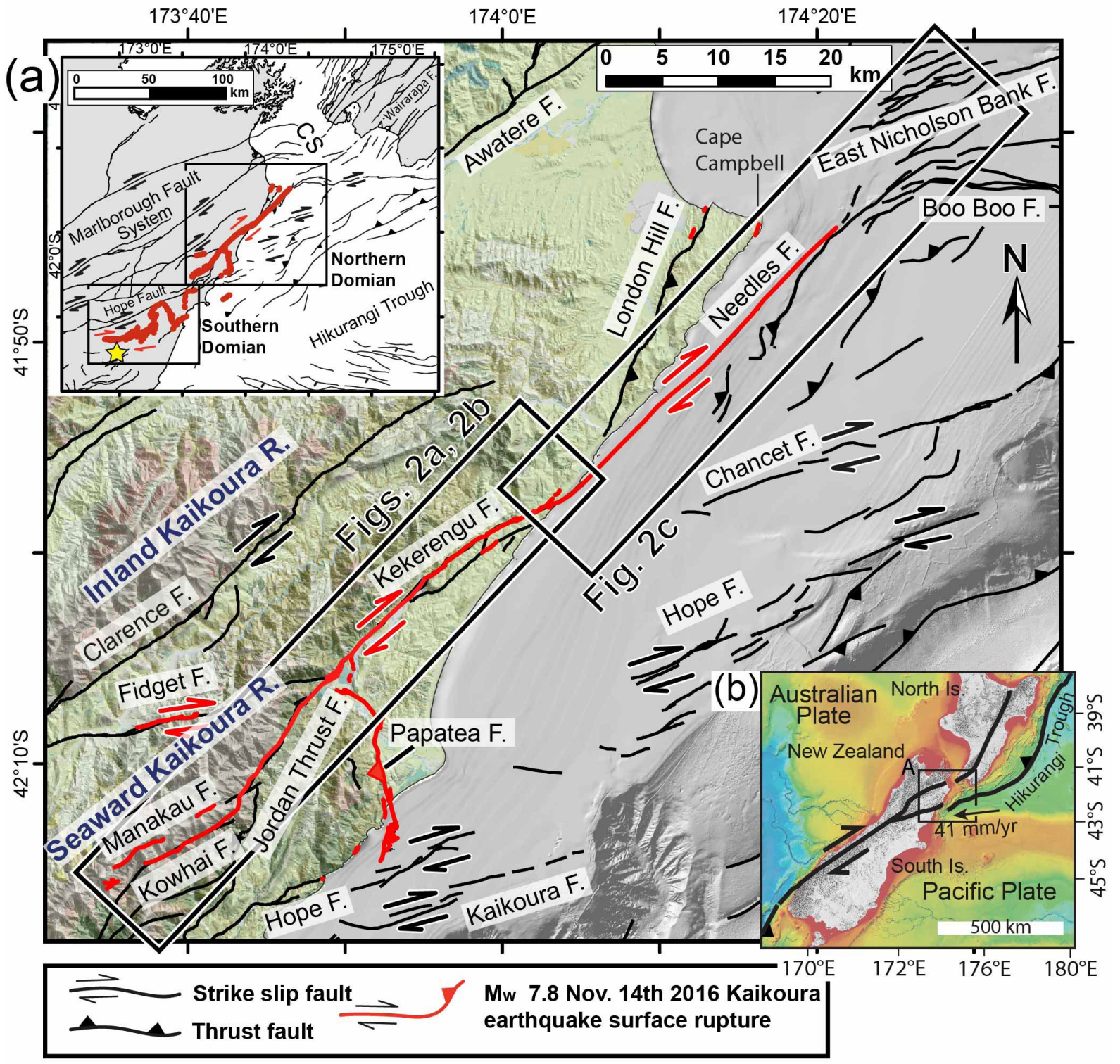

Figure 3.0: Map of study area, with shaded digital elevation and bathymetry model showing the northern domain of surface fault rupture during the Kaikōura earthquake, and active faults that did not rupture in this earthquake (from NZAFD -Langridge et al., 2016). Inset A: Boxes show northern and southern domains of 2016 surface fault rupture. The northern domain is aerial extent of this figure. Kaikoura earthquake epicenter is shown as star (after Kaiser et al., 2017). CS = Cook Strait. Inset B: Australia-Pacific plate boundary through New Zealand showing the De Mets et al., (2010) plate motion vector relative to the Australian plate (arrow), and the location of inset A.

et al., 2017; Stirling et al., 2017; Litchfield et al., 2018) (Fig. 3.0). Scientific response to this event was rapid with both onshore and offshore surveying commencing within days of the earthquake. South of the Hope fault, the surface ruptures in the Kaikōura earthquake are typically characterised by short $(\leq 3.4 \mathrm{~km})$ en echelon or branching segments separated by gaps or stepovers. These form a complex array of dextral-oblique, reverse and sinistral slip ruptures with net surface displacements of up to $5.5 \mathrm{~m}$ (Stirling et al., 2017; Litchfield et al., 2018) (Fig. 3.0). Throughout the remainder of this paper, the collection of surface ruptures 
south of the Hope fault are referred to as the southern domain ruptures. By contrast, the northern domain ruptures to the north of the Hope fault comprise a nearly continuous zone of surface fault rupture over a cumulative strike length of $\sim 83 \mathrm{~km}$ (Fig. 3.0a). The entirety of the previously mapped onshore Kekerengu fault $(27 \mathrm{~km})$ ruptured along with $\sim 30 \mathrm{~km}$ of the offshore Needles fault zone and $30 \mathrm{~km}$ of the onshore Jordan Thrust, Upper Kowhai, and Manakau faults (Fig. 3.0). This northern domain also includes surface fault rupture on the north-northwest-striking Papatea fault (Langridge et al, 2018), and northeast-striking Fidget faults (Litchfield et al., 2018). However, this study focuses on the five major northeast-striking faults that collectively comprise the longest and most continuous component of the 2016 surface rupture. Slip on these five faults was predominantly dextral, and typically included a subordinate vertical component either in a reverse sense (i.e., Kekerengu and Needles faults) or normal (Jordan Thrust, Upper Kowhai and Manakau faults). Of these five faults, the Kekerengu, Jordan Thrust and Needles faults were known to be active prior to this event (we use the word "active" to describe faults with demonstrable movement during the Holocene) (Van Dissen \& Yeats, 1991; Barnes \& Audru, 1999; Townsend, 2001; Barnes et al., 2015). The Upper Kowhai fault was mapped as possibly active (Van Dissen, 1991), and the Manakau fault was unmapped prior to the 2016 rupture. Several other short sections of faults $(<2 \mathrm{~km})$ ruptured the surface within the northern domain: Marfells Beach fault, Cape Campbell fault, Lighthouse fault, Heaver's Creek fault and the Tinline Downs fault (Litchfield et al., 2018).

Surface displacements reach a maximum on the Kekerengu fault of $\sim 12 \mathrm{~m}$, one of the largest five co-seismic surface displacement magnitudes so far observed globally (Sieh, 1978; Baljinnyam, 1993; Lin et al., 2001, Rogers \& Little, 2006; Lin et al., 2007; Wesnousky, 2008; Zinke et al., 2014; Gold et al., 2015). Local strong-motion and high-rate GPS data indicate rupture of three successive asperities on the Kekerengu fault, from southwest to northeast (Holden et al., 2017). The final and largest of these three ruptures nucleated at the southern end of the Kekerengu fault at $\sim 10 \mathrm{~km}$ depth, $\sim 60 \mathrm{~s}$ after the earthquake sequence began, and propagated northeast along the Kekerengu-Needles fault until termination of the earthquake near Cape Campbell (Holden et al., 2017). These seismological and geodetic data suggest this alone contributed a moment release equivalent to a Mw 7.8 earthquake (Holden et al., 2017).

The northern domain of surface faulting is part of the Marlborough Fault System (MFS), 


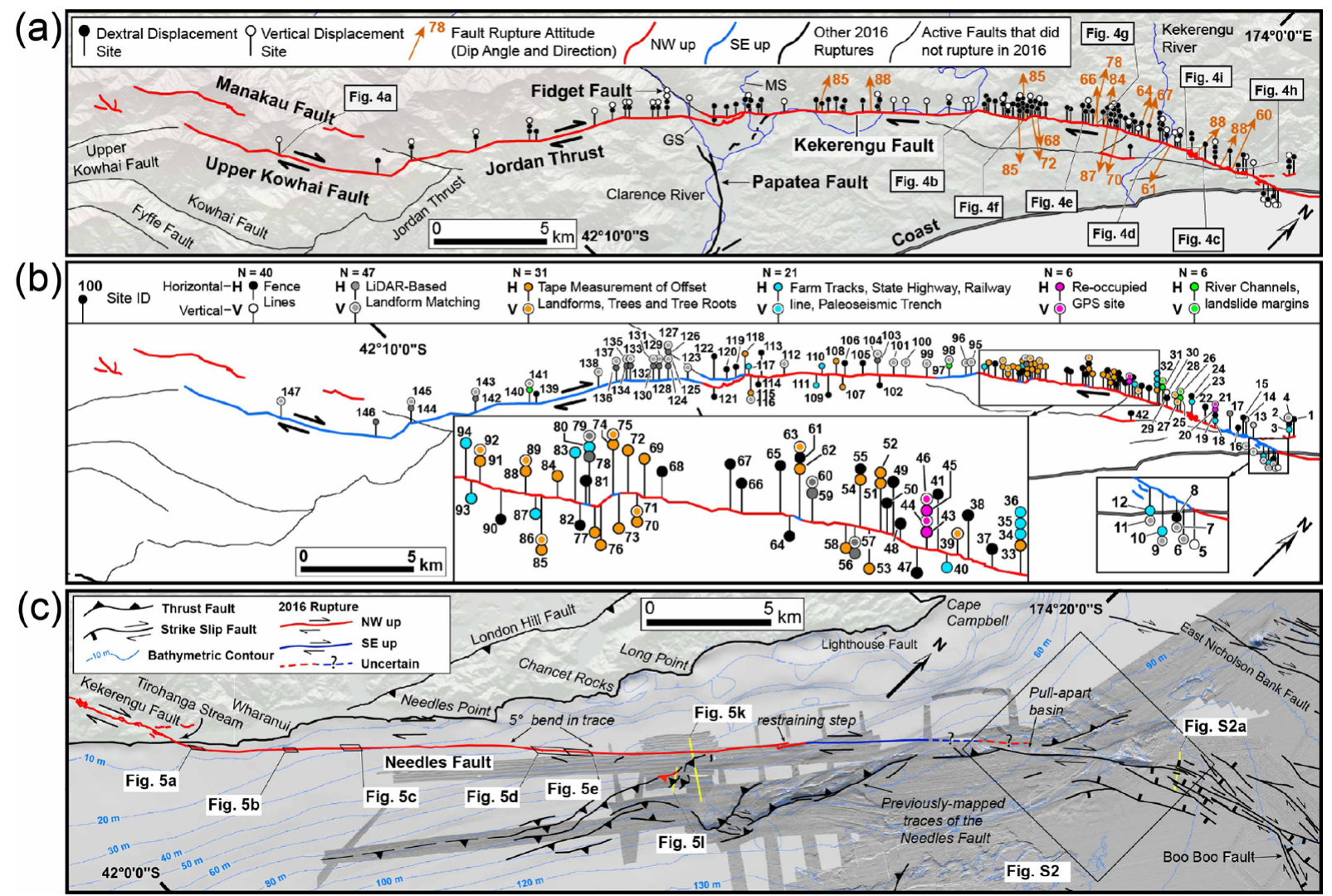

Figure 3.1: Kaikōura earthquake northern domain surface fault ruptures (see Fig. 1A for location). A: extent of onshore surface rupture showing sense of relative uplift along strike, location of displacement measurements, attitude of co-seismic fault plane exposures and locations of sites depicted in Figure 4. MS = Mclean Stream, GS = George Stream. B: Surface rupture site locations colour coded by method and type of offset feature (individual site descriptions are available in the electronic supplement to this article). C: Map of offshore surface rupture on the Needles fault, showing locations of sites depicted in Figures 5 and $\mathbf{S} 2$ and offshore active fault structure that did not rupture the seabed in this earthquake (black lines).

a zone of active dextral-slip faulting that transfers Pacific-Australia plate motion between the Hikurangi subduction zone to the northeast and the Alpine fault to the southwest (Fig. 3.0) (e.g., Wallace et al., 2012). Near Cook Strait, plate motion (Pacific relative to Australia) is $\sim 40 \mathrm{~mm} / \mathrm{yr}$ with an azimuth of $264^{\circ}$ (DeMets et al., 2010). The MFS is underlain at 20-50 $\mathrm{km}$ depth by the southern end of the Hikurangi subduction interface (Eberhart-Phillips and Bannister, 2010), which is inferred to be strongly coupled on the basis of a) late Quaternary dextral-slip-rates on the MFS faults that approximately sum to the full plate motion (e.g., Beanland and Haines, 1998; Litchfield et al., 2014); and b) GPS geodetic data recording contemporary strain accumulation across the MFS (Wallace et al., 2012). Total dextral separation along this northern fault domain is difficult to measure due to the complex structure of the Mesozoic-Cenozoic rocks, however is estimated to be at least 5-6 km across the Kekerengu fault (Townsend, 2001). 


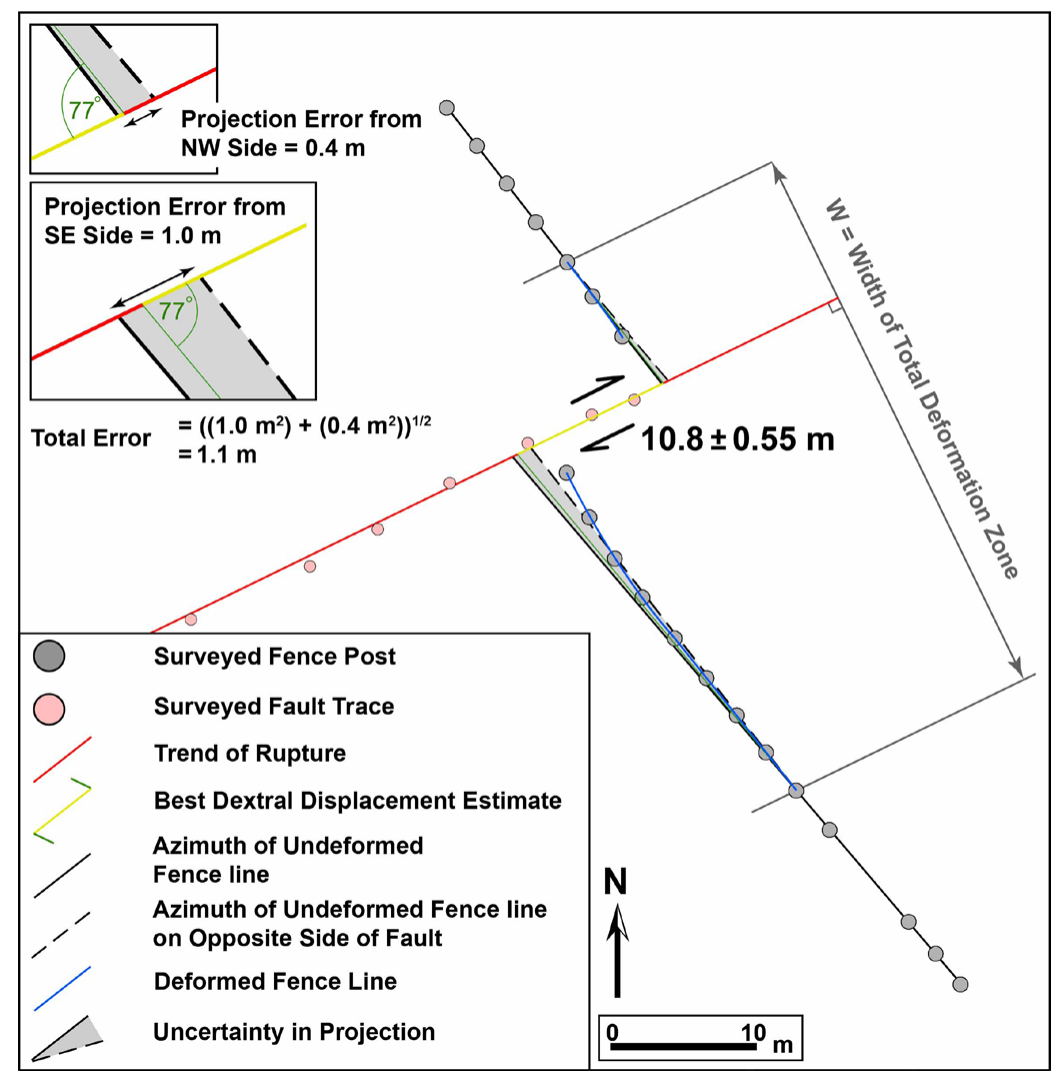

Figure 3.2: Graphical explanation of the method of dextral displacement and uncertainty calculation for linear features such as fence lines. Figure depicts site 29. See text for discussion.

\subsection{Datasets and Methods}

\subsubsection{Onshore}

Immediately after the Kaikoura earthquake, field teams were deployed to the northern domain ruptures and with helicopter support the field teams mapped traces and surveyed ground displacements on the Jordan Thrust and Kekerengu faults. The Manakau and Upper Kowhai faults traverse terrain that made landing difficult, and therefore were only observed in the field from the helicopter. In total, 80 displaced natural and made-made markers were surveyed in the field using a Real-Time Kinematic (RTK) or post-processed GPS ( $\mathrm{n}=42$ sites); or a Total Station theodolite $(n=10)$; or by direct tape measurements $(n=28)$, with the latter two methods being employed in areas of poor satellite signal (Fig. 3.1). Post-earthquake 0.2 m-pixel bare earth LiDAR digital terrain models (DTMs) were used to acquire an additional 37 measurements of displaced landforms across the 2016 rupture. The LiDAR (as well as high-resolution orthorectified aerial photography) was particularly valuable for obtaining slip 
observations in steep alpine terrain that was difficult to access. The types of offset features used in our analysis includes, in order of decreasing abundance: fence lines; river channels, rills, levees or gully margins; farm tracks (4WD roads); the margins of pre-existing landslides; individual trees or roots split by the fault (and matched); narrow spurs; animal tracks; beach dunes; State Highway ( $\mathrm{SH}$ 1); the main trunk railway line; the foundations of a cottage; a hedgerow and the outline of a back-filled paleoseismic trench (Little et al., 2018).

To calculate the horizontal displacement of linear features, linear markers were projected into the fault trace (where slip was nearly pure strike-slip and where heave was negligible); or into a model of the dipping fault surface (where slip was oblique on a non-vertical plane, and where heave must be considered). Marker lines were constructed from surveyed linear features by fitting linear trend lines through all available survey points that define the markers outside of the wider zone of surface rupture ground deformation (Fig. 3.2). This far-field selection of marker line points excludes from consideration points on the distorted, inner part of the marker within the zone of ground deformation. This is where the markers typically deflect with a synthetic sense of drag because of distributed shearing (see deformed fence line in Fig. 3.2). The fitting of undistorted, outer linear trend lines was done independently on both sides of the fault trace. Prior to fault offset, the original linear marker is assumed to have had a single (uniform) trend across the fault zone, and where this was in doubt we confirmed original linearity by examining pre-earthquake imagery. The two un-deflected, outer marker line segments are typically fit by trend lines that have azimuths that differ by as much as $2^{\circ}$. Such discordances in azimuth are likely due to: 1) small deviations from pre-rupture linearity across the fault, and/or 2) small measurement/survey errors.

To evaluate a best-fit displacement across the fault zone, we projected the two marker line segments inwardly to the fault as follows: Each marker was located on a curved line with a constant radius of curvature such that it intersects the fault surface at an identical azimuth to that of the marker segment on the opposite side of the fault (see insets of Fig. 3.2). This approach distributes the angular mismatch between the marker lines on the two sides uniformly across the intervening widths of disturbed ground to yield a best-fit estimate of slip at the fault. Uncertainty for lateral displacement estimates were derived by projecting the two marker lines across the deformation zone assuming no curve. This was done once using the segment's own trend, and once using that of the other segment on the opposite side of the 
fault. These two "end-member" projection azimuths create a triangle of projection uncertainty at the fault plane (see Little et al., 1998) (Fig. 3.2). The most reliable slip markers are fence lines that 1) trend at a right angle to the fault; and 2) were surveyed continuously to a distance well beyond that of the maximum width of observable ground rupture, thus capturing all the fault slip, both distributed and discrete. In most cases, our derived errors in strike-slip displacement were $\pm 0.4 \mathrm{~m}$ or less. Some site measurements provide only a minimum estimate of the total co-seismic slip, for example the offset of a farm track or gully across a discrete fault strand. This is because such features may not span the entirety of the deformation zone, or any distributed deformation may not be able to be distinguished from the features pre-rupture geometry.

To calculate vertical displacements (throw), we focused on rupture sites where the morphology of the ground surface was known prior to the 2016 earthquake, typically where the pre-earthquake topography was relatively flat and where there was no pre-existing scarp. A total of 19 sites located on modern riverbeds or young river terraces met these morphological conditions. At these sites the scarp height measures vertical displacement. Throw was measured using real-time kinematic GPS $(n=4)$ data, directly using a tape measure $(n=7)$, or using profiles across the fault constructed on the post-earthquake LiDAR DTM $(n=30)$. At locations where a topographic gradient exists across the fault scarp (e.g., where the fault crosses steep alpine streams or talus slopes), the surface slope was considered when determining co-seismic throw, after the methods of Caskey (1995). To estimate co-seismic throw in areas with pre-existing fault scarp morphology (six sites within $2 \mathrm{~km}$ of the coast, see Fig. 3.1), we used a 2012 airborne LiDAR DTM to evaluate pre-earthquake scarp topography, and the 2017 LiDAR DTM for post-earthquake topography. First, we considered the magnitude of the 2016 lateral displacement at a location to identify once contiguous surfaces that are now laterally separated across the fault. Next, we drew scarp-normal elevation profiles across the pre- and post-earthquake topographic models to measure the co-seismic vertical displacement (detailed site descriptions are available in the electronic Appendix to this thesis). Throw at a location was calculated by summing the vertical elevation changes on either side of the fault that accrued during the earthquake. For sites where the sign of co-seismic vertical displacement was the same on both sides of the fault, throw is equal to the maximum vertical displacement at the fault. At three sites precise 3D slip vectors could be measured from individual broken roots, which were used as piercing points. Three vertical displacements were 
measured from the height of uphill-facing scarps that traverse active scree cones on steep alpine slopes, both in the field $(n=2)$ and using the post-earthquake LiDAR $(n=1)$.

Additionally, we measured co-seismic displacements at 9 other locations using a MATLAB-based graphical user interface called LaDiCaoz_v2 (Zielke et al., 2015; Haddon et al., 2016). LaDiCaoz uses cross-correlation of high-resolution topographic profiles to measure the horizontal and vertical displacement of offset geomorphic features. A full description of the LaDiCaoz process is contained in Haddon et al. (2016). Optimal values for the horizontal and vertical slip are calculated by LaDiCaoz and then backslipping of the lidar DTM along a simplified vertical fault plane is used to assess the restoration of pre-rupture topography (examples are available in Appendix 2). Iterative backslipping around the optimal value is used to find the range of offset values that can plausibly align the topography and this range of values is considered to approximate the $2 \sigma$ uncertainty range.

\subsubsection{Offshore}

The post-earthquake marine survey response included two surveys led by the National Institude of Water and Atmospheric Research (NIWA). The first survey involved re-deployment of the RV Tangaroa southward from work that was taking place on voyage Tan1613 off the east coast of North Island at the time of the earthquake. Surveying commenced on the northern Marlborough shelf on 19 November 2016, five days after the earthquake. This work included the collection of Kongsberg EM302 $30 \mathrm{kHz}$ multibeam bathymetry and backscatter sonar data over the Chancet, Needles, and western Boo Boo faults, together with acoustic profiling using a hull-mounted TOPAS PS18 parametric sub-bottom profiler (available in Appendix 2). The second survey included deployment of the coastal survey vessel Ikatere on January 6-13th 2017 (survey Ika1701). This survey included the collection of Kongsberg EM2040 $300 \mathrm{kHz}$ multibeam bathymetry data over the nearshore southern $20 \mathrm{~km}$ section of the Needles fault, as well as other faults further south that were activated during the earthquake (Litchfield et al., 2018). Only marine data over the Needles fault and associated structures are presented here.

The Tangaroa survey strategy reflected incoming reports of the onshore field teams on surface rupture magnitudes and locations, combined with preliminary results of continuous GPS 
modelling, which were provided to the offshore science party (e.g., Hamling et al., 2017). We also considered previous knowledge of the Needles fault structure, which was based on analyses of data existing prior to the earthquake (Barnes et al., 2015). Pre-existing bathymetry data included both $30 \mathrm{kHz}$ multibeam echo-soundings collected by NIWA and Land Information New Zealand between 2005 and 2015 (gridded to $10 \mathrm{~m} \mathrm{DEMs),} \mathrm{and} 300 \mathrm{kHz}$ data collected by NIWA from a $10 \mathrm{~km} 2$ area east of Cape Campbell in April 2016 (gridded to 2 $\mathrm{m})$. From these pre-earthquake multibeam bathymetry data, supported by airgun, boomer and $3.5 \mathrm{kHz}$ seismic profiles (available in Appendix 2), Barnes et al. (2015) identified (1) a 10 $\mathrm{km}$ long, linear strike-slip section of the Needles fault about 6-7 km east of Cape Campbell, (2) a complex network of faulting at the junction of the Needles and Boo Boo faults, and (3) a series of 20-25 m-high seafloor scarps associated with inferred oblique thrust traces of the Needles fault lying $\sim 2 \mathrm{~km}$ east of the 2016 Needles fault rupture trace (faults coloured black on Fig. 3.0). None of the pre-existing data, however, were available over the particular trace of the Needles fault that is now known to have ruptured during the Kaikōura earthquake (Fig. 3.0). Consequently, until the Tan1613 and Ika1701 surveys, almost $30 \mathrm{~km}$ of the Needles fault trace nearshore was unknown.

Initially, the Tangaroa Tan1613 post-earthquake survey focussed on the previously mapped traces of the Needles fault, and their intersection with the Boo Boo fault. None of these traces, however, revealed evidence of surface rupture. Two apparently-fresh surface traces with $\sim 1.5$ $\mathrm{m}$ of vertical throw in $\sim 30 \mathrm{~m}$ water depth, $3 \mathrm{~km}$ east of Chancet Rocks, led to the collection of new data along a spectacular linear surface trace now mapped between Kekerengu and Cape Campbell (Fig. 3.1c). Because the Tangaroa Tan1613 survey was largely limited to water depths of $>30 \mathrm{~m}$, the survey covered only the northern section of the trace between Chancet Rocks and Cape Campbell. TOPAS sub-bottom profiles with penetration beneath the seafloor typically of 25-100 m were collected across (1) the main co-seismic rupture trace, (2) the system of right-stepping oblique thrusts to the southeast of the main co-seismic trace, one of which reveals evidence of partial surface rupture during the Kaikōura earthquake (Fig. 3.1c), and (3) the complex network of faulting at the junction of the Needles and Boo Boo faults.

Immediately before the post-earthquake multibeam bathymetric surveys commenced on Tangaroa and Ikatere, sound velocity profiles were obtained with an AML Smart Probe P0835 system, for calibration purposes. The bathymetric data were processed using CARIS HIPS \& 
SIPS V8.1.12 software, and were tidally corrected using an area-specific tidal curve generated from a NIWA tidal model, with all soundings reduced to mean sea level. The processed EM302 bathymetric data were used to construct $2 \mathrm{~m}$ and $5 \mathrm{~m}$ grid resolution digital elevation models (DEM). The higher frequency EM2040 bathymetric data were processed to develop a $0.5 \mathrm{~m}$ grid DEM. These data were imported into ArcGIS V.10.3 for spatial analysis and mapping of tectonic geomorphology.

Variations in the vertical throw of the seafloor were evaluated in detail along $30 \mathrm{~km}$ of the surface trace of the Needles fault. At $1 \mathrm{~m}$ intervals along strike, and in the down-slope direction of the fault scarp, we calculated the height difference between the break in slope at the top and bottom of the scarp, as picked from slope analysis. We tested the throw calculations from random bathymetric profiles constructed normal to the scarp. For display in this paper, this rich dataset has been smoothed to explore only the larger scale variations in throw, and their relationship to fault strike. The throw estimates are considered to have an uncertainty of $\pm 0.2 \mathrm{~m}$ for sections of scarp imaged in the $0.5 \mathrm{~m}$ grid DEM (southern $20 \mathrm{~km}$ ), and $\pm 0.5 \mathrm{~m}$ for sections imaged at $2 \mathrm{~m}$ DEM. No clear evidence for dextral slip on the Needles fault could be identified on the marine co-seismic traces due to an absence of offset piercing points.

\subsection{Surface Rupture Expression}

\subsubsection{Onshore}

The southwestern extent of the northern domain surface ruptures is defined by ground-surface displacements on the Manakau, Upper Kowhai and Jordan Thrust faults that, in part, overlap one another (Fig. 3.1a). These three fault ruptures strike subparallel to each other and, collectively, traverse a southwest to northeast distance of $\sim 21 \mathrm{~km}$ across steep alpine scree slopes and bedrock ridges and valleys in the Seaward Kaikōura Range. Some of the 2016 rupture traces on these three faults have been buried or otherwise destroyed by earthquake-triggered landslides debris (Massey et al., 2018). LiDAR coverage is available for the entirety of the portions of the Upper Kowhai and Jordan Thrust faults that ruptured in 2016, but does not include the Manakau fault rupture. The sinuosity of the surface traces of the Upper Kowhai and Jordan Thrust faults across steep topography indicates that these two faults typically dip 
northwest at moderate angles (approximately 40-70²) (Fig. 3.1a). Conversely, the sinuosity of the Manakau fault's trace indicates that it dips to the southeast. Field visits, flyovers and LiDAR data indicate that the Upper Kowhai and Jordan Thrust faults were uplifted on their southeast (footwall) sides during the 2016 earthquake, creating an oblique-normal sense of slip. Flyovers and high-resolution ortho-photography reveal the Manakau fault ruptured with a normal sense of slip and was uplifted on its northwest (footwall) side. The sense of dipslip on the Jordan Thrust during this earthquake is opposite to its long-term reverse sense of displacement, as indicated by 1) previous mapping where several sites show bedrock on its northwest side thrust up and over Pleistocene-Holocene alluvial gravels to the southeast, and 2) rapid uplift rates of the Seaward Kaikoura Range, located on its hanging wall (Van Dissen \& Yeats, 1991). However, at its north-eastern tip where it overlaps with the Kekerengu fault (a distance of $\sim 2 \mathrm{~km}$ ), the Jordan Thrust ruptured with a reverse sense of dip-slip, and appears to have a shallow northwest dip $\left(<30^{\circ}\right)$ based on its sinuous trace (Fig. 3.1a).

In detail, the rupture traces of the Manakau, Upper Kowhai and Jordan Thrust faults typically consist of an array of several uphill-facing scarps that are spaced 5-15 m apart. Where the ruptures extend across steep scree slopes, they are expressed by 2-5 $\mathrm{m}$ wide swales of reduced slope (Fig. 3.3a, see inset labelled, "Scree Scarp"). We infer that these swales are the result of rapid degradation - during or soon after the earthquake - of uphill-facing scarp free-faces formed in loose boulder scree. In contrast, when the ruptures extend across bedrock slopes, sharply defined, uphill-facing scarps are well preserved. These are typically 0.5 - $1.5 \mathrm{~m}$ high (Fig. 3.3a, see inset labelled, "Bedrock Scarp"), and are located on pre-existing scarps that are evident in pre-earthquake aerial imagery, and therefore only provide a maximum estimate of vertical displacement during the 2016 earthquake. At the tops of some ridge spurs on the Upper Kowhai fault adjacent to the 2016 surface fault rupture, northwest-facing scarps are up to $20 \mathrm{~m}$ high, implying that up-on-the-southeast, oblique-normal slip was not unique to the 2016 earthquake, but has also occurred in the past (Fig. 3.3a, see "Paleoscarp").

Between site 123 and site 118 (Fig. 3.1b), surface ruptures on the Jordan Thrust and Kekerengu faults overlap in map view, and are separated by $\sim 75 \mathrm{~m}$ at their nearest point. Further northeast, between site 101 and site 95, surface rupture on the Kekerengu fault traverses the active braid plain of the Clarence River for a distance of $4 \mathrm{~km}$. In the 14 months following the earthquake the scarp has been somewhat removed by erosion. Moving northeast over a 
(a)

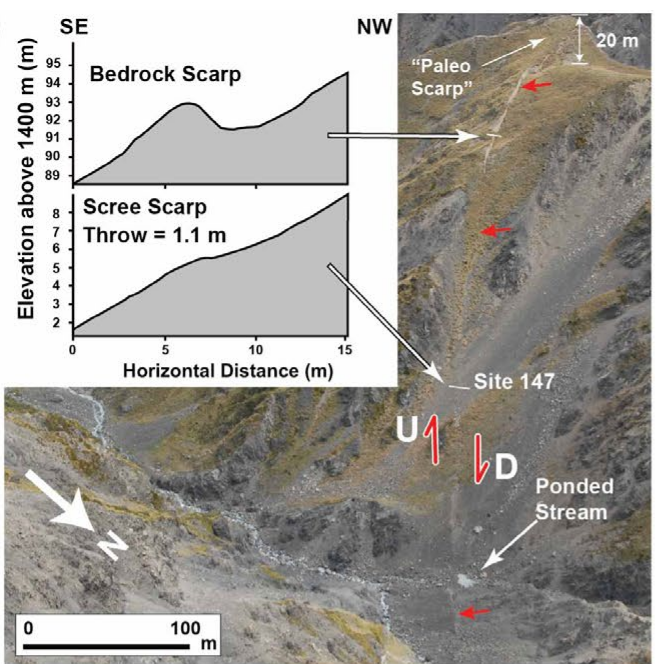

(c)

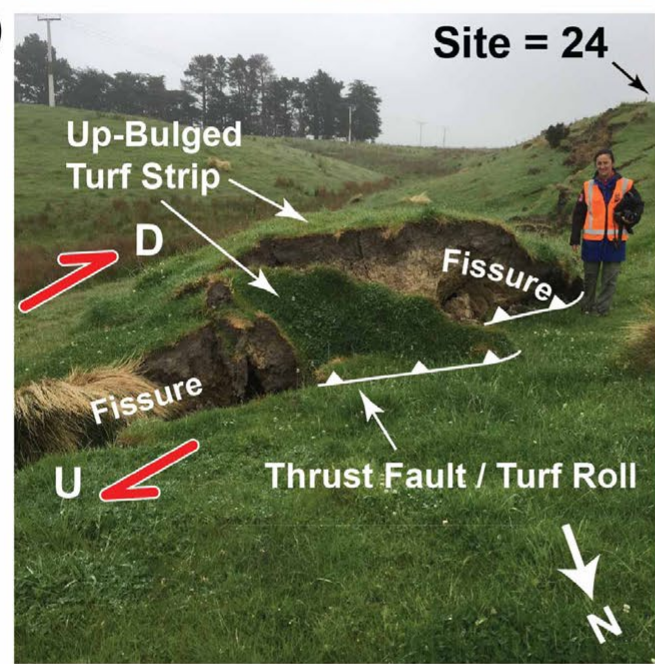

(b)

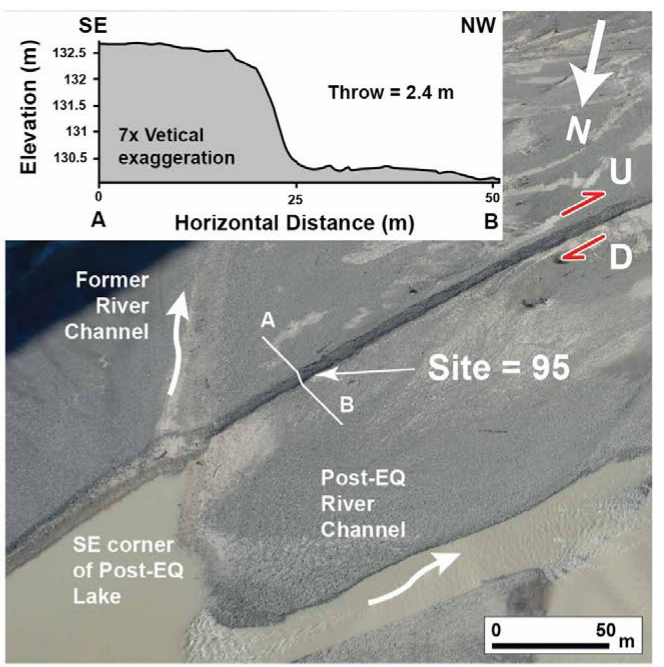

(d)

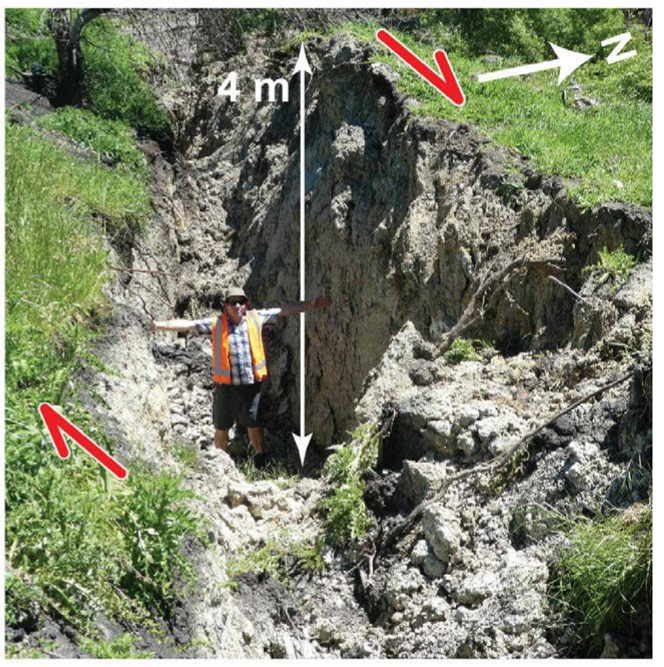

(e)

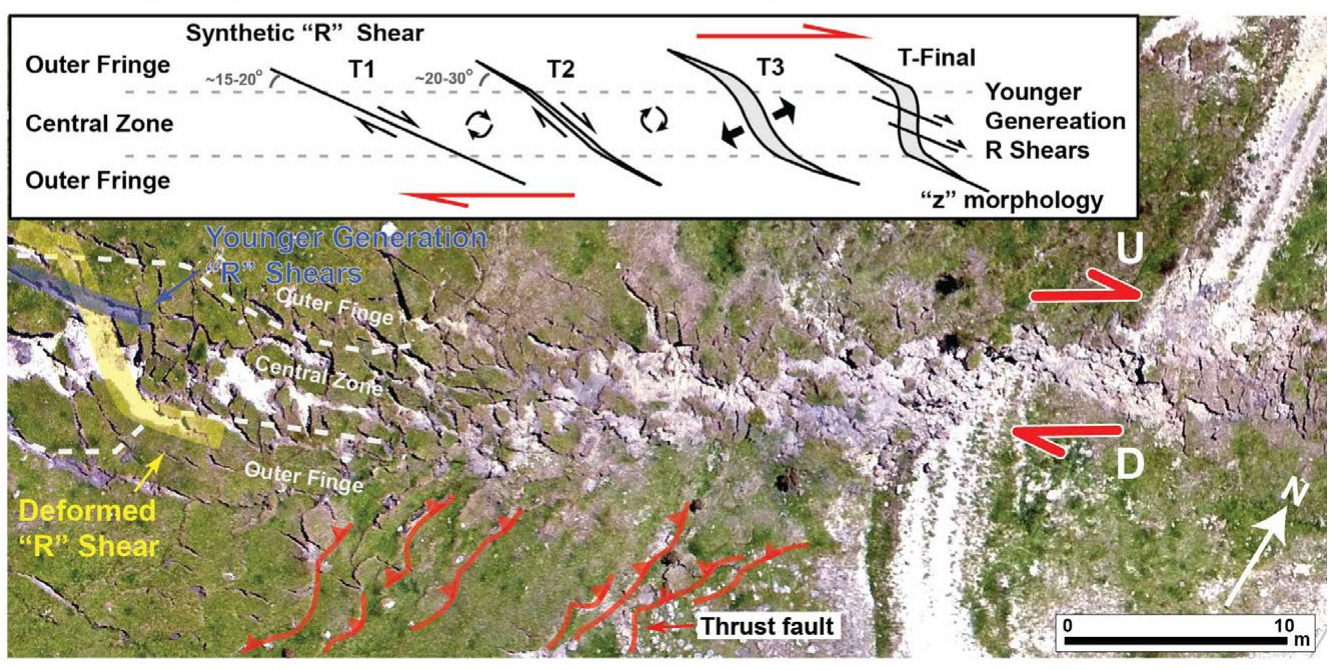

Figure 3.3a: Onshore expressions of surface fault rupture. A: Oblique aerial photograph showing surface fault rupture across steep alpine terrain on the Upper Kowhai fault, as well as a prominent paleo scarp. Short horizontal arrows show location of fault rupture trace. Photograph taken by Will Ries on 14/12/2016. B: Oblique aerial photograph showing the characteristically-linear trace of the Kekerengu fault in modern alluvial gravels, and the diversion of the Clarence River. Photo by Jesse Kearse on 22/11/2016. C: Field Photograph of $1.5 \mathrm{~m}$ high compressional bulge, where the Kekerengu fault surface rupture passes through grassed paddocks. Person for scale. Photo by Mark Hemphill-Haley on 24/11/2016. D: Fault Crevasse, $\sim 1$ $\mathrm{km}$ northeast of site 29. Person for scale. Photo by Tim Little on 21/11/2016. E: Ortho-rectified, unmanned aerial vehicle (UAV) image of a moletrack $\sim 50 \mathrm{~m}$ northeast of site 61. Inset shows evolution of $R$ shears during co-seismic displacement. Photo taken on 23/11/2016. 
(f)

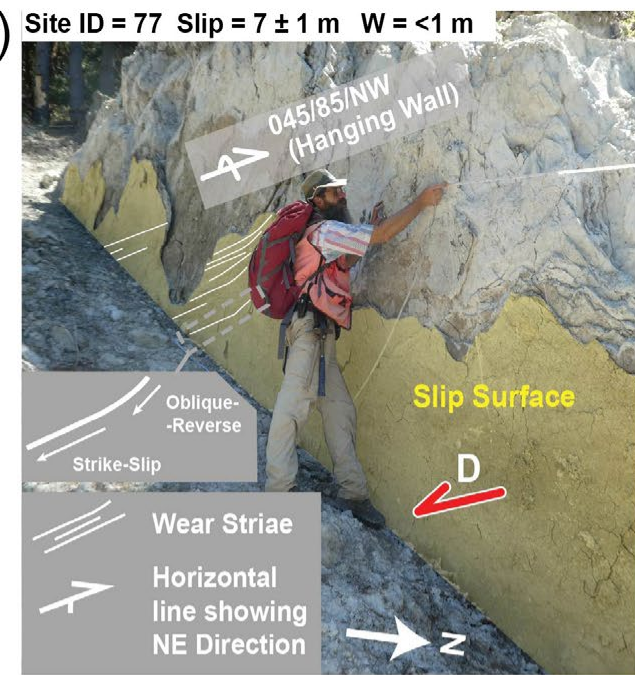

(h)

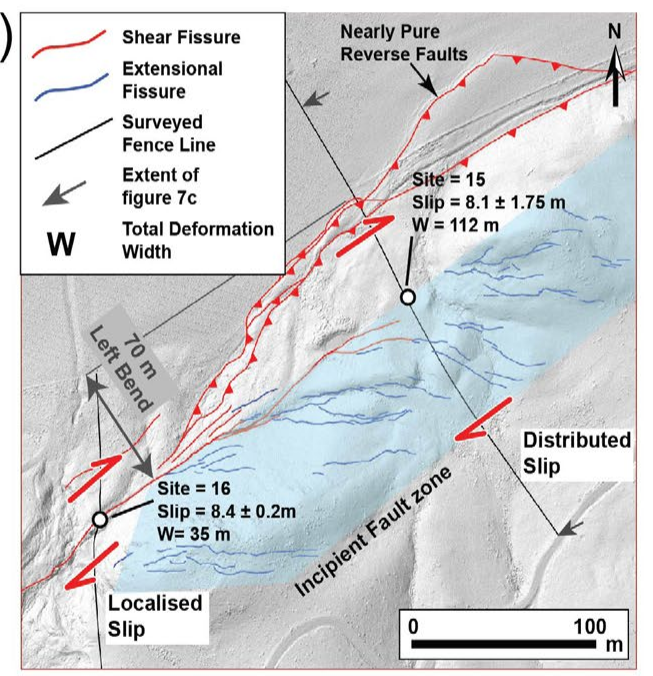

(g)

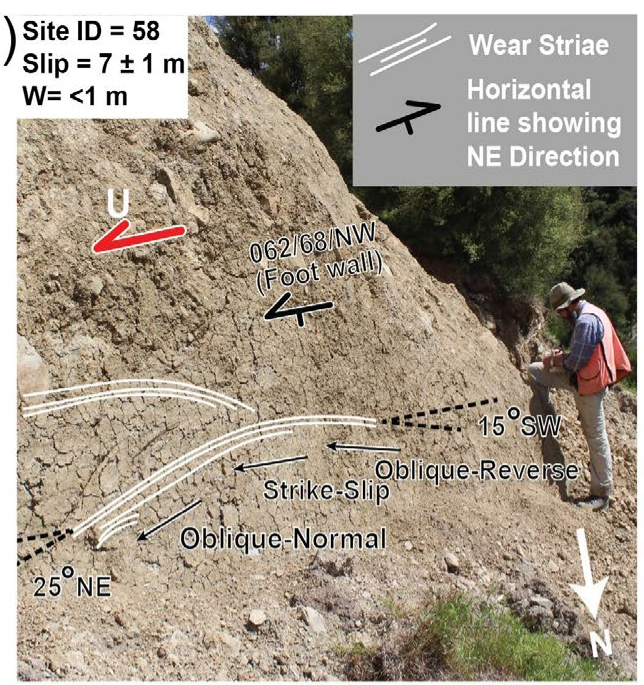

(i)
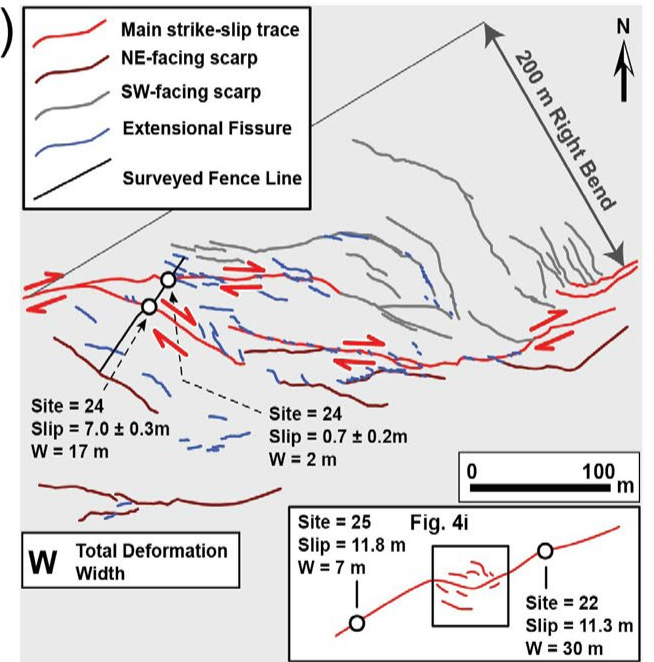

$=30 \mathrm{~m}$

(j)

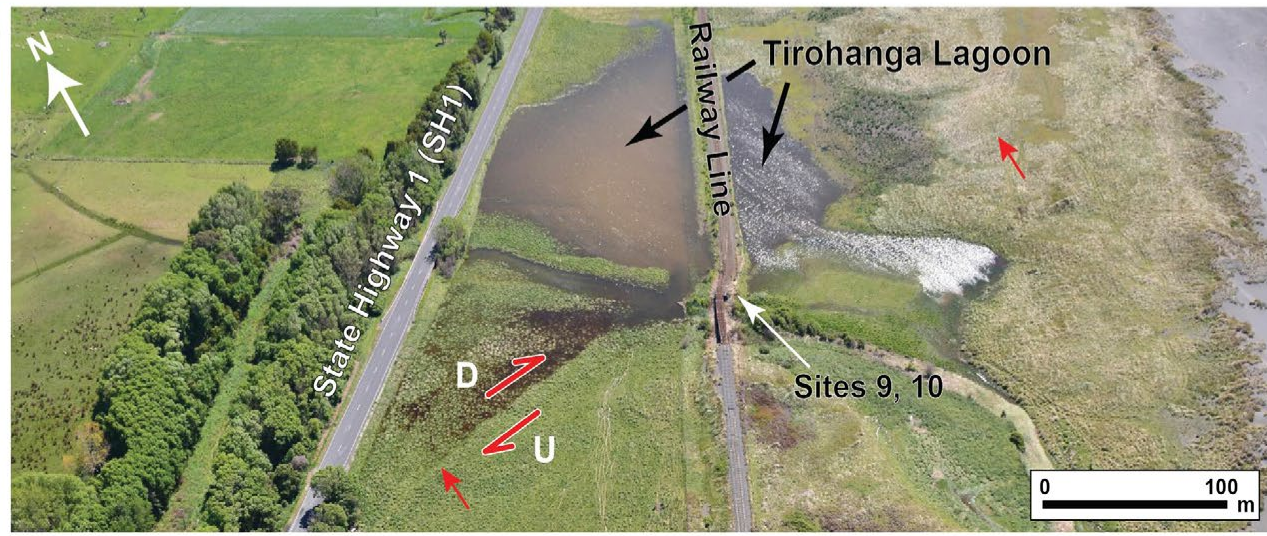

Figure 3.3b: F: Field photograph showing overhanging free face on the southwest side of a steep gully. Wear striae are highlighted with white lines showing an early reverse and later strike-slip displacement. Arrow on slip surface depicts motion of the "missing" footwall. Photo by Tim Little on 25/01/2017. G: Field Photograph showing $2.5 \mathrm{~m}$-long wear striae, inscribed in soft gouge on a footwall free face. Note the initial oblique-reverse motion, later strike-slip and final oblique-normal motion. Bold slip arrow depicts motion of the "missing" hanging wall. Photo by Kate Clark on 24/11/2016. H: LiDAR-derived digital terrain model (DTM) shaded from a 315 azimuth, with superimposed co-seismic fault rupture. Incipient fault zone and surveyed fence lines at sites 15 and 16 are shown, see text for discussion. I: detailed map of surface fault rupture surrounding a releasing bend on the Kekerengu fault. Note the $\sim 110^{\circ}$ strike of the main strike-slip fault trace at site 24 , which is $\sim 40^{\circ}$ clockwise of the fault strike at either end (see inset of Fig. 4i). J. Oblique aerial photograph showing Tirohanga Lagoon which formed after the earthquake. Vertical arrows show location of the fault rupture trace. Photo by Dougal Townsend on 18/11/2016. 
distance of $<500 \mathrm{~m}$, the rupture swings in strike from $\sim 050^{\circ}$ to $\sim 035^{\circ}$, and becomes upthrown on its southeast side (Fig. 3.1a). The morphology of 2016 surface fault rupture along the Kekerengu fault is relatively linear and least complex where it crosses gravel-rich deposits within a braided fluvial plain (Fig. 3.3b). This is also true for other regions along the 2016 surface rupture that cross recent unconsolidated sediment. For example, on the seabed along the Needles fault (Fig. 3.4g). Prior to its erosion, the $050^{\circ}$ striking reach of scarp on the braid plain of the Clarence River was between 1.5 (site 101) and $2.5 \mathrm{~m}$ high (site 100) and 4-5 m wide. Along the more transpressive segment that strikes $\sim 035^{\circ}$, the height of the (now eroded) scarp varied between $2.4 \mathrm{~m}$ (site 95) and $4 \mathrm{~m}$ (site 98), whereas the scarp width was up to $10 \mathrm{~m}$ (site 95). An obvious covariance of strike angle with scarp height is an attribute of the Clarence River section of the Kekerengu fault that is shared with other parts of the 2016 rupture that traverse unconsolidated sediment (e.g., site 25 and Fig. 3.4g). During the earthquake, unconsolidated alluvial gravels on the hangingwall of the fault in the Clarence River collapsed - probably instantaneously — to expand the scarp from an original width of perhaps $\sim 2 \mathrm{~m}$ to its final, stable width of 4-10 m. About $100 \mathrm{~m}$ northeast of site 95 , just south of where the fault exits the gorge of the Clarence River, a $400 \mathrm{~m}$-long, $100 \mathrm{~m}$-wide lake formed where the river was impounded against the upstream-facing rupture scarp (Fig. 3.3b).

From the Clarence River to the coast (between site 99 and site 5), a distance of $14 \mathrm{~km}$, the trace of the surface rupture deformation zone changes strike clockwise by $25^{\circ}$. The fault dips predominantly to the northwest at $65-85^{\circ}$, as revealed by field observations of the fault plane in bedrock (see below), yet along several short sections ( $<500 \mathrm{~m}$ long, locations shown by arrows on Fig. 3.1a) it dips locally at a steep angle $\left(>75^{\circ}\right)$ to the southeast. Overall, we infer that the fault is everywhere steeply northwest-dipping or near-vertical at depth. Throughout these local reversals in fault dip direction, the sense of co-seismic throw remained predominantly reverse. In other words, where the fault dips northwest, the northwest-side was uplifted, and where it dips southeast, the southeast side was uplifted; so that in almost all cases it remains dextral-reverse. The exception to this is along a $\sim 2 \mathrm{~km}$ long stretch near the coast where the fault has an up-to-the-southeast, oblique-normal sense of slip, and where Tirohanga Stream was locally impounded against the fault scarp to form a lagoon between the railway line and SH 1 (Clark et al., 2017) (Fig. 3.1b, between site 17 and site 5).

Surface fault rupture deformation along the $14 \mathrm{~km}$ section of the Kekerengu fault be- 
tween the Clarence River and the coast is expressed in diverse ways. Along this section of the Kekerengu fault, surface rupture extended across/through the steep walls of many deeply-incised stream canyons (e.g., sites 77, 59, 58, 39). Strike-slip displacement of these walls by 8-10 m created near-planar free faces up to $10 \mathrm{~m}$ wide in the slip direction, and up to $30 \mathrm{~m}$ long in a down-slope direction. Where the fault dipped steeply northwest, dextral offset of southwest-facing valley walls exhumed the fault plane on the footwall side, producing gravitationally-stable free faces. In contrast, slip on the same fault on the opposite side of the canyon produced overhanging free faces that typically collapsed, possibly during the earthquake otherwise shortly thereafter. An example of a free face at site 77 is depicted in Figure 3.3f. There, a hanging-wall free face in relatively strong bedrock remained intact despite its overhanging dip angle of $85^{\circ}$. The surfaces of nearly all free faces were smeared with a 1-2 cm thick layer of soft fault gouge. For several weeks after the earthquake, fine wear striae were preserved on these free faces. Individual striae were commonly traceable as continuous tracks over lengths of 2-6 m, and most were distinctly curved. Figure $3.3 \mathrm{~g}$, for example, depicts a footwall free face along which the striae curve from a $15^{\circ}$ southwest pitch to a $25^{\circ}$ northeast pitch in a right to left, "downstream" direction (the frame of reference of "downstream" is the motion of the missing hanging-wall block). Most striae curved in a "downstream" direction from an initial $\sim 15^{\circ}$ oblique-reverse pitch, to become horizontal - or in some cases transitioning into a slightly oblique-normal pitch - over a distance of 0.5 to 2 $\mathrm{m}$. Regardless of the local dip direction of the fault (northwest or southeast), the curvature at most sites records an initial, relatively short phase of dextral-reverse slip followed by a longer displacement phase of nearly pure dextral strike-slip.

In places where surface rupture extended through areas covered by a pronounced grassland turf-mat (up to $\sim 50 \mathrm{~cm}$ thick comprised of A-horizon soil and many entwined grass roots - in this case a mixture of exotic rye and clover) (e.g., between site 67 and site 62 and between site 23 and site 16), deformation is commonly focused in a 5-15 m wide strip of strongly sheared, fissured and up-buckled turf layers, collectively known as a "moletrack" (Koto, 1893) (Figs. 3.3c and 3.3e). Near the outer fringes of the moletrack, where limited shear displacement has occurred, near-vertical secondary faults strike 20-30 clockwise of the main rupture zone where they are typically arranged in an en echelon fashion at a mean spacing of $\sim 5 \mathrm{~m}$ from one another. We infer that these faults may have nucleated as synthetic Riedel (R) shears at a strike angle of $\sim 15-20^{\circ}$ to the overall fault trace (e.g., Tchalenko, 1970), 
but that they were later rotated clockwise about a vertical axis by $5-10^{\circ}$ during continued earthquake shearing. This outer, low-strain part of the zone is typically 2-4 $\mathrm{m}$ wide. Here the synthetic R shears are 3-4 m long and typically accommodate up to $40 \mathrm{~cm}$ of dextral shear displacement. The faults are dilated (gaping) and therefore have accommodated some extensional opening orthogonal to the fracture walls. These hybrid (shear + extension) fissures are on average 1-1.5 $\mathrm{m}$ deep, and they gape a distance of $0.3-0.5 \mathrm{~m}$ in width. In the central 2-5 $\mathrm{m}$ of the same moletrack — which is the high-strain part of the rupture deformation zone- the same faults strike at clockwise angles of up to $80^{\circ}$ to the mean strike of the rupture zone, and thus each individual $\mathrm{R}$ shear describes a distinctly " $\mathrm{Z}$ " shaped form overall as it traverses the moletrack (Fig. 3.3e). The strongly rotated, inner segments of the R shears are more widely gaped (aperture of up to $1.5 \mathrm{~m}$ ) than are the contiguous outer segments of the same fault (inset of Fig. 3.3e). This is an expectable consequence of the $\mathrm{R}$ shear being rotated (as a result of shearing during the earthquake) into the extensional quadrant of incremental strain in the central, highest-strain part of the rupture zone (e.g., Ramsay and Huber, 1987). As the faults rotated clockwise, an additional increment of extension caused further widening of the deforming $\mathrm{R}$ shear, so that in the central zone the fractures are more fissure-like than faultlike (inset of Fig. 3.3e). The magnitude of rotation of the fractures between the outer and inner parts of the moletrack suggests a finite shear strain $(\gamma)$ of $\sim 3.0$ in the central part of the fault zone. These $\mathrm{R}$ shears are commonly cross-cut by a younger suite of fractures that strike $\sim 20-30^{\circ}$ clockwise of the main rupture zone, and which are inferred to form during the final stages of fault movement (Fig. 3.3e). We infer that strongly rotated $\mathrm{R}$ shears of this type are probably unique to large magnitude (i.e., slip of 8-11 m) strike-slip ruptures, and that they would not be developed where slip is less. Between one fissure and the next, strips of grassy turf are compressionally buckled or twisted to form folded mounds of turf that are up to $1.5 \mathrm{~m}$ high (Fig. 3.3c). Layer-parallel compression of these northeast to southwest trending strips is an expected consequence of distributed dextral shearing. The outer margins of compressional bulges are typically bounded by $0.5-1.5$ m-long thrust faults (e.g., Fig. 3.3c) that, together with folding of the hanging-wall turf-mat, accommodate up to $1.5 \mathrm{~m}$ of finite shortening.

In other areas where slip on the Kekerengu fault was strongly localized into a single, near-vertical fault plane in bedrock, and where a large magnitude of dextral slip (e.g., $~ 10$ $\mathrm{m}$ ) was translated through a releasing bend, a more dramatic type of fault fissure developed. Called "fault crevasses" by us, these deep cracks may be up to $4 \mathrm{~m}$ deep, 2 m wide, and 8-10 
$\mathrm{m}$ long (Fig. 3.3d). The deeper parts of some crevasses were observed to be smeared with near-horizontal wear striae. The wide gaping of the fissure walls together with the sub-horizontal pitch of the striae indicate that fault crevasses resulted from (very) large strike-slip translation of a fault block through a releasing bend bounded by steeply dipping faults.

Between site 86 and site 5, the trace of the rupture deflects to the right (site 24) and to the left (sites 85, 77, 17 and 16) across releasing and restraining bends, respectively, that are up to $200 \mathrm{~m}$ wide (as measured perpendicular to the average strike of straight fault segments either side of the bend). Surface fault rupture deformation in the largest of these oblique-slip zones is the widest and most distributed rupture-related deformation that we observed. The releasing bend at site 24 , at the western end of this stretch, has a distributed deformation zone with an across-strike width of $\sim 300 \mathrm{~m}$ (as measured perpendicular to the average strike of faults within the bend (Fig. 3.3i). The zone contains numerous oblique-normal fault scarps-many of them strongly curved - and extensional fissures. Individual co-seismic scarps displace the ground surface by up to $1 \mathrm{~m}$ vertically, are up to $2 \mathrm{~m}$ deep and up to $0.5 \mathrm{~m}$ wide. Scarps to the northeast of this central trace show a down-to-the-southwest sense of throw, whereas the opposite sense is observed on the southwest side. These curved scarps are superimposed on the crests of pre-existing topographic breaks and together they down-drop a rhombic-shaped pull-apart graben (Fig. 3.3i). We now recognise the pre-existing topography at this bend to represent a suite of paleo scarps, and suggest that this event replicated the style of deformation that accompanied previous earthquakes. Two faults at the centre of this graben strike $\sim 110^{\circ}$ - which is $\sim 50^{\circ}$ clockwise of the nearby fault segments to the east and west (inset of Fig. 3.3i). These two strands together carry $7.7 \pm 0.4 \mathrm{~m}$ of dextral-slip (Fig. 3.3i). This is an underestimate of the total strike-slip accommodated inside the graben, because it does not include slip on any other faults. By comparison, the total dextral displacement being fed into this bend from the west is $11.8 \pm 0.3 \mathrm{~m}$ (site 25) and that "exiting" to the east is $11.3 \mathrm{~m}$ (site 22). Thus, most of the co-seismic dextral-slip (at least $\sim 7.7 \mathrm{~m}$ ) was translated directly through the releasing bend rather than being converted into localized extension inside the pull-apart.

A restraining bend cuts through bedrock hillslopes about $2 \mathrm{~km}$ to the northeast of site 24 (Fig. 3.3h). As is characteristic of most other restraining bends along the 2016 rupture, it is marked by oblique-reverse rupture traces that bound elevated topography on the uplifted side of the Kekerengu fault. The traces strike north-northeast and approximately follow the base 
of slopes, parallel to the topographic contours (Fig. 3.3h). Many of the base-of-slope faults appear to be chiefly reverse, as expressed, for example, by a turf roll that is overridden on its upslope side (for example of turf roll, see figure 3.3c). An $80 \mathrm{~m}$-wide distributed deformation zone in hard limestone bedrock lies adjacent to the restraining bend (Fig. 3.3h). The zone strikes $\sim 050^{\circ}$, subparallel to the mean strike of the Kekerengu fault, and appears to be "bypassing" the restraining bend. Internally, the zone contains an array of en echelon extensional fissures. The fissures are 10-50 $\mathrm{m}$ long, gape $0.3-0.5 \mathrm{~m}$ in width, and penetrate up to $3 \mathrm{~m}$ vertically into the ground. They strike $30-50^{\circ}$ clockwise of the overall strike of the belt. A surveyed fence line across the deformation zone (site 15, Fig. 3.3h) reveals that the belt of fissuring deformed a zone of distributed dextral shear, across which $8.1 \pm 1.75 \mathrm{~m}$ of dextral-slip was accommodated during the earthquake over a total width of $112 \mathrm{~m}$. We interpret the deformation in this zone to have initiated with the formation of en echelon extensional fissures in the hard limestone bedrock. Later in the 2016 rupture, the intervening slat-like strips of bedrock rotated clockwise about a vertical axis to accommodate continued dextral shearing. In short, the zone appears to represent an incipient fault zone that is developing in hard bedrock - one that is currently "attempting" to bypass the restraining bend to form a straighter fault.

Minor surface rupture occurred on the Heaver's Creek fault, an active splay of the Kekerengu fault, located $<2 \mathrm{~km}$ to the SE (Fig. 3.1a). The surface rupture was characterised by a narrow ( $<3 \mathrm{~m}$-wide) zone of discontinuous surface cracking along an $\sim 2 \mathrm{~km}$ portion of its mapped trace. A fence line that extended across this ground cracking showed displacement of $0.2 \pm 0.2 \mathrm{~m}$.

\subsubsection{Offshore}

The offshore Needles fault has a total length of about $47 \mathrm{~km}$ (Fig. 3.1c) and co-seismic surface rupture involved the southern $30-35 \mathrm{~km}$ of the fault. At a first order, the trace of the 2016 Needles fault rupture is near-linear, almost continuous, and has an average strike of $045^{\circ}$ (Figs. 3.1c and 3.4). Offshore of Tirohanga Stream at the coast, the $30^{\circ}$ change in the strike between the mapped traces of the Needles and Kekerengu faults occurs abruptly over a distance of $2.5 \mathrm{~km}$. Beyond this bend, the overall strike of the Needles Fault varies along its length by only $\sim 5^{\circ}$. The sense of throw evident on the seabed is up to the northwest along the 

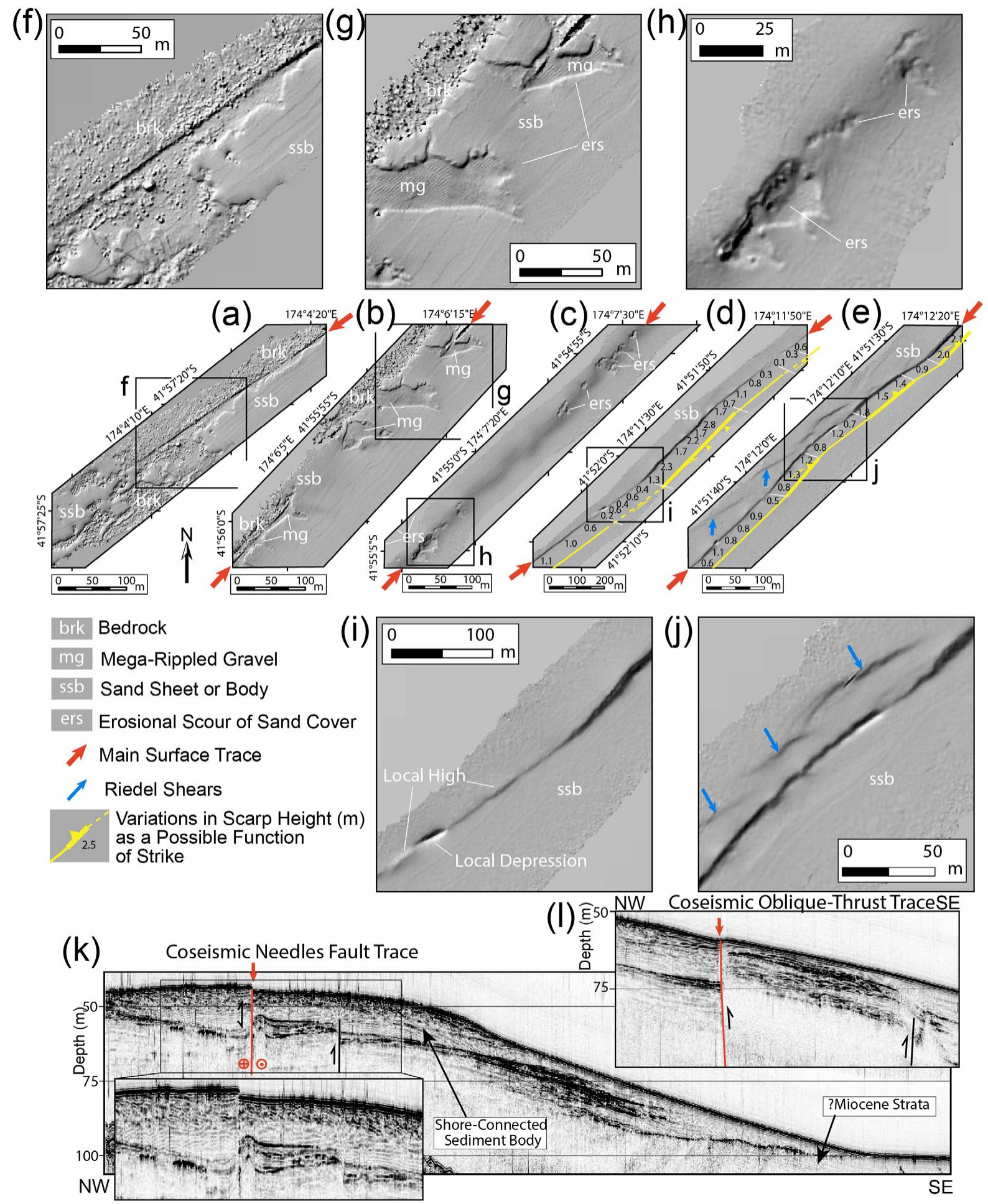

Figure 3.4: Offshore expression of seabed rupture on the Needles fault. A, B, F, G: Characteristic expression of seabed rupture in $<15 \mathrm{~m}$ water depth, where a thin veneer of sediment partially covers bedrock. $\mathrm{C}, \mathrm{H}$ : Seabed rupture in water depths $\sim 20 \mathrm{~m}$, where the scarp is a smooth ramp typically 1-2 m high. Note erosional scours shown in H. D, E, I, J: Seabed rupture in water depths between 30-40 m, where scarp forms a steep ramp in an inferred sandy substrate. Note the local covariance in fault strike and scarp height in D and E. K, L: TOPAS sub-bottom seismic reflection profiles across the seabed rupture of the Needles (K) and a northwest-verging splay (L), showing co-seismic displacement of the shore-connected sediments. See Figure 2c for profile locations. 
southern half of the trace, and mixed along the northern half.

There are three significant geometric irregularities along the fault trace. From the southwest, the first irregularity is a broad right bend in the trace over a $5 \mathrm{~km}$ length of the fault between Needles Point and Chancet Rocks, between 13 and $18 \mathrm{~km}$ along the strike of the fault (Fig 3.1c). This feature involves a $5^{\circ}$ change in average strike of the fault, has an acrossstrike width of about $600 \mathrm{~m}$, and occurs in 25-30 m water depth. The second irregularity is a restraining stepover east of Long Point, $25 \mathrm{~km}$ along the strike of the fault, lying in about 45 $\mathrm{m}$ water depth. This stepover is associated with a bathymetric ridge lying between two traces that are spaced $130-150 \mathrm{~m}$ apart, overlap by $600 \mathrm{~m}$, and are $10^{\circ}$ oblique to the main trace. This feature coincides with a change in the throw on the fault, from northwest-up along the trace southwest of the stepover, to southeast-up along the trace immediately northeast of it. The third geometric irregularity occurs $35 \mathrm{~km}$ along the strike of the fault, east-southeast of Cape Campbell, in about $100 \mathrm{~m}$ water depth. This feature comprises a releasing stepover associated with an elongate pull-apart basin that has $\sim 8 \mathrm{~m}$ of bathymetric relief (Figs. 3.1c and A2.1, Appendix 2). The two traces on either side of the basin are separated by 180-440 m, and they overlap along strike by $1.5 \mathrm{~km}$. North of the pull-apart basin, the linear trace identified prior to November 2016 from pre-existing data strikes $050^{\circ}$ over $7 \mathrm{~km}$, before splaying into a distributed zone of deformation that is up to $2.3 \mathrm{~km}$ in width and with average strike of $070^{\circ}$ (Figs. 3.1c and A2.1, Appendix 2).

Details of the surface trace of the Needles fault, and evidence for co-seismic rupture are illustrated in Figures 3.4a to 3.4i. A remarkably straight and continuous scarp, upthrown to the northwest, is observed in bedrock offshore of Tirohanga Stream and Wharanui (Fig. 3.1c) in water depths of $<15 \mathrm{~m}$ (Figs. 3.4a, 3.4b, 3.4d, 3.4e). The scarp and bedrock are partially covered by a veneer of sediment inferred to comprise sand and mega-rippled gravel. These images are characteristic of the trace over the southern $6 \mathrm{~km}$ of strike length, near to shore. We infer that the scarp formed during the 14 November, 2016 earthquake, and that its discontinuity reflects later storm wave transport of sediment and partial burial of the trace prior to the survey on 6 January 2017 (see below). The $6 \mathrm{~km}$ section of the trace northeast of Wharanui lies in water depths of about $20 \mathrm{~m}$, and is characterised by a smooth ramp typically 1-2 $\mathrm{m}$ high, formed in an inferred sandy substrate (Fig. 3.4f). The sediment cover along the fault trace is characterised by discontinuous erosional scour holes, that likely formed by focussing 
of post-earthquake storm wave energy against the curved bathymetry of the newly formed scarp (Fig. 3.4c). Still further northeast, in water depths of about 30-40 m east of Needles Point and Chancet Rocks, the surface trace is characterised by a steep, irregular scarp that reaches a maximum height of about $3.5 \mathrm{~m}$ (Figs. $3.4 \mathrm{~g}, 3.4 \mathrm{~h}, 3.4 \mathrm{i}$, and $3.4 \mathrm{j}$ ). The scarp reveals variations in fault strike of up to $10-15^{\circ}$ at scales of $101-102 \mathrm{~m}$ distance along strike. These strike changes are typically accompanied by changes in scarp height, with the more restraining segments having scarp heights up to $1.5 \mathrm{~m}$ higher than adjacent releasing segments - similar to what is observed onshore where ruptures pass through loose gravels. Discontinuous oblique traces about 40-80 m in length, lying 20-30 m west of the main scarp, are inferred to be R shears (vertical arrows in Figs. 3.4h and 3.4j).

The northwest-up surface trace is clearly visible in TOPAS sub-bottom profiles (e.g., Fig. $3.4 \mathrm{k}$ ). The profiles reveal that the displaced, shore-connected sediment body reaches 14-17 $m$ thickness, and that it thins and down-laps onto bedrock strata exposed at the seabed in the hanging wall of oblique thrust faults further offshore (Fig. 3.1c). While no dextral offsets can be inferred using the multibeam bathymetric data, the vertical offsets in the profiles are consistent with the interpretation that the net slip on the fault along this section is dominantly dextral with a subordinate reverse component. The profiles also reveal that the sense of throw is not constant with depth below the seabed at any one location. While this likely reflects dextral displacement in and out of the plane of the profile sections (i.e. the juxtaposition of adjacent swales and ridges, creating apparent vertical offset in profile view), it indicates that the surface rupture kinematics may have varied in previous earthquakes.

Previous modelling of inner shelf sediment transport in the southern Cook Strait region by Carter and Lewis (1995) provides the most compelling evidence that the surface trace illustrated in Figure 3.4 is extremely young and therefore entirely the result of co-seismic rupture associated with the 14 of November, 2016 Kaikōura earthquake. They demonstrated that regular storm waves with periods of 10-16 s and heights of 2.3-4.3 m result in the mobilisation of fine- to coarse-grained sand and granules in water depths of $<100 \mathrm{~m}$. Such conditions occur in the region at annual and shorter time scales. This analysis is consistent with the above evidence for sediment transport along the southern fault trace in $<30 \mathrm{~m}$ water depth, between the earthquake and 5 January 2017 (Fig. 3.4d to 3.4f). Their study indicates that at timescales of 101-102 years, there is an extremely poor potential for preservation of 
fault traces formed in such sediments in water depths of $<50-60 \mathrm{~m}$, over the southern $\sim 30 \mathrm{~km}$ of the fault. Moreover, the compatibility of the marine scarp measurements and the nearby coastal uplift data (both presented below) support our interpretation that the marine surface trace illustrated in Figure 3.4 is entirely the result of co-seismic rupture associated with the 2016 Kaikōura earthquake. We suspect, however, that the fault scarp along the northern section of the fault east-southeast of Cape Campbell, in water depths of $>90 \mathrm{~m}$, may include an inherited component from one or more previous earthquakes.

We found no evidence for recent surface rupture along the northern section of the fault east of Cape Campbell (Fig. A2.1, Appendix 2), as based on a multibeam bathymetric difference analysis of $2 \mathrm{~m}$ gridded DEMs acquired before and after the Kaikōura earthquake. Furthermore, TOPAS sub-bottom profiles acquired across the complex splay faulting towards the northern end of the fault, and across the western trace of the Boo Boo fault, revealed no evidence of a fresh seafloor scarp formed in post-glacial sediments ( $<20 \mathrm{ka})$ (e.g., Fig. A2.1a, Appendix 2) (Barnes et al., 2015).

Additionally, we document evidence of partial rupture of one of the $030^{\circ}$-striking, southeast-dipping thrust faults located southeast of the Needles fault (Fig. 3.1c). We observe an arcuate surface scarp about $900 \mathrm{~m}$ long in the multibeam bathymetry data, in $60 \mathrm{~m}$ water depth, about $3.7 \mathrm{~km}$ east of Chancet Rocks. This fault scarp has a height of $1.5 \mathrm{~m}$, and is upthrown to the southeast (e.g., Fig. 3.4i). The surface rupture represents about $6-10 \%$ of the total length of the fault, as mapped using TOPAS sub-bottom profiles.

\subsection{Co-seismic Slip Distribution}

\subsubsection{Horizontal Slip Distribution}

The along-strike distribution of co-seismic dextral surface fault rupture displacement is presented in Figure 3.5b (for individual site details the reader is referred to the electronic Appendix to this thesis), extending $\sim 83 \mathrm{~km}$ from the southwestern extent of the Manakau and Upper Kowhai faults to the northeastern extent of seabed rupture of the Needles fault. Note that in Figure 3.5, where multiple strands of the Kekerengu fault overlap, dextral displace- 


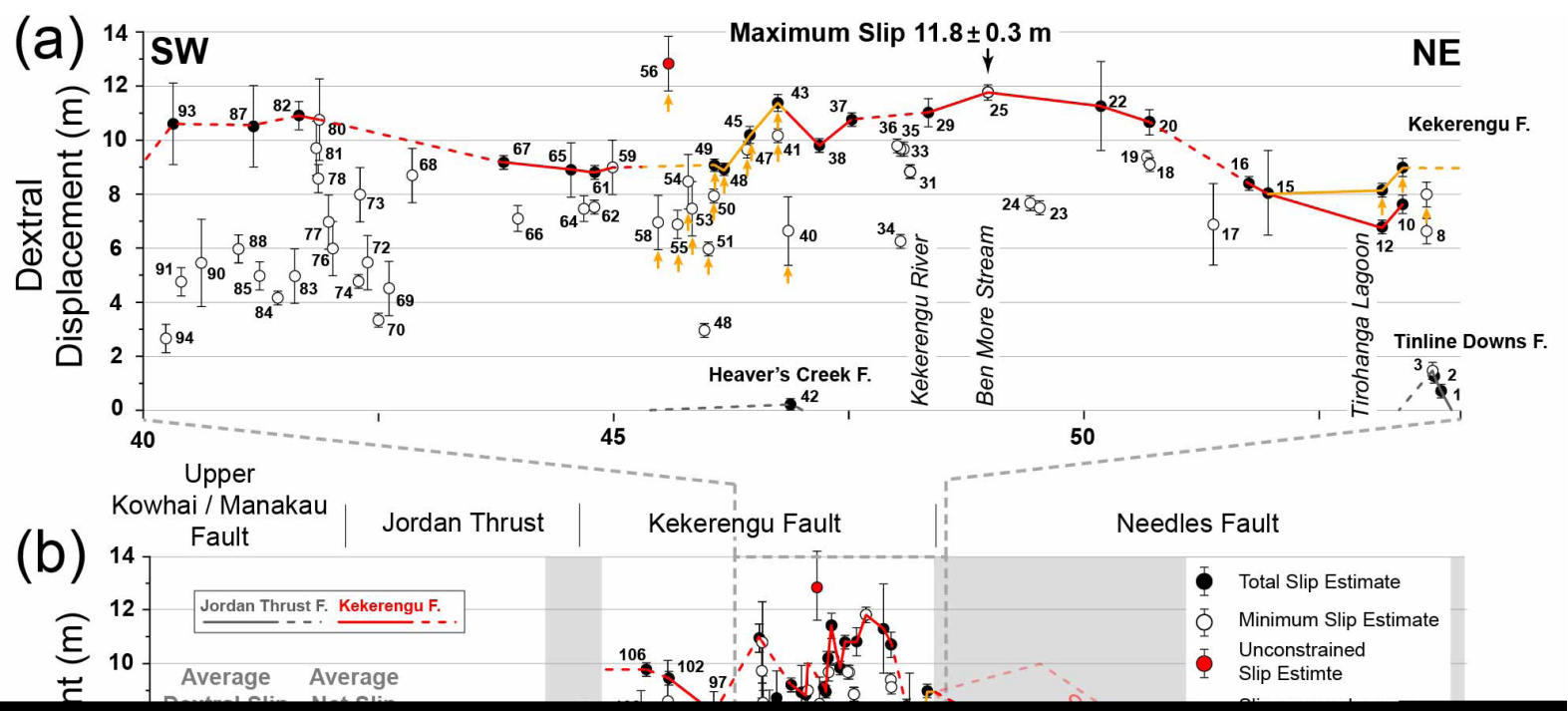

Figure 3.5: Distribution of dextral and vertical surface rupture displacement along the Upper Kowhai, Manakau, Jordan Thrust, Kekerengu and Needles faults resulting from the 2016 Kaikoura earthquake. Site numbers relate to Figure $2 \mathrm{~b}$ and Table $\mathrm{S1}$ (available in the electronic supplement to this article). A: Enlarged view of the central high in dextral surface rupture displacement along the Kekerengu fault, including the maximum dextral slip of $11.8 \pm 0.3 \mathrm{~m}$ at site 25 . Vertical arrows denote sections of the Kekerengu fault where slip has been summed across the Heaver's Creek and Tinline Downs faults. B: Dextral surface rupture displacement along the entire $\sim 83 \mathbf{~ k m}$ of continuous surface rupture along the Upper Kowhai, Manakau, Jordan Thrust, Kekerengu and Needles faults. Papatea fault intersection and Needles fault are highlighted in with vertical grey bars. Bold dashed line on the Needles fault represents the curve used to estimate average slip, dashed lines above and below refer to the curves used to place error bounds on this estimation. $C$ : Distribution of vertical surface rupture displacement and fault azimuth. Curve of offshore vertical displacement has been interpolated from a smoothed dataset of individual point measurements. Sites refer to Figure $2 \mathrm{~b}$ and Table S2 (available in the electronic supplement to this article). Large numbers " 1 ", " 2 ", " 3 " and " 4 " on the fault azimuth curve refer to particular bends in the fault that are cited in the text.

ment has been summed across all strands. The onshore part of the strike-slip envelope defines a semi-bell shaped distribution of slip (Fig. 3.5b). No lateral offsets could be measured along the $27 \mathrm{~km}$-long rupture of the offshore Needles fault because of the absence of suitable markers on the flat seabed. Figure 3.5b shows possible lateral slip distributions for this section of the fault as dashed lines and includes bell-shaped, triangular and semi-elliptical slip 
envelopes. Southwest of site 146 on the Upper Kowhai and Manakau faults, displacement was difficult to accurately quantify due to inaccessibility issues, lack of LiDAR coverage on the Manakau fault, and a paucity of piercing points with which to measure displacement. Between site 146 and the southwestern tip of the rupture, we assume a linear decrease in dextral slip from northeast to southwest (Fig. 3.5b). On the Jordan Thrust, between site 144 and site 124, dextral slip rises linearly $(\sim 0.6 \mathrm{~m} / \mathrm{km})$ from approximately 1 to $8 \mathrm{~m}$ (Fig. $3.5 \mathrm{~b})$. At its northern tip, the Jordan Thrust overlaps the Kekerengu fault, and here the two faults share $7.1 \pm 0.5 \mathrm{~m}$ of dextral slip, each accommodating $\sim 3.5 \mathrm{~m}$ (sites 121 and 122, Fig. 3.5b). Along the central $\sim 10 \mathrm{~km}$ of the slip distribution (between site 93 and site 20) (Fig. 3.5a), dextral surface rupture displacement is at its maximum ( 10-12 $\mathrm{m})$. This section of the 2016 rupture includes the maximum observed dextral-slip of $11.8 \pm 0.3 \mathrm{~m}$ at Ben More Stream (site 25 ), and eight additional sites where slip is $>10.5 \mathrm{~m}$. In the area to the northeast of the central slip high, between site 16 and site 5 strike-slip is $8-9 \mathrm{~m}$. Here the Tinline Downs fault splays northeast off the Kekerengu fault (Fig. 3.1a) and carries $1.5 \mathrm{~m}$ of dextral slip. This value was added to the three coastal offsets on the Kekerengu fault (sites 12, 10 and 8), resulting in total dextral-slip of $9 \pm 0.4 \mathrm{~m}$ ( site 10$)$.

A more detailed inspection of the dextral slip profile reveals areas where the envelope deviates from the above-described simplified shape. For example, a discontinuity in horizontal slip gradient is located across the intersection of the Papatea fault surface rupture with the greater Kekerengu fault (Figs. 3.1a and 3.5b). Across this zone of fault intersection, in a southwest direction—-between site 106 and site 114—slip drops from $\sim 10 \mathrm{~m}$ to $7.3 \pm 0.2 \mathrm{~m}$. This drop in dextral-slip on the "greater" Kekerengu fault zone is an expected result of the observed uplift, shortening and reverse-sinistral slip on the Papatea fault that intersects it to the east (Hamling et al., 2017; Langridge et al., 2018).

\subsubsection{Vertical Slip Distribution}

Onshore. The along-strike distribution of vertical surface fault rupture displacement is presented in Figure 3.5c (for individual site details the reader is referred to the electronic Appendix to this thesis). Between site 116 and site 5 (Fig. 3.5c), throw is a largely up-to-thenorthwest and reverse, with magnitudes averaging $\sim 1.5 \mathrm{~m}$, and locally exceeding $2 \mathrm{~m}$. By contrast, from the southwest tip of the rupture to site 123, throw is up-to-the-southeast and 
has normal sense. Magnitudes here are variable and range between 0.5-3.6 $\mathrm{m}$. This reversal in sense of throw straddles the Papatea fault intersection (Figs. 3.1a and 3.5c). InSAR data show that during the Kaikōura earthquake, the northwest-dipping Jordan Thrust fault (and its hanging wall to the northwest) was uplifted by 2-3 m; whereas to the southeast of the Jordan Thrust, the footwall block was uplifted by 5-6 m (Hamling et al., 2017); thereby inducing a relative component of normal displacement across the Jordan Thrust in the Kaikōura earthquake (excluding the northernmost c. $2 \mathrm{~km}$ of the fault where it overlaps with the Kekerengu fault).

Along the dominantly northwest-up section of the Kekerengu fault, three reversals in throw are associated with distinct bends in the fault (sites 98, 79, 63, Fig. 3.5c). Two restraining bends (labels "1" and "2", Fig. 3.5c) coincide with up-to-the-southeast displacement on southeast-dipping fault planes (sites 98 and 79); and therefore, the sense of throw remains reverse. In contrast, an up-to-the-southeast throw at site 63 is located within a releasing bend (label "3", Fig. 3.5c) where the fault dips to the northwest, thus producing an oblique-normal sense of slip. Along the $2 \mathrm{~km}$ stretch of rupture at the coast (between site 14 and site 6, Fig. $3.5 \mathrm{c}$ ) where the Kekerengu fault bends $35^{\circ}$ to the east to strike $075^{\circ}$, differential LiDAR data reveal that both sides of the fault subsided by up to $2.5 \pm 0.2 \mathrm{~m}$ during the earthquake (Clark et al., 2017). Here the fault maintained a northwest dip and had an up-to-the-southeast oblique-normal sense of throw, of 2-2.5 $\pm 0.2 \mathrm{~m}$. Immediately after the earthquake, a large lagoon formed on both sides of the Kekerengu fault between the railway line and SH 1 ("Tirohanga Lagoon", Figs. 3.5a and 3.3j), as Tirohanga Stream was impounded against the fault scarp. This lagoon persisted for 7 months before being artificially drained. The coastal subsidence is most likely the result of lateral-slip being translated through an easterly releasing bend (label“4", Fig. 3.5c). Moving northeast towards the coast, where the fault crosses coastal sand dunes (between site 7 and site 5), throw on the fault reverts from up-to-the-southeast $(2.0 \pm 0.2 \mathrm{~m}$, probably normal) to up-to-the-northwest $(1.2 \pm 0.2 \mathrm{~m}$, probably reverse).

Offshore. The vertical displacement along the Needles fault fits a curved slip envelope, however without a best-fit analysis it is unclear whether it is more bell-shaped or semi-elliptical (Fig. 3.5c). The maximum throw of $3.5 \mathrm{~m}$ occurs between Wharanui and Needles Point, about $11 \mathrm{~km}$ along the fault (Figs. 3.1c and 3.5). The general throw profile coincides 
with maximum measurements of coastal uplift nearby, incorporating field measurements of displaced tidal biota, as well as pre- and post-earthquake LiDAR differencing (Clark et al., 2017). The maximum coastal uplift of $2.9 \mathrm{~m}$ relative to sea-level was measured approximately $5 \mathrm{~km}$ northeast of where the Kekerengu fault exits the coast.

There is a general reduction in throw through the $5^{\circ}$ bend in the fault trace between Needles Point and Chancet Rocks (Fig. 3.5c). We infer this to indicate that this section of the fault has reduced oblique reverse displacement and relatively higher dextral displacement. The bend therefore is not a classic releasing bend, but facilitates transfer of oblique slip between sections of the fault to the southwest and northeast of it. Similar variations in throw as a function of strike are also apparent at smaller-scales (101-102 m) (e.g., Figs. 3.4g and 3.4h).

More than $20 \mathrm{~km}$ along the strike of the Needles fault, there is a general increase in throw (Fig. 3.5c). The large values measured occur across the restraining stepover northeast of Long Point and on parts of the southeast-up section. We consider that anomalously high measurements in the northeast reflect a compound scarp, with more than one event represented by the total scarp height. Despite this reversal in sense of throw at the fault, on-land coastal deformation and InSAR data show co-seismic uplift, suggesting reverse slip at depth on the Needles fault (Hamling et al., 2017; Clark et al., 2017).

\subsubsection{Across-Strike Distribution of Dextral Slip}

The surveyed post-earthquake shape of 14 previously-straight fence lines that crossed the entire deformation zone of the Kekerengu fault show that it varies in width between 13 and $122 \mathrm{~m}$. These linear features also reveal that on average, most dextral slip (80\%) was accommodated within the central $43 \%$ of the ground deformation zone (Fig. 3.6a). The remaining displacement was accommodated outside of this central zone as more diffuse, distributed shear extending to the outer margins of the deformation zone (e.g., Figs. 3.2, 3.6b). These fourteen fences (each available in the electronic Appendix to this thesis) crossed the surface rupture deformation zone at high angles $\left(55-90^{\circ}\right)$ and extended beyond the main surface rupture trace for distances of 15-200 m (Fig. 3.6). As inferred from deflection of the otherwise linear fences, the overall width of this deformation zone ranged between 13-112 $\mathrm{m}$ and averaged $\sim 50 \mathrm{~m}$. Where the total width of deformation was $30 \mathrm{~m}$ or less $(\mathrm{n}=4), 80 \%$ of the 
(a)

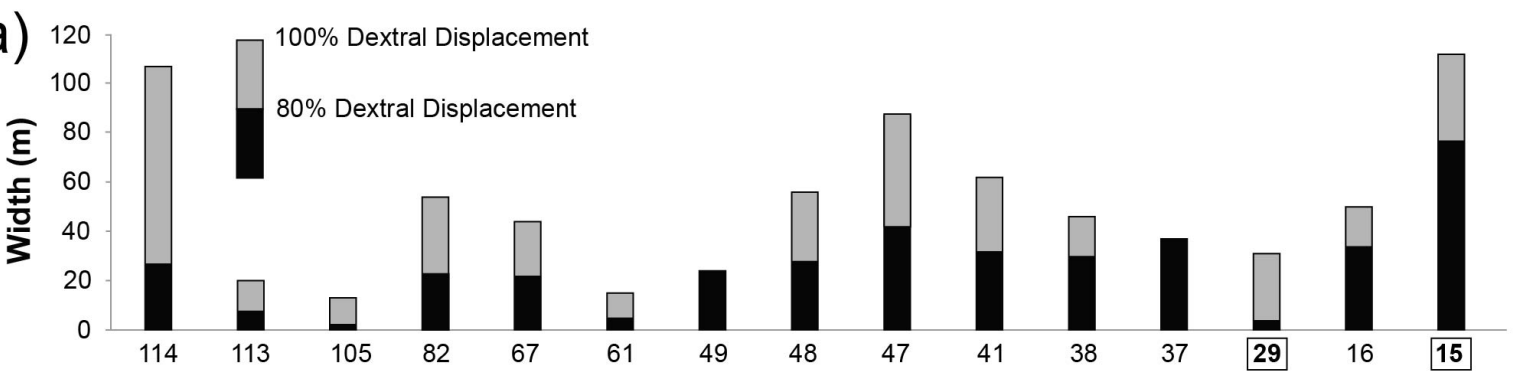

(b)

Site ID

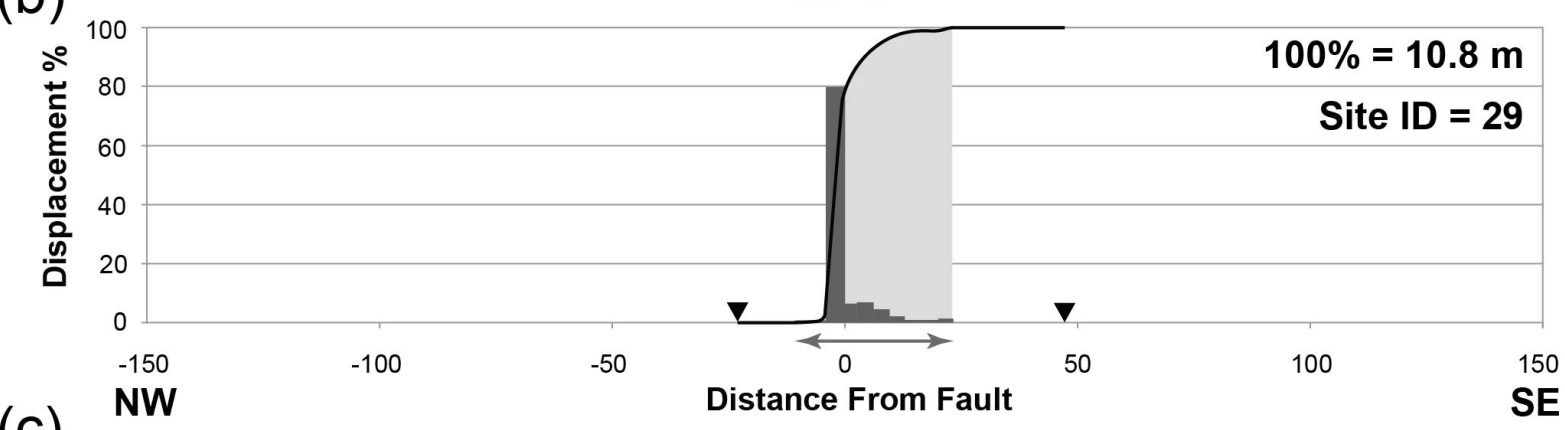

(c)

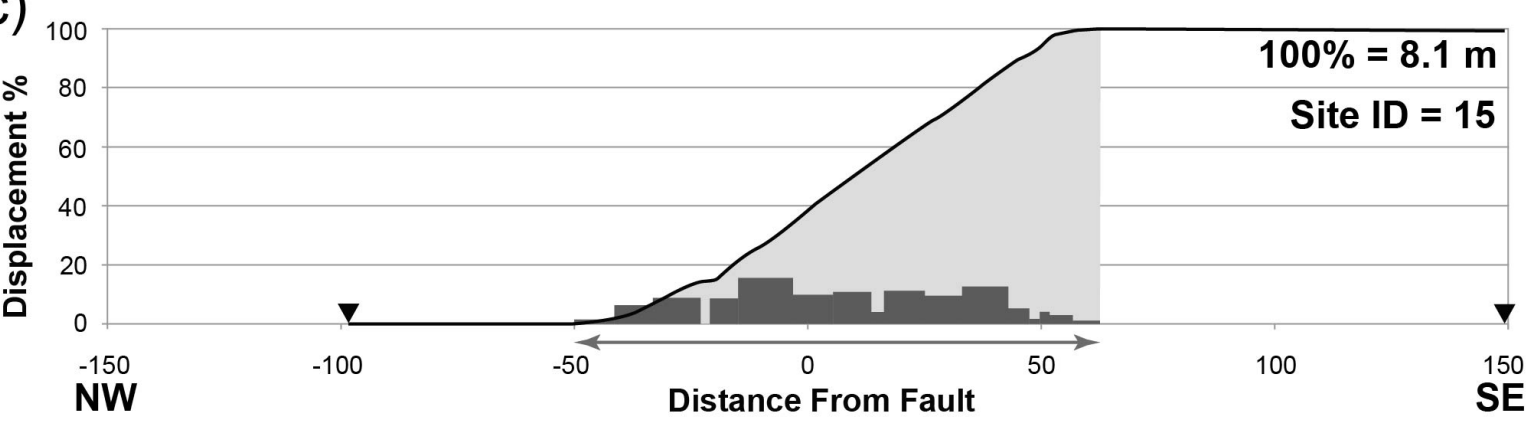

Figure 3.6: A: Histograms showing the relationship between width of surface rupture deformation zone $(100 \%$ displacement, grey bars) and the width across which $80 \%$ of the total dextral displacement is accommodated $(80 \%$ displacement, black bars) for 15 sites. B, C: Plots of cumulative dextral surface rupture displacement and histograms of displacement distribution at sites 29 and 15, respectively. Black arrow heads in $B$ and $C$ denote the extent of the surveyed fence lines. Double-headed arrows depict width of fault zone (100\% displacement).

dextral slip was distributed across the central $25 \%$ of the deformation zone ( $<7.5 \mathrm{~m}$ wide). Here, displacement gradients were highest, with finite shear strains $(\gamma)$ between 0.7-3.3. Elsewhere, where total deformation widths were $>30 \mathrm{~m}(\mathrm{n}=10)$, mean finite shear strains $(\gamma)$ were between 0.07-0.4. These results do not completely resolve the magnitude of strain localization, as incremental slip measurements are limited to the spacing of fence posts, which are between 3-38 m. For an end-member example of this at site 37 (Fig. 3.6a), there are no fence posts within the deformation zone with which to measure displacement gradients, and therefore only a maximum width of deformation can be estimated (these two sites are not included in averaging calculations). In a case of widely distributed slip (mean finite shear strain $\gamma=$ 0.07 ) (site 15, Figs. 3.3h, 3.6b), $>8.1 \mathrm{~m}$ of dextral slip was nearly evenly distributed across the $112 \mathrm{~m}$ total width of deformation, formed in hard limestone bedrock that we infer (see above) to be deforming by extension fracturing and vertical-axis rotation of bedrock strips. A 
(a)

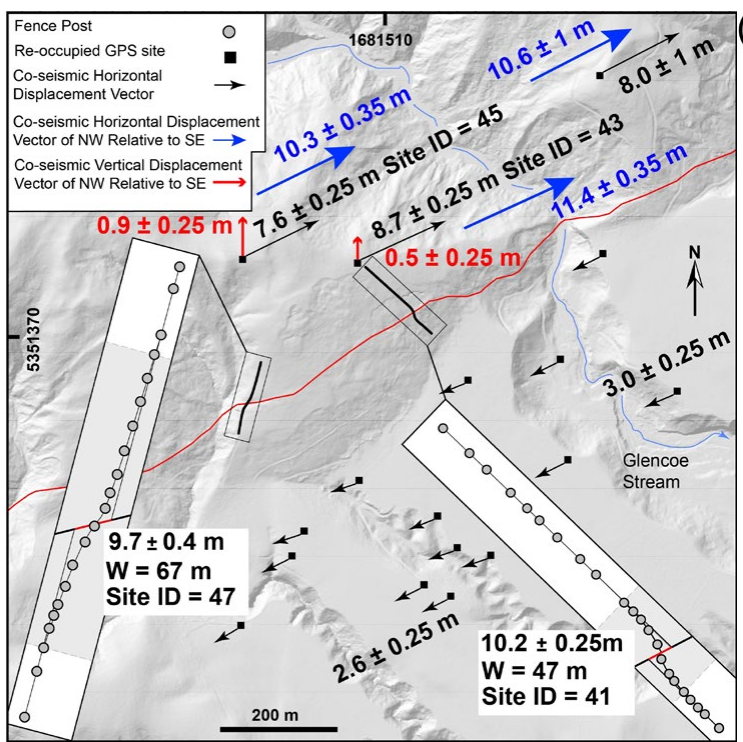

(b)

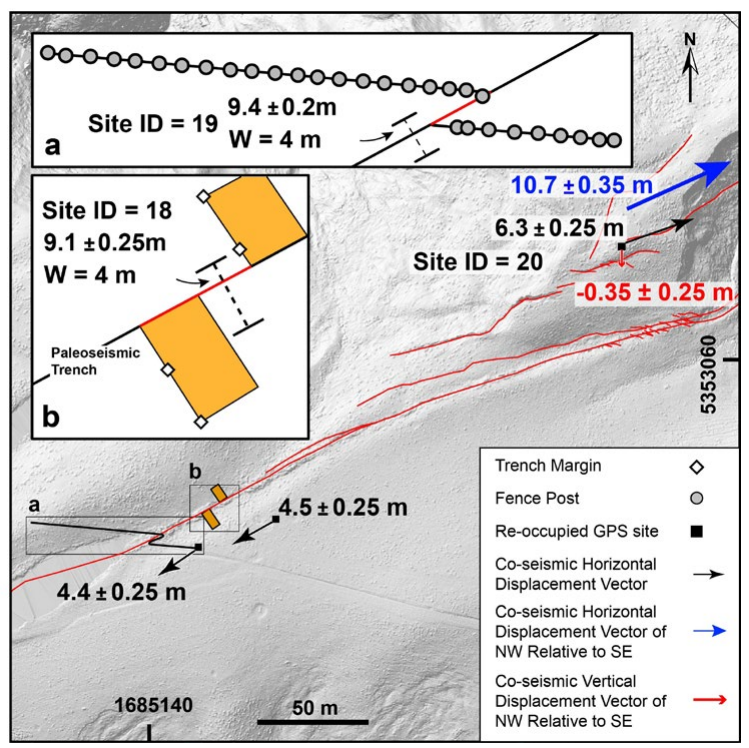

Figure 3.7: Networks of re-surveyed fence posts (black squares) showing co-seismic horizontal displacement vectors, and horizontal and vertical co-seismic displacement of the northwest side of the fault relative to the southeast side. A: Co-seismic displacement map including re-surveyed fence post network and two fence lines displaced across the fault (sites 37 and 40). B: Co-seismic displacement map including three re-surveyed fence posts and an offset paleo-seismic trench.

notable feature of displacement at this site is that the fence was cut by only two extensional fissures (Fig. 3.3h), across which there is no significant discontinuity in displacement (Fig. $3.6 \mathrm{~b}$ ). The remaining $\geq 7.5 \mathrm{~m}$ of displacement was accommodated without any obvious rupturing at the ground surface. This suggests that along the Kekerengu fault during the 2016 rupture, shear strains $(\gamma)$ in excess of $\sim 0.1$ were needed before recognizable discrete shears formed on the ground surface.

Estimates of horizontal displacement using fence lines that extend beyond the width of observable ground deformation are probably still underestimates of total dextral displacement. We used a network of fence posts - first surveyed in January 2016, and repeated one month after the earthquake - that extend up to $700 \mathrm{~m}$ across the Kekerengu fault to calculate the horizontal and vertical displacement during the earthquake (Fig. 3.7). The GPS-derived relative fault displacements $(n=4)$ were between $7-12 \%$ larger than coincident dextral offsets estimated from deflected fence lines inside the same survey network. These displacements were much larger (up to a factor of 4) on the northwest side of the fault than on the southeast side (Fig. 3.7), an observation that agrees with InSAR data from Hamling et al (2017). Despite the width of coverage, no discernible horizontal or vertical displacement gradient is observed beyond the deformation zone covered by the fence lines - the additional displacement must therefore occur between the ends of the fence lines and the nearest re-occupied fence post - a width of $260 \mathrm{~m}$ (Fig. 3.7a). These vector displacements are not, strictly speak- 
ing "strike-slip", as their azimuths are not exactly parallel to the strike of the fault. However, unrealistic amounts of shortening and uplift across the fault would be required for this to account for the difference of $1.2 \mathrm{~m}$ in horizontal slip between site 41 and site 43 (Fig. 3.7). Up to $1.2 \pm 0.35 \mathrm{~m}(10 \%)$ of additional dextral displacement was distributed outside of the zone of fence line deflection, over widths of 100-350 m (Fig. 3.7) as low shear strains ( $\gamma$ ) of up to 0.01 . This fringing zone of diffuse dextral shear may not be noticed even if fence lines were to extend this far and therefore would be detected only with methods that derive displacement by precisely locating features before and after an earthquake. This has implications for Single Event Displacement (SED) and slip rate estimates derived from restored geomorphic piercing points across narrow fault zone widths $(<50 \mathrm{~m})$. These types of measurements will potentially systematically underestimate the total surface displacement across faults and therefore underestimate long-term slip rates (e.g., Dolan and Haravitch, 2014; Zinke et al., 2014; Milliner et al., 2016).

Based on the re-survey of fence lines in January of 2017, which were first surveyed in November 2016, no afterslip was measured across the northern domain of surface faulting during the two months following this event.

\subsection{Discussion}

\subsubsection{Magnitudes of Slip and Surface Slip Distribution}

This study has documented, for the first time, direct observation of large co-seismic surface fault rupture extending continuously from on land to offshore. Previous studies have recorded direct observations of submarine fault rupture (Fujiwara et al., 2011: Escartin et al., 2016), or correlated fresh submarine fault scarps with historic earthquakes (Reicherter and Hübscher, 2007; Aksoy et al., 2010), but this research represents the first post-seismic dataset of ground surface and seabed rupture, carried out immediately following a large magnitude earthquake.

By integrating the slip profile of Figure 3.5b, we calculate average dextral-slip of 5.2 $\pm 1 \mathrm{~m}$ for the $\sim 83 \mathrm{~km}$ of near-continuous surface rupture of the Manakau, Upper Kowhai, 
Jordan Thrust, Kekerengu and Needles faults. An average net slip value of $5.5 \pm 1 \mathrm{~m}$ was calculated by including the vertical component of fault motion. These average slip values were calculated by dividing the total area under the dextral-slip curve by the surface rupture length $(83 \mathrm{~km})$. Because no lateral offsets could be measured along the $30-35 \mathrm{~km}$-long rupture of the Needles fault, any calculation of an average dextral slip magnitude for the entire rupture therefore requires assumptions to be made regarding the distribution of dextral slip on the Needles fault — for example by inferring an average $\mathrm{H}: \mathrm{V}$ ratio there, or by assuming a particular shape of the dextral-slip profile. Although bell-shaped slip envelopes (e.g., Fig. 3.5b) have been observed on other large strike-slip earthquake ruptures, for example: the 1999 Izmit (Barka et al., 2002) and the 2001 Kunlun (Xu et al., 2006; Lin and Nishikawa, 2007), semi elliptical (Haeussler et al., 2004; Zinke et al., 2014; Gold et al., 2015; Haddon et al., 2016) and triangular slip distributions also occur (e.g., Sieh, 1978; Jonsson et al., 2002). InSAR and campaign GPS data on land adjacent to the Needles fault, and extending northeast to Cape Campbell, show that the magnitude of co-seismic horizontal displacement is comparable to geodetic observations near the Kekerengu fault (Hamling et al., 2017). If these geodetic data adjacent to the Needles fault are representative of horizontal slip on the Needles fault, this would imply a more semi-elliptical pattern of displacement (e.g., Fig. 3.5b). However, because we do not observe any lateral displacement at the Needles fault we chose the simplest possible offshore slip pattern—one that assumes a uniform slip gradient (i.e., linear gradient and triangular slip profile shape) from the most northeastern observed value at the coast, to reach zero at the inferred offshore rupture tip, $\sim 30 \mathrm{~km}$ to the northeast (Fig. 3.5b). We acknowledge that a linear gradient in dextral-slip on the Needles fault may either underestimate or overestimate the average dextral-slip magnitude in that region. Therefore we adopt two additional slip distribution shapes for the Needles fault (bell-shaped, and semi-elliptical, see Figure 3.5b), which are used to place error bounds on our determination of average dextral-slip of $5.2 \pm 1 \mathrm{~m}$.

Our co-seismic slip distribution, based primarily on detailed field surveys at the fault rupture agrees well with displacements produced from far-field methods (InSAR_-Hamling et al., 2017; pixel correlation of optical satellite images-Hollingsworth et al., 2017), and with coastal uplift data (Clark et al., 2017). Unlike these techniques, however, our methods are sensitive to short wavelength variations $(0.5-2 \mathrm{~km})$ in slip magnitude that are typical of deformation within tens of metres of the primary fault rupture (e.g., Rockwell et al., 2002; 

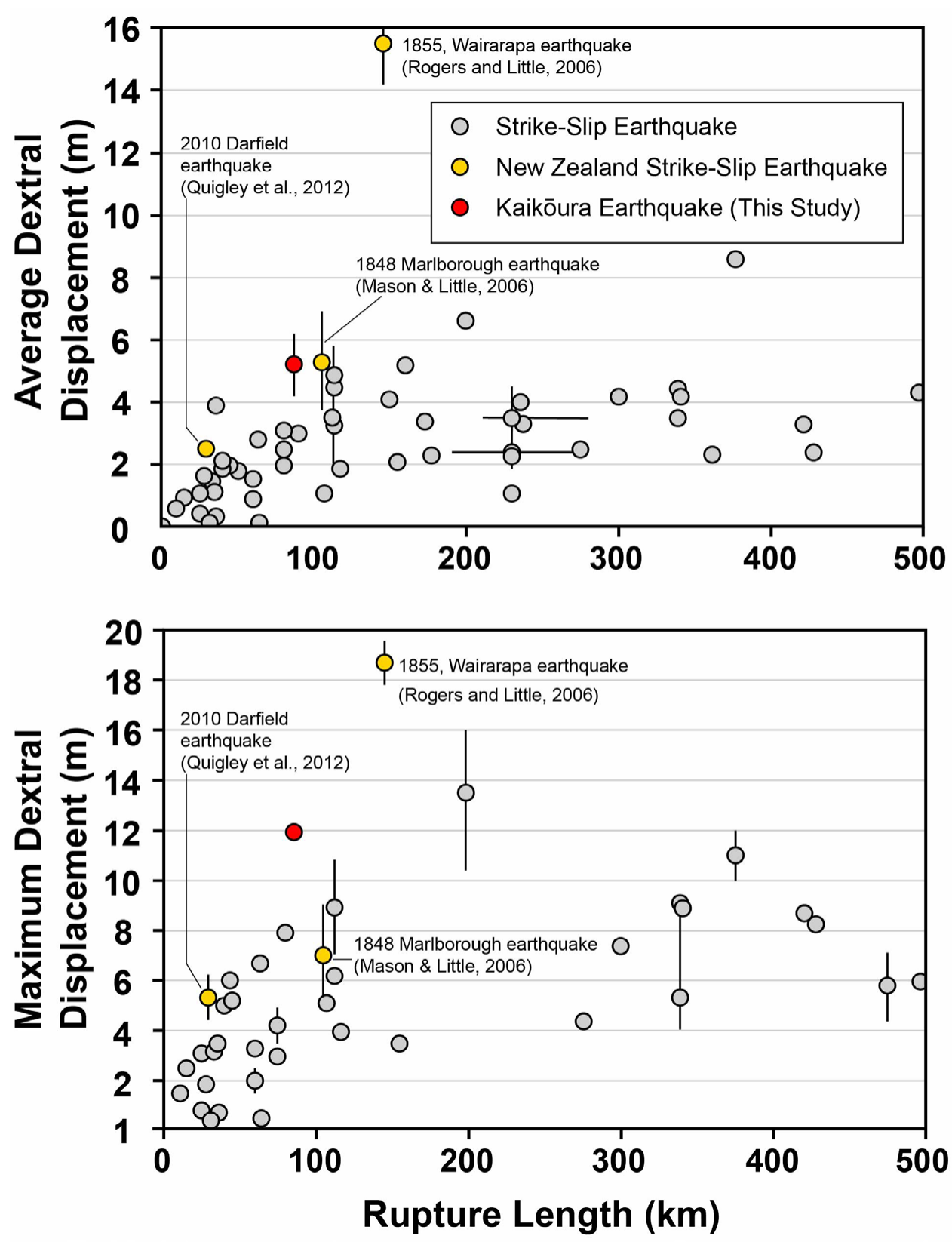

Figure 3.8: Scatter plot comparing the displacement and rupture length of the 2016 Kaikōura earthquake and other New Zealand surface rupturing strike-slip earthquakes to a global catalogue of surface rupturing strike-slip earthquakes, from Biasi et al. (2013) and Wesnousky (2008). Adapted from Haddon et al. (2016).

Haeussler et al., 2004; Quigley et al., 2012). Maximum dextral offsets are $12 \mathrm{~m}$ in both satellite and field-based assessments, confirming this rupture to be the 5th largest SED observed globally (Sieh, 1978; Baljinnyam, 1993; Lin et al., 2001, Rogers \& Little, 2006; Lin et al., 2007; Wesnousky, 2008; Zinke et al., 2014; Gold et al., 2015)

The ratio $(\mathrm{D} / \mathrm{L})$ of both maximum and mean surface displacement $(\mathrm{D})$ to surface rupture length (L) on the Kekerengu and contiguous faults in the Kaikoura earthquake is unusually 
large compared to the global catalogue of surface rupturing strike-slip earthquakes (Fig. 3.8). Rogers \& Little (2006) proposed that the anomalously large slip (D) of the 1855 Wairarapa earthquake relative to its length (L) was the result of an unusually large down-dip extent of rupture. The same explanation is proposed here for the Kekerengu (and contiguous) faults during the Kaikōura earthquake with rupture extending down-dip a large distance (W) relative to the strike length (L), and relative to the down-dip extent (W) of most other upper crustal fault ruptures. $\mathrm{W}$ is typically thought to be limited by the base of the seismogenic zone at $\sim 10-15 \mathrm{~km}$ depth (Scholz, 2002). However, elastic dislocation models for the Kaikōura earthquake based on the inversion of satellite geodesy, GPS and coastal deformation data produce a best-fit slip model with significant slip on the Kekerengu fault extending to at least $25 \mathrm{~km}$ depth (Hamling et al., 2017; Clark et al., 2017). Thus, the independent far-field ground deformation data support our explanation for the anomalously high D/L ratio of the Kekerengu fault during the Kaikōura earthquake.

\subsubsection{Co-seismic 3-D Surface Displacement around a Bend in the Kekerengu-Needles} Fault.

To consider the co-seismic slip on the Kekerengu-Needles fault relative to the wider deformation field during the earthquake, we integrate our on-fault 3D slip vectors with the far-field ground deformation data from InSAR, campaign GPS (Hamling et al., 2017), and coastal deformation measurements (Clark et al., 2017). Between site 95 (14 km from the coastline) and the near-shore Needles fault trace-from southwest to northeast - the Kekerengu fault bends smoothly to the right, and immediately offshore makes an anticlockwise bend to connect with the more northerly-striking Needles fault (Figs. 3.1b, 3.1c, and 3.9). The azimuth of the on-fault 3D slip vectors (bold black arrows of relative fault motion in Fig. 3.9), and near-fault re-surveyed fence post displacements ("local displacements" Fig. 3.9) both approximately parallel this curved trajectory of the fault trace. Along this curved fault trace on-fault displacement remains consistently strike-slip, maintaining a high ratio of strike-slip to shortening or heave of $>8: 1.5$. Northwest of the anticlockwise sweep in slip trajectories near the Kekerengu-Needles fault junction (in its inner arc region), co-seismic displacements inferred from InSAR similarly suggest an anticlockwise "sweeping" pattern of horizontal displacements, with the ground motion remaining subparallel to fault strike (Fig. 3.9). Consistent with this description of persistent translational motion through this arc, the Kekeren- 


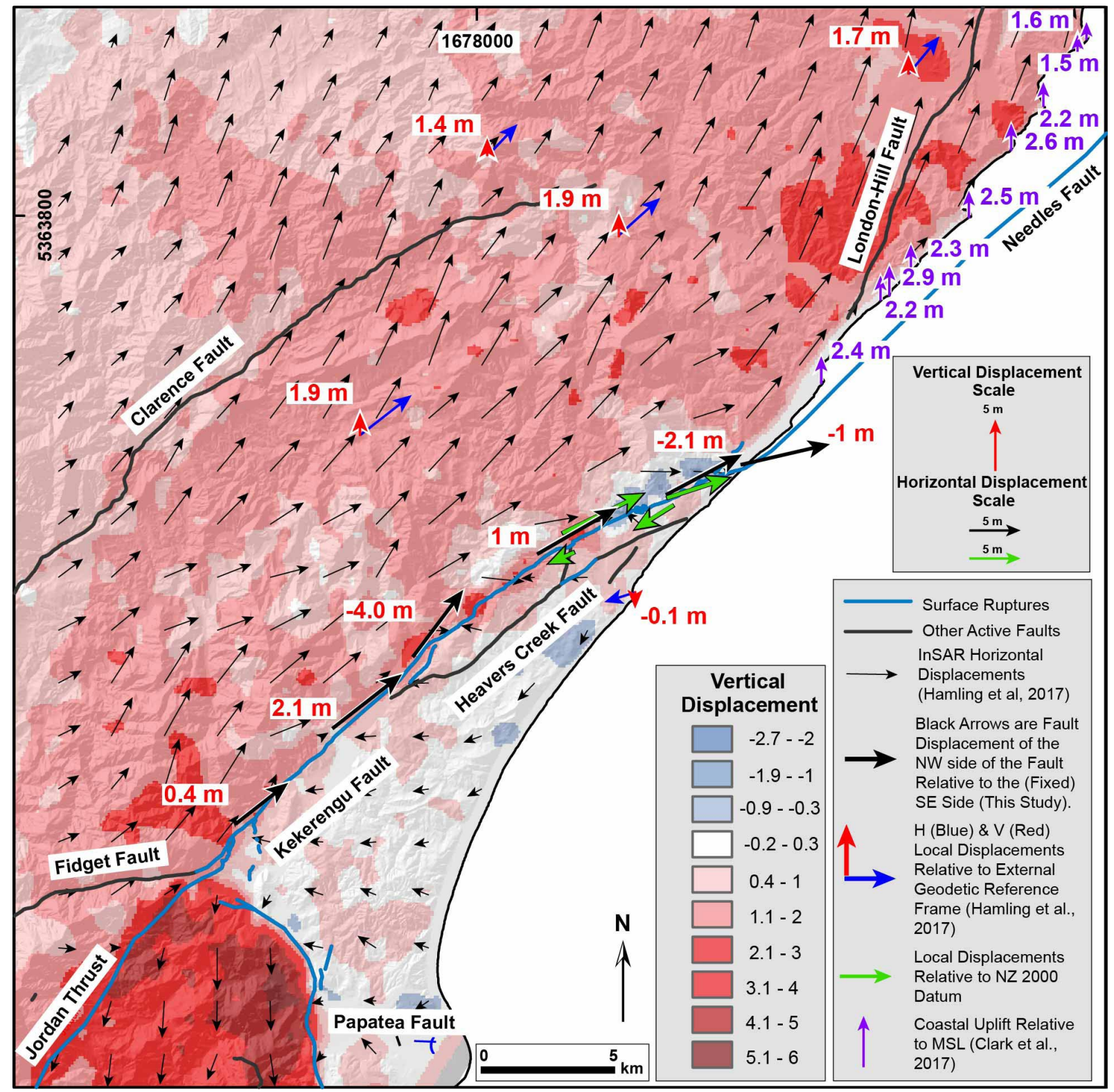

Figure 3.9: Kinematic map comparing co-seismic displacement measured by a suite of different techniques. Background shading refers to co-seismic vertical displacement from InSAR data, whereas thin black vectors refer to co-seismic horizontal displacement from the same dataset published in Hamling et al., (2017). Bold black arrows are the azimuth and magnitude of the on-fault co-seismic slip vectors plotted as the motion of the northwest side of the fault relative to the southeast side. Vertical and horizontal co-seismic displacements of campaign GPS sites are shown as vector pairs. Vectors showing co-seismic displacement deduced from re-surveyed fence posts (see Fig. 7) and coastal uplift (form Clark et al., 2017) also shown. All displacements are displayed at the same scale.

gu-Needles fault junction is not as strongly compressive a restraining bend as might be expected from the $35^{\circ}$ change in strike in map view. While most obvious adjacent to the fault trace itself, the anticlockwise sweeping pattern of horizontal motions extends northwest away from the fault surface trace for $\sim 20 \mathrm{~km}$ before no longer being apparent.

To the northwest of the Kekerengu and Needles faults, the GPS and InSAR data reveal that there is a wide zone that experienced uplift of between 0.4 and $2.9 \mathrm{~m}$ during the earthquake 
(Fig. 3.9). If the Kekerengu fault maintains its very steep near surface dip of $\geq 70^{\circ}$ to depth, then the 25-30 km width of this off-fault domain of uplift on the hanging wall of the is not attributable (in a simple way) to the reverse component of slip on the Kekerengu-Needles fault. Clark et al.'s (2017) elastic dislocation model inputs a constant dip of $\sim 60^{\circ}$ on a planar Kekerengu fault, whereas Holden et al. (2017) use a dip of $\sim 55^{\circ}$. Such shallow dips could help to explain the large width of the uplifted zone, and could be representative at depth if the fault is listric, but that dip is not representative of the fault at the surface. Our observations (above) indicate that along the curved fault trace, crust accommodated co-seismic slip by right-lateral deformation around the restraining bend, whereas farther afield from it, convergence and uplift were accommodated. This style of partitioning of oblique motion above a steep oblique-slip fault (strike-slip near the fault, contraction away from it) has been attributed by Bowman et al. (2003) to upward elastoplastic propagation of an oblique-slip rupture from depth, and these authors relate it to the 3D strain field ahead of a mixed-mode rupture tip. We note that the geodetically observed zone of uplift occurs on the inner arc of the anticlockwise-sweeping, horizontal displacement vector field. Simplistically, such a pattern of hanging wall contraction and uplift might provide a kinematic solution to the crustal dilatation required by the arc-like slip pattern. Alternatively, the off-fault zone of uplift might be the result of reverse-slip on northwest-dipping blind structures to the northwest of the Kekerengu fault (e.g., Van Dissen and Yeats, 1991; Nicol and Van Dissen, 2002), or the Kekerengu fault may be listric and shallow in dip with depth. We note that InSAR slip vectors are rotated anticlockwise towards the northeast of the Needles fault rupture (Fig. 3.9), and that this change appears to coincide with a change in sense of throw along the Needles Fault (Fig. 3.1c).

Rupture of the Papatea fault during the Kaikōura earthquake had a significant effect on the kinematics of Jordan Thrust and Upper Kowhai faults, and on the transfer of dextral slip between the Kekerengu and Jordan Thrust faults. Sinistral-reverse slip on the Papatea fault was observed in the field (Langridge et al., 2018) and is consistent with 3D displacement vectors derived from InSAR data (Hamling et al., 2017). The data shows a southward "extrusion" of the western side of the Papatea fault (referred to as the "Papatea block" by Hamling et al., 2017) (Fig. 3.9). Extension across the Jordan thrust and Upper Kowhai faults-which bound the northwestern edge of the Papatea block - is an expected result of sinistral-reverse slip on the Papatea fault. This slip effectively "extracts" the footwall of the Jordan Thrust and Up- 
per Kowhai faults southward, causing a local normal sense of dip-slip on those faults to the west of their intersection with the Papatea fault, in accordance with our field observations. In addition, southwest across the Papatea fault junction, we observed an $\sim 2 \mathrm{~m}$ a drop in the magnitude of dextral strike-slip along the Kekerengu-Jordan faults (Fig. 3.5b).

The observed normal dip-slip on the Jordan Thrust and drop in strike-slip magnitude by $\sim 2$ $\mathrm{m}$ on Kekerengu-Jordan fault system to the west of the Papatea fault are only to be expected in earthquakes that involve simultaneous rupturing of all of these faults. How often has this happened in the past? The elevated topography of the Seaward Kaikoura Range (Fig. 3.0) is a consequence of the dominantly oblique-reverse kinematics of the Jordan Thrust and Upper Kowhai faults in the long term (Van Dissen and Yeats, 1991), a relationship that implies that Papatea fault-co-rupturing earthquakes have not been the norm. Yet uphill-facing, apparently extensional scarps observed on the Upper Kowhai fault (Fig. 3.3a) suggest that footwall extraction may have occurred during previous earthquakes, which presumably also involved the Papatea fault.

\subsubsection{On-Fault Deformation Resulting From Large Strike-Slip Displacement}

Relatively few strike-slip earthquakes with large surface displacements ( $>8 \mathrm{~m})$ have been observed in modern times, and many of these have occurred in remote areas (e.g., 2001 Kunlun earthquake - Lin \& Nishikawa, 2007; 2002 Denali earthquake - Haeussler et al., 2004; 2013 Balochistan earthquake - Zinke et al., 2014) making field access difficult. The Kaikōura earthquake therefore provides an opportunity to document unique aspects of large-scale on-fault ground deformation. Metre-scale moletrack development, canyon wall free faces and deep fault crevasses seen along the ground surface rupture of the Kekerengu fault may be particular to very large strike-slip displacements of 8-12 m. Surface rupture in areas of well-developed soil and grass cover formed 5-15 m-wide moletracks. Studies that focused on moletrack development during strike-slip surface ruptures with relatively low $(<4 \mathrm{~m})$ finite displacement have suggested that strike-slip is accommodated by an en echelon array of Riedel (R) and/or tensional cracks ( $\mathrm{T}$ ) and intervening compressional push-up structures (P) (Rao et al., 2011; Lin and Chiba, 2017). The oblique structures are inferred to strike at an angle that is today only slightly different from that at the time of their formation. In contrast, we find that R-shears formed during early stages of moletrack development were later dilated 
(extended) and strongly rotated clockwise in the central shear zone in response to the accrual large finite strike-slip displacement (Fig. 3.3e). Local strips of turf and bedrock are rotated and shortened between adjacent dilated R-shears, creating compressional bulges up to $1.5 \mathrm{~m}$ high (Fig. 3.3c).

Free faces at canyon walls that are 7-10 $\mathrm{m}$ long in the slip direction are another example of ground rupture deformation that reflects the especially large co-seismic strike-slip that took place in the Kaikōura earthquake (Fig. 3.3). The curved trajectory of slip striae on them show a temporal change in the slip direction during co-seismic fault movement, something that was also observed following the $2011 \mathrm{Mw} 6.6$ Iwaki earthquake (Japan) where up to $2 \mathrm{~m}$ of slip occurred (Otsubo et al., 2013). We infer that this curvature in co-seismic slip direction reflects stress changes during the earthquake and that they in part reflect the magnitude of stress drop (e.g., Guatteri and Spudich, 1998), a topic that will be the subject of further studies by the authors. Finally, deep fault crevasses along strike slip faults are only to be expected in large magnitude-slipping earthquakes. Similar features were documented by Haeussler et al., (2004) on the strike-slip Denali fault rupture following a 2002 earthquake in Alaska, where strike-slip displacement was up to $8.8 \mathrm{~m}$. We suggest that these deep fault crevasses are characteristic of local releasing segments along large displacement strike-slip ruptures.

\subsubsection{Width of Surface Fault Rupture Deformation and Implications for Seismic Hazard}

The narrowest and most continuous zones of surface fault rupture are located where the rupture propagated through loose surficial materials in areas of low topographic relief such as alluvial gravels (Fig. 3.3b) or sand sheets on the seabed (Fig. 3.4g). These same parts of the fault also exhibit the strongest correlation between changes in strike angle and magnitude of fault throw at the local scale, as might be expected where slip has been strongly localized on a single plane (Fig. 3.4g). Elsewhere, deformation was typically distributed more widely, especially near major fault bends (e.g., sites 15 and 24). Such structural irregularities on the Kekerengu fault are relatively few compared to those along the Greendale fault that ruptured in the $2010 \mathrm{Mw} 7.1$ Darfield earthquake, which included a series of disconnected $\sim 0.5-2 \mathrm{~km}$ long segments (Quigley et al., 2012). The abundance of step overs between these segments on the Greendale rupture trace - likely due, in part, to rupture through thick overlying alluvial gravels and low cumulative displacement in the buried bedrock fault zone - created a gen- 
erally wide distribution of surface fault rupture deformation that commonly exceeded $100 \mathrm{~m}$ (Van Dissen et al., 2013). Overall on the Kekerengu fault at a length scale of $10^{0}-10^{1} \mathrm{~km}$, the geometry of fault rupture zone is remarkably straight and connected (Fig. 3.1a), and the width of the deformation zone perpendicular to fault strike is narrow (e.g., Fig. 3.6b). Nevertheless, our results also document along-strike changes in the width of surface rupture deformation. In particular, observable surface fault rupture deformation may encompass a zone of diffuse shear strain up to several hundred meters wide, especially in areas of structural and topographical complexity.

In fault mapping studies for surface rupture hazard avoidance and engineering applications (such as pipe-line fault crossings) the geomorphic expression of the fault scarp, and in particular its width, is often taken into consideration as a proxy for the deformation zone width for future surface rupture earthquakes. At two locations on the Kekerengu fault it is pertinent to note that outside the zone of observable fence deformation (e.g., Fig. 3.7), dextral displacement still increased by up to an additional $\sim 10 \%$ for another several hundred metres away from the fault beyond the observable fence deformation. If we regard the zone of observable fence deformation as that portion along the fault that generates the geomorphic expression of the fault scarp, then there is still additional strain outside the geomorphically expressed fault deformation zone. This supposition potentially has implications with regard to the appropriateness, or otherwise, of the usage of set-back distances when characterizing faults for the purpose of surface rupture hazard avoidance. In California, a set-back distance of c. $15 \mathrm{~m}$ (50 feet) is utilized (e.g., Hart and Bryant, 1997), and in New Zealand a $20 \mathrm{~m}$ setback distance is recommended (Kerr et al., 2004; Van Dissen et al., 2006). If the set-back distance is added to the width of the geomorphically expressed fault deformation zone, as is common practice in New Zealand (e.g., Villamor et al., 2012), then this combined zone (setback + geomorphic expression) more than likely encompasses the region of highest ground strains that pose the greatest threat to structures built on, or near, a surface fault rupture. Nevertheless, our two Kekerengu fault examples (Fig. 3.7) suggest that outside the combined zone there could still be the possibility of encountering minor fault rupture deformation, and though the strains induced by these minor deformations are likely to be quite small, they may still be relevant to engineered structures that are hypersensitive to ground displacement and where damage avoidance, and not just collapse avoidance, is paramount. 


\subsection{Conclusions}

Ground surface and seabed fault rupture extending from the Seaward Kaikoura Ranges to near Cape Campbell represents the longest $(\sim 83 \mathrm{~km})$ and most continuous component of the Mw 7.82016 Kaikoura earthquake ruptures. This comprised $53 \mathrm{~km}$ of onshore fault rupture, including the Upper Kowhai, Manakau, Jordan and Kekerengu, faults, and 30-35 km of the offshore Needles fault (Fig. 3.1). This study is the first to report detailed co-seismic surface slip distributions on a network of crustal faults surveyed both onshore and offshore immediately following a large magnitude earthquake. Our analysis of co-seismic horizontal and vertical surface rupture displacements and rupture morphology indicates that along the Upper Kowhai, Manakau, Jordan, Kekerengu and Needles faults, the earthquake ruptured with an average net slip (primarily dextral) of $5.5 \pm 1 \mathrm{~m}$, and maximum net slip (primarily dextral) of $11.9 \pm 0.3 \mathrm{~m}$. For the $\sim 83 \mathrm{~km}$ continuous rupture length of the above five faults, these slip magnitudes are unusually large compared to a global catalogue of other large magnitude strike-slip earthquakes and may reflect a deeply penetrating rupture. The wide zone of hanging-wall uplift and a sweeping pattern of horizontal displacement surrounding the eastern part of the Kekerengu-Needles faults, suggests slip-partitioning of oblique motion in the near surface, with a significant portion of co-seismic contractional deformation (and uplift) being accommodated off-fault in the hanging-wall crust to the northwest. The Jordan Thrust, an oblique-reverse range-front fault responsible for long-term hanging wall uplift of the Seaward Kaikoura Ranges, ruptured in this earthquake mostly with a normal sense of dipslip. Rupture of the Kekerengu fault in 2016 produced a suite of ground surface structures, including fault crevasses, moletracks that contain strongly rotated and dilated R-shears, and large free faces with curved wear striae that may be unique to very large co-seismic strikeslip displacements.

\subsection{Acknowledgements}

Funding for the post-earthquake fault rupture field survey was provided by GeoNet, with the support of its sponsors New Zealand Earthquake Commission (EQC), GNS Science, and Land Information New Zealand, and Ministry of Business, Innovation and Employment 
(MBIE) response funding, provided through the Natural Hazards Research Platform (grant 2017-GNS-01-NHRP), and GNS Science MBIE strategic science investment funding (GNSSSIF-TSZ). Subsequent analysis of on-fault data was funded by the Earthquake Commission. Support for fieldwork by Kearse, Little, and Van Dissen was provided by the Earthquake Commission as part of their contribution to the scientific community's response to the earthquake. Support for field work for Hemphill-Haley was provided by NSF sponsored GEER (Geotechnical Extreme Events Reconnaissance). Land Information New Zealand, New Zealand Transport Authority, Environment Canterbury, Marlborough District Council, Aerial Surveys Ltd and AAM NZ Ltd are thanked for providing high quality LiDAR data. The authors thank Nicola Litchfield for coordination of post-earthquake field work. Logistical support in the field was provided by Zoe Juniper. Funding for the offshore fault mapping work with $R V$ Ikatere was provided by MBIE through the Natural Hazards Research Platform (grant C05X0907). NIWA survey staff Susi Woelz, Tim Kane and Will Quinn collected and processed the marine data. The RV Tangaroa survey was funded by MBIE through the Endeavour Fund (grants C05X1605 and COPR1702) and the Tangaroa Reference Group. Advice on the use of LaDiCaoz was provided by Olaf Zielke. InSAR data used in Figure 10 was kindly provided by Ian Hamling. Land owners in Kekerengu area are thanked for uninterrupted access to the fault rupture. The authors would also like to thank the Ashley Streig, anonymous reviewer and Tim Stahl, all of whom provided constructive reviews that improved the quality of this article. We acknowledge here that the field work for this study could not have been accomplished without the help of many scientists from across the world, who spent many hours of their time. 
J. Kearse, 2018 


\section{Chapter Four: Wear Striae Formed on the Kekerengu Fault during the 2016 Kaikoura Earthquake}

\subsection{Introduction}

Wear striae are sets of grooves or striations that are carved onto fault plane surfaces as shear displacement is accumulated during an earthquake (Twiss and Moores, 1992). As one side of a fault slides past the other, small asperities present within one or the other fault blocks act as abrasive tools to engrave a path on the opposite side of the fault surface, which typically consists of clay-rich fault gouge in a near surface environment. Because wear striae are formed by fault movement, their orientation is parallel to the direction of most recent fault slip. Figure 4.1 depicts a free face of the Emerson fault abraded with wear striae that formed during the 1992 Landers earthquake in California (Arrowsmith and Rhodes, 1994).

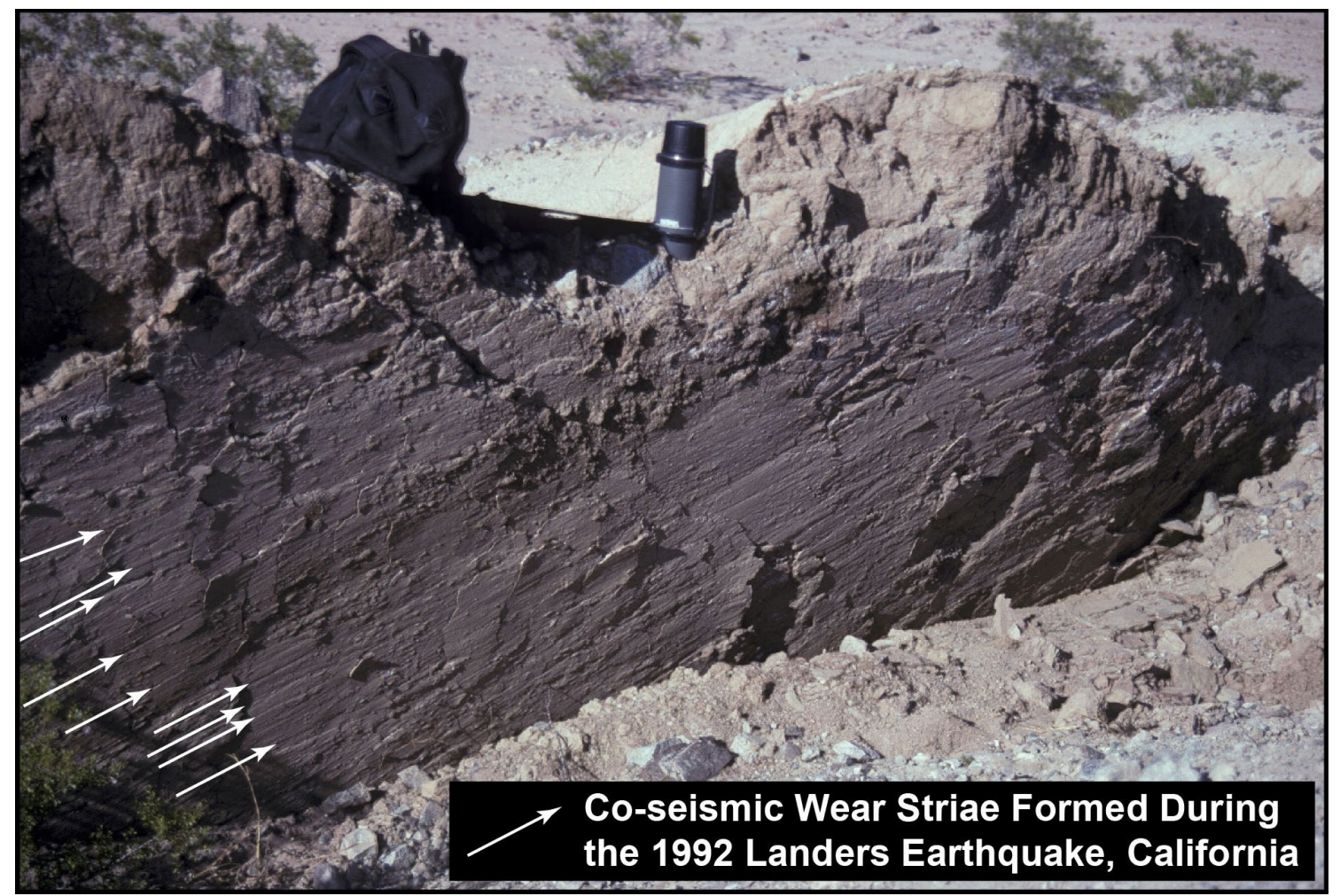

Figure 4.1: Field Photograph depicting a freshly-exposed free face of the Emerson fault, formed during the 1992 Landers earthquake. Note the parallel sets of wear striae. Photograph by K.M. Cruikshank. url: http://web.pdx.edu/ i1kc/photographs/Earthquakes/Landers/index.html 
During the 2016 Kaikoura earthquake-response fieldwork in the days to months following the event, I documented 24 sites on the Kekerengu fault where freshly exposed fault surfaces were decorated with wear striae. These features were ephemeral and were completely eroded away within $3-4$ months of their formation. The purpose of this chapter is to document each site along the Kekerengu fault where wear striae were observed, and to interpret these data in terms of the direction and evolution of slip during the Kaikōura earthquake. Slip directions derived from both co-seismic wear striae and surveyed 3D displacement of offset features (e.g., fence lines) are also compared at locations where both sets of data are available.

\subsection{Methods of Data Collection}

Data were collected between 19/11/2016 and 16/02/2017 on the Kekerengu fault over an along-strike distance of $10 \mathrm{~km}$, as far southwest as the Clarence River gorge. The instruments used to record wear striae orientations were a geological compass, level bubble, protractor,

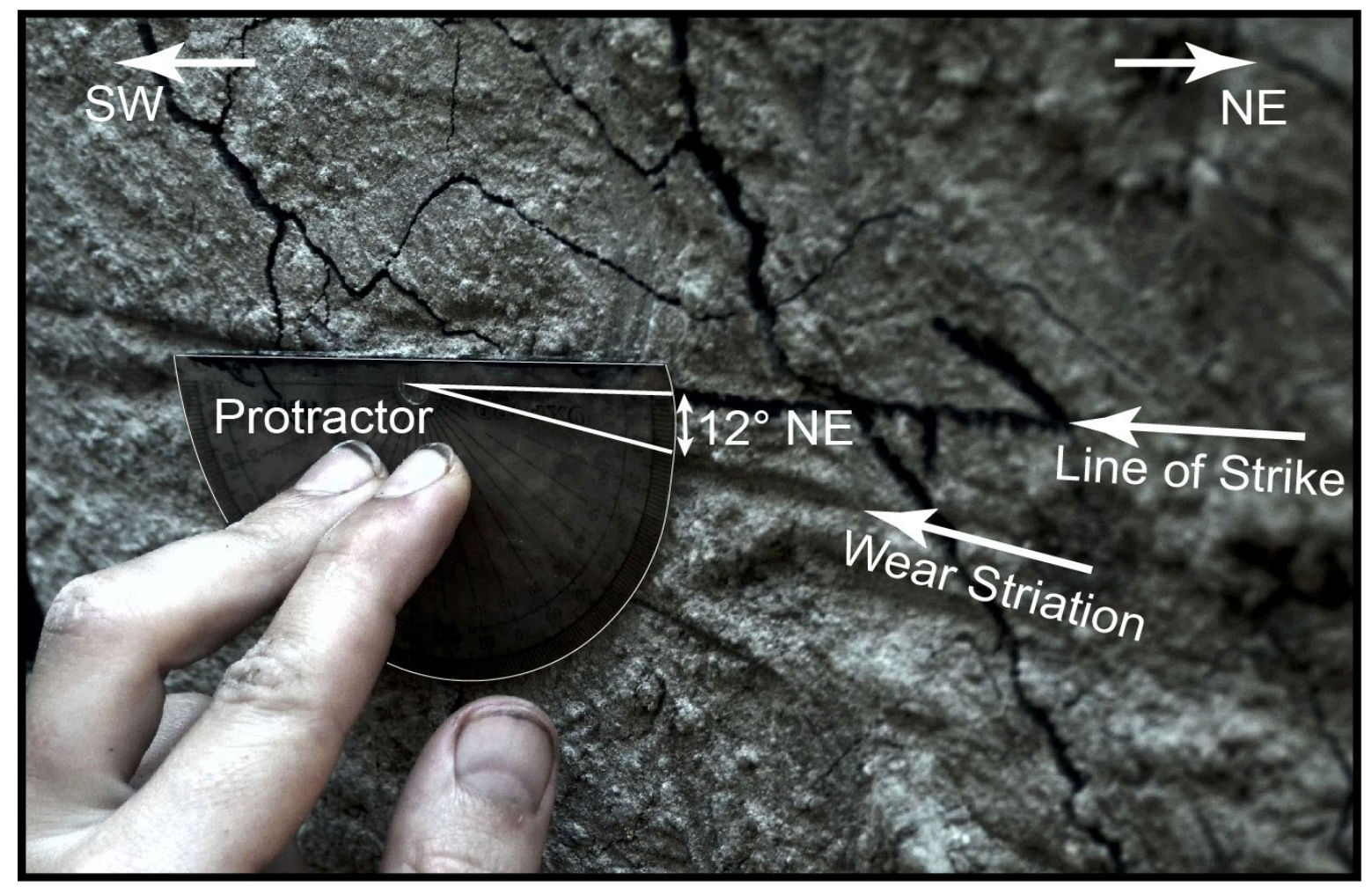

Figure 4.2: Close up photograph of an exposed Kekerengu fault plane depicting the use of a protractor to measure the pitch angle $\left(12^{\circ}\right)$ of a wear striation. Photograph: S. Taylor-Offord. 
felt-tip black marker, a camera and a held-held GPS device. Data collection at each site was executed in three stages: First, a level line of strike was inscribed onto the fault surface adjacent to the striae. This was a reference line from which a strike and dip or the fault plane was measured. Second, a protractor was placed onto the fault surface parallel to the strike line to measure the pitch angle and direction of the striae (Fig. 4.2). Third, the site was photographed. Each site was then assigned a unique letter and its location stored as a way point using the GPS. It was common for wear striae on the Kekerengu fault to be curved. In such cases, the above process was repeated for the steepest and shallowest parts of the curved striae, and photographs and sketched maps depicted the curved trajectory of the striae on the fault surface.

\subsubsection{Calculating Direction of Co-seismic Net Slip}

Co-seismic net slip vectors have been calculated for wear striae sites that are $<100 \mathrm{~m}$ from surveyed offset features that yielded precise estimates of the both the vertical and lateral co-seismic displacement during the earthquake. The vertical and lateral magnitudes of slip were projected onto a fault plane that was assumed to have the same attitude as the one on which the wear striae were measured. In this way, pitch angle and direction were assigned to each net displacement measurement, for comparison against the correlative slip striae orientation at the same site. The magnitude of the surveyed slip vectors are typically greater than the maximum observed length of any observed wear striae, therefore I only report direction of the surveyed vectors.

\subsection{Surface Rupture Morphology}

Kaikōura earthquake rupture along the Kekerengu fault was expressed at the ground surface in diverse ways. At some locations the zone of deformation was less than $5 \mathrm{~m}$ wide and consisted of moletrack fissures and compressional bulges, whereas elsewhere it was $>100 \mathrm{~m}$ wide with many separate faults and fissures within the zone. When interpreting wear striae data, it is important to consider the type of ground deformation feature they were found on, and how slip on that feature may relate to the slip across the entire surface rupture at that site. For example, wear striae found on a surface that has accommodated the total 2016 co-seis- 


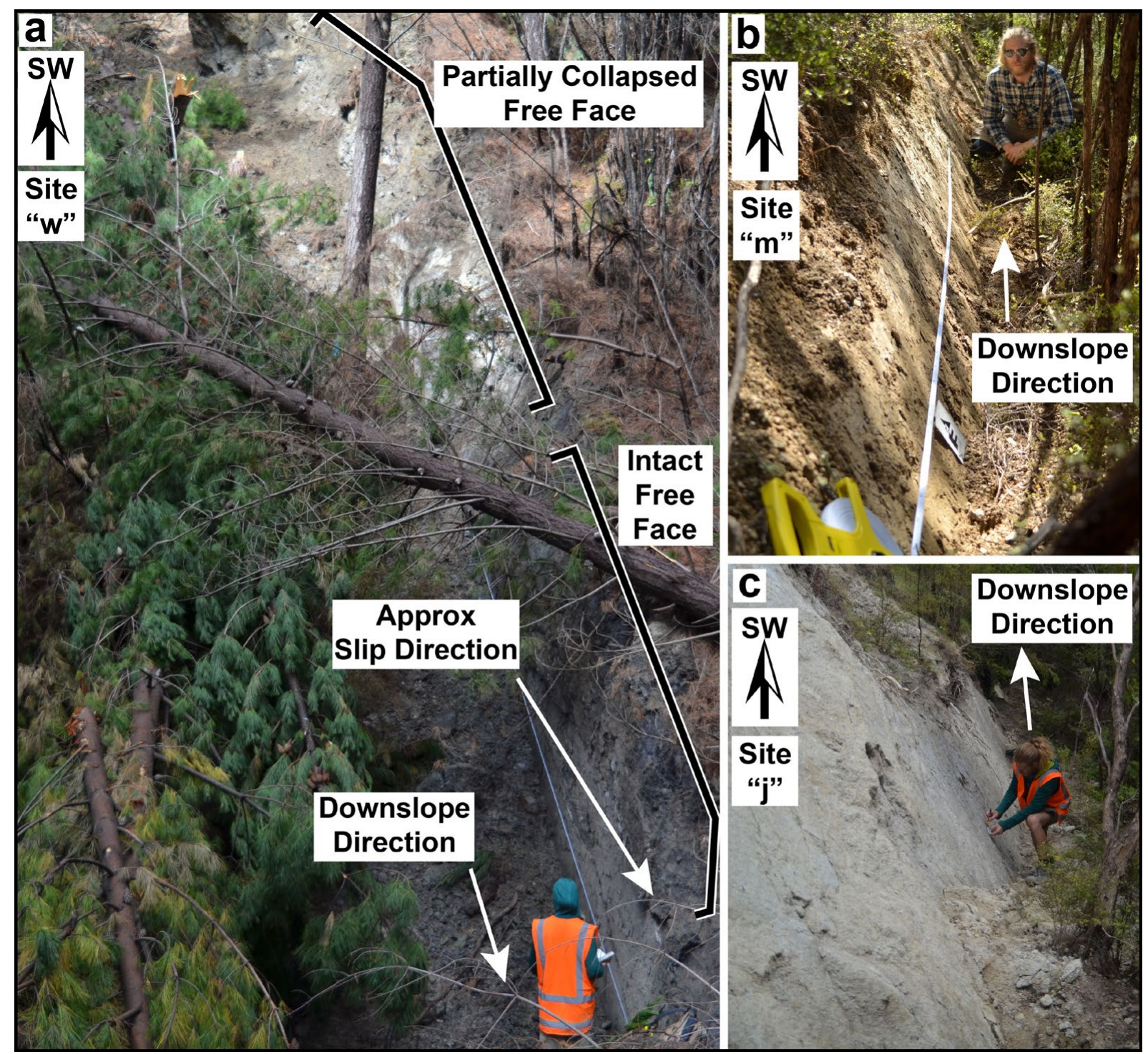

Figure 4.3: Examples of free faces on the Kekerengu fault at sites "w" (a), "m" (b) and "j" (c) (locations shown in Figure 4.7). (a) depicts the unusual situation of a southeast-dipping fault plane, and therefore a stable footwall free face on the southwest side of the canyon. Photographs: S. Taylor-Offord.

mic shear displacement may be interpreted differently than striae found on a single oblique dextral shear fissure that opened within a wide zone of distributed deformation. To give the different habitats for slip striae data an observation context, I will here describe briefly the variety of rupture morphology present at sites which contain wear striae observations.

\subsubsection{Bedrock Free Faces}

Kekerengu surface fault rupture cut across and laterally displaced many deeply-incised 
stream canyons during the Kaikōura earthquake. Dextral displacement of the steep bedrock walls of these canyons (slopes between $20-35^{\circ}$ ) exposed large areas of fault surface, known as free faces. These could be up to $30 \mathrm{~m}$ long in a down-slope direction and were up to $10 \mathrm{~m}$ wide in the slip direction (Fig. 4.3a). The combination of a northwest-dipping fault plane and a dextral sense of strike slip during the earthquake, produced stable footwall free faces on the northeast sides of the canyons, and mostly unstable overhanging faces were often formed on the southwest sides. The opposite relationship pertianed to parts of the fault that locally dipped southeast (i.e. unstable free faces on the northeast sides, and stable free faces on the southwest sides). Overhanging faces commonly (but not always) collapsed, presumably during the earthquake or shortly thereafter. Some stable footwall free faces also collapsed shortly after the earthquake. Figure 4.3 a depicts an outcrop where the Kekerengu fault dips to the southeast and where it displaced the southwest side of a steep canyon wall (slope $30^{\circ}$ ), thus exhuming a gravitationally-stable (not overhanging) footwall. Due to the width of the large free faces - as measured in the slip direction — often being equal or comparable to the

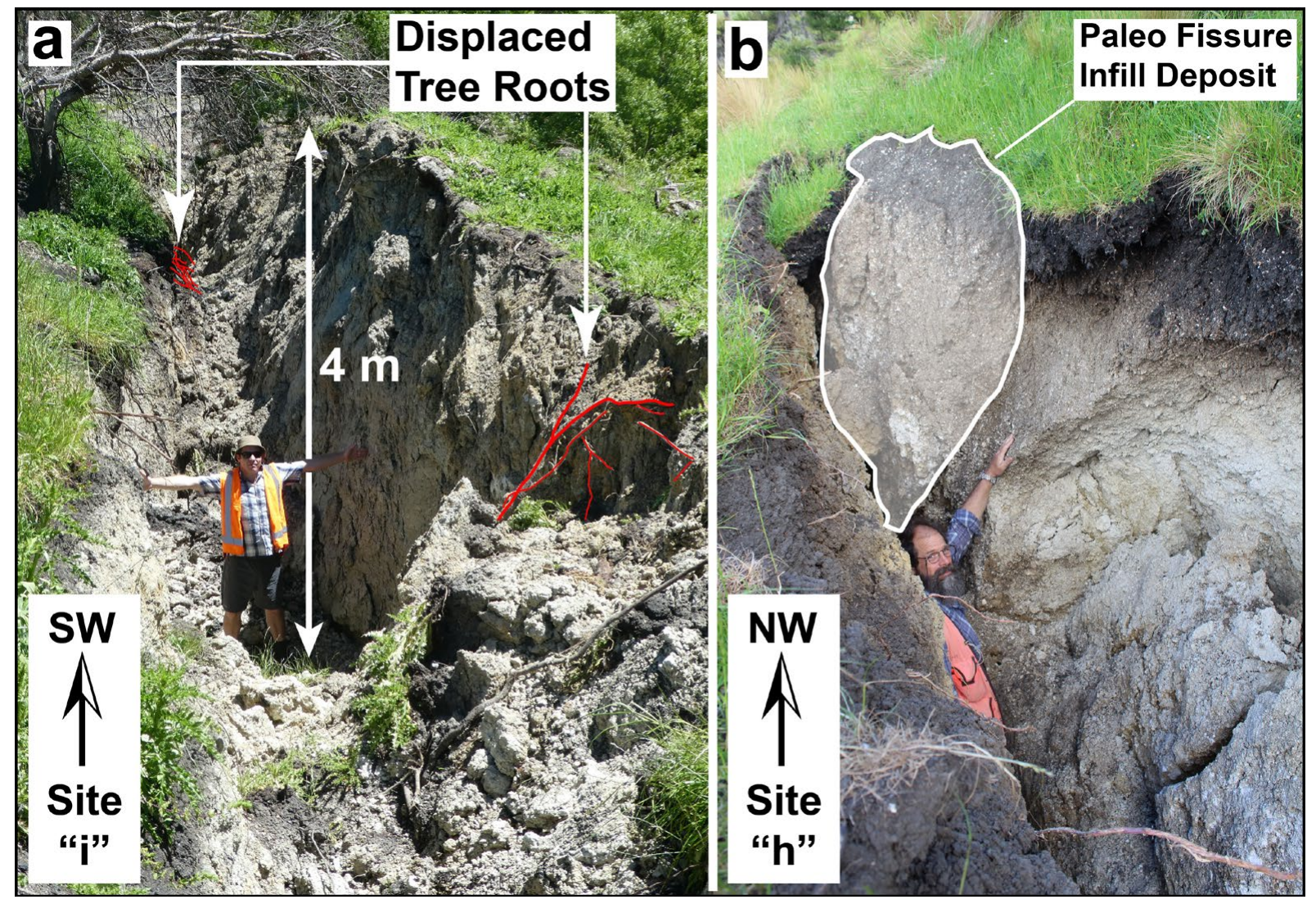

Figure 4.4: Example of fault crevasses on the Kekerengu fault at sites "i" (a) and " $h$ " (b). (a) note the displaced root network (red lines) that is laterally separated by $8.5 \mathrm{~m}$, and demonstrates the large degree of strain localisation during the earthquake at this location. The locations of sites $i$ and $h$ are shown in Figure 4.7. Photographs: (a) T. Little (b) K. Clark. 
magnitude of strike-slip displacement determined from offset features nearby, it is inferred that the fault surface bounding them accommodated most of the 2016 co-seismic displacement (i.e. 9 - $12 \mathrm{~m}$ ). These free faces were commonly smeared with a 1-2 cm-thick layer of fault gouge, which in the days to weeks following the earthquake remained moist, soft and easily pliable. This was especially true of free faces that were sheltered from the sun, wind and rain beneath forest cover (e.g., site w, Fig. 4.3). Free faces that were not shaded suffered from more rapid dehydration and exfoliation of their clay-rich gouge as it was baked in the sun. Rain splash and slope wash across these surfaces also caused significant degradation. It is onto this surface gouge layer that wear striae were embedded. Regardless of their location however, aprons of debris sourced from the fault surface were deposited at the base of each free face.

\subsubsection{Crevasses}

At several locations on the Kekerengu fault where slip was highly localised to a single fault strand, that strand bent to the right to create a sharp releasing section (see Chapter 2). There the ground surface was split open to form deep fault crevasses (Fig. 4.4). Penetrating up to $4 \mathrm{~m}$ into the ground, extending up to $10 \mathrm{~m}$ along strike, and up to $2 \mathrm{~m}$ wide these features were one of the more dramatic types of ground deformation observed on the Kekeren$\mathrm{gu}$ fault after the earthquake. The formation of one particular crevasse during the Kaikōura earthquake (site i, Fig. 4.4), cut and dextrally separated a network of tree roots by $8.5 \mathrm{~m}$ (and $1 \mathrm{~m}$ vertically), demonstrating that this structure did indeed accommodate the majority of co-seismic displacement at this site. Verification of displacement magnitudes across other crevasse sites was not always possible; however, it is inferred that they too accommodated a large portion of the total co-seismic displacement (e.g., site h, Fig. 4.4). Site h for example is located on a single strand that lies at the centre of $300 \mathrm{~m}$-wide graben. This central strand is shown to accommodate $\sim 7 \mathrm{~m}$ of strike-slip displacement less than $100 \mathrm{~m}$ along strike from site $\mathrm{h}$, yet there may up to $\sim 5 \mathrm{~m}$ of additional dextral displacement accommodated on other sub-parallel structures less than $50 \mathrm{~m}$ away within the graben.

During the months after the earthquake, the deep morphology of the crevasses offered the inner walls protection from the sun, and thus the gouge surfaces were preserved for longer (up to 4 months) than other, more exposed places. Wear striae were found mostly in the 

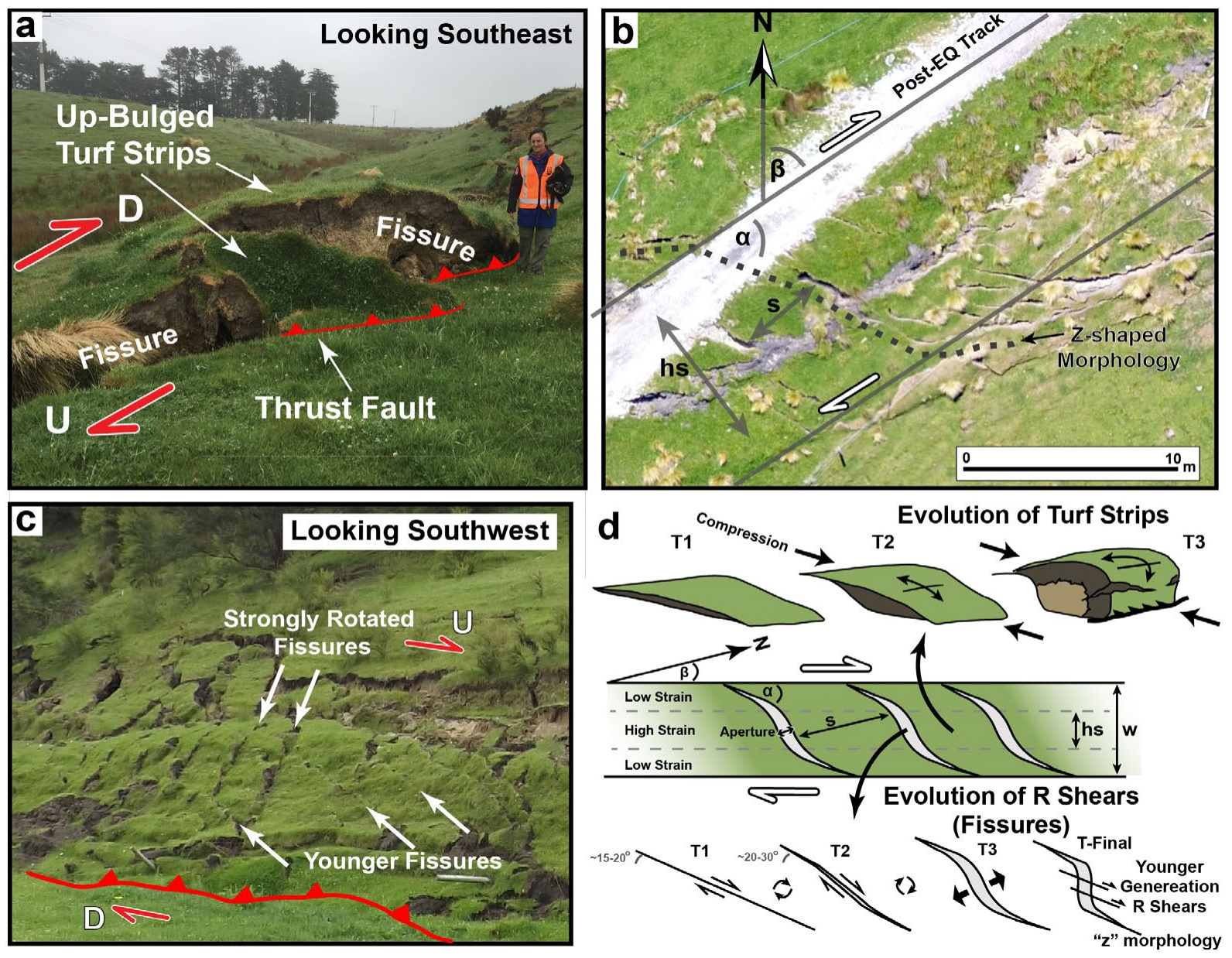

Figure 4.5: Photographs of moletrack deformation. (a) Photograph of prominent up-bulged turf strips. (b) Unmanned-aerial-vehicle photograph of moletrack fissures, showing example of rotated fissures. (c) Photograph of a moletrack showing cross-cutting of strongly rotated fissures by younger fissures. (d) Cartoon depicting the various dimensions and evolution of a moletrack: $\beta=$ strike of deformation zone, $\alpha=$ strike of fissures relative to the strike of the deformation zone, $s=$ fissure spacing, $w=$ width of deformation zone, hs = width of central high-strain part of deformation zone. Photographs: (a) M. Hemphill-Haley (c) N. Litchfield

deepest parts of the crevasse, where the surfaces were the most planar, presumably due to a relative lack of gravitational collapse, compared to the those parts nearer the ground surface. The floor of each crevasse was mantled with debris calved or otherwise eroded from the crevasse walls, much like the base of free faces exposures. Because the crevasses have openned by up to $2 \mathrm{~m}$, a complete record of co-seismic slip is not expected to be engraved on their walls. Moreover, it is likely that extension-related straie would be most common on crevasse walls, as this type of feature would accompany the last-increment of displacement before the initiation of crevasse-wall separation.

\subsubsection{Moletracks}


Another prominent type of surface rupture deformation along the Kekerengu fault was moletracks (Fig. 4.5). Surface rupture deformation is referred to as a moletrack when the ground is strongly sheared, fissured and up-buckled, such that new relief is created across the zone (Koto, 1893). After the Kaikōura earthquake, 5 - 15 m wide moletracks were common along the Kekerengu fault in areas where the ground surface as mantled with thick soil (up to $50 \mathrm{~cm}$ ) with a dense, cohesive turf mat. Near the outer fringes of the moletracks, where limited shear displacement has occurred, near vertical secondary faults strike $20-30^{\circ}$ clockwise of the main rupture zone ( $\alpha$, Figs. $4.5 \mathrm{~b}$ and $4.5 \mathrm{~d}$ ), where they are typically arranged in an en echelon fashion, and spaced between $2-5 \mathrm{~m}$ apart (for my definition of spacing, see Figs. $4.5 \mathrm{~b}$ and $4.5 \mathrm{~d}$ ). We infer that these faults nucleated as synthetic Riedel (R) shears at an angle $\alpha=15-20^{\circ}$ (Tchalenko, 1970) and later rotated clockwise about a vertical axis by $5-10^{\circ}$ at the outer margins of the ground deformation zone during continued earthquake shearing. For a definition of the angle $\alpha$, see Figures $4.5 \mathrm{~b}$ and $4.5 \mathrm{~b}$. This outer, low strain part of the moletrack zone is typically $2-4 \mathrm{~m}$ wide. Here the R shears are $3-4 \mathrm{~m}$ long, and each typically accommodate up to $40 \mathrm{~cm}$ of dextral displacement. The faults are dilated into open fissure structures and clearly accommodated some extensional opening $(0.3-0.5 \mathrm{~m})$ orthogonal to the fissure walls. These hybrid (shear + extension) fissures are on average $1-1.5 \mathrm{~m}$ deep. In the central $2-5 \mathrm{~m}$ of the same moletrack-which is the highest-strain part of the rupture deformation zone - the same Riedel faults strike at angles $\alpha$ up to $80^{\circ}$, and thus each $\mathrm{R}$ shear describes a z-shaped form overall as it traverses the moletrack (Figs. 4.5b and 4.5e). These strongly rotated fissures are typically more widely gaped than are the contiguous outer segments of the same fault, (up to $1.5 \mathrm{~m}$ ), and have an average aperture of $0.5 \mathrm{~m}$ (Fig. 4.5b,e). Thus rotation of a fissure was accommodated by dilation with more rotation associated with more opening or gaping of the fissure. Wear striae were found on the walls of four of these hybrid fissures. A younger generation of R shears cutting older, more strongly rotated ones, strike at angles of $\alpha=20-30^{\circ}$. These commonly cut across the strongly deformed, central moletrack deformation zone, and are inferred to form during the final stages of fault movement. Compressional bulges up to $1.5 \mathrm{~m}$ high form between one fissure and the next, as the intervening turf strips are rotated, shortened and up-buckled within the high strain part of the moletrack (Fig. 4.5a,e). The outer margins of these up-bulged strips are commonly bounded by $0.5-1.5 \mathrm{~m}$-long thrust faults with steeply dipping hanging walls (Fig. $4.5 \mathrm{a}$ ), which are thrust over the undisturbed sections of ground by up to $1.5 \mathrm{~m}$. Based on these observations, we would expect to see extensional-related striae, associated with the initiation of fissure 
opening. R shears, much like the crevasses, can only be expected to form wear striae during part of the earthquake - the part between their nucleation and the separation of their walls.

\subsection{Results}

All individual site information is catalogued in Appendix 3, which compiles photographs and stereographic projections for the 24 fault surface localities documented in this thesis. Two examples are shown below in Figures 4.8 and 4.9. This dataset contains measurements made on footwalls $(n=19)$ and hanging walls $(n=3)$ of the Kekerengu fault, and on parts of the fault that dip both northwest $(n=18)$ and southeast $(n=4)$. In order to summarise these measurements in a coherent way, Figure 4.6 presents all site information rendered as if in a single direction of view. The chosen direction of view is towards the southeast and tracks the movement of the northwest side of the Kekerengu fault relative to the southeast (see inset of Figure 4.6).

When interpreting Figure 4.6 it is important to recognise that, for upright free faces that dip northwest (black boxes, Fig. 4.6), wear striae arrows pitching towards the southwest (striae inclined down and to the right) denote a component of reverse motion at that site, whereas arrows pitching towards the northeast (striae inclined down and to the left) indicate a normal component. The opposite is true for southeast-dipping overhanging free faces (orange boxes, Fig. 4.6). Wear striae arrows all have tips that point to the northeast in this reference frame, as this is the direction that the northwest side of the fault moved during the earthquake (dextral sense of strike-slip). To facilitate analysis, wear striae sites have been classified by the type of ground deformation feature they are associated with. In particular, wear striae found within a moletrack are enclosed within blue boxes, while striae found on the walls of a crevasse are enclosed in teal. All other wear striae were observed on free faces, and are coloured either black (northwest dip direction) or orange (southeast dip direction), depending on their direction of dip. Figure 4.7 illustrates the spatial relationship of wear striae sites along the Kekerengu fault, by plotting wear striae attitude as a trend and plunge arrow emanating from the strike and dip symbol that corresponds to the fault surface from which it was measured. Where possible, the trend and plunge of finite slip directions have also been shown as red arrows. The colours within Figure 4.7 are the same as those in Figure 4.6. 


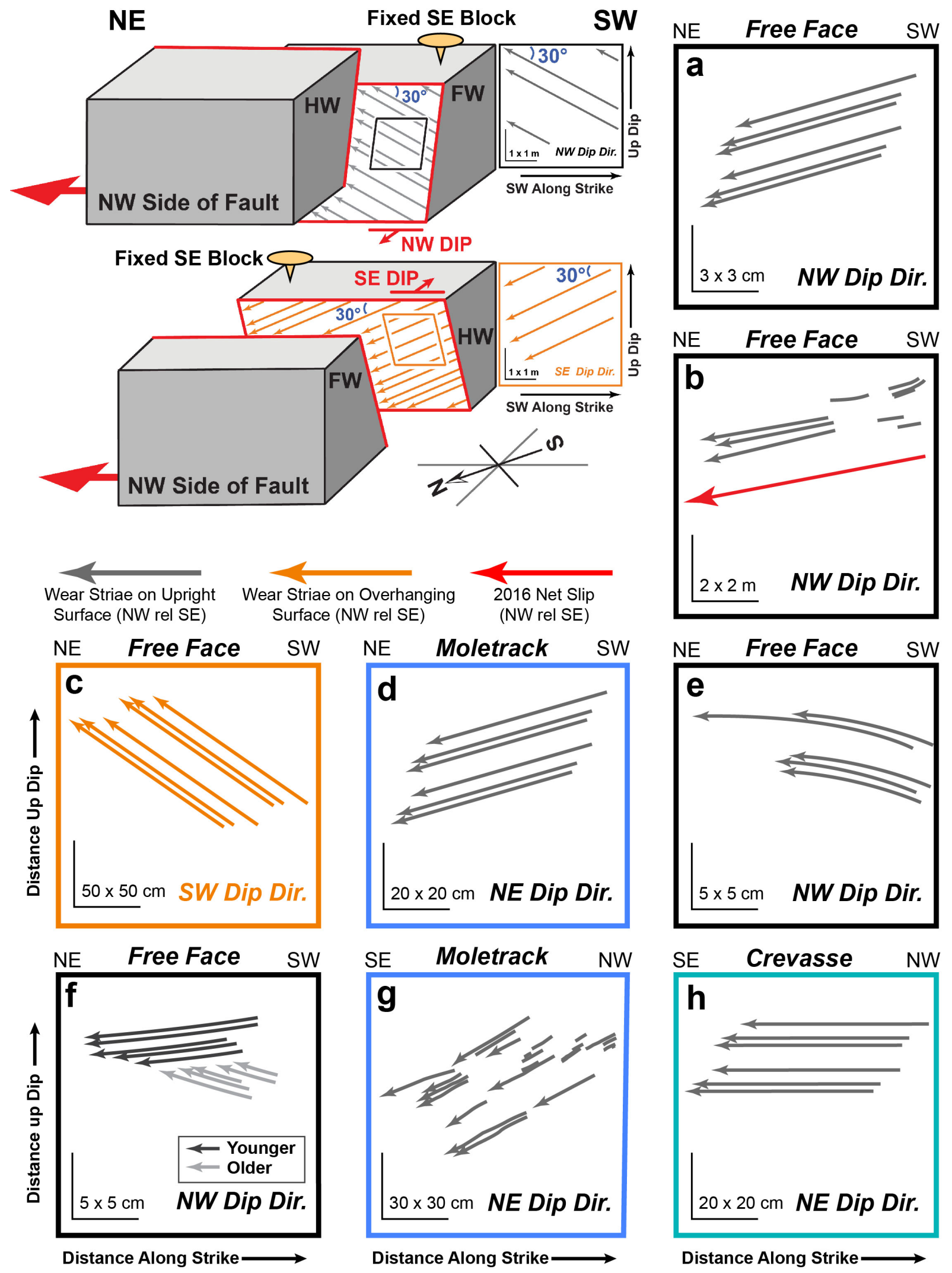

Figure 4.6: Collection of wear striae measurements from each site (square boxes, with site ID inside the top left corner). Top left diagram illustrates the reference frame for each site. Orange boxes are overhanging free faces, black boxes are upright free faces, blue boxes are moletrack sites, and teal boxes are crevasse sites. Red arrows show 2016 net slip direction. 

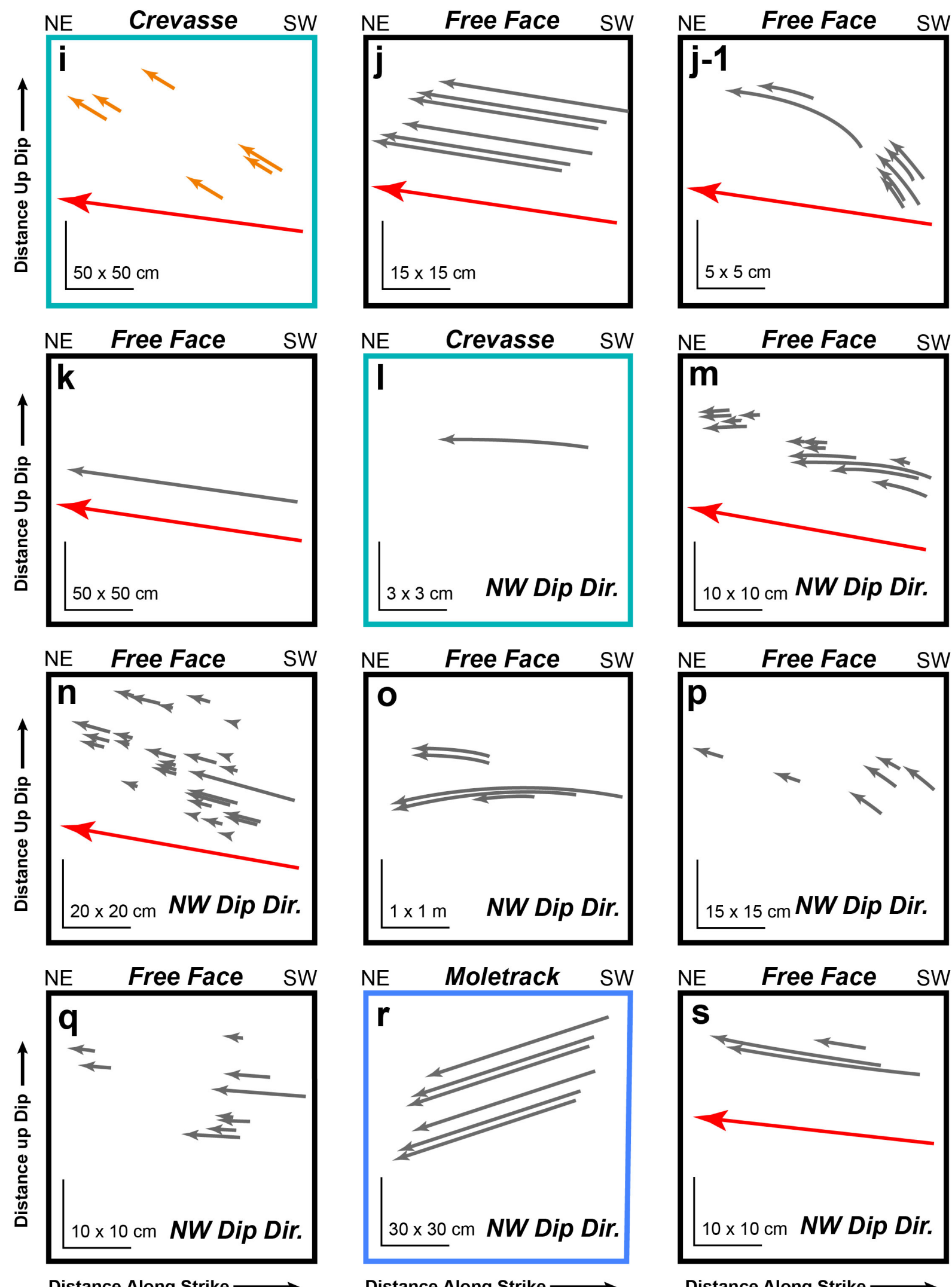

Distance Along Strike $\longrightarrow$

Distance Along Strike $\longrightarrow$

Figure 4.6 continued. 

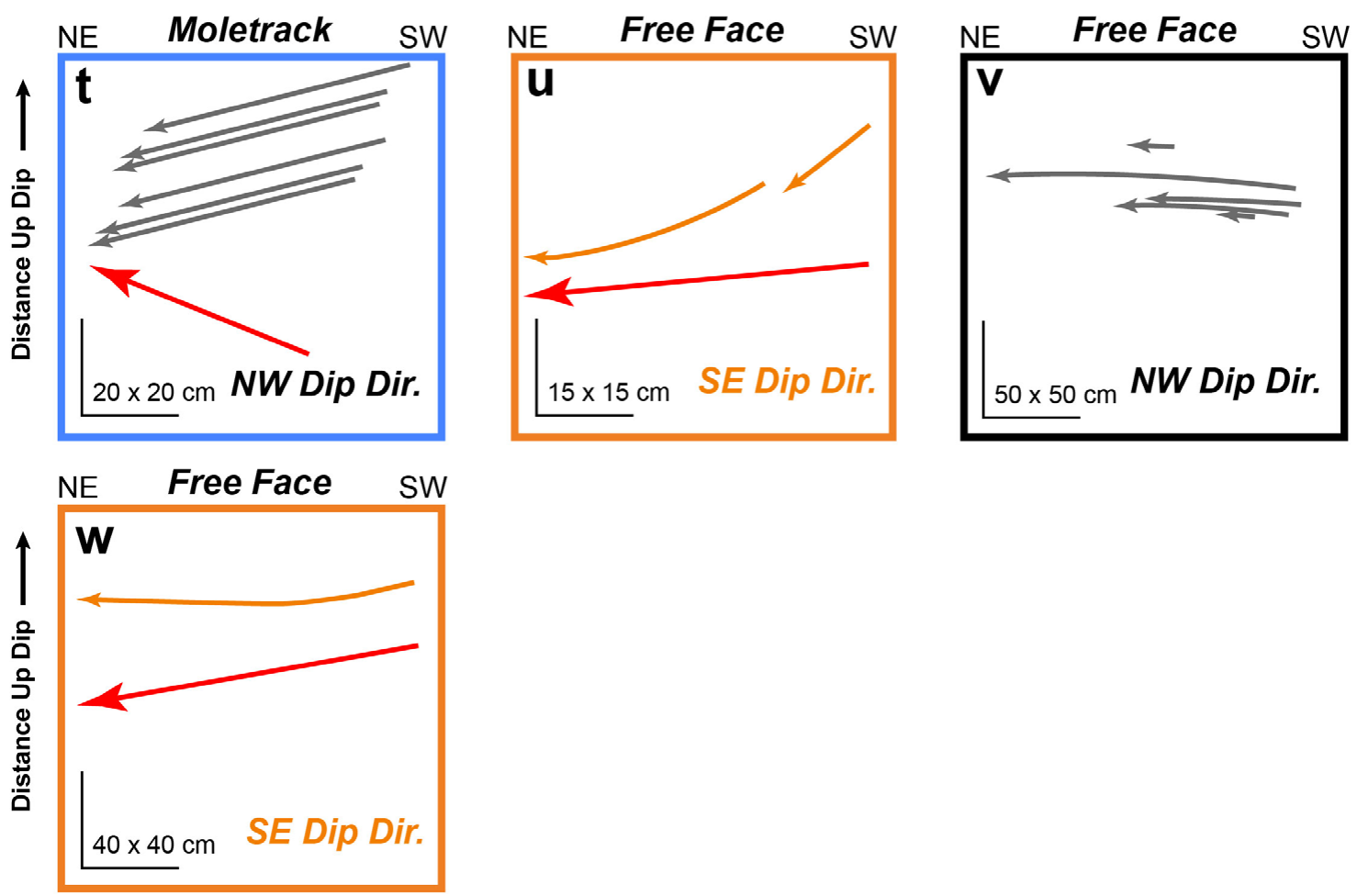

Distance Along Strike

Figure 4.6 continued

4.4.1 Co-seismic Wear Striae on the Kekerengu Fault: Geometry and Spatial Distribution

The vast majority of wear striae were observed on northwest-dipping free-face surfaces $(\mathrm{n}=17)$, and these mainly pitch in a southwest direction, indicative of dextral-reverse motion (Figs. 4.6 and 4.7). In places where free faces on the Kekerengu fault dip to the southeast, striae mainly plunge northeast, again indicitave of dextral-reverse motion. The exception to this pattern lies at the northeast end of the Kekerengu fault where free faces at sites "a", "b" and "c" host wear striae whose plunge directions show the opposite pattern to above, revealing dextral-normal slip (Fig. 4.7). This is to be expected as these sites lie along a more eastwest-striking, releasing section of the Kekerengu fault that experienced up-to-the-southeast, dextral-normal displacement during the earthquake. An interesting feature unique to the striae found on free faces is their distinctly curved pattern (e.g., Fig. 4.8) and their greater length (e.g., Fig. 4.9). Some wear striae show large changes in pitch angle over short distances (e.g., $46^{\circ}$ over $<20 \mathrm{~cm}$, site "j-1", Fig. 4.6), while others show a much more gradual transition $\left(2^{\circ}\right.$ over $\sim 1 \mathrm{~m}$, site "v", Fig. 4.6). In the frame of reference of Figure 4.6, all curved striae initiate at a steep pitch angle (higher $\mathrm{H}: \mathrm{V}$ ratio) and transition to a more shallow pitch angle (lower 


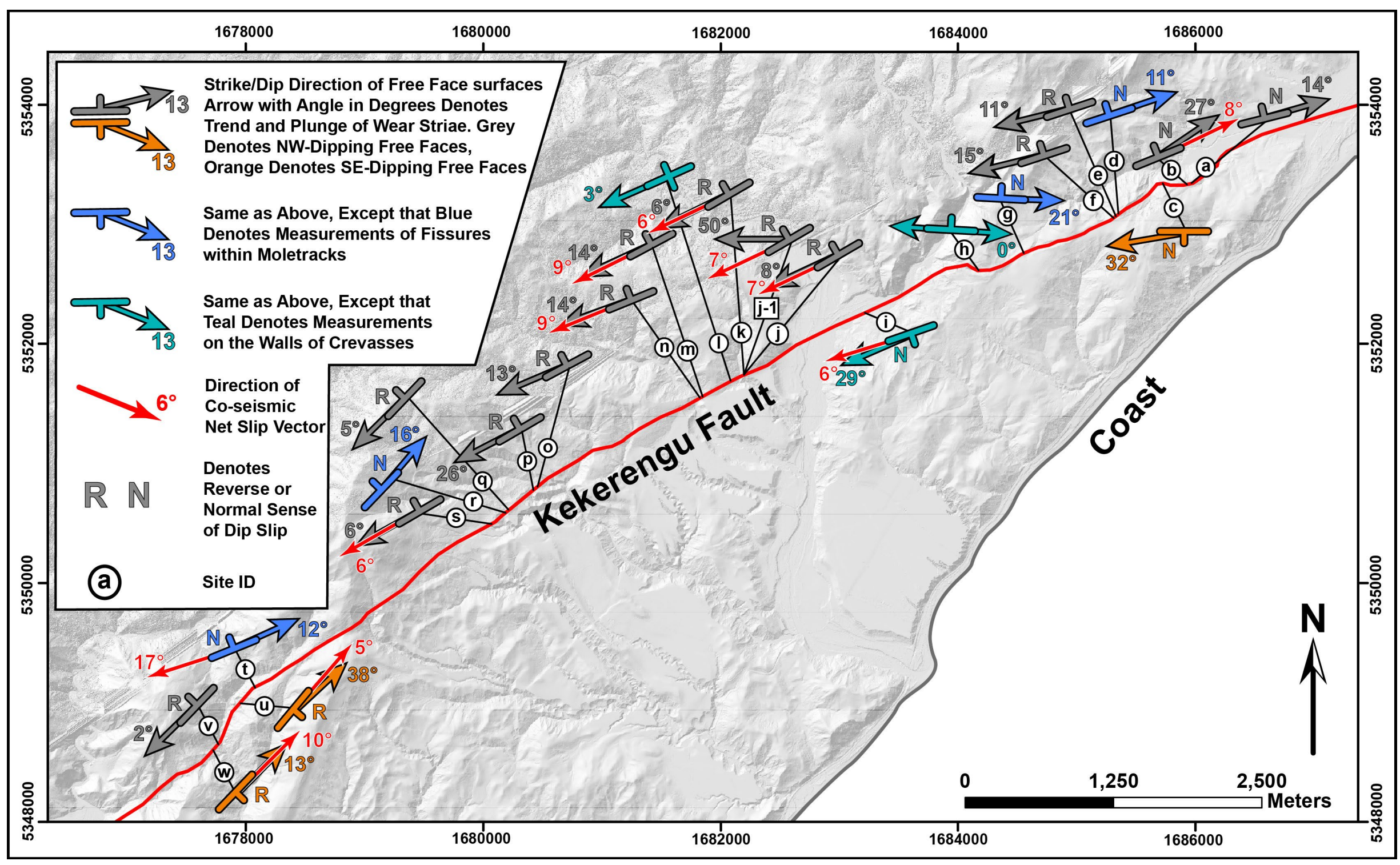

Figure 4.7: Spatial distribution and orientation of wear straie measurements on the Kekerengu fault coloured by type of ground deformation feature (colours are the same as in Figure 4.6). Net slip directions derived from nearby offset features are superimposed on selected wear striae measurements 
$\mathrm{H}: \mathrm{V}$ ratio, except for site "o", Fig. 4.6) over distances commonly less than $0.5 \mathrm{~m}$. Most of these curved trajectories terminate in a pitch angle within a few degrees of horizontal (e.g., Fig. 4.8), and some also terminate in a pitch direction opposite from their initial direction. In other words the curved slip path commonly creates a rainbow-like (e.g., site "o", Fig. 4.6) or half-rainbow-like appearance (e.g., Fig. 4.8). At sites "f" and "w", older, more steeply-pitching striae are crosscut by younger striae that have pitch angles closer to horizontal (Fig. 4.9).

Striae found inside the fissures of moletracks all plunge to the northeast on northwest-dipping fault surfaces, with the exception of site "g", which plunges to the southeast (azimuth of $091^{\circ}$ ) (Fig. 4.7). This striae direction indicates a dextral-normal component of slip. Mo-

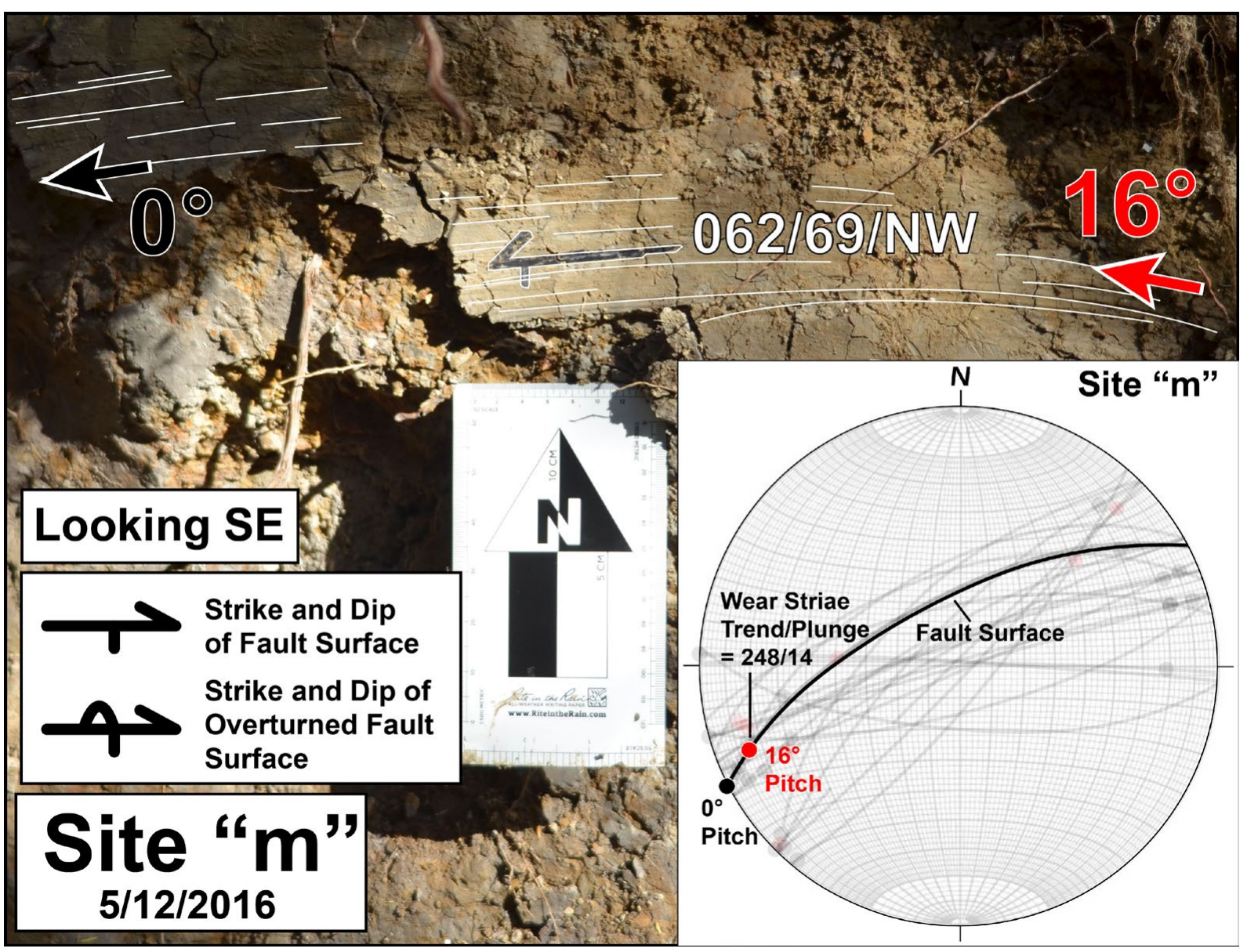

Figure 4.8: Summary of site "m" showing orientation of wear striae and attitude of fault surface. Inset showing lower-hemishoere stereographic projection of site data. Red part of curved striae denotes steepest part, black part denotes end shallowest part. Photograph: S. Taylor-Offord. 


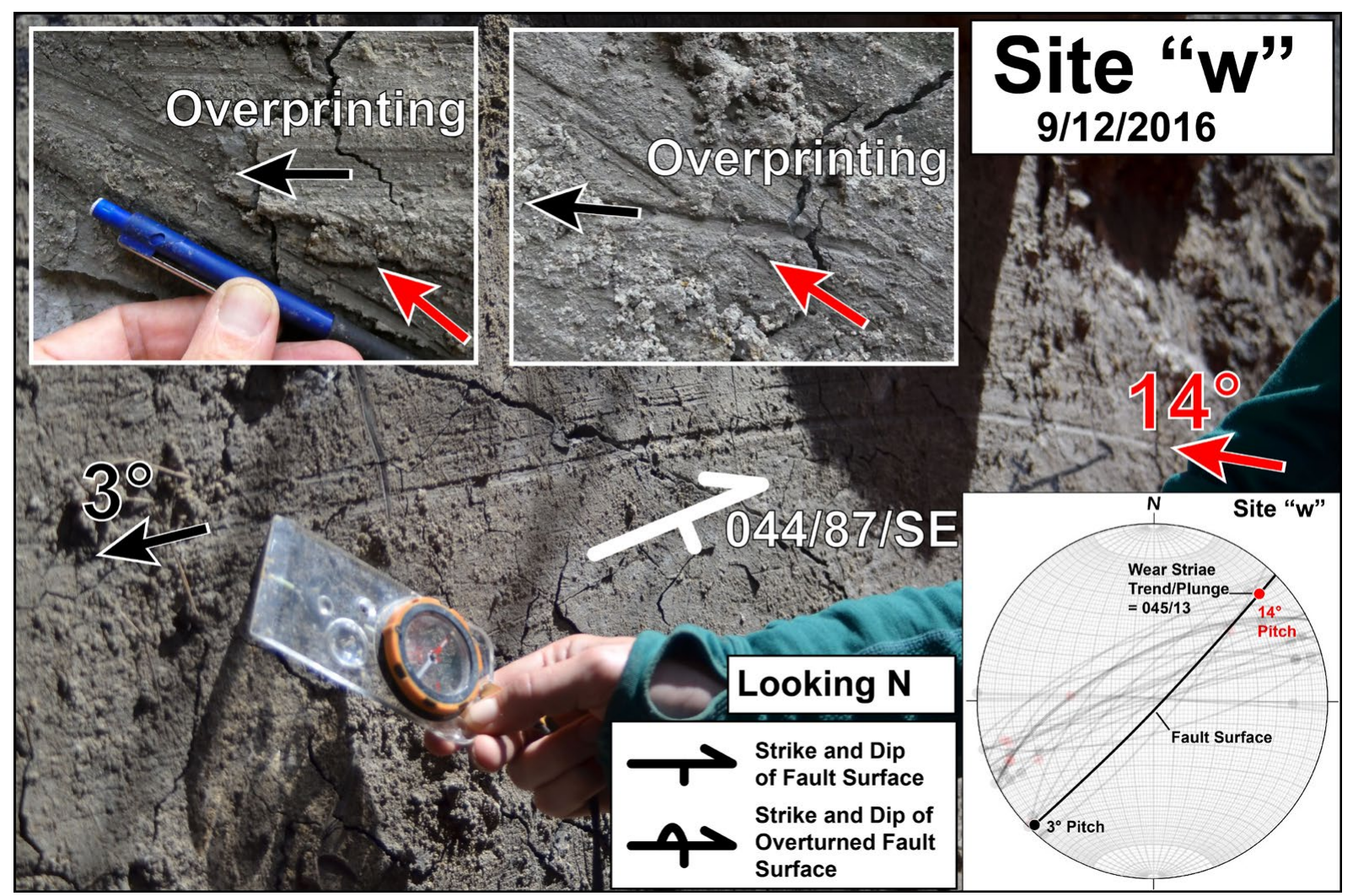

Figure 4.9: Summary of site "w" showing orientation of wear striae and attitude of fault surface. Not e the overprinting relationship. Inset showing lower-hemishoere stereographic projection of site data. Red part of curved striae denotes steepest part, black part denotes end shallowest part. Inset shows overprinting of older striae at this site. Photographs: S. Taylor-Offord.

letrack wear striae were all linear, and were better preserved than most others, as they were mainly located below the ground surface, and out of direct sun light.

Three crevasses on the Kekerengu fault preserved linear wear striae on their walls (Figs. 4.6 and 4.7). The most impressive and well-developed of these crevasses (site “i”, Figs. 4.4 and 4.6) has southwest pitching striae indicative of dextral-normal motion. The other two crevasse sites contain either near-horizontal straie or have near-vertical walls, suggesting little dip-slip motion during their inscription.

Most wear striae formed on the Kekerengu fault during the Kaikōura earthquake were only traceable over short distances $(<50 \mathrm{~cm})$; however, several free faces contained striae $>1 \mathrm{~m}$ long. It is likely no coincidence that the longest, continuous striae (6 $\mathrm{m}$ in length) was recorded only four days after the Kaikōura earthquake (site "b"). Most other striae that were collected weeks to months after the earthquake, occupied small 'windows' on the fault surface surrounded by slope wash debris or areas where the slip surface had collapsed (e.g., Fig. 4.8). 
Co-seismic net slip vectors derived from offset features such as fence lines (Chapter Three) correlate remarkably well with the directions of their accompanying wear striae (Figs. 4.6 and 4.7). Site " $k$ " for example, contains a $1 \mathrm{~m}$-long linear striation that is parallel to the finite slip direction derived from a nearby offset feature (Fig. 4.6). Where curved striae were observed, they initiated at a pitch angle steeper (by up to $50^{\circ}$ ) than that of the co-seismic net slip direction, and become sub-parallel to this 2016 net slip direction over a distances $<0.5 \mathrm{~m}$ (e.g., site "j-1", Fig. 4.6). These striae were observed on 10 out of 17 free faces and ranged in length from $15 \mathrm{~cm}$ (site q) to $6 \mathrm{~m}$ (site b). Linear wear striae on the walls of the crevasse at site i pitch southwest at an angle that is $23^{\circ}$ steeper than the co-seismic net slip direction; however, are only tracable over maximum lengths of $30 \mathrm{~cm}$ (Fig. 4.6). Site $\mathrm{t}$ is unusual in that it had wear striae on a moletrack fissure wall that pitched in an opposite direction to the survyed co-seismic net slip direction derived from a displaced tree root less than $20 \mathrm{~m}$ along strike (Fig. 4.7).

\subsection{Discussion}

The most notable result of the analysis of wear striae found on the Kekerengu fault is the curved and/or cross-cutting trajectories of the striae found on most of the free-face exposures. These striation geometries indicate that the near-surface slip direction of the Kekerengu fault

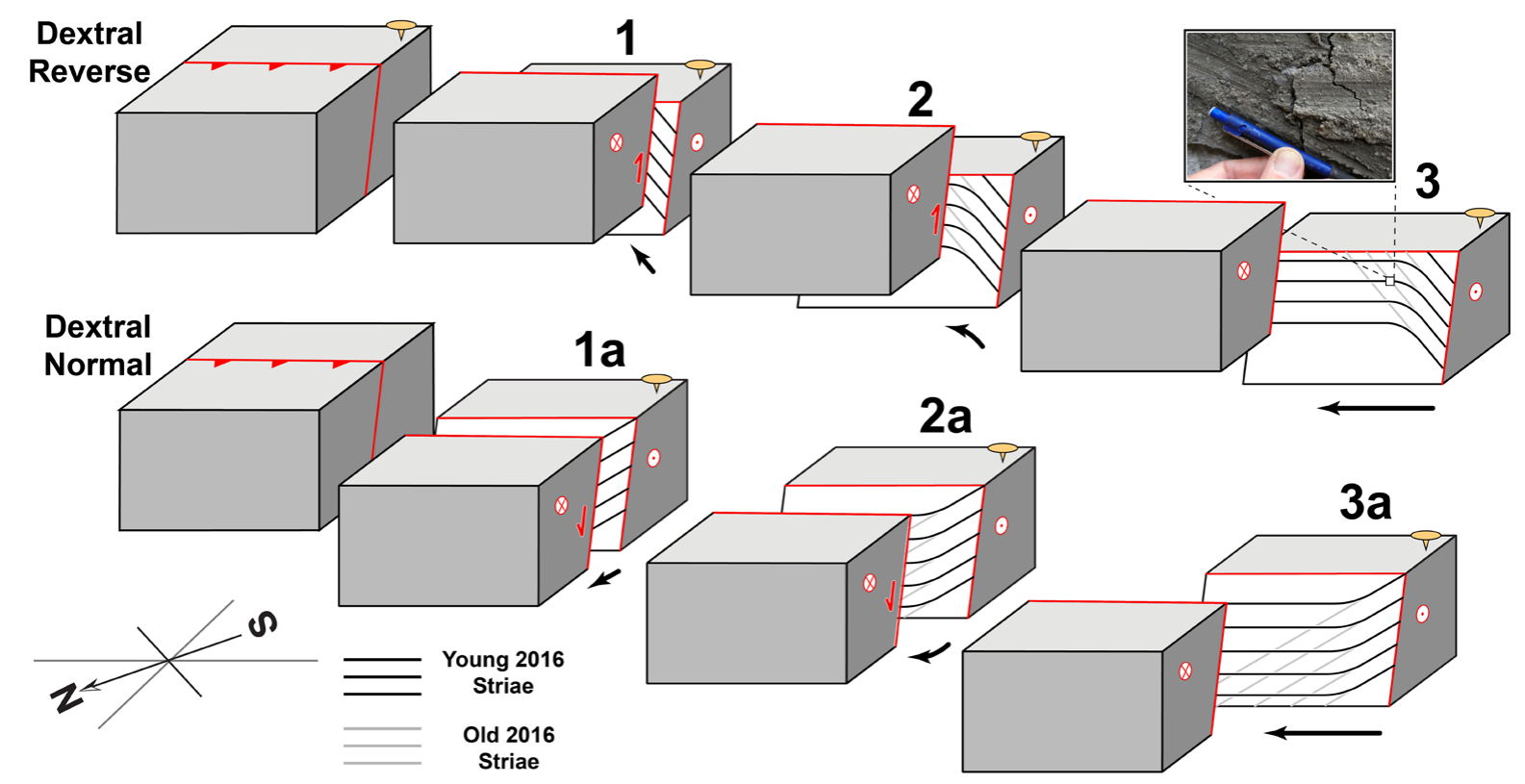

Figure 4.10: Cartoon depicting the formation of curved wear striae in three stages. Ruptuire initates as oblique slip, either in a dextral reverse (1) or dextral normal (1a) sense. Later, the slip direction rotates to become mainly dextral-slip $(2,2 a)$. Finally, a long-lived period of dextral slip $(3,3 c)$. Reference frame is the motion of the northwest block relative to the fixed southeast block. 
changed with time during the Kaikōura earthquake. Initially, rupture involved a relatively large component of dip-slip motion-mostly as dextral-reverse (southwest of site "c"), but also as dextral-normal (sites "a" "b" and "c") — compared to the overall, co-seismic net displacement (Fig. 4.10, parts 1 and 1a). Later in the earthquake sequence, wear striae record a consistent pattern of deflection of the slip direction towards nearly pure dextral-slip (Fig. 4.10, parts 2 and 2a). This deflection was followed by a final, sustained period (up to $5.5 \mathrm{~m}$ ) of nearly-pure dextral-slip, which lasted until co-seismic displacement ceased on the Kekerengu fault (Fig. 4.10, parts 3 and 3a).

Lengths of individual straie seen of Kekeregnu fault exposures produced during the Kaikoura earthquake are all less than the corresponding magnitude of co-seismic net slip observed by surveying nearby offset features. In other words, nowhere on the Kekrengu fault was there a striation that recorded the full co-seismic slip history of the Kekerengu fault during the earthquake. This could be due to (1) the disintegration of the abrasive tools during earthquake shear, (2) "capturing" of abrasive tools by the other side of the fault, thereby terminating the engraving process (3) transient separation of the two fault blocks in the near surface during earthquake shear — due to either fault roughness, or dynamic separation — such that they are not in contact for the entire duration of co-seismic displacement (4) progressive overprinting of older parts of wear striae with younger striae (5) post-seismic erosion of the fault surface, destroying any full record that may have been otherwise preserved. It is likely that the lack of full striation record is due to some combination of (3), (4) and (5) as there was no systematic variation in width as a function of length of individual striations that would suggest (1) occurred. Similarly, no abrasive tools were observed at the terminus of any striations to suggest (2) occurred. This highlights the importance of rapid deployment of field parties following a large magnitude earthquake, as important slip history can be lost to erosion in the initial days to weeks following these events.

Good agreement between the slip directions recorded by wear striae and the linear, co-seismic net slip directions derived from nearby offset features is to be expected if they both have the same origin, and sample the same incremental duration of earthquake slip. Some sites do show an initially large difference in the pitch angle between incremental striae directions and co-seismic net slip directions determined from 3-d surveys of displaced features (e.g., sites " $i$ " and "j-1", Fig. 4.6). The striae traces record short-lived slip increments representing $<10 \%$ 
of co-seismic net displacement. The subsequent period of near-pure dextral slip must have been dominant overall, indicated by its sub-parallelism with the co-seismic net slip direction. In the crevasse setting (e.g., site "i"), extension and separation of the fault blocks orthogonal to the fault, must also be considered, yet the interpretation is the same; initially-steep pitch angles indicate early dextral-normal displacement, which was followed by near-pure dextral motion. The lack of sub-horizontally pitching striae at site $i$ can be explained by the initial opening of the crevasse, in which case there would be no further production of wear striae that could record any remaining displacement. Similarly, the locally-extensional environment of open fissures within moletracks is reflected by the consitent northeast directions of pitch for striae on northwest-dipping fissures planes, indicative of dextral-normal displacement. Any deformation associated with these features that occurs after their period of dilative opening and gaping will not be recorded in the wear striae engraved on their walls.

Temporal changes in the slip rake during fault ruptures have been observed in the wear-striae record of several other historic earthquakes. For example the 1957 MS 8.0 Gobi-Altai earthquake (Floensov and Solonenko, 1965), the 1969 ML 6.2 Pariahuanca earthquake (Philip and Megard, 1977), the 1974 ML 6.9 Izu-Hanto-Oki earthquake (Kakimi et al., 1977), the 1980 MS 7.3 El Asnam earthquake (Philip and Meghraoui, 1983), the 1992 Mw 7.3 Landers earthquake (Arrowsmith and Rhodes, 1994), the 1995 ML 7.2 Kobe earthquake (Otsuki et al., 1997), the $2008 \mathrm{Mw} 7.9$ Wenchuan earthquake (Liu-Zeng et al., 2010), and the $2011 \mathrm{Mw}$ 6.6 Iwaki earthquake (Otsubo, et al., 2013) all show evidence for changes in the co-seismic slip direction with time at individual sites along their surface rupture trace. It has been shown in previous studies that temporal variability in slip direction at a point on the fault plane during co-seismic displacement may relate to the component of the stress tensor resolved as shear traction tangential to the fault surface, prior to rupture (Guatteri and Spudich, 1998). Assuming a slip-weakening friction law, Guatteri and Spudich (1998) modelled temporal slip variation at points on the fault surface during dynamic rupture, under differing levels of initial shear traction resolved on the fault surface. Their results indicate that during dynamic rupture with initially high shear traction (much higher than the co-seismic stress drop and dynamic stresses), slip directions remain sub-parallel to the direction of initial shear stress resolved on the fault. If, however, initial stresses are low relative to the co-seismic stress drop and dynamic stresses, a relatively large co-seismic stress drop may create dynamic stress purturbations large enough to result in a shear traction that varies with time. Applied to the 2016 
rupture of the Kekerengu fault, these results suggest a relatively low initial shear stress and a near-complete drop in static stress during the Kaikoura earthquake.

A recent study by Wang et al., (2017) incorporated local and teleseismic waveforms, geodetic (InSAR and GPS), and tsunami data to investigate the rupture process of the Kaikoura earthquake. Their analysis resolved a symultaneous rupture of both the Kekerengu fault and the underlying subduction interface. Moreover, the seismological data enabled them to investigate the evolution of rupture and slip direction with time, separately for both the Kekerengu fault and the subduction zone. Their results suggest a unilateral northeast rupture propagation along the Kekerengu fault (accompanied by symultaneouss plate interface slip beneath) and a progession from pure reverse motion to pure strike slip. This indpendent analysis therefore supports our interpretation that, during the Kaikōura earthquake, slip on the Kekerengu fault initiated as dextral reverse and later changed direction to become dominantly strike-slip. Moreover, these geoloical and seismological datasets indicate that time-varying co-seismic slip directions are not just a near-surface artifact, and that observations made at surface fault exposures may be representative of slip at depth during an earthquake. 
J. Kearse, 2018 


\section{Chapter Five: Conclusions}

This thesis has documented the onshore to offshore, ground surface (and seabed) deformation and co-seismic slip distribution associated with a large-magnitude strike-slip earthquake of large slip magnitude. I have shown that with contemporary survey techniques, valuable datasets can be acquired that document the surface deformation associated with large-magnitude earthquakes in unprecedented detail.

Chapter two of this thesis documented the spatial extent of ground deformation along 53 $\mathrm{km}$ of onshore surface rupture on the Kekerengu, Jordan Thrust, Upper Kowhai and Manakau faults from the east coast of the South Island, to the Seaward Kaikoura range. This chapter demonstrated the ability of contemporary survey methods, collected shortly after an earthquake - such as LiDAR and orthorectified aerial photography - to capture sub-meter-scale deformation along a well-exposed strike-slip surface rupture. As these features are now largely eroded away, this chapter represents an important archive of the along-strike variation in internal structure and width of a strike-slip surface rupture zone, resulting from large co-seismic strike-slip displacemtns of 9-12 m.

Chapter Three documented the first account of detailed co-seismic surface-slip distributions on a network of crustal faults surveyed both onshore and offshore immediately following a large magnitude earthquake. Our analysis of co-seismic horizontal and vertical surface displacements indicates that along the Upper Kowhai, Manakau, Jordan Thrust, Kekerengu and Needles faults, the earthquake ruptured with an average net slip (mainly dextral) of $5.5 \pm$ $1 \mathrm{~m}$, and maximum net slip of $11.9 \pm 0.3 \mathrm{~m}$. These slip magnitudes are unusually large when considering the continuous $\sim 83 \mathrm{~km}$ length of the five faults which ruptured, compared to the global catalogue of other large magnitude strike-slip earthquakes. This may reflect a deeply penetrating rupture. This chapter also demonstrated how the across-strike distribution-and width - of near-surface lateral displacement can vary along strike (widths between 13 and $122 \mathrm{~m}$ ). On average, $80 \%$ of lateral slip was concentrated within the central $43 \%$ of the total width of the displacement zone.

The wide zone of hanging-wall uplift and a sweeping pattern of horizontal displacement 
surrounding the eastern part of the Kekerengu-Needles faults, suggests slip-partitioning of oblique motion in the near surface, with a significant portion of co-seismic contractional deformation (and uplift) being accommodated off-fault in the hanging-wall crust to the northwest. The Jordan Thrust, an oblique-reverse range-front fault responsible for long-term hanging wall uplift of the Seaward Kaikoura Ranges, ruptured in this earthquake mostly with a normal sense of dip-slip. Rupture of the Kekerengu fault in 2016 produced a suite of ground surface structures, including fault crevasses, moletracks that contain strongly rotated and dilated R-shears, and large free faces with curved wear striae that may be unique to very large co-seismic strike-slip displacements.

Through the compilation of wear striae measurements along $10 \mathrm{~km}$ of the Kekerengu fault, Chapter 4 detailed the evolution of surface slip on the Kekerengu fault. These results have shown a progression in slip from dextral reverse, to dextral strike slip on the Kekerengu fault during the Kaikoura earthquake. This suggests low, pre-earthquake shear traction resolved on the Kekerengu fault. These surface slip data align with other studies of changing slip direction with time during the Kaikoura earthquake, and add to a global collection of co-seismic slip striae that show a temporal change in the direction of fault slip during large-magnitude earthquake ruptures. 


\section{Appendix 1 - Catalogue of Field Photographs along the Kekerengu Fault Network}

In this appendix is an ordered compilation of photographs that depict salient features of the Kekerengu Fault Network surface rupture. These images were taken with a handheld camera, either while standing on the ground or from the seat of a helicopter. Included within this catalogue are supplementary images from both UAV surveys, and from orthorectified aerial photographic surveys flown with fixed-wing aircraft.

Images are coded with numbers that refer to specific locations along the trace of the Kekerengu Fault Network, and which can be found in Chapter 2. The date each image was captured is also included next to the location code for completeness. 

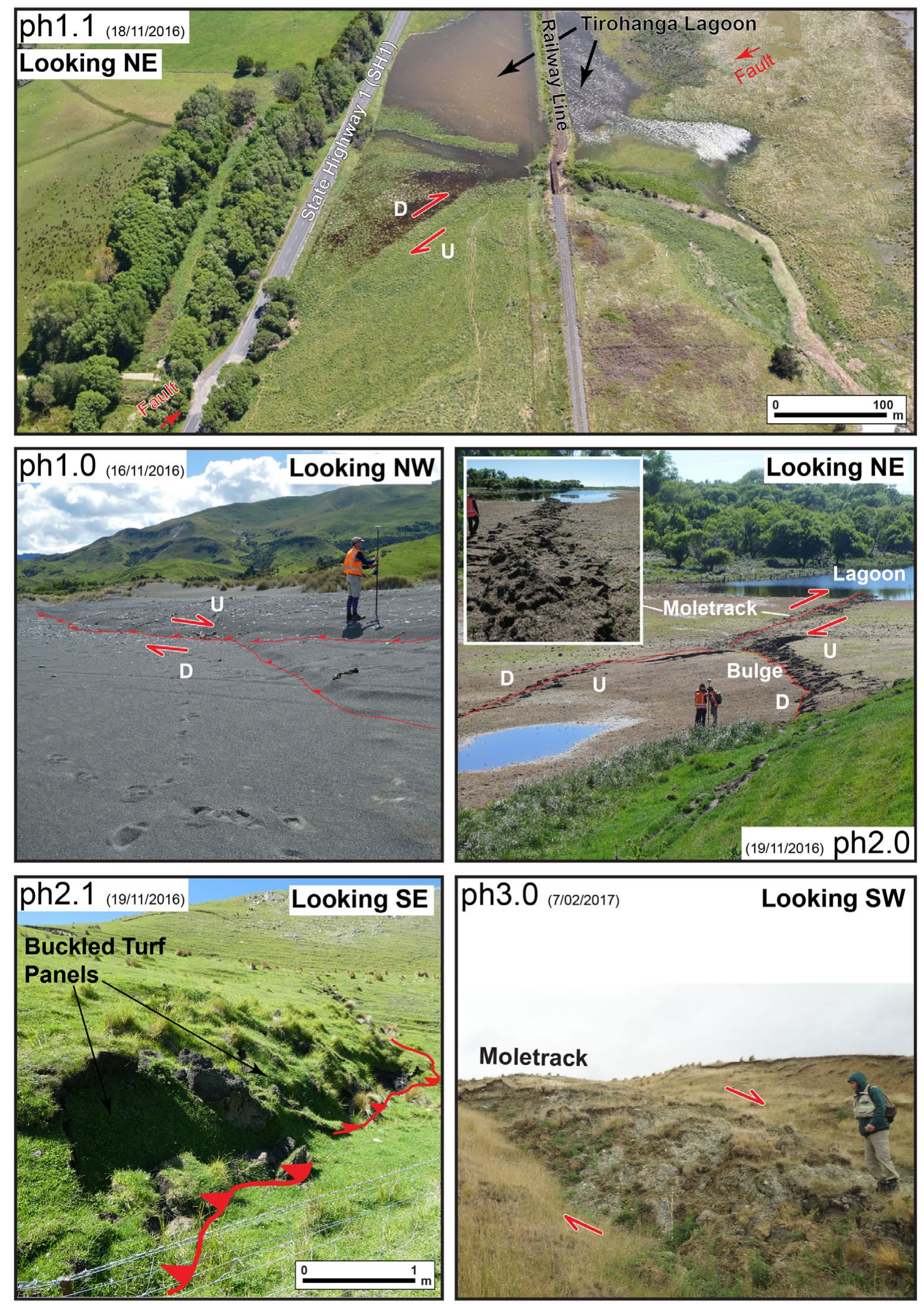

Figure A1.0: Collection of field photographs from the Kekerengu fault. Images are located within map tiles \#1 \#2 and \#3 of section 2.3.1 of Chapter Two. 

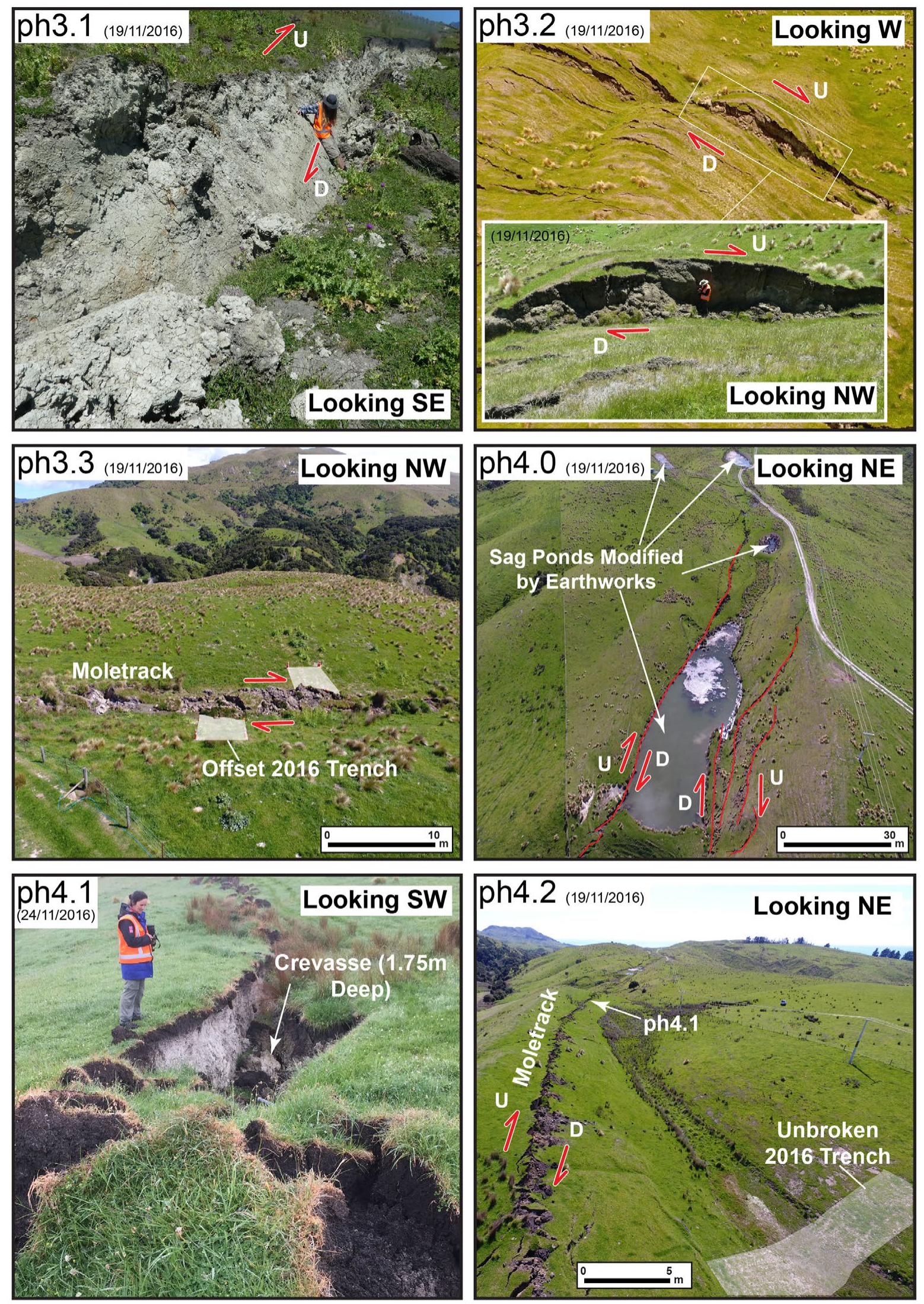

Figure A1.1: Collection of field photographs from the Kekerengu fault. Images are located within map tiles \#3 and \#4 of section 2.3.1 of Chapter Two. 

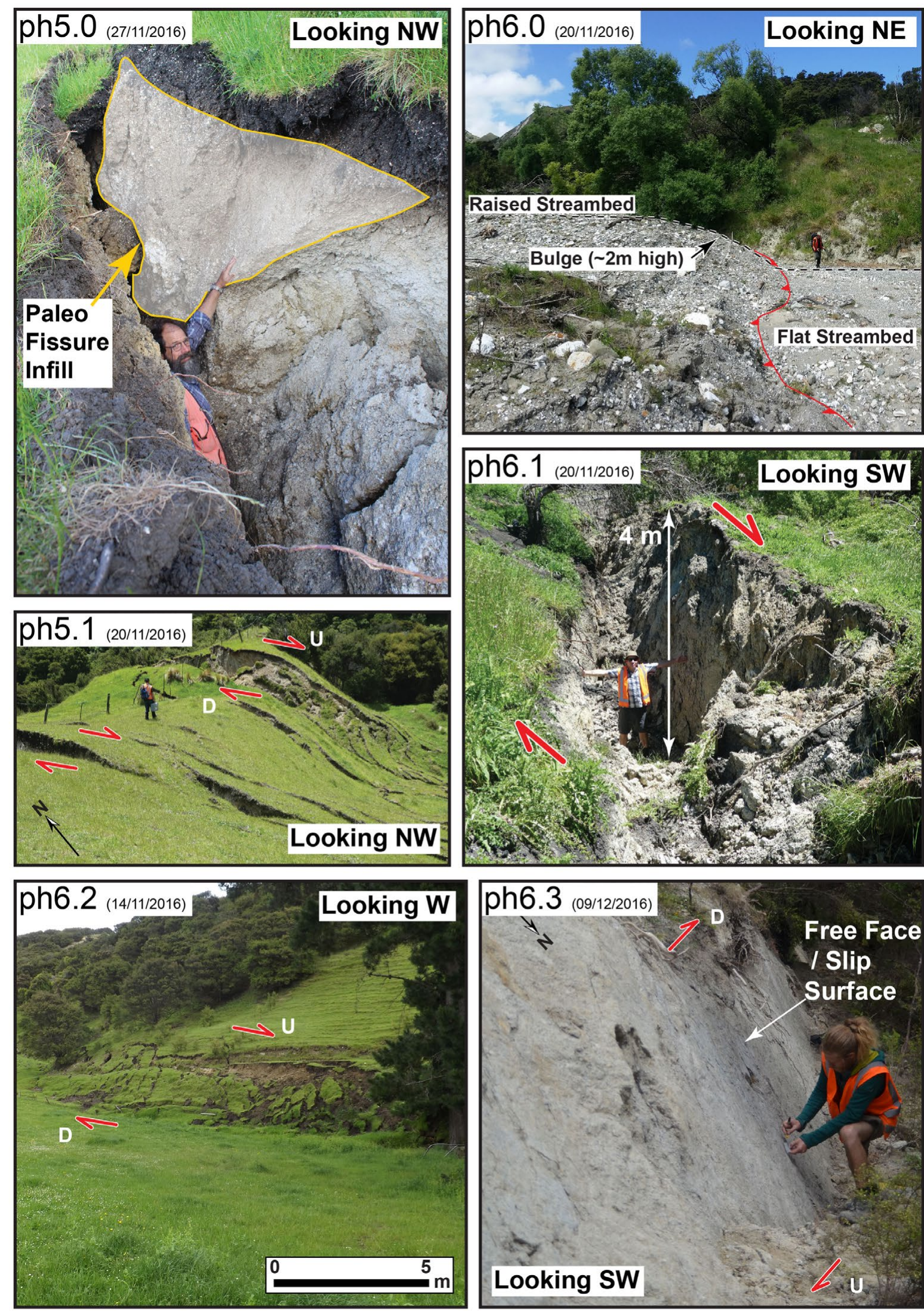

Figure A1.2: Collection of field photographs from the Kekerengu fault. Images are located within map tiles \#5 and \#6 of section 2.3.1 of Chapter Two. 

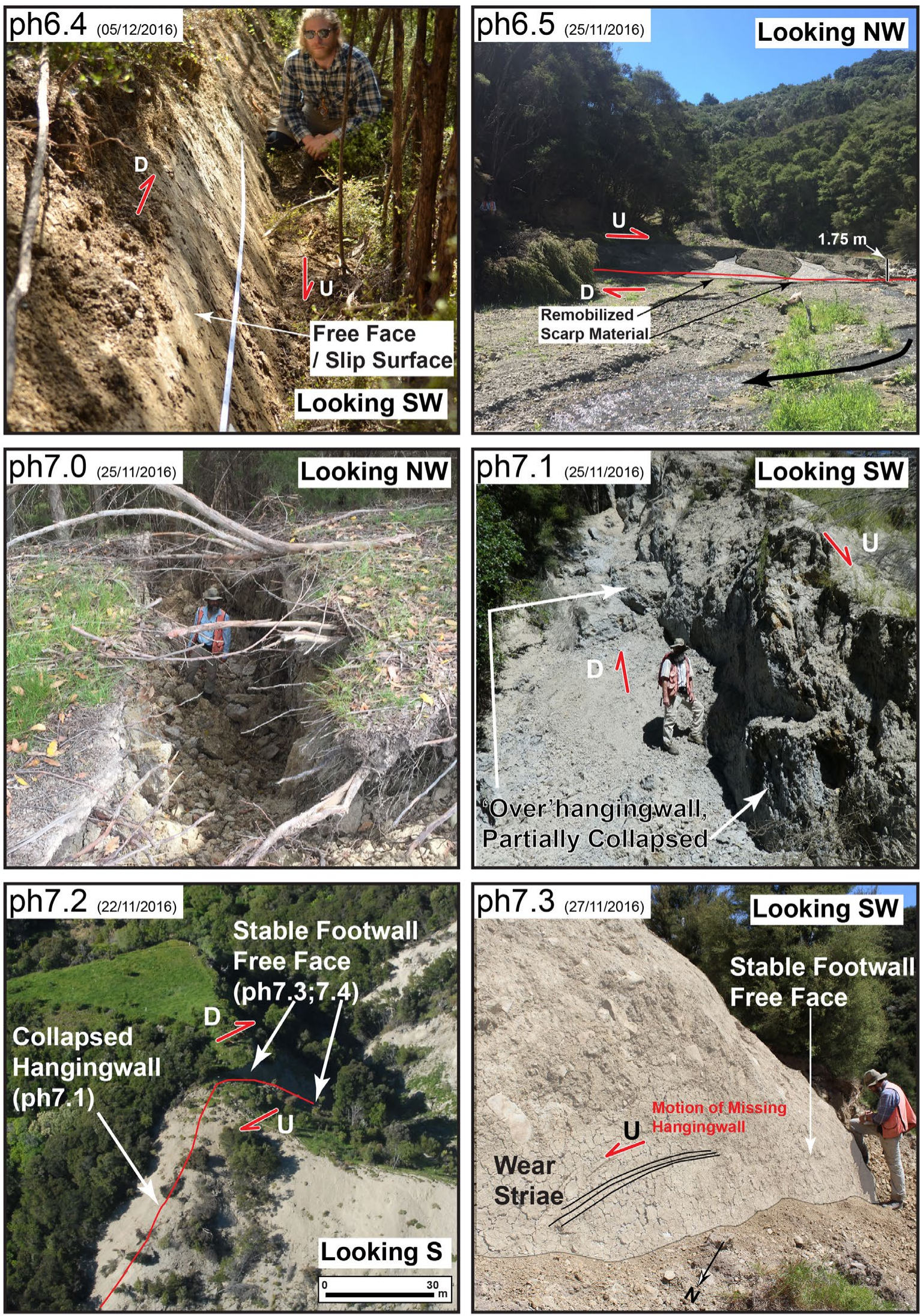

Figure A1.3: Collection of field photographs from the Kekerengu fault. Images are located within map tiles \#6 and \#7 of section 2.3.1 of Chapter Two. 

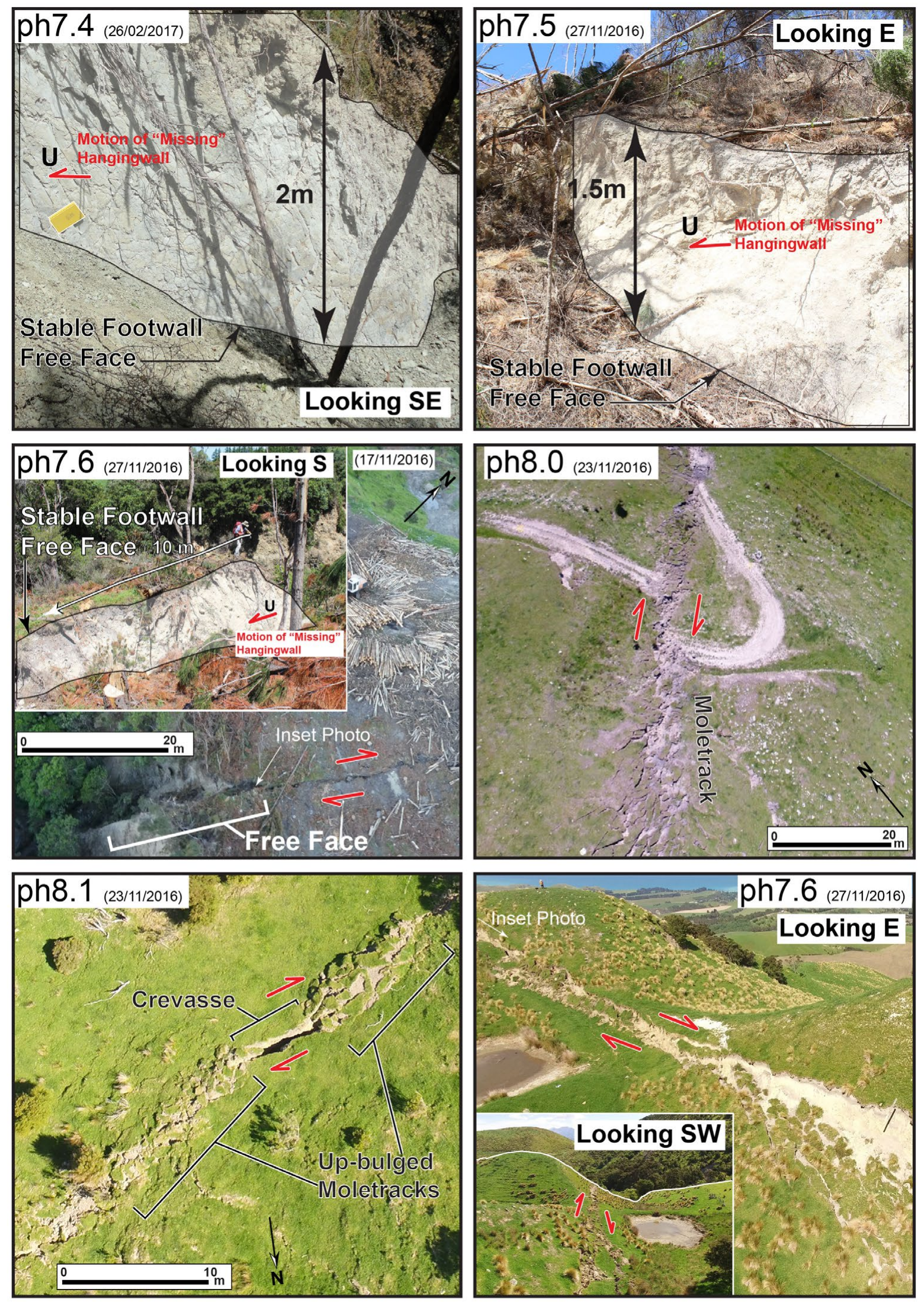

Figure A1.4: Collection of field photographs from the Kekerengu fault. Images are located within map tiles \#7 and \#8 of section 2.3.1 of Chapter Two. 

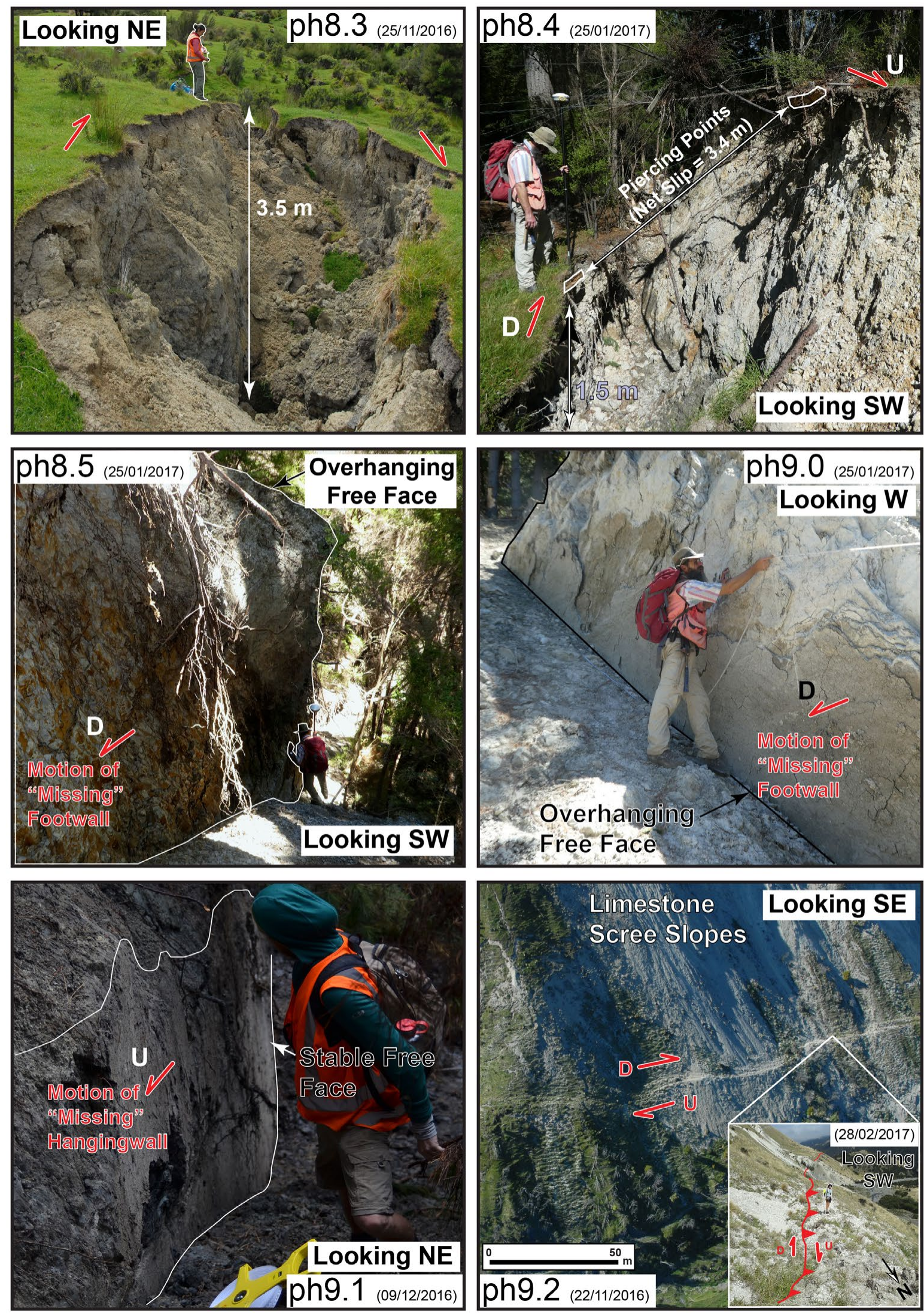

Figure A1.5: Collection of field photographs from the Kekerengu fault. Images are located within map tiles \#8 and \#9 of section 2.3.1 of Chapter Two. 

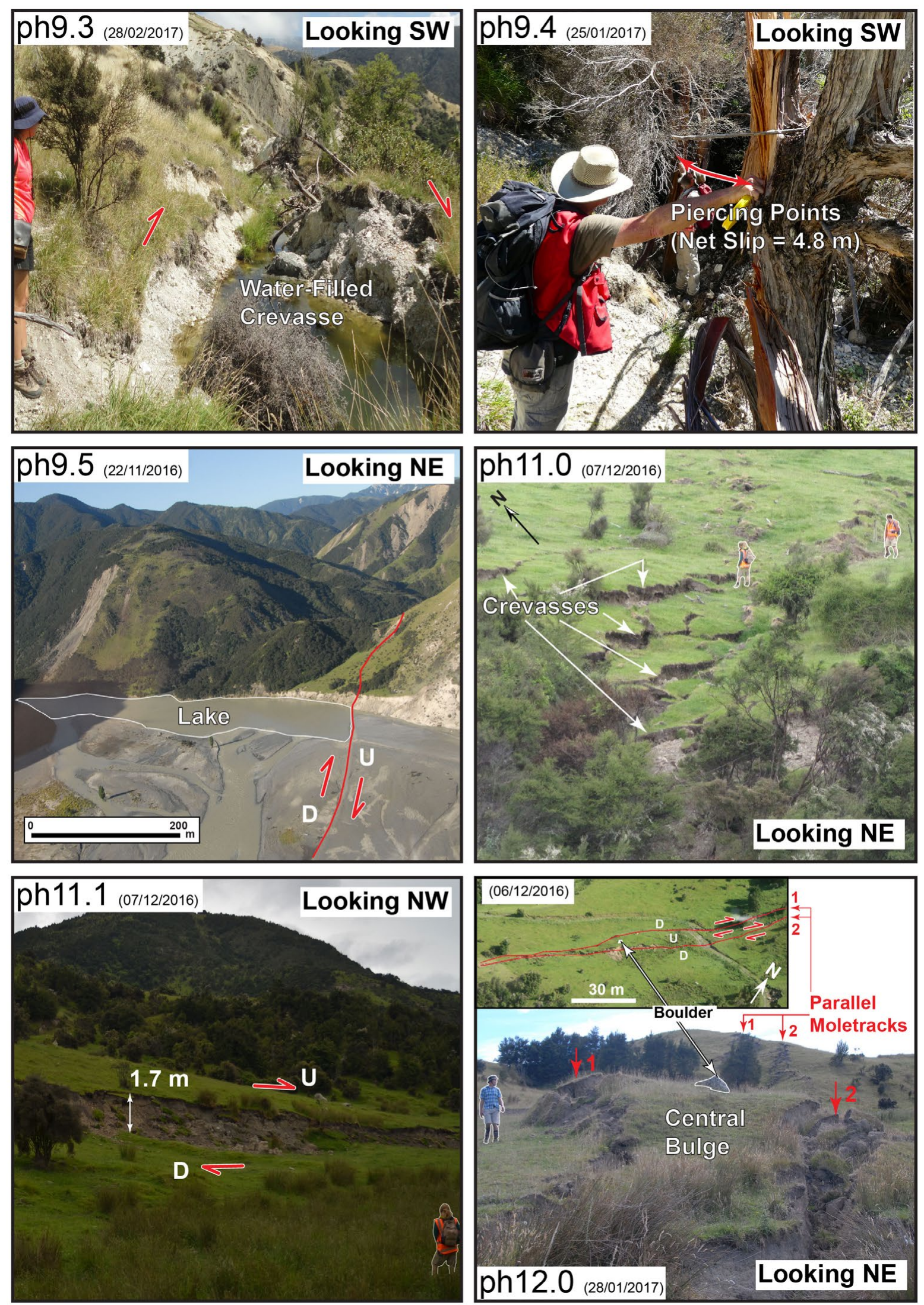

Figure A1.6: Collection of field photographs from the Kekerengu fault. Images are located within map tiles \#9 \#11 and \#12 of section 2.3.1 of Chapter Two. 

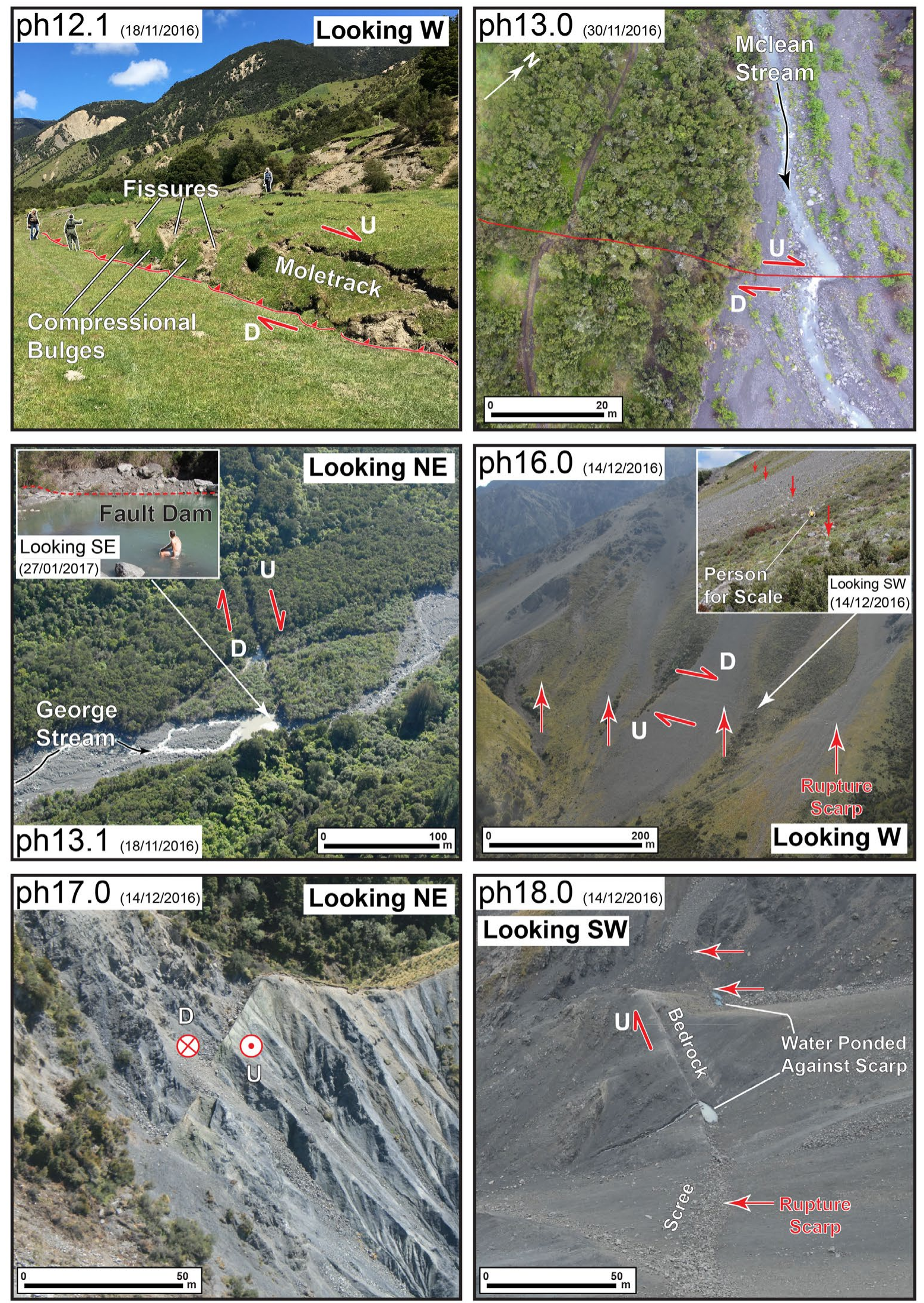

Figure A1.7: Collection of field photographs from the Kekerengu, Jordan and Upper Kowhai faults. Images are located within map tiles \#12 \#13 \#16 \#17 and \#18 of section 2.3.1 of Chapter Two. 


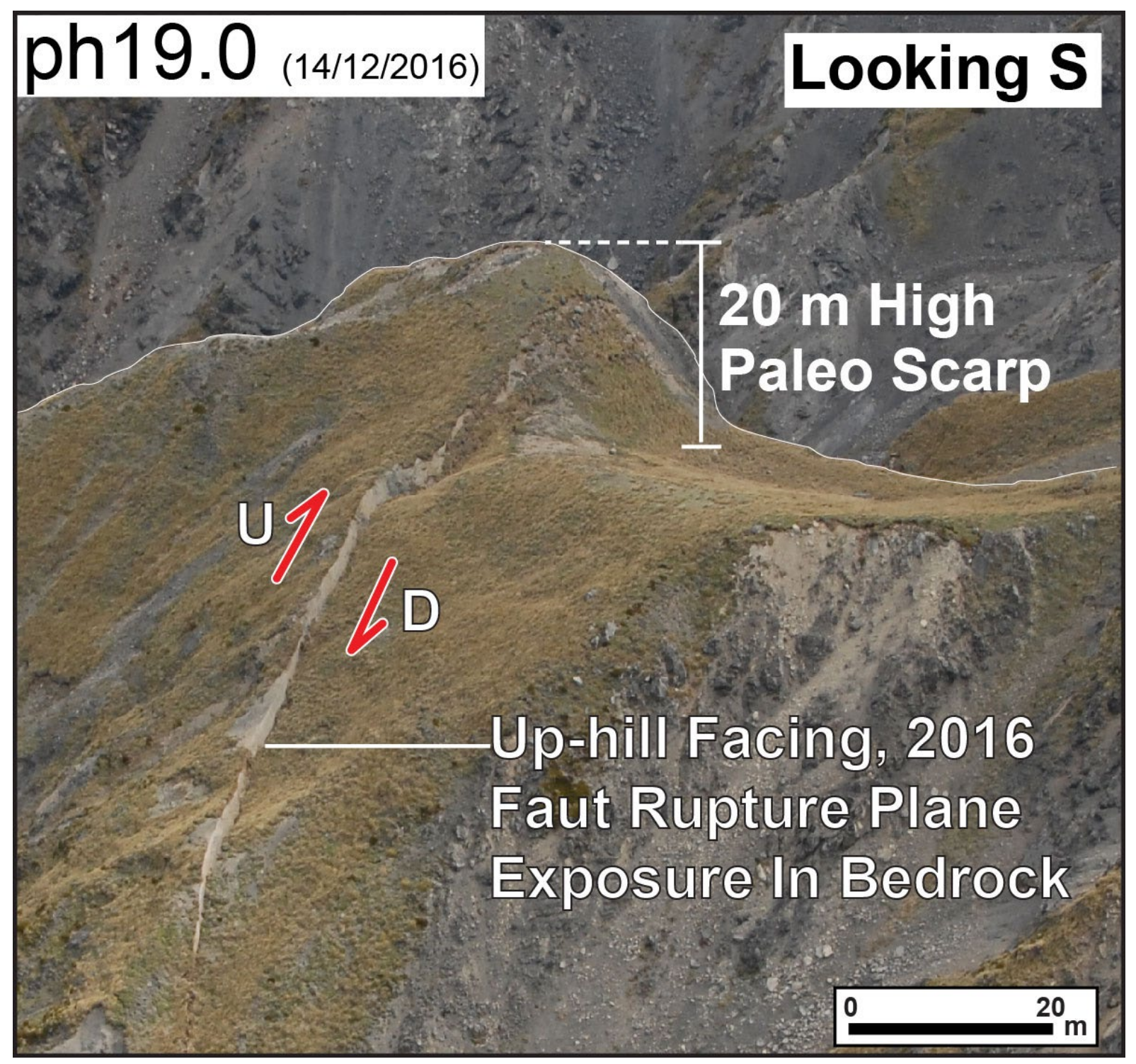

Figure A1.8: Field photographs from the Upper Kowhai fault. Image is located within map tile \#17 of section 2.3.1 of Chapter Two. 


\section{Appendix 2 - Supplimentary Tables and Figure for Chapter Three}

Authors

Jesse Kearse (corresponding author), Timothy A. Little, Russ J. Van Dissen, Philip M. Barnes, Robert Langridge, Joshu Mountjoy, Will Ries, Pilar Villamor, Kate J. Clark, Adrian Benson, Geoffroy Lamarche, Matthew Hill, Mark Hemphill-Haley

This supplement contains data tables and offset site images, that could not be included in the main text, but which support chapter Three. Additional figures that accompany the offshore data are also included here.

This Appendix contains four items and one electronic suppliment.

Table A2.0

This file contains tabled data of horizontal displacement site information.

Table A2.1

This file contains tabled data of vertical displacement site information.

Figure A2.0

This figure shows marine shipping track data that was available prior to the 2016 Kaikoura earthquake.

Figure A2.1

This figure shows the bathymetry in the region of earthquake termination.

Other

This electronic file contains 83 .jpg files, and 1 .pdf file

File "legend.jpg" is an explanatory figure to accompany supplementary figures depicting 
horizontal displacements- e.g. "Site_1.jpg" "Site_2.jpg” etc.

Files "Site_1.jpg" through to "Site_147.jpg" depict detailed maps, cross-sections and photographs of individual sites where horizontal and vertical displacement was calculated. File titles refer to individual site IDs in tables S1 and S2

File "LaDiCaoz.pdf" is an explanatory text file outlining details relevant to images in files "S3_1" and S3_2".

Files "S3_1" and "S3_2" show micro-topographic maps detailing individual sites measured using LaDiCaoz.

Files "S4_15.jpg" through to "S4_114" contain histograms of across-strike dextral displacement profiles at 14 individual sites. Numbers after underscores in file titles refer to 


\section{Table S1. Site Information for Horizontal Offsets}

\begin{tabular}{|c|c|c|c|c|c|c|c|c|c|}
\hline Site ID & Easting & Northing & $\begin{array}{c}\text { Distance Along Rupture } \\
\text { (m) From SW - NE } \\
\end{array}$ & Feature & Method & Strike of Fault & Trend of Feature & Dextral Displacement (m) & Uncertainty (m) \\
\hline 1 & 1687748 & 5354950 & 53761 & Fence Line & RTK GPS & 040 & 005 & 0.8 & 0.4 \\
\hline 2 & 1687746 & 5354832 & 53717 & Fence Line & RTK GPS & 073 & 139 & 1.3 & 0.4 \\
\hline 3 & 1687725 & 5354826 & 53711 & Farm Track & RTK GPS & 073 & 186 & 1.5 & 0.6 \\
\hline 8 & 1687618 & 5354066 & 53388 & Farm Track & RTK GPS & 069 & 038 & 6.7 & 1.0 \\
\hline 10 & 1687393 & 5354000 & 53156 & Railway Line & RTK GPS & 076 & 035 & 7.5 & 0.6 \\
\hline 12 & 1687200 & 5353947 & 52956 & State Highway 1 (SH1) & RTK GPS & 072 & 041 & 6.8 & 0.5 \\
\hline 15 & 1686278 & 5353573 & 51952 & Fence Line & RTK GPS & 052 & 146 & 8.1 & 3.5 \\
\hline 16 & 1686117 & 5353447 & 51748 & Fence Line & RTK GPS & 048 & 356 & 8.4 & 0.4 \\
\hline 17 & 1685720 & 5353346 & 51356 & Ridge Line & LiDAR & 096 & 173 & 7.0 & 3.0 \\
\hline 18 & 1685166 & 5352985 & 50694 & Trench Margin & RTK GPS & 062 & 146 & 9.1 & 0.5 \\
\hline 20 & 1685166 & 5352985 & 50694 & Re-Occupied Fence Posts & RTK GPS & 062 & 040 & 10.7 & 0.7 \\
\hline 19 & 1685143 & 5352972 & 50669 & Fence Line & RTK GPS & 062 & 095 & 9.4 & 0.4 \\
\hline 22 & 1684678 & 5352806 & 50178 & Fence Line & Total Station & 084 & 048 & 11.3 & 3.8 \\
\hline 23 & 1684058 & 5352639 & 49522 & Farm Track & RTK GPS & 107 & 153 & 7.5 & 0.4 \\
\hline 24 & 1684044 & 5352644 & 49502 & Fence Line & RTK GPS & 107 & 032 & 7.7 & 0.7 \\
\hline 25 & 1683551 & 5352426 & 48971 & Channel Levee & RTK GPS & 055 & 165 & 11.8 & 0.6 \\
\hline 29 & 1682962 & 5352176 & 48337 & Fence Line & Total Station & 064 & 141 & 10.8 & 1.2 \\
\hline 31 & 1682800 & 5352084 & 48152 & Channel Levee & RTK GPS & 073 & 020 & 8.9 & 0.4 \\
\hline 33 & 1682677 & 5352017 & 48006 & Farm Track & $\mathrm{OP}$ & 061 & 153 & 9.7 & 0.6 \\
\hline 34 & 1682648 & 5352011 & 47976 & Cottage Foundation & Tape Measure & 061 & N/A & 6.2 & 0.6 \\
\hline
\end{tabular}

Table A2.0: Index of site measurements corresponding to Chapter Three 


\begin{tabular}{|c|c|c|c|c|c|c|c|c|c|}
\hline 35 & 1682634 & 5352005 & 47959 & Farm Track & $\mathrm{OP}$ & 061 & 160 & 9.7 & 1.2 \\
\hline 36 & 1682620 & 5351990 & 47941 & Hedge Row & $\mathrm{OP}$ & 061 & 127 & 9.8 & 0.6 \\
\hline 37 & 1682261 & 5351767 & 47524 & Fence Line & Total Station & 070 & 139 & 10.8 & 0.4 \\
\hline 38 & 1681952 & 5351628 & 47185 & Fence Line & Total Station & 066 & 155 & 9.8 & 0.5 \\
\hline 40 & 1681662 & 5351445 & 46854 & Farm Track & Total Station & 060 & 175 & 6.7 & 2.4 \\
\hline 41 & 1681560 & 5351407 & 46739 & Fence Line & RTK GPS & 058 & 136 & 10.2 & 0.5 \\
\hline 42 & 1682178 & 5350585 & 46666 & Fence Line & RTK GPS & 045 & 133 & 0.25 & 0.4 \\
\hline 43 & 1681560 & 5351407 & 46606 & Re-Occupied Fence Posts & RTK GPS & 058 & $\mathrm{~N} / \mathrm{A}$ & 11.4 & 0.7 \\
\hline 45 & 1681560 & 5351407 & 46606 & Re-Occupied Fence Posts & RTK GPS & 058 & $\mathrm{~N} / \mathrm{A}$ & 10.2 & 0.7 \\
\hline 47 & 1681281 & 5351269 & 46477 & Fence Line & Total Station & 076 & 20 & 9.7 & 0.8 \\
\hline 48 & 1681061 & 5351151 & 46181 & Fence Line & Total Station & 070 & 141 & 9.0 & 0.4 \\
\hline 49 & 1680961 & 5351121 & 46068 & Fence Line & Total Station & 082 & 020 & 9.1 & 0.4 \\
\hline 50 & 1680923 & 5351120 & 46056 & Fence Line & RTK GPS & 069 & 115 & 8.0 & 0.4 \\
\hline 51 & 1680885 & 5351099 & 46011 & Small Spur & Tape Measure & 057 & 120 & 6.0 & 2.0 \\
\hline 52 & 1680860 & 5351080 & 45991 & Tree & Tape Measure & 054 & $\mathrm{~N} / \mathrm{A}$ & 3.0 & 0.4 \\
\hline 53 & 1680725 & 5350996 & 45831 & Small Spur & Tape Measure & 055 & 140 & 7.5 & 2.0 \\
\hline 54 & 1680692 & 5350970 & 45791 & Small Spur & Tape Measure & 052 & 140 & 8.5 & 2.0 \\
\hline 55 & 1680613 & 5350910 & 45676 & Fence Line & RTK GPS & 057 & 017 & 6.9 & 1.3 \\
\hline 56 & 1680538 & 5350881 & 45629 & Terrace Edge & LiDAR LaDiCaoz & 052 & 122 & 12.8 & 3.0 \\
\hline 58 & 1680449 & 5350809 & 45471 & Free Face & Tape Measure & 054 & 054 & 7.0 & 2.0 \\
\hline 59 & 1680073 & 5350487 & 44986 & Free Face & LiDAR LaDiCaoz & 058 & 058 & 9.0 & 5.0 \\
\hline 61 & 1679906 & 5350413 & 44796 & Fence Line & RTK GPS & 065 & 168 & 8.9 & 0.4 \\
\hline
\end{tabular}

Table A2.0: Index of site measurements corresponding to Chapter Three 


\begin{tabular}{|c|c|c|c|c|c|c|c|c|c|}
\hline 62 & 1679901 & 5350411 & 44793 & Tree Root & Tape Measure & 065 & 170 & 7.5 & 0.4 \\
\hline 64 & 1679800 & 5350359 & 44686 & Fence Line & RTK GPS & 060 & 105 & 7.5 & 0.8 \\
\hline 65 & 1679672 & 5350282 & 44539 & Fence Line & RTK GPS & 058 & 089 & 8.9 & 1.7 \\
\hline 66 & 1679261 & 5349912 & 43982 & Fence Line & RTK GPS & 059 & 115 & 7.1 & 0.8 \\
\hline 67 & 1679139 & 5349827 & 43834 & Fence Line & RTK GPS & 056 & 172 & 9.2 & 0.5 \\
\hline 68 & 1678324 & 5349283 & 42855 & Fence Line & RTK GPS & 060 & 026 & 8.7 & 2.3 \\
\hline 69 & 1678108 & 5349152 & 42607 & Fence Line & Tape Measure & 060 & 035 & 4.6 & 2.0 \\
\hline 70 & 1678062 & 5349125 & 43556 & Tree Root & Tape Measure & 060 & 010 & 3.4 & 0.4 \\
\hline 72 & 1677953 & 5348998 & 42381 & Thawleg & Tape Measure & 032 & 130 & 5.5 & 2.0 \\
\hline 73 & 1677898 & 5348944 & 42304 & Small Spur & Tape Measure & 030 & 085 & 8.0 & 2.0 \\
\hline 74 & 1677862 & 5348925 & 42284 & Tree Root & Tape Measure & 030 & 160 & 4.8 & 0.4 \\
\hline 76 & 1677803 & 5348674 & 42020 & Thawleg & Tape Measure & 044 & 168 & 6.0 & 2.0 \\
\hline 77 & 1677770 & 5348641 & 41970 & Free Face & Tape Measure & 045 & 045 & 7.0 & 2.0 \\
\hline 78 & 1677722 & 5348597 & 41907 & Thawleg & LiDAR LaDiCaoz & 045 & 110 & 8.5 & 3.0 \\
\hline 80 & 1677705 & 5348588 & 41871 & Farm Track & Total Station & 040 & 130 & 10.8 & 3.2 \\
\hline 81 & 1677658 & 5348540 & 41836 & Fence Line & Total Station & 045 & 093 & 9.7 & 2.2 \\
\hline 82 & 1677521 & 5348438 & 41661 & Fence Line & RTK GPS & 048 & 147 & 10.9 & 0.9 \\
\hline 83 & 1677460 & 5348432 & 41621 & Farm Track & Tape Measure & 055 & 132 & 5.0 & 2.0 \\
\hline 84 & 1677318 & 5348329 & 41448 & Tree & Tape Measure & 048 & $\mathrm{~N} / \mathrm{A}$ & 4.2 & 0.4 \\
\hline 85 & 1677164 & 5348170 & 41233 & Channel Levee & Tape Measure & 040 & 085 & 5.0 & 1.0 \\
\hline 87 & 1677026 & 5348096 & 41083 & Vegetation & $\mathrm{OP}$ & 055 & $\mathrm{~N} / \mathrm{A}$ & 10.5 & 3.0 \\
\hline 88 & 1676971 & 5348058 & 41013 & Landslide_Margin & Tape Measure & 053 & 126 & 6.0 & 1.0 \\
\hline
\end{tabular}

Table A2.0: Index of site measurements corresponding to Chapter Three 


\begin{tabular}{|c|c|c|c|c|c|c|c|c|c|}
\hline 90 & 1676671 & 5347847 & 40614 & Fence Line & RTK GPS & 060 & 025 & 5.5 & 3.4 \\
\hline 91 & 1676402 & 5347706 & 40406 & Tree & Tape Measure & 062 & $\mathrm{~N} / \mathrm{A}$ & 4.8 & 0.5 \\
\hline 93 & 1676350 & 5347691 & 40356 & Vegetation & $\mathrm{OP}$ & 062 & N/A & 10.6 & 3.0 \\
\hline 94 & 1676228 & 5347643 & 40226 & Farm Track & Tape Measure & 062 & 135 & 2.7 & 1.0 \\
\hline 97 & 1675225 & 5346450 & 38560 & Channel Levee & LiDAR & 033 & 114 & 8.2 & 1.0 \\
\hline 102 & 1672926 & 5344387 & 35480 & Fence Line & RTK GPS & 057 & 092 & 9.5 & 0.4 \\
\hline 103 & 1672864 & 5344347 & 35415 & Channel Levee & LiDAR & 049 & 141 & 8.6 & 3.0 \\
\hline 105 & 1672424 & 5343881 & 51770 & Fence Line & RTK GPS & 052 & 129 & 8.0 & 1.3 \\
\hline 106 & 1671851 & 5343299 & 33945 & Fence Line & RTK GPS & 071 & 014 & 9.8 & 0.4 \\
\hline 107 & 1671800 & 5343276 & 33890 & Animal Track & Tape Measure & 065 & 190 & 7.0 & 2.0 \\
\hline 108 & 1671538 & 5343090 & 33565 & Log & Tape Measure & 070 & 123 & 8.0 & 2.0 \\
\hline 109 & 1671280 & 5342850 & 33220 & Fence Line & RTK GPS & 042 & 107 & 6.6 & 2.0 \\
\hline 110 & 1671097 & 5342619 & 32925 & Farm Track & Tape Measure & 057 & 125 & 5.8 & 2.0 \\
\hline 111 & 1670934 & 5342492 & 32723 & Farm Track & Tape Measure & 057 & 195 & 5.5 & 2.0 \\
\hline 113 & 1669227 & 5340727 & 30245 & Fence Line & RTK GPS & 056 & 178 & 7.3 & 0.4 \\
\hline 114 & 1669166 & 5340618 & 30075 & Fence Line & RTK GPS & 051 & 102 & 7.6 & 0.4 \\
\hline 115 & 1668860 & 5340449 & 29793 & Channel Levee & Tape Measure & 051 & 132 & 6.5 & 2.0 \\
\hline 117 & 1668808 & 5340413 & 29723 & Farm Track & Tape Measure & 051 & 120 & 5.8 & 1.0 \\
\hline 118 & 1668722 & 5340332 & 29606 & Fence Line & Tape Measure & 051 & 120 & 5.8 & 1.0 \\
\hline 119 & 1668471 & 5339915 & 29616 & Fence Line & RTK GPS & 021 & 086 & 3.5 & 0.4 \\
\hline 120 & 1668247 & 5339546 & 29216 & Fence Line & RTK GPS & 049 & 127 & 2.1 & 0.4 \\
\hline 121 & 1667835 & 5338820 & 28450 & Fence Line & RTK GPS & 086 & 177 & 3.7 & 0.8 \\
\hline
\end{tabular}

Table A2.0: Index of site measurements corresponding to Chapter Three 


\begin{tabular}{|c|c|c|c|c|c|c|c|c|c|}
\hline 122 & 1667736 & 5339112 & 28547 & Fence Line & RTK GPS & 051 & 177 & 3.4 & 0.4 \\
\hline 124 & 1666416 & 5337773 & 26115 & Edge of Landslide & LiDAR & 043 & 120 & 8.0 & 1.0 \\
\hline 126 & 1666406 & 5337770 & 26105 & Thawleg & LiDAR & 043 & 120 & 12 & 1.0 \\
\hline 128 & 1666224 & 5337584 & 25845 & Thawleg & LiDAR & 043 & 125 & 9.5 & 2.5 \\
\hline 130 & 1666127 & 5337487 & 25708 & Thawleg & LiDAR & 043 & 125 & 5.5 & 1.0 \\
\hline 132 & 1665063 & 5336489 & 24269 & Ridge Line & LiDAR & 046 & 120 & 6.5 & 1.0 \\
\hline 134 & 1664937 & 5336369 & 24107 & Terrace Riser & LiDAR LaDiCaoz & 036 & 118 & 3.3 & 2.0 \\
\hline 136 & 1664759 & 5335937 & 23550 & Thawleg & LiDAR LaDiCaoz & 030 & 115 & 1.7 & 2.0 \\
\hline 139 & 1662900 & 5332862 & 20865 & Fenceline & RTK GPS & 075 & 152 & 3.9 & 0.4 \\
\hline 140 & 1662640 & 5332718 & 20573 & Rill & RTK GPS & 055 & 137 & 4.6 & 0.4 \\
\hline 142 & 1661202 & 5331040 & 17580 & Thawleg & LiDAR & 028 & 130 & $2 . .0$ & 1.0 \\
\hline 144 & 1659673 & 5328686 & 14700 & Thawleg & LiDAR LaDiCaoz & 030 & 085 & 1.2 & 1.0 \\
\hline 146 & 1658885 & 5327077 & 12761 & Ridge & LiDAR LaDiCaoz & 055 & 143 & 2.8 & 1.6 \\
\hline
\end{tabular}

Table A2.0: Index of site measurements corresponding to Chapter Three 


\begin{tabular}{|c|c|c|c|c|c|c|c|c|}
\hline Site ID & Easting & Northing & $\begin{array}{l}\text { Distance Along Fault } \\
\text { (m) From SW - NE }\end{array}$ & Feature & Method & $\begin{array}{c}\text { Strike of } \\
\text { Fault }\end{array}$ & $\begin{array}{c}\text { Vertical Displacement } \\
\text { (m) Positive }=\text { NW up, } \\
\text { Negative }=\text { SE up } \\
\end{array}$ & Uncertainty $(\mathrm{m})$ \\
\hline 4 & 1687725 & 5354826 & 53711 & Farm track & LiDAR (Differential) & 073 & 1.1 & 0.5 \\
\hline 5 & 1687830 & 5354116 & 53606 & Beach Gravel & RTK GPS & 083 & 1.2 & 0.5 \\
\hline 6 & 1687699 & 5354088 & 53468 & Sand Dunes & LiDAR (Differential) & 075 & -2.0 & 0.5 \\
\hline 7 & 1687617 & 5354067 & 53388 & Sand Dunes & LiDAR (Differential) & 075 & -2.0 & 0.5 \\
\hline 9 & 1687393 & 5354000 & 53156 & Railway Line & LiDAR (Differential) & 076 & -2.4 & 0.5 \\
\hline 11 & 1687200 & 5353947 & 52956 & State Highway 1 (SH1) & LiDAR (Differential) & 072 & -2.3 & 0.5 \\
\hline 13 & 1686686 & 5353791 & 52416 & Cropped Field & LiDAR (Differential) & 065 & -2.5 & 0.5 \\
\hline 14 & 1686399 & 5353669 & 52106 & Landscape & LiDAR (Differential) & 065 & -2.4 & 0.5 \\
\hline 21 & 1685166 & 5352985 & 50694 & Re-Occupied Fence Posts & RTK GPS & 062 & 0.35 & 0.5 \\
\hline 26 & 1683551 & 5352426 & 48971 & Channel Levee & RTK GPS & 055 & 1.8 & 0.4 \\
\hline 27 & 1683484 & 5352387 & 48895 & Flat River Gravels & Tape Measure & 065 & 1.0 & 0.4 \\
\hline 28 & 1683333 & 5352313 & 48725 & Flat Paddock & Tape Measure & 062 & 2.5 & 0.5 \\
\hline 30 & 1682962 & 5352176 & 48337 & Flat Paddock & RTK GPS & 070 & 0.4 & 0.4 \\
\hline 32 & 1682800 & 5352084 & 48152 & Channel Levee & RTK GPS & 073 & 0.8 & 0.4 \\
\hline 39 & 1681810 & 5351570 & 47033 & Flat River Gravels & Tape Measure & 065 & 1.75 & 0.4 \\
\hline 44 & 1681560 & 5351407 & 46739 & Re-Occupied Fence Posts & RTK GPS & 058 & 0.5 & 0.5 \\
\hline 46 & 1681560 & 5351407 & 46427 & Re-Occupied Fence Posts & RTK GPS & 058 & 0.9 & 0.5 \\
\hline 57 & 1680538 & 5350881 & 45629 & Terrace Edge & LiDAR LaDiCaoz & 052 & 1.3 & 1.0 \\
\hline 60 & 1680073 & 5350487 & 44986 & Terrace Edge & LiDAR LaDiCaoz & 058 & 1.0 & 1.0 \\
\hline
\end{tabular}

Table A2.1: Index of site measurements corresponding to Chapter Three 


$\begin{array}{llllcclcl}63 & 1679903 & 5350414 & 44793 & \text { Tree Root } & \text { Tape Measure } & 065 & -1.6 & 0.4 \\ 71 & 1678062 & 5349125 & 43556 & \text { Tree Root } & \text { Tape Measure } & 060 & 1.2 & 0.4 \\ 75 & 1677863 & 5348923 & 42284 & \text { Tree Root } & \text { Tape Measure } & 035 & -0.85 & 0.4 \\ 79 & 1677722 & 5348597 & 41907 & \text { Thawleg } & \text { LiDAR LaDiCaoz } & 045 & -1.6 & 1.0 \\ 86 & 1677164 & 5348170 & 41233 & \text { Channel levee } & \text { Tape Measure } & 040 & 1.5 & 0.4 \\ 89 & 1676969 & 5348058 & 41013 & \text { Talus slope } & \text { Tape Measure } & 053 & 0.7 & 0.4 \\ 92 & 1676402 & 5347706 & 40343 & \text { Tree } & \text { Tape Measure } & 062 & 0.4 & 0.4 \\ 95 & 1675815 & 5347200 & 39515 & \text { River Gravels } & \text { LiDAR } & 032 & -2.4 & 0.4 \\ 96 & 1675667 & 5346992 & 39265 & \text { River Gravels } & \text { LiDAR } & 037 & -2.4 & 0.4 \\ 98 & 1675225 & 5346450 & 38560 & \text { River Gravels } & \text { LiDAR } & 031 & -4.1 & 0.4 \\ 99 & 1674490 & 5345764 & 37570 & \text { River Gravels } & \text { LiDAR } & 050 & 2.1 & 0.4 \\ 100 & 1673790 & 5345172 & 36647 & \text { River Gravels } & \text { LiDAR } & 050 & 2.5 & 0.4 \\ 101 & 1673386 & 5344837 & 36125 & \text { River Gravels } & \text { LiDAR } & 050 & 1.5 & 0.4 \\ 104 & 1672854 & 5344332 & 35389 & \text { River Gravels } & \text { LiDAR LaDiCaoz } & 049 & 2.1 & 0.4 \\ 112 & 1669915 & 5341458 & 31253 & \text { River Gravels } & \text { LiDAR } & 038 & 2.2 & 0.4 \\ 116 & 166860 & 5340449 & 29793 & \text { Channel Levee } & \text { LiDAR LaDiCaoz } & 051 & 0.4 & 0.5 \\ 123 & 1667155 & 5338496 & 27113 & \text { River Gravels } & \text { LiDAR } & 058 & -3.0 & -1 \\ 125 & 1666416 & 5337773 & 26115 & \text { Landslide Margin } & \text { LiDAR } & 043 & -1.5 & -1 \\ 127 & 1666406 & 5337770 & 26105 & \text { Thawleg } & \text { LiDAR } & 043 & -1 & 0.4 \\ 129 & 1666224 & 5337584 & 25845 & \text { Thawleg } & \text { LiDAR } & 043 & -1.5 & 0.7 \\ 131 & 1666127 & 5337487 & 25708 & \text { Thawleg } & \text { LiDAR } & 043 & -3.6 & 0.5 \\ 133 & 1665063 & 5336489 & 24269 & \text { Thawleg } & \text { LiDAR } & 046 & -0.8 & 0.5\end{array}$

Table A2.1: Index of site measurements corresponding to Chapter Three 


$\begin{array}{llllcclll}135 & 1664937 & 5336369 & 24107 & \text { Terrace Riser } & \text { LiDAR LaDiCaoz } & 036 & -1.8 & 0.5 \\ 137 & 1664759 & 5335937 & 23550 & \text { Thawleg } & \text { LiDAR LaDiCaoz } & 030 & -2.1 & 0.5 \\ 138 & 1664407 & 5335437 & 23022 & \text { Terrace Riser } & \text { LiDAR LaDiCaoz } & 030 & -1.5 & 0.5 \\ 141 & 1662526 & 5332614 & 20563 & \text { Rill } & \text { LiDAR } & 055 & -0.7 & 0.5 \\ 143 & 1661200 & 5331040 & 17580 & \text { Thawleg } & \text { LiDAR } & 028 & -0.2 & 0.2 \\ 145 & 1659674 & 5328699 & 14700 & \text { Thawleg } & \text { LiDAR LaDiCaoz } & 030 & -0.6 & 0.5 \\ 147 & 1655503 & 5324867 & 8720 & \text { Talus slope } & \text { LiDAR } & 058 & -0.7 & 0.5\end{array}$

Table A2.1: Index of site measurements corresponding to Chapter Three 


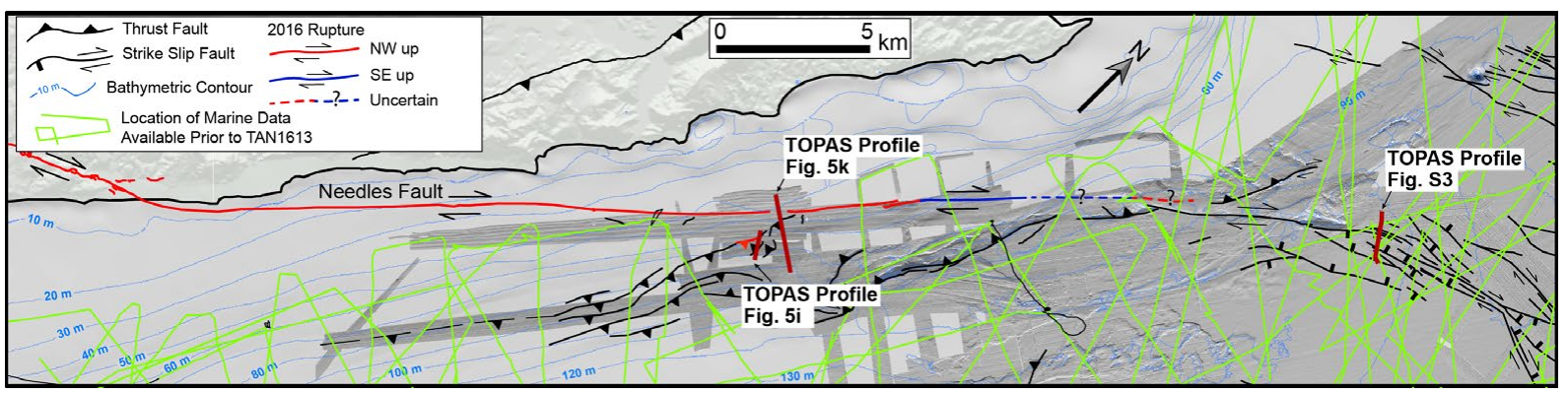

Figure A2.0: Marine shipping track data (green lines) outlining where pre-2016 offshore datasets were available for the Needles fault. Data from NIWA

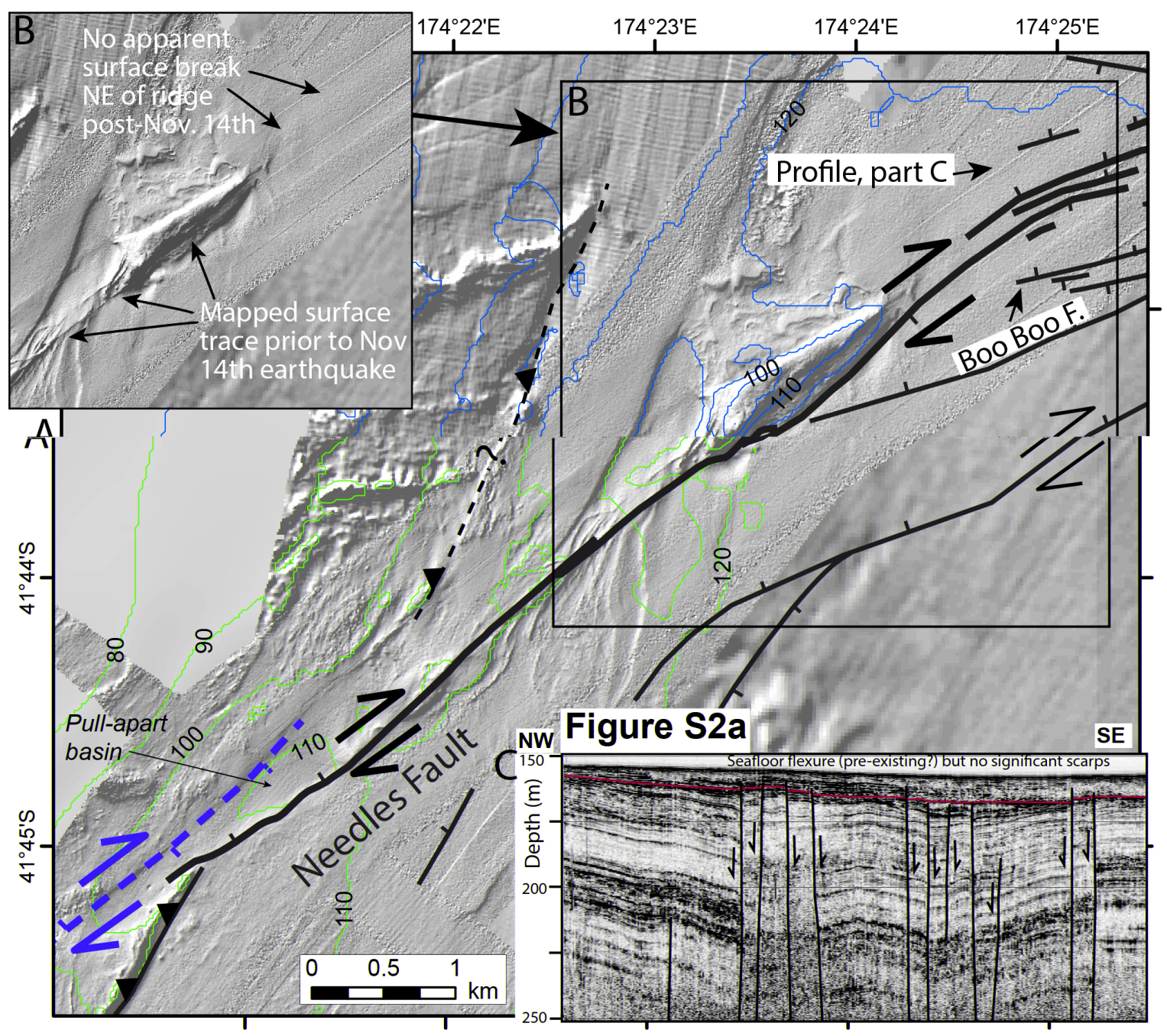

Major traces of the Needles Fault inferred not
to have ruptured in the Nov. 16th Kaikoura earthquake $100 \quad$ Water depth $(\mathrm{m})$
Other active faults
$\begin{aligned} & \text { Possible northern section of the surface break of Nov. 14th } 2016 \mathrm{Mw} 7.8 \\ & \text { Kaikoura Earthquake }\end{aligned}$

Figure A2.1: Bathymetry in the region of 2016 Kaikoura earthquake rupture termination. "Figure S2a" shows sub-floor seismic reflection data, location is contained within Figure A2.0, however is labelled "Figure S3" in that image. 


\section{Appendix 3 - Individual Site Summaries for Chapter Four}
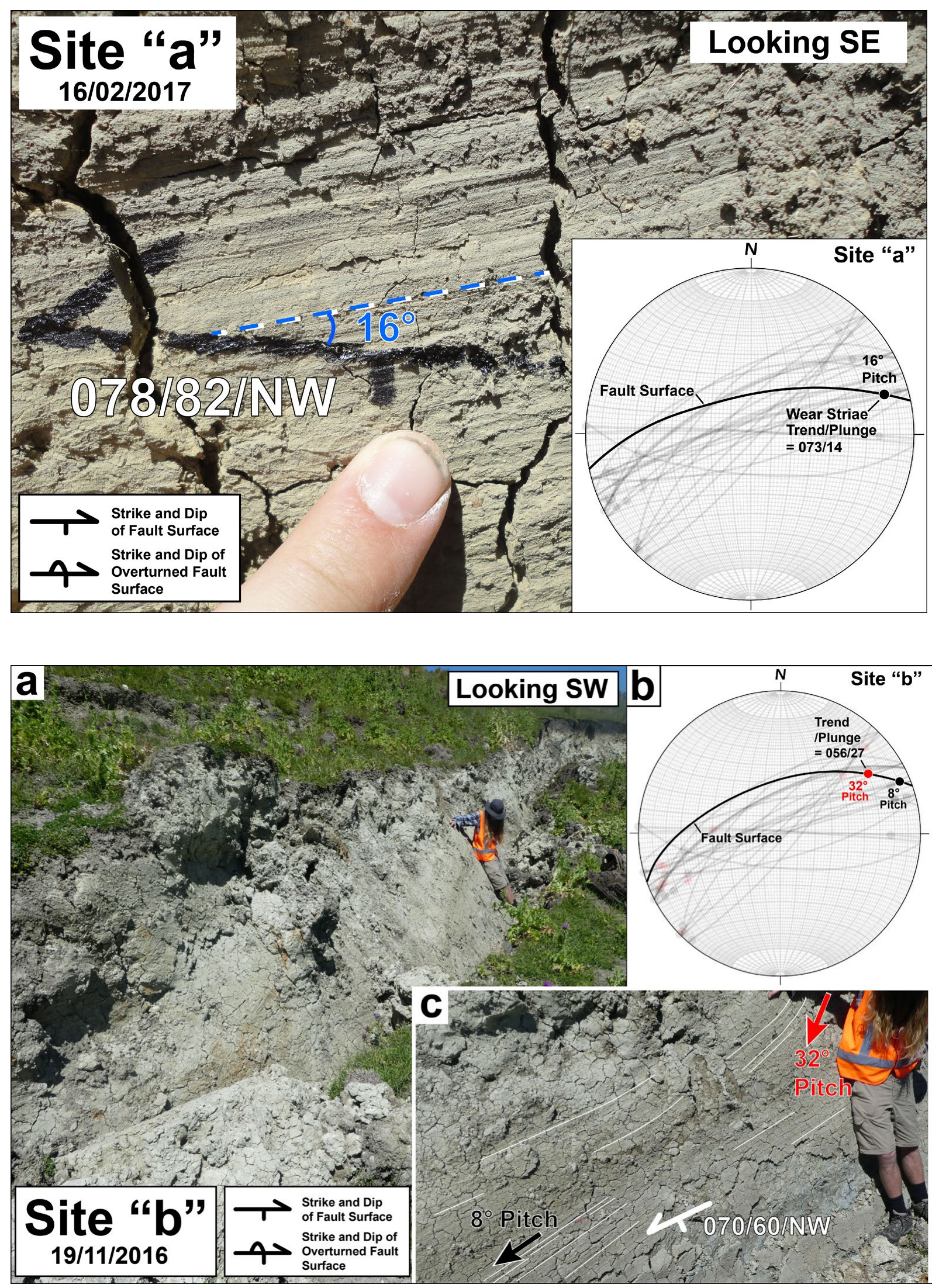

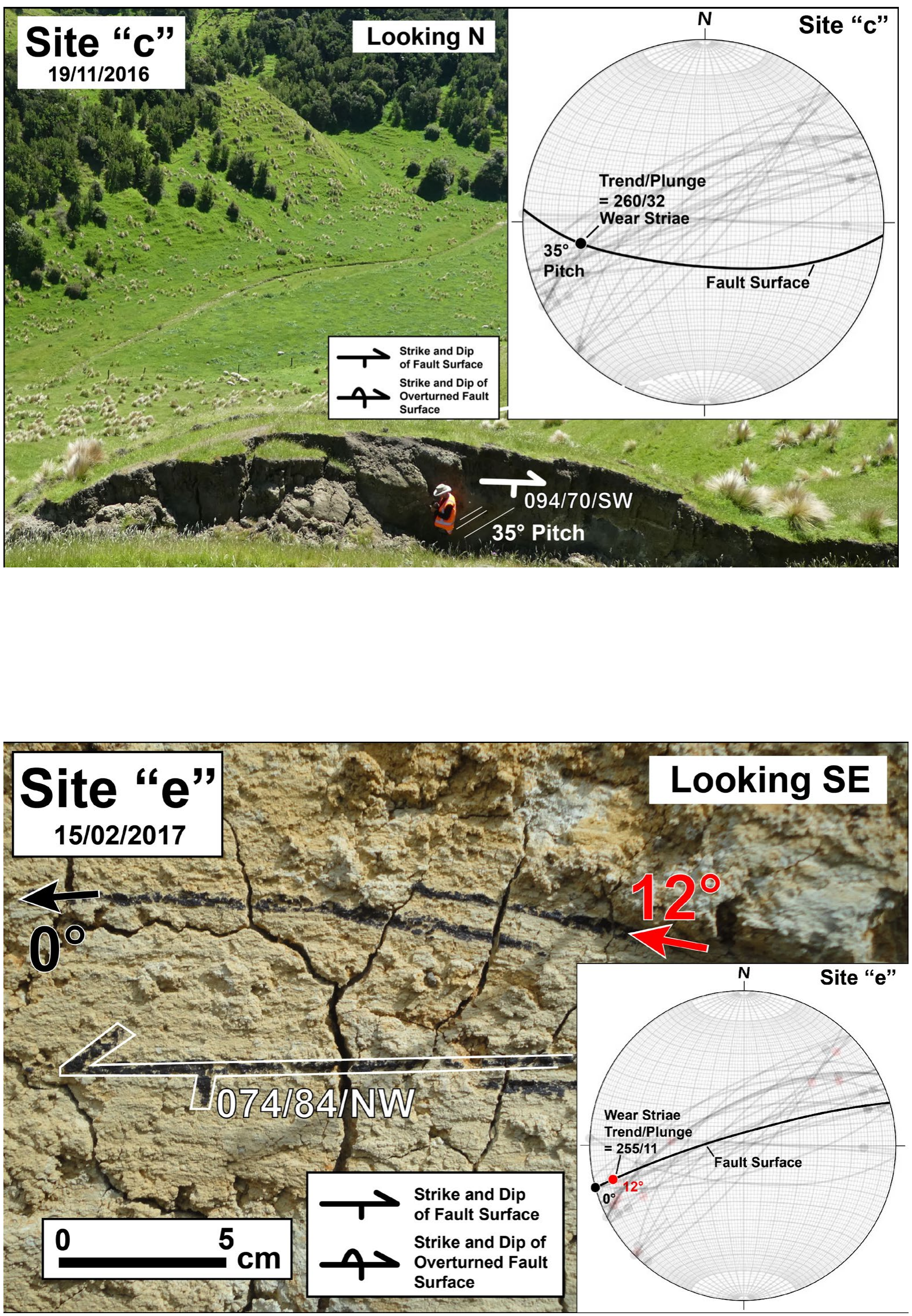

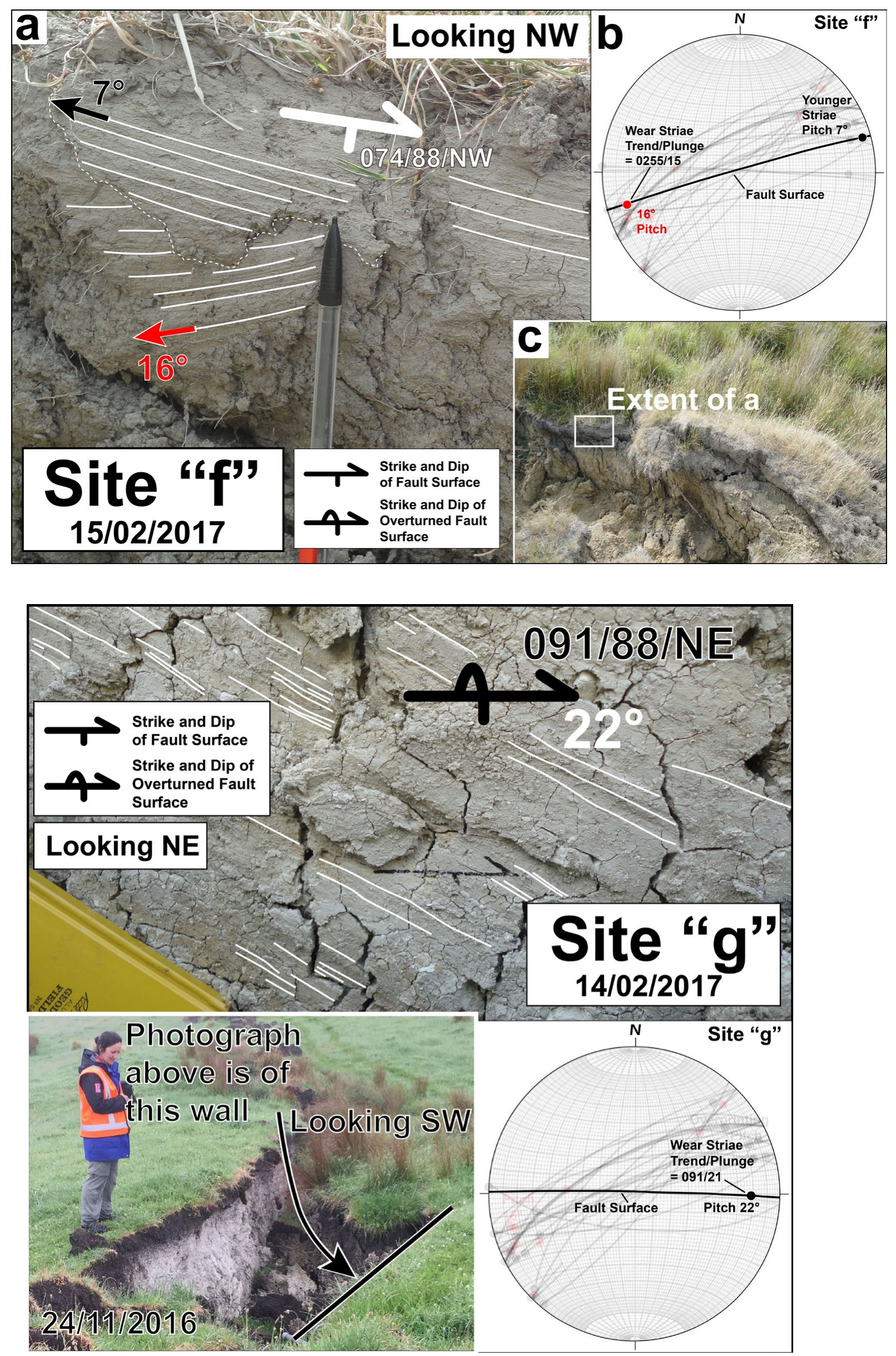

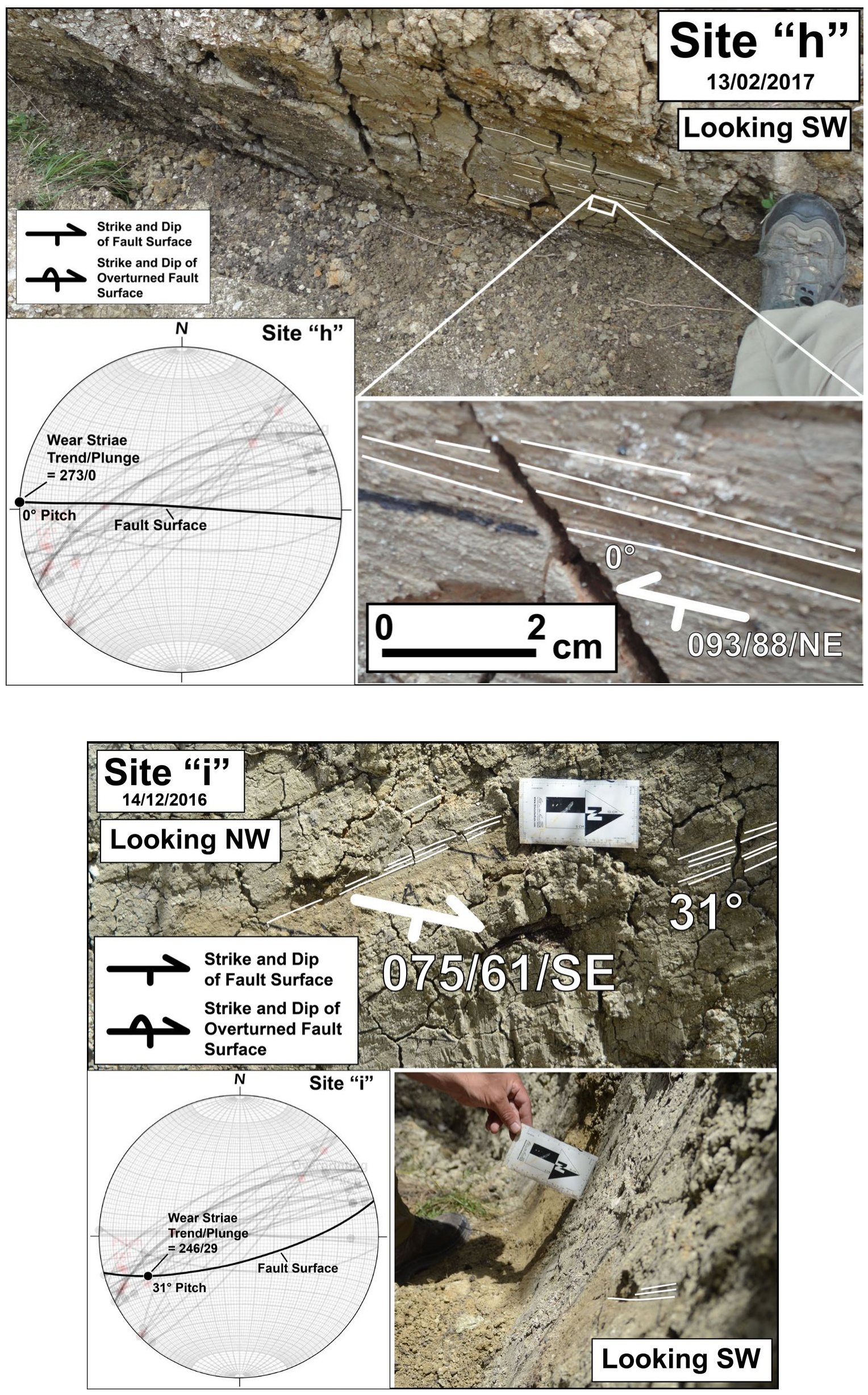

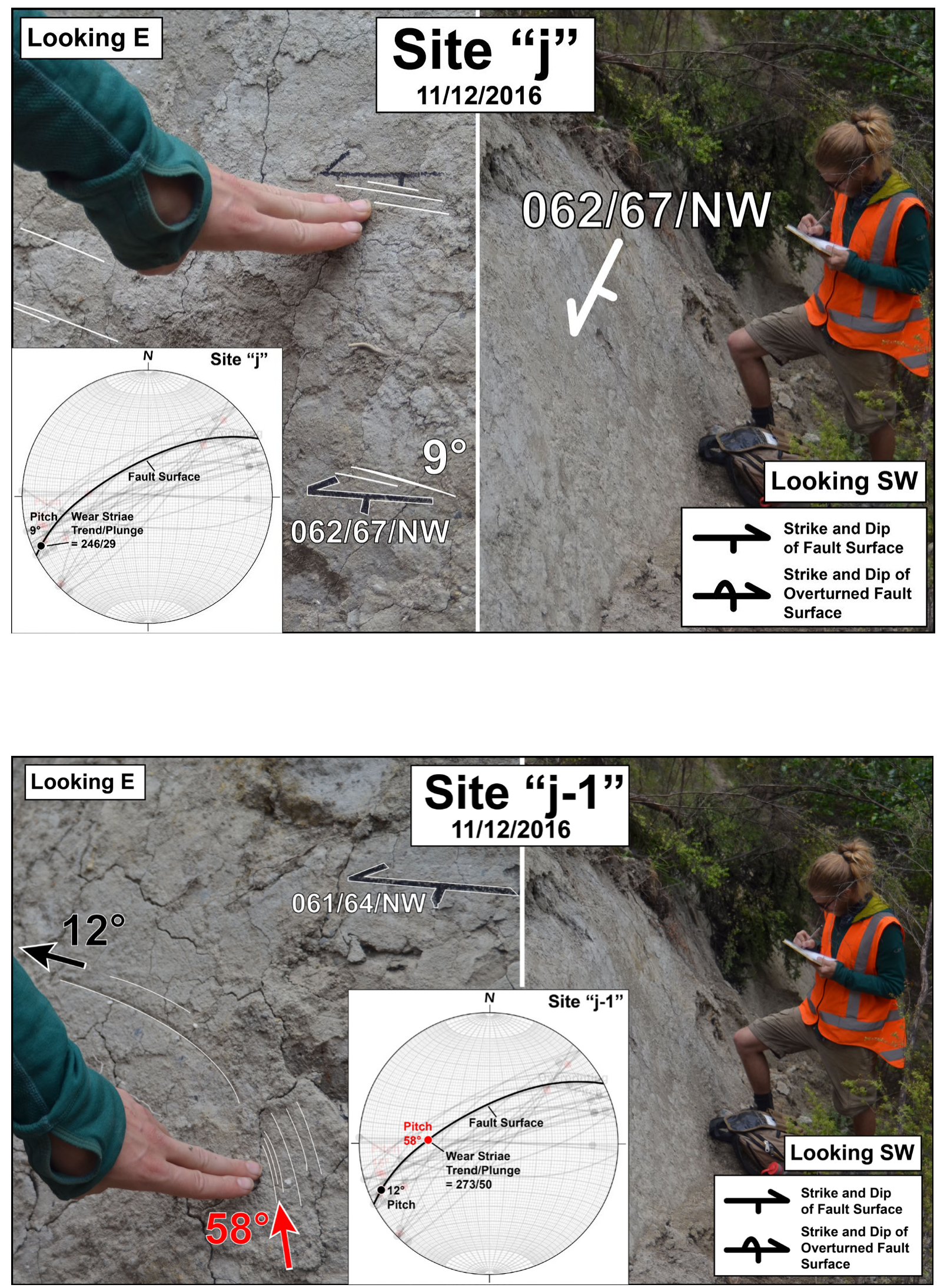

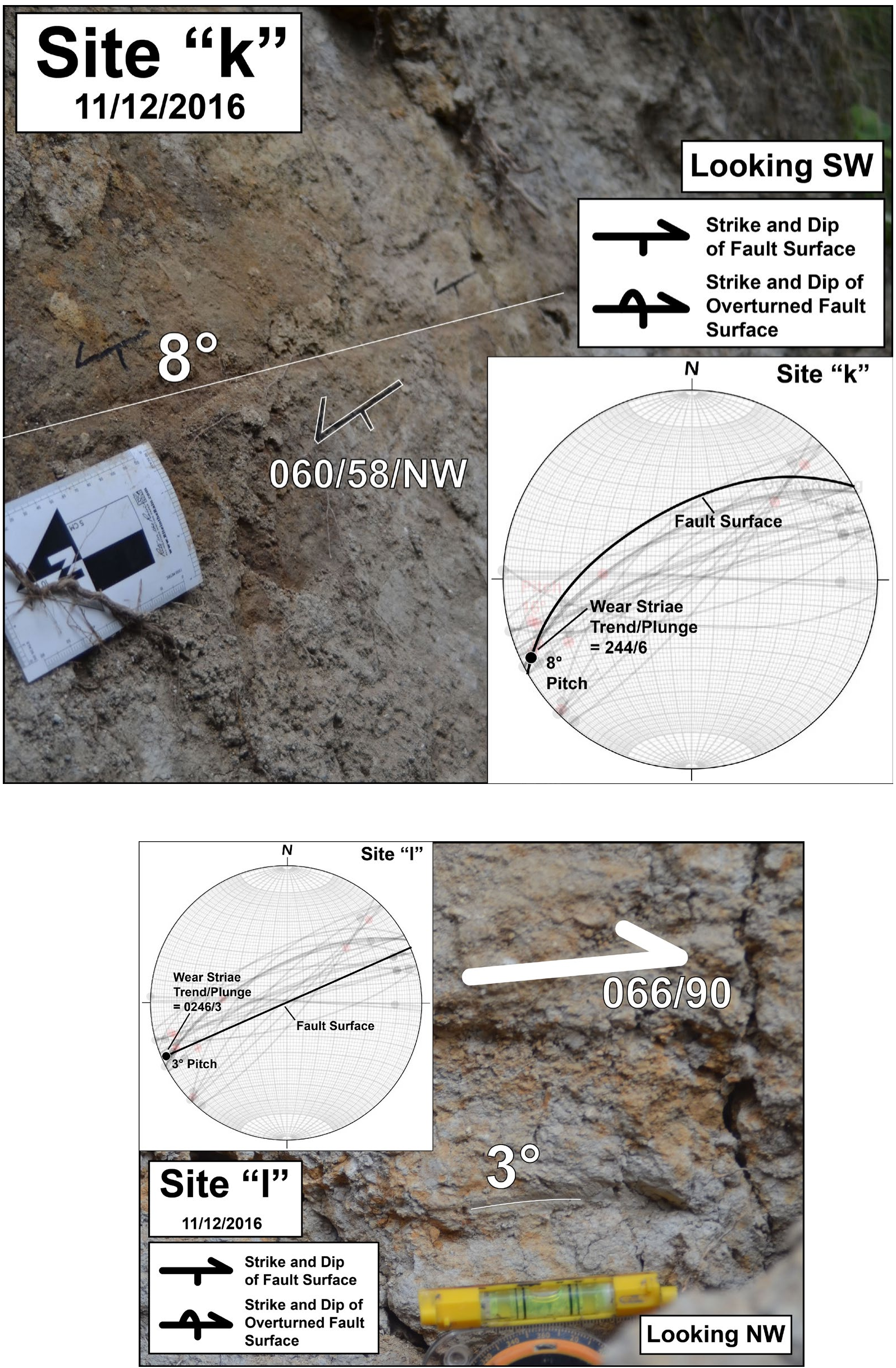

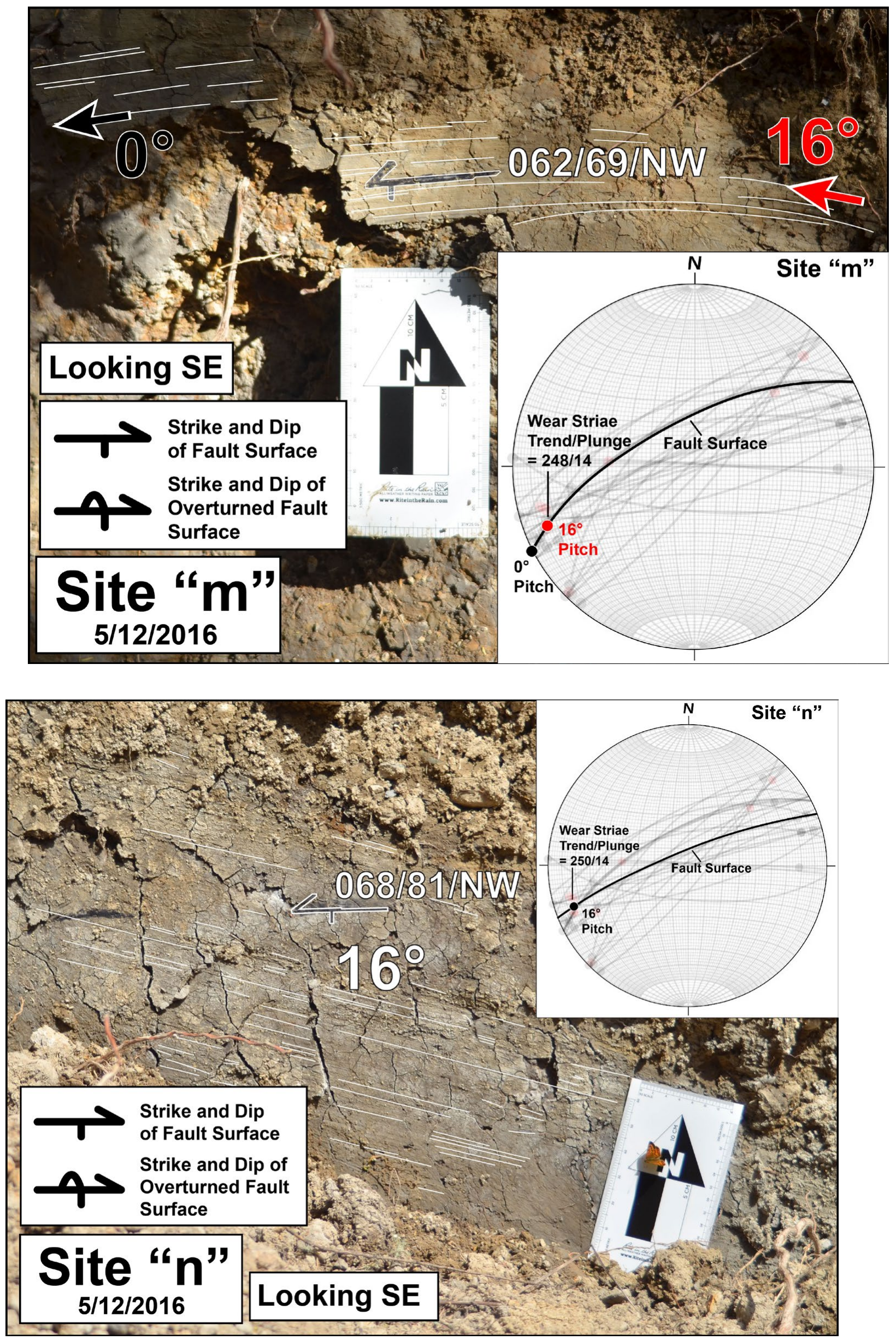

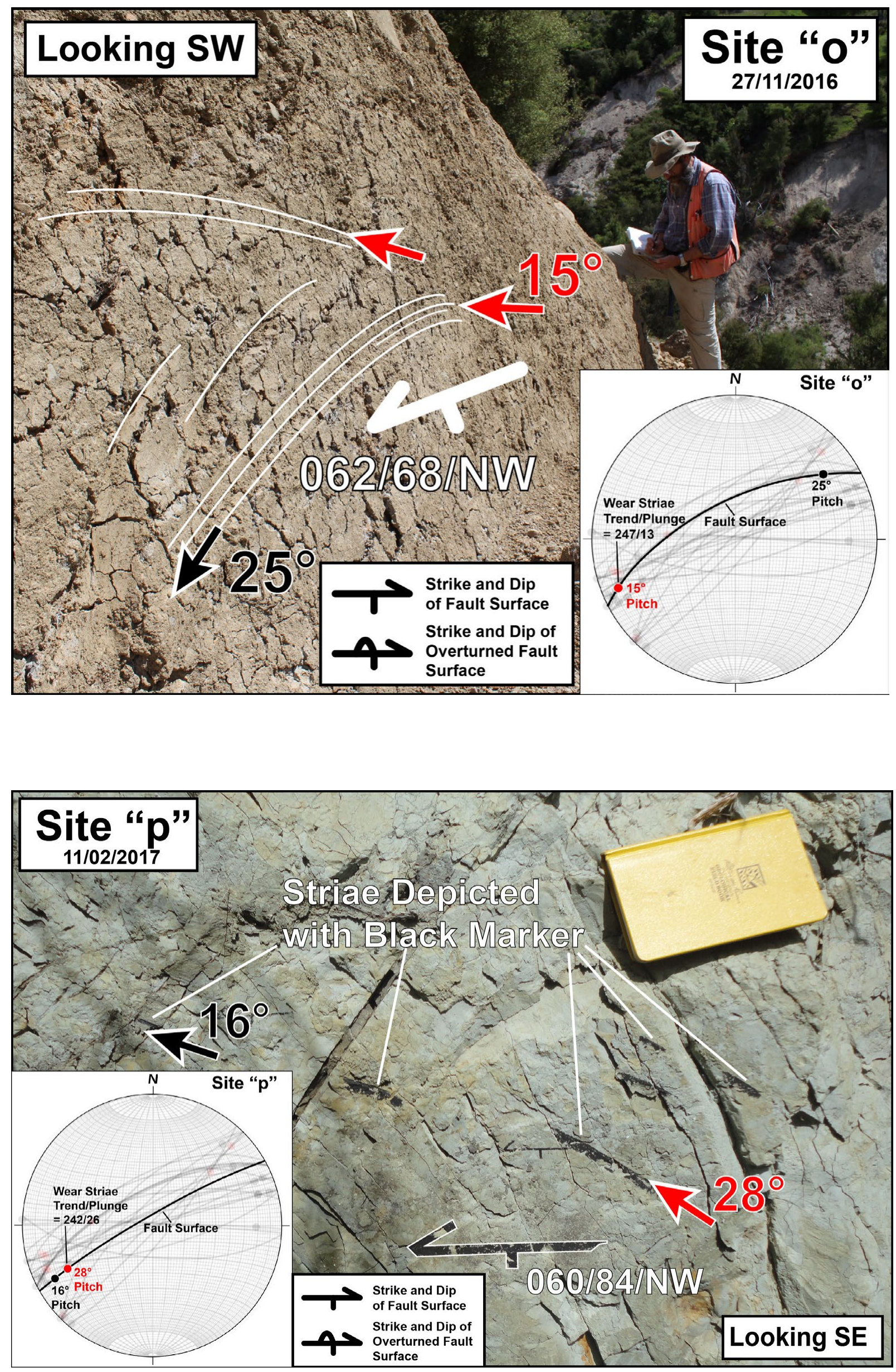

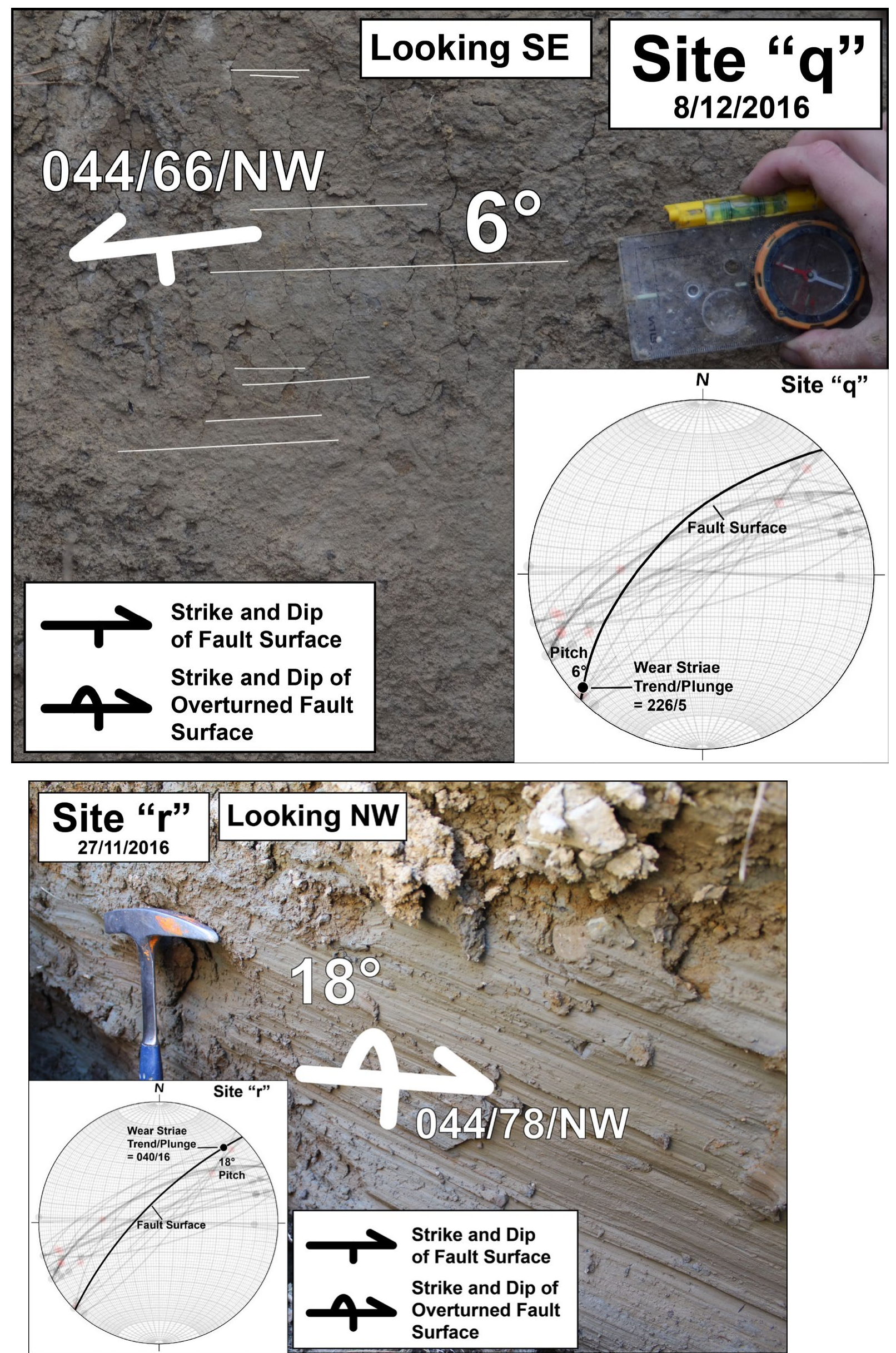

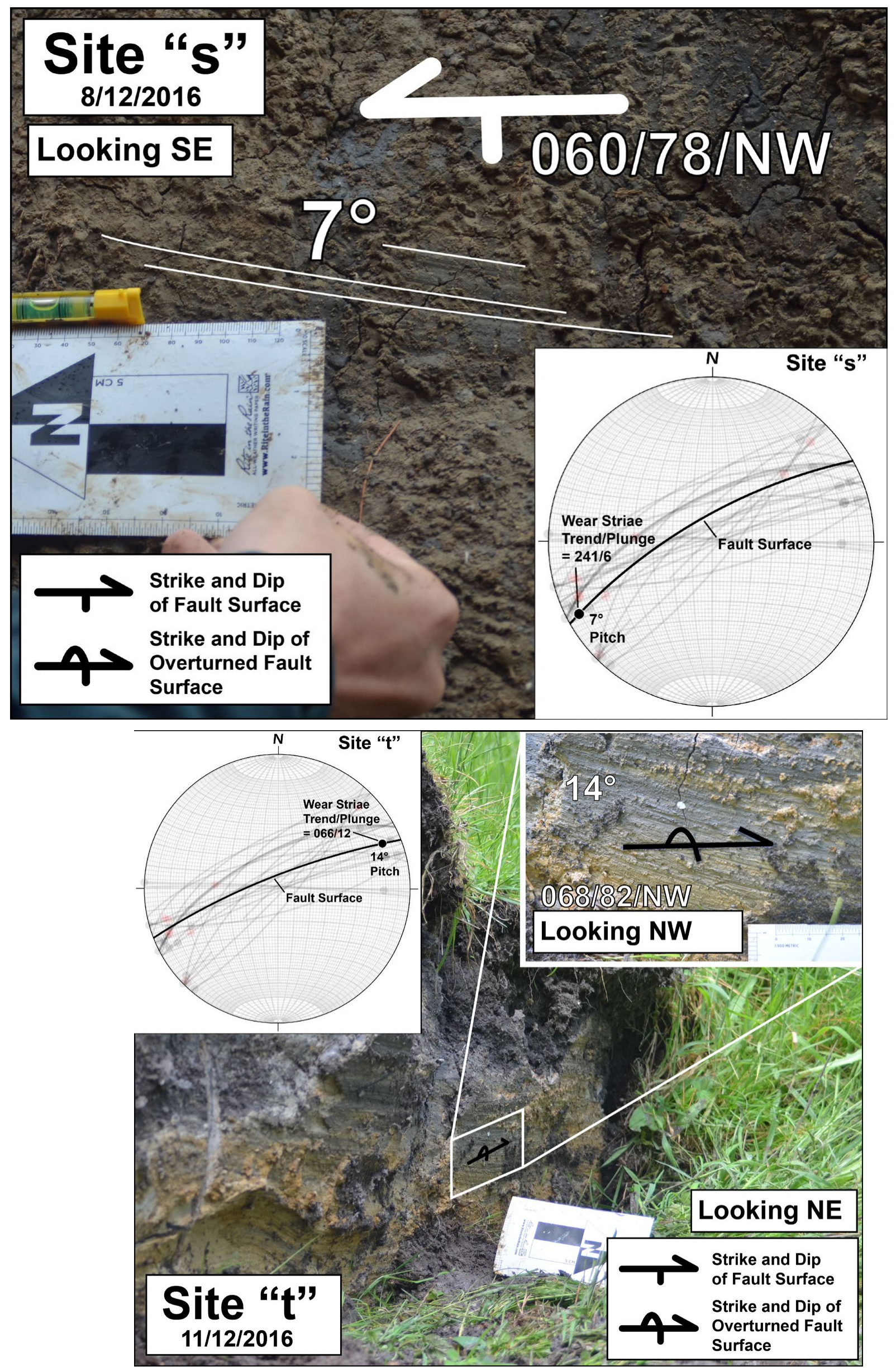

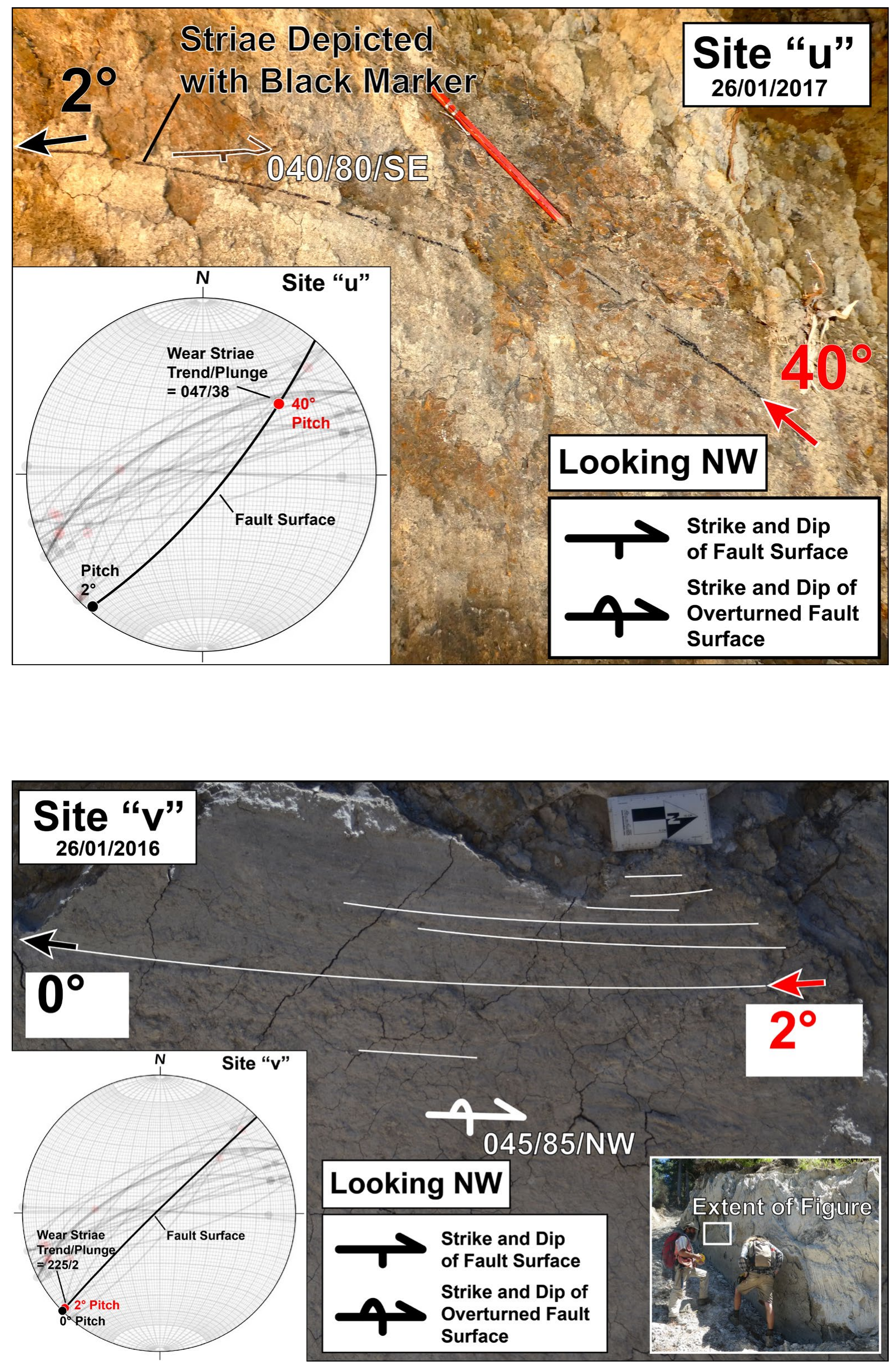


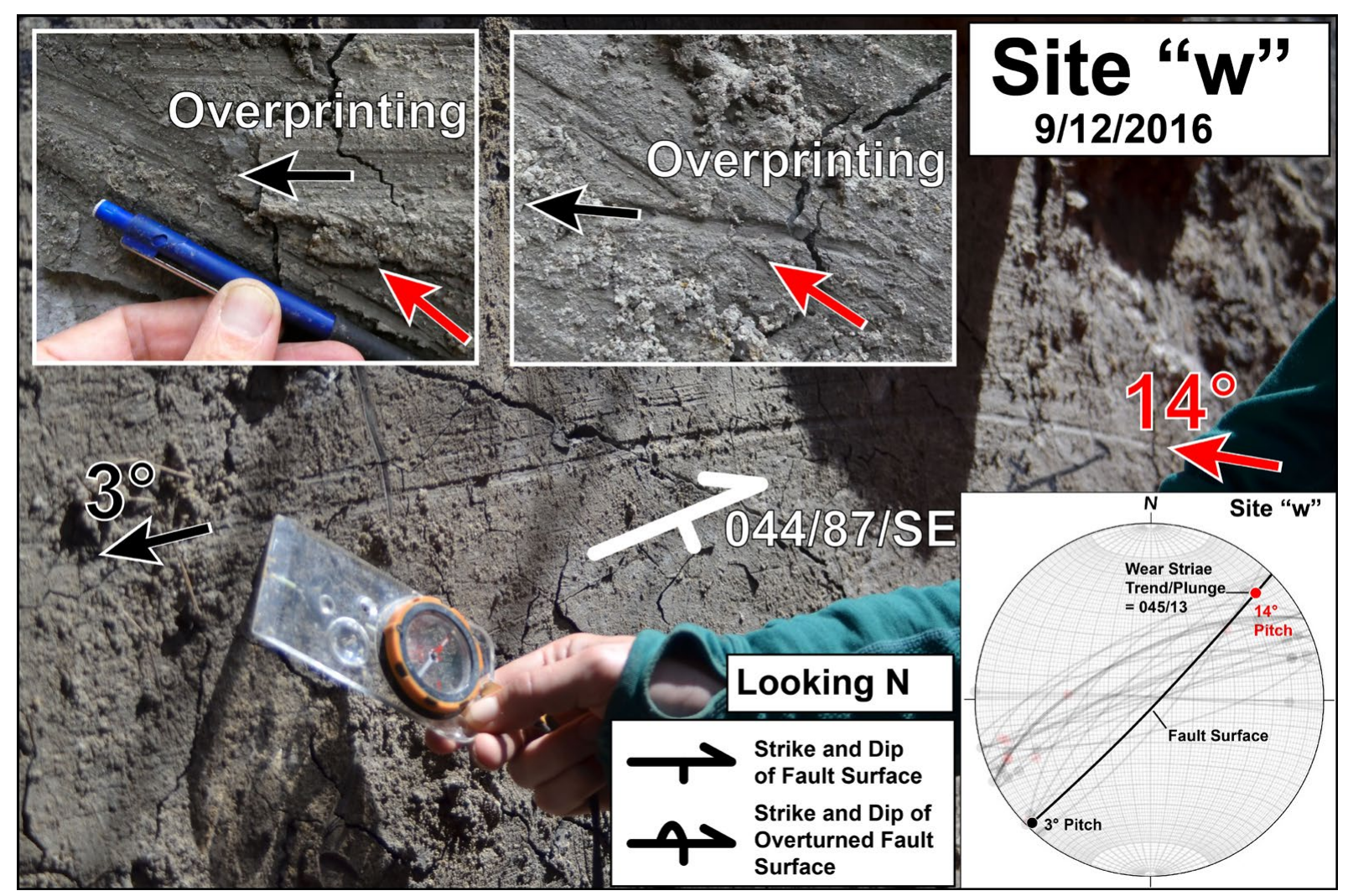


Appendix 3 


\section{References}

Aksoy, M. E., M. Meghraoui, M. Vallée, and Z. Çakır (2010). Rupture characteristics of the AD 1912 Mürefte (Ganos) earthquake segment of the North Anatolian fault (western Turkey), Geology 38, 991-994.

Ramón Arrowsmith, J., \& Rhodes, D. D. (1994). Original forms and initial modifications of the Galway Lake Road scarp formed along the Emerson fault during the 28 June 1992 Landers, California, earthquake. Bulletin of the Seismological Society of America, 84(3), 511-527.

Baljinnyam, I. (Ed.). (1993). Ruptures of major earthquakes and active deformation in Mongolia and its surroundings, Geol. Soc. Am. 181, 1-62.

Barnes, P. M., and J. C. Audru, (1999). Recognition of active strike-slip faulting from high-resolution marine seismic reflection profiles: Eastern Marlborough fault system, New Zealand, Geol. Soc. Am. Bull. 111, 538-559.

Barnes, P. M., F. C Ghisetti, A. R. Gorman, J. M. Bull, M. N. Çağatay, S. Woelz, J. J. Mountjoy, G. Lamarche, J. A. Collins. C. Castellazzi. (2015). Active submarine faulting in North Canterbury and eastern Marlborough, South Island, New Zealand. NIWA Client Report WLG2015-39. p. 72.

Berryman, K. R. (1992). The Alpine fault, New Zealand: Variation in Quaternary structural style and geomorphic expression. Ann. Tectonicae Suppl to Vol VI, 126-163.

Barka, A., H. S Akyüz, E. Altunel, G. Sunal, Z. Cakir, A. Dikbas, B. Yerli, R. Armijo, B. Meyer, J. B. de Chabalier et al., (2002). The surface rupture and slip distribution of the 17 August 1999 Izmit earthquake (M 7.4), North Anatolian fault, Bull. Seismol. Soc. Am. 92, 43-60.

Beanland, S., and J. Haines, (1998). The kinematics of active deformation in the North Island, New Zealand, determined from geological strain rates, New Zeal. J. Geol. Geophys. 41, 311-323.

Benson, A. M., Little, T. A., Van Dissen, R. J., Hill, N., \& Townsend, D. B. (2001). Late Quaternary paleoseismic history and surface rupture characteristics of the eastern Awatere strike-slip fault, New Zealand. GSA Bulletin, 113(8), 1079-1091.

Biasi, G. P., R. J. Weldon, and T. E. Dawson (2013). Appendix F-Distribution of slip in ruptures, U.S. Geol. Surv. Open File Rep., 1165, 65 pp.

Bowman, D., G. C. P. King, and P. Tapponier, (2003). Slip partitioning by elastoplastic propagation on oblique slip at depth, Science 300, 1121-1123.

Carter, L. and K. Lewis, (1995). Variability of the modern sand cover on a tide and storm driven inner shelf, south Wellington, New Zealand, New Zeal. J. Geol. Geophys. 38, 451-470.

Caskey, S. J., (1995). Geometric relations of dip slip to a faulted ground surface: new nomograms for estimating components of fault displacement. J. Struct. Geol 17, 1197-1202.

Clark, K. J., E. K. Nissen, J. D. Howarth, I. J. Hamling, J. J. Mountjoy, W. F. Ries, K. Jones, S. Goldstien, U. A. Cochran, P. Villamor et al., (2017). Highly variable coastal deformation in the 2016 Mw7.8 Kaikōura earthquake reflects rupture complexity along a transpressional plate boundary, Earth Planetary Sci. Lett. 474, 334-344.

Cubrinovski, M., Bray, J. D., de la Torre, C., Olsen, M., Bradley, B., Chiaro, G., ... \& Krall, T. (2018). Liquefactio-induced damage and CPT characterization of the reclamations at CentrePort, Wellington. Bulletin of the Seismological Society of America.

DeMets, C., R. G. Gordon, and D. F. Argus, (2010). Geologically current plate motions. Geophys. J. Int. 181, 1-80.

Dolan, J. F., and B. D. Haravitch, (2014). How well do surface slip measurements track slip at depth in large strike-slip earthquakes? The importance of fault structural maturity in controlling on-fault slip versus off-fault surface deformation, Earth Planetary Sci. Lett. 388, 38-47.

Eberhart-Phillips, D., and S. Bannister, (2010). 3-D imaging of Marlborough, New Zealand, subducted plate and strikeslip fault systems, Geophys. J. Int. 182, 73-96.

Escartín, J., F. Leclerc, J. A. Olive, C. Mevel, M. Cannat, S. Petersen, N. Augustin, N. Feuillet, C. Deplus, A. Bezos et al., (2016). First direct observation of coseismic slip and seafloor rupture along a submarine normal fault and implications for fault slip history, Earth Planetary Sci. Lett. 450, 96-107.

Florensov, N. A., \& Solonenko, V. P. (1965). The Gobi-Altai Earthquake (p. 424). Israel Program for Scientific Translations.

Fujiwara, T., S. Kodaira, T. No, Y. Kaiho, N. Takahashi, and Y. Kaneda, (2011). The 2011 Tohoku-Oki earthquake: Displacement reaching the trench axis, Science 334, 1240-1240.

Gold, R. D., N. G. Reitman, R. W. Briggs, W. D. Barnhart, G. P. Hayes, and E. Wilson, (2015). On-and off-fault de- 
formation associated with the September 2013 M w 7.7 Balochistan earthquake: implications for geologic slip rate measurements, Tectonophysics 660, 65-78.

Guatteri, M., and P. Spudich, (1998). Coseismic temporal changes of slip direction: the effect of absolute stress on dynamic rupture, Bull. Seismol. Soc. Am. 88, 777-789.

Haddon, E. K., C. B. Amos, O. Zielke, A. S. Jayko, and R. Bürgmann, (2016). Surface slip during large Owens Valley earthquakes, G-cubed 17, 2239-2269.

Hart, E. W., and W. A. Bryant (1997). Fault-rupture hazard zones in California: Alquist-Priolo earthquake fault zoning act with index to earthquake fault zones maps. California Department of Conservation, Division of Mines and Geology Special Publication, 42, 39 p.

Haeussler, P. J., D. P. Schwartz, T. E. Dawson, H. D. Stenner, J. J. Lienkaemper, B. Sherrod, F. R. Cinti, P. Montone, P. A. Craw, A. J. Crone et al., (2004). Surface rupture and slip distribution of the Denali and Totschunda faults in the 3 November 2002 M 7.9 earthquake, Alaska, Bull. Seismol. Soc. Am. 94, S23-S52.

Hamling, I. J., S. Hreinsdóttir, K. Clark, J. Elliott, C. Liang, E. Fielding, N. Litchfield, P. Villamor, L. Wallace, T. J. Wright et al (2017). Complex multifault rupture during the $2016 \mathrm{Mw} 7.8$ Kaikoura earthquake, New Zealand. Science, 356 , no. 6334 .

Holden, C., Y. Kaneko, E. D’Anastasio, R. Benites, B. Fry, and I. J. Hamling. (2017). The 2016 Kaikōura Earthquake Revealed by Kinematic Source Inversion and Seismic Wavefield Simulations: Slow Rupture Propagation on a Geometrically Complex Crustal Fault Network. Geophys. Res. Lett. 44, 11,320-11,328.

Hollingsworth, J., L. Ye, and J.P. Avouac (2017). Dynamically triggered slip on a splay fault in the Mw 7.8, 2016 Kaikoura (New Zealand) earthquake, Geophys. Res. Lett. 44, 3517-3525.

Jónsson, S., H. Zebker, P. Segall, and F. Amelung, (2002). Fault slip distribution of the 1999 Mw 7.1 Hector Mine, California, earthquake, estimated from satellite radar and GPS measurements, Bull. Seismol. Soc. Am. 92, 1377-1389.

Kaiser, A., N. Balfour, B. Fry, C. Holden, N. Litchfield, M. Gerstenberger, E. D’Anastasio, N. Horspool, G. McVerry, J. Ristau et al (2017). The 2016 Kaikōura, New Zealand, Earthquake: Preliminary Seismological Report, Seismol. Res. Lett. 88, 727-739.

Kakimi, T., Y. Kinugasa, Y. Suzuki, K. Kodama, and T. Mitsunashi (1977).Geological research on the Izu-Hanto-oki earthquake of 1974, Spec.Rept. Geol. Surv. Japan 6, 35 pp.

Kerr, J., S. Nathan, R. Van Dissen, P. Webb, D. Brunsdon, A. King, (2004). Planning for development of land on or close to active faults: A guideline to assist resource management planners in New Zealand, Published by the Ministry for the Environment ME number 565: 67.

Khajavi, N., Langridge, R. M., Quigley, M. C., Smart, C., Rezanejad, A., \& Martín-González, F. (2016). Late Holocene rupture behavior and earthquake chronology on the Hope fault, New Zealand. GSA Bulletin, 128(11-12), 1736-1761.

Koto, B. (1893). On the cause of the great earthquake in central Japan, 1891.

Langridge, R., Campbell, J., Hill, N., Pere, V., Pope, J., Pettinga, J., ... \& Berryman, K. (2003). Paleoseismology and slip rate of the Conway Segment of the Hope Faultat Greenburn Stream, South Island, New Zealand. Annals of Geophysics.

Langridge, R. M., \& Berryman, K. R. (2005). Morphology and slip rate of the Hurunui section of the Hope Fault, South Island, New Zealand. New Zealand Journal of Geology and Geophysics, 48(1), 43-57.

Langridge, R. M., Villamor, P., Basili, R., Almond, P., Martinez-Diaz, J. J., \& Canora, C. (2010). Revised slip rates for the Alpine fault at Inchbonnie: Implications for plate boundary kinematics of South Island, New Zealand. Lithosphere, 2(3), 139-152.

Langridge, R. M., Almond, P. C., \& Duncan, R. P. (2013). Timing of late Holocene paleoearthquakes on the Hurunui segment of the Hope fault: Implications for plate boundary strain release through South Island, New Zealand. Bulletin, 125(5-6), 756-775.

Langridge, R. M., W. F. Ries, N. J. Litchfield, P. Villamor, R. J. Van Dissen, D. J. Barrell, M. Rattenbury, D. Heron, S. Haubrock, D. Townsend et al., (2016). The New Zealand active faults database, New Zeal. J. Geol. Geophys. 59, 86-96.

Langridge, R. M., J. V. Rowland, P. Villamor, J. Mountjoy, C. Madugo, D. Townsend, A. Canva, K. Clark, R. J. Van Dissen, W. Ries et al., (2018) Geology, co-seismic rupture and slip across the Papatea fault and its role in the 2016 Kaikōura Earthquake, New Zealand., Bull. Seismol. Soc. Am.

Lin, A., T. Ouchi, A. Chen, and T. Maruyama, (2001). Co-seismic displacements, folding and shortening structures along the Chelungpu surface rupture zone occurred during the 1999 Chi-Chi (Taiwan) earthquake, Tectonophysics 330, 225-244. 
Lin, A., and M. Nishikawa (2007). Coseismic lateral offsets of surface rupture zone produced by the $2001 \mathrm{Mw} 7.8 \mathrm{Kun}-$ lun earthquake, Tibet from the IKONOS and QuickBird imagery. Int. J. Rem. Sens. 28, 2431-2445.

Lin, A., and M. Nishikawa, (2007). Coseismic lateral offsets of surface rupture zone produced by the $2001 \mathrm{Mw} 7.8 \mathrm{Kun}$ lun earthquake, Tibet from the IKONOS and QuickBird imagery, Int. J. Rem. Sens. 28, 2431-2445.

Lin, A., and T. Chiba (2017). Coseismic conjugate faulting structures produced by the $2016 \mathrm{Mw} 7.1$ Kumamoto earthquake, Japan. J. Struct. Geol. 99, 20-30.

Litchfield, N. J., R. Van Dissen, R. Sutherland, P. M. Barnes, S. C. Cox, R. Norris, R. Beavan, R. Langridge, P. Villamor, K. Berryman et al., (2014). A model of active faulting in New Zealand, New Zeal. J. Geol. Geophys. $57,32-56$.

Litchfield, N. J., P. Villamor, R. J. Van Dissen, A. Nicol, P. Barnes, D.J.A. Barrell, J. Pettinga, R. M. Langridge, T. Little, J. Mountjoy, et al. (2018). Surface fault rupture from the Mw 7.8 2016 Kaikoura earthquake, New Zealand, and insights into factors controlling multi-fault ruptures, Bull. Seismol. Soc. Am.

Little, T. A., R. Grapes, and G. W. Berger, (1998). Late Quaternary strike slip on the eastern part of the Awatere fault, South Island, New Zealand, Geol. Soc. Am. Bull. 110, 127-148.

Little, T. A., R. Van Dissen, J. Kearse, K. Norton, W. Ningsheng, (2018). Kekerengu fault, New Zealand: timing and size of Late Holocene surface ruptures, Bull. Seismol. Soc. Am.

Liu-Zeng, J., Wen, L., Sun, J., Zhang, Z., Hu, G., Xing, X., ... \& Xu, Q. (2010). Surficial slip and rupture geometry on the Beichuan fault near Hongkou during the M w 7.9 Wenchuan earthquake, China. Bulletin of the Seismological Society of America, 100(5B), 2615-2650.

Mason, D. P., Little, T. A., \& Van Dissen, R. J. (2006). Rates of active faulting during late Quaternary fluvial terrace formation at Saxton River, Awatere fault, New Zealand. Geological Society of America Bulletin, 118(11-12), 14311446.

Mason, D. P., \& Little, T. A. (2006). Refined slip distribution and moment magnitude of the 1848 Marlborough earthquake, Awatere Fault, New Zealand. New Zealand Journal of Geology and Geophysics, 49(3), 375-382.

Mason, D., Brabhaharan, P., \& Saul, G. (2017). Performance of road networks in the 2016 Kaikōura earthquake: observations on ground damage and outage effects. In Proceedings 20th NZGS geotechnical symposium. Napier.

Massey, C., D. E. Townsend, Y. Rathje, B. Kaneko, N. Lukovic, B. Horspool, I. Bradley, J. Hamling, K. Wartman, J. Allstadt, et al., (2018). Landslides triggered by the Mw 7.814 November 2016 Kaikōura Earthquake, New Zealand, Bull. Seismol. Soc. Am.

Milliner, C. W. D., J. F. Dolan, J. Hollingsworth, S. Leprince, and F. Ayoub, (2016). Comparison of coseismic nearfield and off-fault surface deformation patterns of the $1992 \mathrm{Mw} 7.3$ Landers and 1999 Mw 7.1 Hector Mine earthquakes: Implications for controls on the distribution of surface strain, Geophys. Res. Lett. 43, 19.

Nicol, A., and R. Van Dissen, (2002), Up-dip partitioning of displacement components on the oblique-slip Clarence Fault, New Zealand, J. Struct. Geol. 24, 1521-1536.

Oskin, M. E., J. R. Arrowsmith, A. H. Corona, A. J. Elliott, J. M. Fletcher, E. J. Fielding, P. O. Gold, J. Javier Gonzalez Garcia, K. W. Hudnut, Jing Liu-Zeng et al., (2012). Near-field deformation from the El Mayor-Cucapah earthquake revealed by differential LIDAR, Science 335, 702-705.

Otsubo, M., N. Shigematsu, K. Imanishi, R. Ando, M. Takahashi, and T. Azuma, (2013). Temporal slip change based on curved slickenlines on fault scarps along Itozawa fault caused by 2011 Iwaki earthquake, northeast Japan, Tectonophysics 608, 970-979.

Otsuki, K., Minagawa, J., Aono, M., \& Ohtake, M. (1997). On the curved striations of Nojima seismic fault engraved at the 1995 Hyogoken-Nambu earthquake, Japan. J. Seismol. Soc. Japan, 49, 451-460.

Peltzer, G., P. Rosen, F. Rogez, \& K. Hudnut, (1998). Poroelastic rebound along the Landers 1992 earthquake surface rupture. J. Geophys.Res. Solid Earth, 103, 30131-30145.

Philip, H., \& Megard, F. (1977). Structural analysis of the superficial deformation of the 1969 Pariahuanca earthquakes (central Peru). Tectonophysics, 38(3-4), 259-278.

Philip, H., \& Meghraoui, M. (1983). Structural analysis and interpretation of the surface deformations of the El Asnam earthquake of October 10, 1980. Tectonics, 2(1), 17-49.

Quigley, M., R. Van Dissen, N. Litchfield, P. Villamor, B. Duffy, D. Barrell, K. Furlong, T. Stahl, E. Bilderback, and D. Noble (2012). Surface rupture during the $2010 \mathrm{Mw} 7.1$ Darfield (Canterbury) earthquake: Implications for fault rupture dynamics and seismic-hazard analysis, Geology 40, 55-58.

Ramsay, J. G., \& Huber, M. I. (1987). The techniques of modern structural geology (Vol. 2). Academic press.

Rao, G., A. Lin, B. Yan, D. Jia, X. Wu, and Z. Ren, (2011). Co-seismic Riedel shear structures produced by the $2010 \mathrm{M}$ 
w 6.9 Yushu earthquake, central Tibetan Plateau, China, Tectonophysics 507, 86-94.

Reicherter, K., and C. Hübscher, (2007). Evidence for a seafloor rupture of the Carboneras Fault Zone (southern Spain): Relation to the 1522 Almería earthquake? J. Seismol. 11, 15-26.

Rockwell, T. K., S. Lindvall, T. Dawson, R. Langridge, W. Lettis, and Y. Klinger, (2002). Lateral offsets on surveyed cultural features resulting from the 1999 Izmit and Düzce earthquakes, Turkey, Bull. Seismol Soc. Am. 92, 79-94.

Rodgers, D. W., and T. A. Little (2006). World's largest coseismic strike-slip offset: The 1855 rupture of the Wairarapa Fault, New Zealand, and implications for displacement/length scaling of continental earthquakes, J. Geophys. Res. B. Solid Earth Planets 111, B12408.

Scholz, C. H. (2002). The mechanics of earthquakes and faulting, 2nd ed., 471pp., Cambridge univ. press., New York.

Sieh, K. E. (1978). Slip along the San Andreas fault associated with the great 1857 earthquake, Bull. Seismol. Soc. Am. 68, 1421-1448.

Stirling, M., T. Goded, K. Berryman, and N. Litchfield, (2013). Selection of earthquake scaling relationships for seismic hazard analysis, Bull. Seismol. Soc. Am. 103, 2993-3011.

Stirling, M., N. J. Litchfield, P. Villamor, R. J. Van Dissen, A. Nicol, J. Pettinga, P. Barnes R. M. Langridge, T. Little, D. J. A. Barrel et al, (2017), The Mw7. 82016 Kaikōura earthquake: Surface fault rupture and seismic hazard context, Bull. New. Zea.1 Soc. Earthquake Eng. 50, 73-84.

Tchalenko, J. S., (1970). Similarities between shear zones of different magnitudes, Geol. Soc. Am. Bull. 81, 1625-1640.

Townsend, D. B. (2001). Neogene evolution of the Pacific-Australia plate boundary zone in NE Marlborough, South Island, New Zealand, Ph.D thesis, Victoria University of Wellington

Twiss, R. J., \& Moores, E. M. (1992). Structural geology. Macmillan.

Villamor, P., N. Litchfield, D. Barrell, R. Van Dissen, S. Hornblow, M. Quigley, S. Levick, W. Ries, B. Duffy, J. Begg, et al., (2012). Map of the 2010 Greendale Fault surface rupture, Canterbury, New Zealand: application to land use planning, New Zeal. J. Geol. Geophys. 55, 223-230.

Van Dissen, R.J., (1991). An evaluation of seismic hazard in the Kaikoura region, Southeastern Marlborough, New Zealand Geological Survey Records 43, 93-99.

Van Dissen, R., D. Heron, J. Becker, A. King, and J. Kerr, (2006). Mitigating active fault surface rupture hazard in New Zealand: development of national guidelines, and assessment of their implementation. in proceedings, 8th U.S. National Conference on Earthquake Engineering, San Francisco, California, 18-22 April, 2006. Paper No. 633, 10 p.

Van Dissen, R., S. Hornblow, M. Quigley, N. Litchfield, P. Villamor, A. Nicol, D. J. A. Barrel, P. Sasnett, K. Newton (2013). Towards the development of design curves for characterising distributed strike-slip surface fault rupture displacement: An example from the 4 September, 2010, Greendale Fault rupture, New Zealand, In Proceedings of the 19 th NZGS (New Zealand Geotechnical Society) Geotechnical Symposium, Queenstown, New Zealand 20-23.

Van Dissen, R., R. S. and Yeats, (1991). Hope fault, Jordan thrust, and uplift of the seaward Kaikoura Range, New Zealand, Geology 19, 393-396.

Wallace, L. M., P. Barnes, J. Beavan, R. Van Dissen, N. Litchfield, J. Mountjoy, R. Langridge, G. Lamarche, and N. Pondard (2012). The kinematics of a transition from subduction to strike-slip: An example from the central New Zealand plate boundary, J. Geophys. Res. 117, no. B02405.

Wang, T., Wei, S., Shi, X., Qiu, Q., Li, L., Peng, D., ... \& Barbot, S. (2018). The 2016 Kaikōura earthquake: Simultaneous rupture of the subduction interface and overlying faults. Earth and Planetary Science Letters, 482, 44-51.

Wells, D. L., and K. J. Coppersmith (1994). New empirical relationships among magnitude, rupture length, rupture width, rupture area, and surface displacement, Bull. Seismol. Soc. Am. 84, 974-1002.

Wesnousky, S. G. (2008). Displacement and geometrical characteristics of earthquake surface ruptures: Issues and implications for seismichazardn analysis and the process of earthquake rupture, Bull. Seismol. Soc. Am. 98, 1609-1632.

Xu, X., G. Yu, Y. Klinger, P. Tapponnier, and J. Van Der Woerd (2006). Reevaluation of surface rupture parameters and faulting segmentation of the 2001 Kunlunshan earthquake (Mw 7. 8), northern Tibetan Plateau, China, J. Geophys. Res. 111, no. B05316.

Zielke, O., Y. Klinger, and J. R. Arrowsmith (2015). Fault slip and earthquake recurrence along strike-slip faults-Contributions of highresolution geomorphic data, Tectonophysics 638, 43-62.

Zinke, R., J. Hollingsworth, and J. F. Dolan (2014). Surface slip and off-fault deformation patterns in the $2013 \mathrm{Mw}$ 7.7 Balochistan, Pakistan earthquake: Implications for controls on the distribution of nearsurface coseismic slip, Geochem. Geophys. Geosys. 15, 5034-5050. 
J. Kearse, 2018 
